Washington University in St. Louis

Washington University Open Scholarship

Arts \& Sciences Electronic Theses and

Dissertations

Arts \& Sciences

Summer 8-15-2020

\title{
A Mega-Analysis of Personality Prediction: Robustness and Boundary Conditions
}

Emorie Danielle Beck

Washington University in St. Louis

Follow this and additional works at: https://openscholarship.wustl.edu/art_sci_etds

Part of the Personality and Social Contexts Commons

\section{Recommended Citation}

Beck, Emorie Danielle, "A Mega-Analysis of Personality Prediction: Robustness and Boundary Conditions" (2020). Arts \& Sciences Electronic Theses and Dissertations. 2303.

https://openscholarship.wustl.edu/art_sci_etds/2303

This Dissertation is brought to you for free and open access by the Arts \& Sciences at Washington University Open Scholarship. It has been accepted for inclusion in Arts \& Sciences Electronic Theses and Dissertations by an authorized administrator of Washington University Open Scholarship. For more information, please contact digital@wumail.wustl.edu. 
WASHINGTON UNIVERSITY IN ST. LOUIS

Department of Psychological and Brain Sciences

Dissertation Examination Committee:

Joshua J Jackson, Chair

David Condon

Tammy English

Patrick L Hill

Randy Larsen

Tom Oltmanns

A Mega-Analysis of Personality Prediction:

Robustness and Boundary Conditions

by

Emorie Danielle Beck

A dissertation presented to

The Graduate School

of Washington University in partial fulfillment of the requirements for the degree of Doctor of Philosophy

August 2020

St. Louis, Missouri 
(C) 2020, Emorie Danielle Beck 


\section{Table Of Contents}

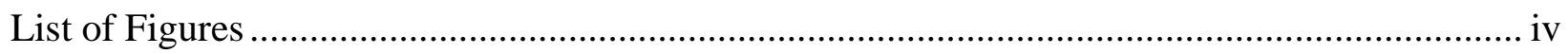

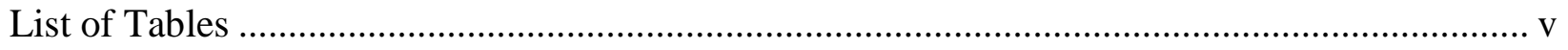

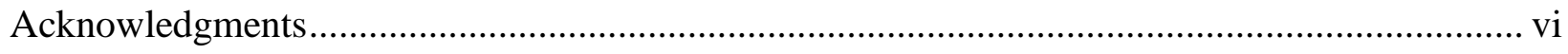

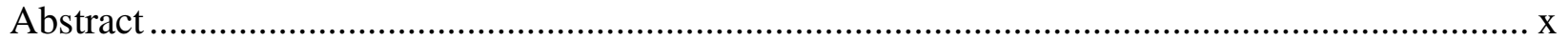

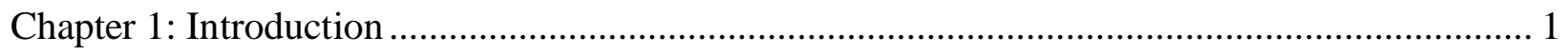

1.1 Does personality predict important outcomes? .................................................. 4

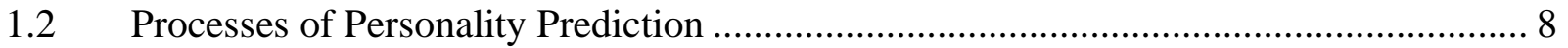

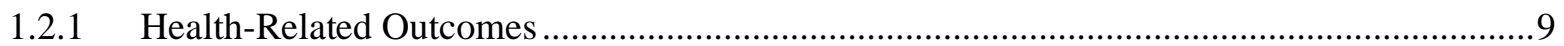

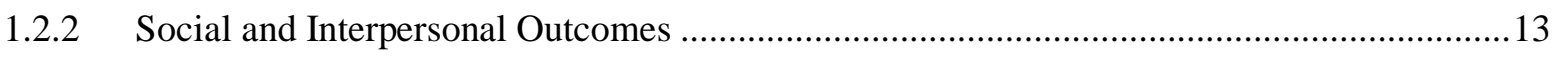

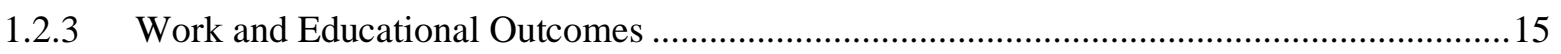

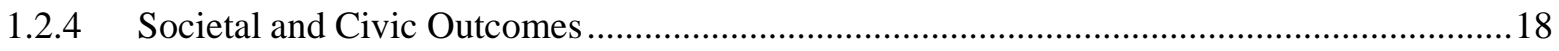

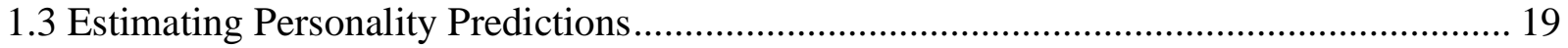

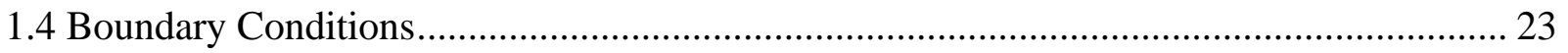

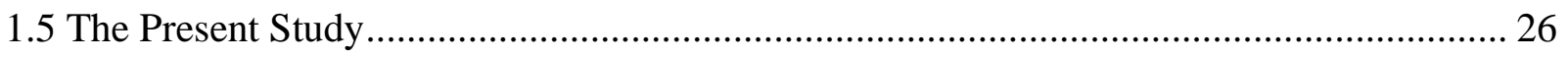

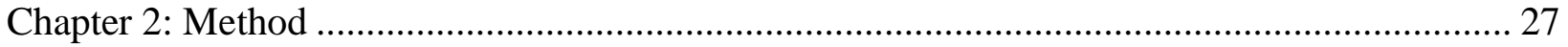

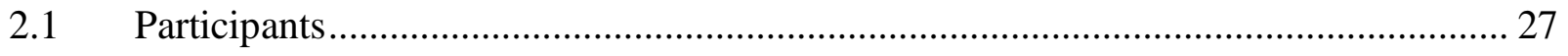

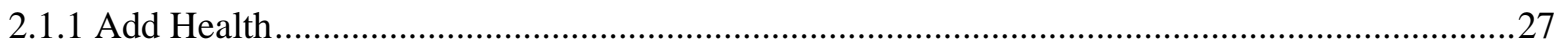

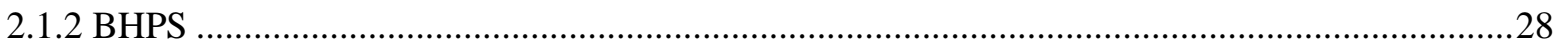

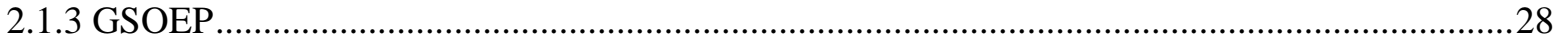

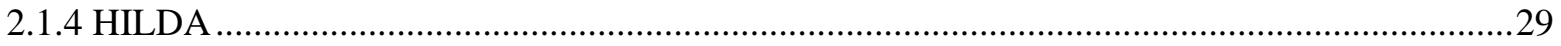

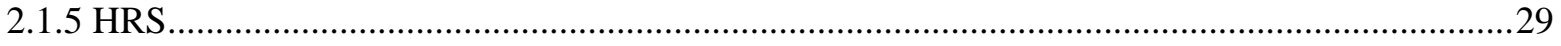

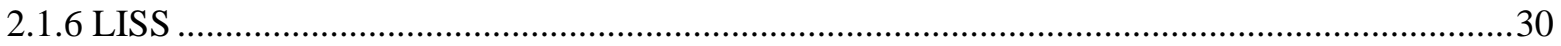

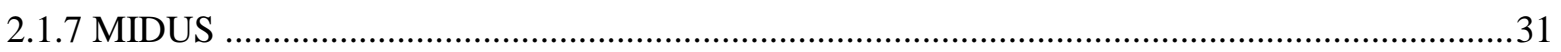

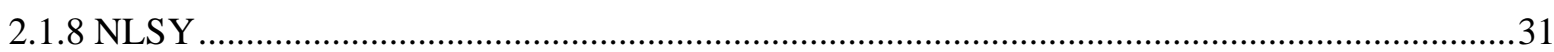

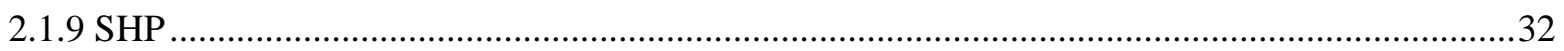

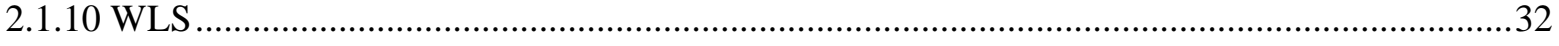

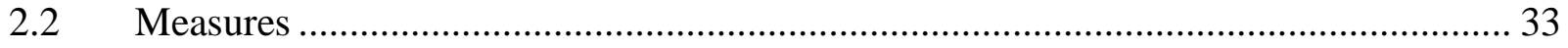

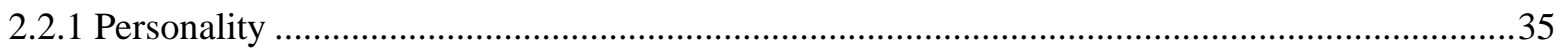

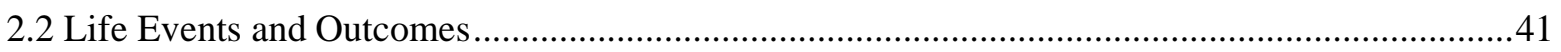

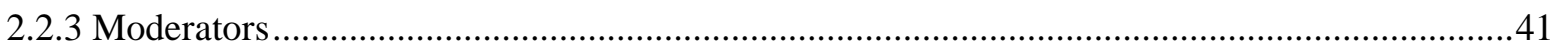

2.2.4 Matching Variables and Specification Curve Covariates ...................................................42 


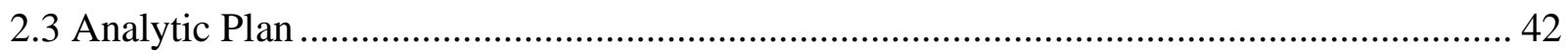

2.3.1 Study 1: Propensity Score Matched Mega-Analysis of Longitudinal Studies .........................42

2.3.2 Study 2: Specification Curve Analysis of Longitudinal Studies ............................................46

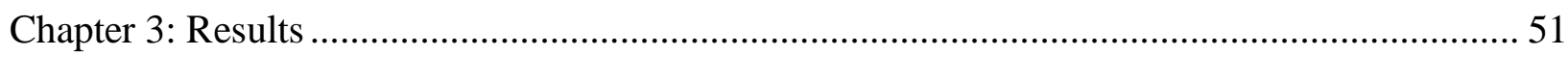

3.1 Study 1: Propensity Score Matching ........................................................................ 51

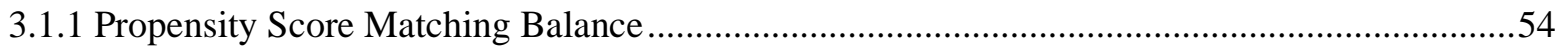

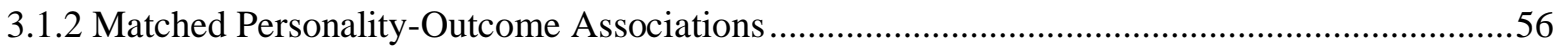

3.1.3 Moderators of Matched Personality-Outcome Associations ................................................69

3.2 Study 2: Specification Curve Analysis ..................................................................... 84

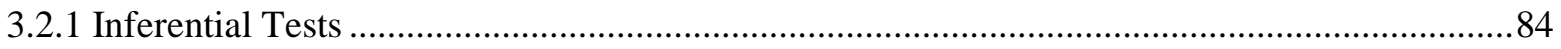

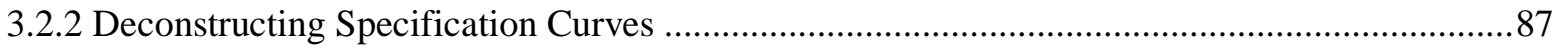

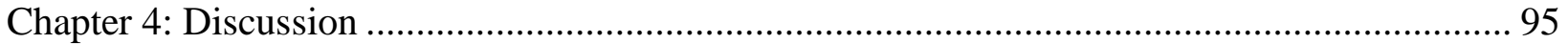

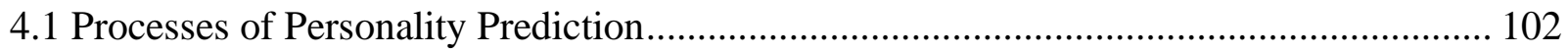

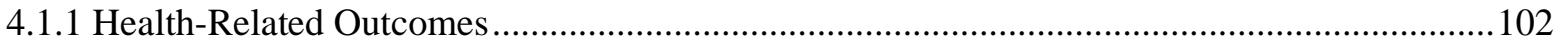

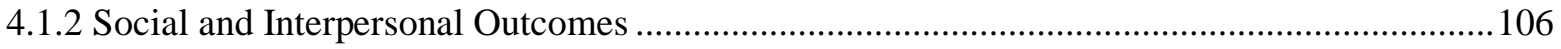

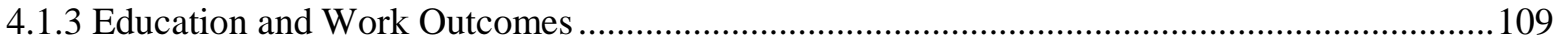

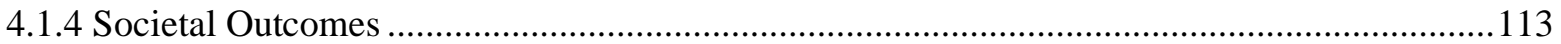

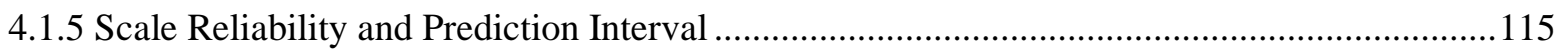

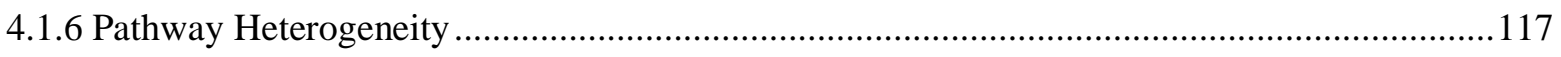

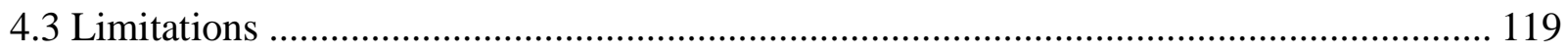

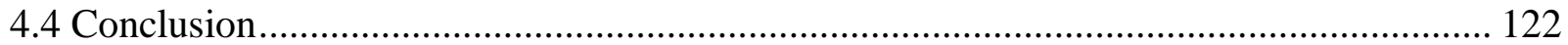

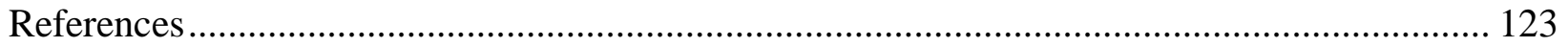




\section{List of Figures}

Figure 1.1: Sample standardized mean differences between singles and beginners across baseline measures in matched (filled) and unmatched (unfilled) circles from Wagner et al. (2015)

Figure 1.2: Sample specification curve of birth order predicting Locus of Control from Rohrer et al. (2017)

Figure 3.1: Balance plots of mean-level differences (Cohen's $d$ ) of continuous variables between those who did or did not experience divorce in the matched (filled-in points) and unmatched (unfilled points) samples of those with Conscientiousness data in each study.

Figure 3.2: Odd ratios fixed $\left(\gamma_{10}\right)$ effects of personality characteristics on outcomes (dots) following propensity score matching

Figure 3.3: Odds ratios of fixed $\left(\gamma_{10}\right)$ and study-specific $\left(\beta_{1 j}\right)$ effects of personality characteristics on mortality (dots) following propensity score matching

Figure 3.4: Simple effects of all personality-outcome associations that were reliably moderated by age

Figure 3.5: Simple effects of all personality-outcome associations that were reliably moderated by gender $(0=$ male, $1=$ female $)$.

Figure 3.6: Simple effects of all personality-outcome associations that were reliably moderated by parental education $(0=$ high school or less, $1=$ college, $2=$ beyond college).

Figure 3.7: Simple effects of all personality-outcome associations that were reliably moderated by prediction interval

Figure 3.8: Specification Curve of mega-analytic estimates of Social Support predicting divorce across studies

Figure 3.9: Specification Curve of mega-analytic estimates of Conscientiousness predicting a major health event across studies.

Figure 3.10: Specification Curve of mega-analytic estimates of Self-Esteem predicting contact with the criminal justice system across studies

Figure 3.11: Specification Curve of mega-analytic estimates of Neuroticism predicting mortality across studies 


\section{List of Tables}

Table 2.1: Personality and Outcome Measures Across Data Sets .............................................35

Table 2.2: List of Personality Measures, Scales, and Available Waves Across Studies ...............37

Table 2.3: Specification Curve Analysis Specifications for Each Outcome .............................49

Table 3.1: Descriptive Statistics of Matched and Raw Samples for Those Who

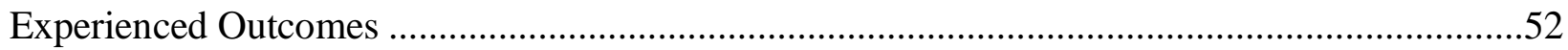

Table 3.2: Mega-Analytic and Study-Specific Personality-Outcome Associations in

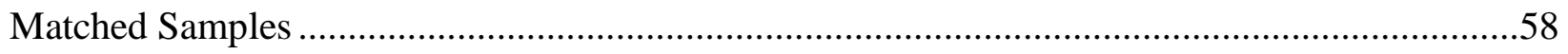

Table 3.3: Level 2 Standard Deviations of Personality-Outcome Associations in

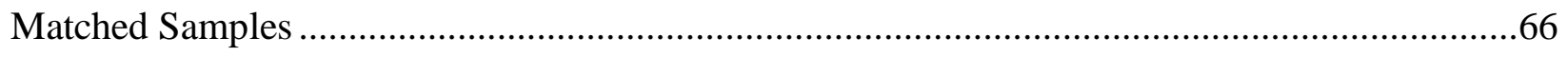

Table 3.4: Fixed Effect Moderators of Personality-Outcome Associations ...............................71

Table 3.5: Results of the Permutation Based Inference Tests from Specification Curve

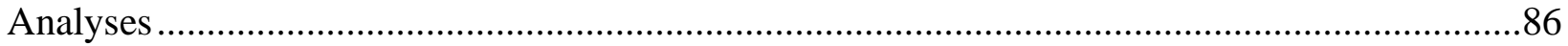

Table 4.1: Significant Moderators of Propensity Score Matched Models and Critical

Covariates of Specification Curve Analyses...... 


\section{Acknowledgments}

First, I'd like to thank my advisor, Josh Jackson, whose mentorship and friendship has been important in the work I've done and the work I've yet to do. Through long discussions, many drinks, and white boards full of ideas, we pushed each other to think differently and move in new directions, which was exactly what I needed in an advisor.

Second, to my family, who has been there for all the ups and downs as I've tried to navigate this adulthood thing. Without your support, I would not be the first doctor in the family. My mother, in particular, has always been my biggest fan, even when I took more than I gave. But all of you - Mom, Dad, Erica, Grandma and Grandpa Derrieux, Grandma Beck, Adam, Aunt Sheila and Jay, Aunt Linda, Aunt Jeannie, Brennan, and Augie (of course) - gave me unwavering support, made space for me when I would appear, and were so foundational making me the person I've been, the one I am now, and the one I'll become. To my sister, Erica, I'm so grateful graduate school gave us an opportunity to reconnect. I'm so in awe of the woman and mother you are and the choices you've made. And to Grandpa Beck, who would have been so proud, and my Dad, who is also so proud, I will always keep your name, placing it in history, making it all of our legacy. And to the other family who I've lost along the way - Uncle Norbert, Uncle Billy, and Uncle Steve - I hope I've made you proud. To my partner Andrew, who had deal with the daily dissertation meltdowns during an unexpected quarantine and global pandemic, I can't imagine completing this without your love, patience, and dumb sense of humor. Finally, to Augie, you were born the day I moved to St. Louis and you'll turn 4 the day I officially leave graduate school, you gave me so much love, so many laughs, and a respite away from the daily grind. 
Third, to my friends - my second family - who were there for the daily grind with me, and I can't imagine having never met you. You've all taught me to be more authentic, more in the moment, and to trust others and let down my walls. To Marina, who was always there to listen, question destructive thoughts, and try something new, and who pushed me to be more present, more inclusive, and to set more boundaries, I'm so grateful Wash U brought us together, and I'm so excited for where we'll go next. To Yvette, through all the wine nights, dilemmas, bad dates, cheese, and ice cream, we've both grown a lot over the almost decade of knowing each other, and I'm so grateful that St. Louis gave us a second chance at our friendship. To the Spiral Squad - Kat, Scott, and Sri - and the beautiful magic of meeting the right people exactly when you need them, I loved our laughter and late nights (and I'm sorry for your hangovers). Your support was thoughtful, careful, and fun, and I'm excited for the next time we all get to be together again. To Emily and Isaac, my oldest friends, who have supported me even when I was absentee, I'm so proud of you both, of the choices you've made, what you've overcome, and the paths you've taken. To Olivia, for your support, your cats, and your prescient (and hilarious) commentary, I'm so grateful Yvette brought us all together. To Jessica, my friend from the first day or grad school, thank you for always believing in me. I believe in you so much and am so proud of all you've accomplished and all you'll accomplish in the future. To Megan, I thank you for your support and want you to know how proud I am of the choices you've made and what you've accomplished. To Stuti - I had to write yours last because I've struggled to find any words to explain how much you mean to me. You've stood by me through my best and worst moments and behaviors. Through the tears and the gin, through the imposter syndrome and uncertainty, we've stood by each other (virtually), and I'm so excited to be back in the same city with you again. 
To Gordon Allport (of course), who wrote the first dissertation on personality traits and largely founded the field, I've yet to have an idea that you didn't anticipate or write about. Despite this, you dedicated your career and your legacy to your students and set the standard I want for myself.

Finally, to every person who has believed in me, afforded me opportunities, and listened to me. I look forward to paying it forward.

Emorie Danielle Beck

Washington University in St. Louis

August 2020 
Dedicated to both my Augies.

One whose birth punctuated my $\mathrm{PhD}$.

And one who would have been so proud. 


\section{ABSTRACT OF THE DISSERTATION}

A Mega-Analysis of Personality Prediction: Robustness and Boundary Conditions

by

\section{Emorie Danielle Beck}

Doctor of Philosophy in Social and Personality Psychology

Washington University in St. Louis, 2020

Professor Joshua J Jackson, Chair

Decades of research suggest that personality is an important and robust predictor of life outcomes. However, previous investigations of personality-outcome associations have not adequately accounted for reverse causality and selection bias nor have they examined the boundary conditions of the effects, which has left the robustness conditions of personalityoutcome associations unknown. The present study examines the robustness and boundary conditions of personality prediction using 14 personality characteristics to predict 14 health, social, education/work, and societal life outcomes across eight different person- and study-level moderators in 10 longitudinal panel studies in a mega-analytic framework coupled with propensity score matching to control for selection bias and specification curve analysis to test boundary conditions. In doing so, it is perhaps the most comprehensive test of personality prediction to date, both in scope and through the measures to taken to ensure that the estimates of personality-outcome associations were robust. Despite these measures, personality was a robust predictor of outcomes in both the propensity score matching and specification curve analysis studies. Moreover, relative to main effects of personality predicting outcomes, there were fewer moderators of personality-outcome associations. In sum, personality prediction, even over decades, was quite robust - across studies, personality characteristics, outcomes, moderators, and covariates. Personality is a powerful predictor of life outcomes. 


\section{Chapter 1: Introduction}

Personality traits are relatively stable, dispositional patterns that differentiate people from one another (Roberts, Wood, \& Caspi, 2008). Moreover, personality traits predict many important life outcomes, such as marriage (Kelly \& Conley, 1987; Malouff, Thorsteinsson, Schutte, Bhullar, \& Rooke, 2010; Specht, Egloff, \& Schmukle, 2011), life expectancy (Jackson, Connolly, Garrison, Leveille, \& Connolly, 2015; Jokela et al., 2013; Martin, Friedman, \& Schwartz, 2007; Turiano, Chapman, Gruenewald, \& Mroczek, 2015), and health (Hampson, 2012; Weston, Hill, \& Jackson, 2015). Much research has examined what personality predicts (see Ozer \& Benet Martinez, 2006, and Soto, 2019, for reviews), including which personality traits are the strongest predictors of different outcomes (see Roberts, Kuncel, Shiner, Caspi, \& Goldberg, 2007).

Even with numerous studies and meta-analyses that demonstrate personality prospectively predicts consequential life outcomes, almost all studies capture a biased estimate of the effect. Despite attempts at random sampling, two main reasons impede understanding whether personality prospectively predicts important outcomes: selection bias and reverse causality. Selection bias occurs because personality prediction models typically do not account for a broad range of covariates. As a result, it is unclear whether personality traits predict important outcomes at the levels reported or if unaccounted for third variables are responsible for the association. For example, personality traits are associated with age (Donnellan \& Lucas, 2008; Soto, John, Gosling, \& Potter, 2011), gender (Weisberg, DeYoung, \& Hirsh, 2011; Soto et al., 2011), socioeconomic status (Roberts et al., 2007), along with a host of other variables that are 
treated as causal variables within their own literatures. But, these variables are routinely left out of prediction models, or at best, used haphazardly.

Further complicating estimation is reverse causality, as it could bias estimates because many of outcomes that personality prospectively predicts are also associated with personality. For example, Conscientiousness predicts physical health status (e.g., Weston, Hill, \& Jackson, 2015). But there is evidence that physical health status also impacts personality trait change (Jackson, Weston \& Schultz, 2017; Turiano et al,. 2012). Thus, the direction of the relationships among personality and consequential outcomes make it difficult to tease apart their relationships if the outcome is not accounted for or the assessment is separate across time. Unfortunately, a lot of personality-outcome associations are cross sectional, which makes it impossible to investigate reverse causality (Soto, 2019). Thus, the existent work examining personality prediction cannot disentangle selection effects of personality from selection bias of other background characteristics, like health, work factors, and socioeconomic status. In other words, people who experience the life events that personality predicts might differ from those who do not in important ways that also influence personality.

A related, but separate concern is in the potential for heterogeneity in effects. That is, while there is consensus that personality traits should be predictive of outcomes, it is less well explored in what contexts and under what conditions these predictions apply. Indeed, despite evidence that personality-outcome associations are reproducible when following the same procedures (Soto, 2019), there is evidence of cross-sample heterogeneity in personality-outcome associations in large scale panel studies (see Jokela et al., 2013). While some care has been taken to collect representative samples, a systematic investigation of for whom the effects apply has not been examined. As a result, the boundary conditions of personality prediction are largely 
unknown. However, there are a myriad of examples of mixed results in the personality prediction literature, which are likely indicative of boundary conditions of prediction rather than a lack of robustness of personality prediction.

This heterogeneity — or potential for it —is further masked through inconsistent covariate use. The choice of covariates is largely determined by their availability in a specific data set or by their perceived relevance by a specific group of researchers. Because such covariates can be consequential - changing the presence, direction, and magnitude of a personality-outcome associations - covariate inclusion can have consequences for the seeming robustness of personality-outcome associations.

Although recent work indicates that past studies linking personality and outcomes crosssectionally are highly reproducible (see Soto, 2019), this merely means that similar results can be found given similar procedural and analytic choices and does not define the boundary conditions of prediction. In other words, reproducibility means the results are reliable, not valid, which is different than saying (1) that these results are robust to other procedural or analytic choices and (2) that there is a true causal relationship between personality and outcomes. As a result, despite seemingly reliable patterns of prediction, there is almost no evidence concerning the boundaries of and moderators of personality prediction, which is a critical concern in understanding what personality predicts, for whom it predicts, and why it does so.

In the present study, using 10 longitudinal panel studies, I will examine whether 14 measures of personality at a baseline assessment predict the future experience of 14 life events and outcomes that occur throughout the lifespan independently of selection bias of other background characteristics and of procedural and analytic procedures. Previous work has 
examined the predictive power of personality on life events using these samples, but the present study (1) uses a mega-analytic procedure of 10 longitudinal panel studies to test (2) whether selection effects persist after accounting for background characteristics via propensity score matching and (3) specification curve analysis to examine the boundary conditions of personalityoutcome associations.

\subsection{Does personality predict important outcomes?}

Personality is reliable predictor of a number of outcomes, including major life events, such as divorce (e.g., Solomon \& Jackson, 2014a; Specht et al., 2011), career success (e.g., Judge, Higgins, Thoresen, \& Barrick, 1999; Rothmann \& Coetzer, 2003), and major health events (e.g., Weston, Hill, \& Jackson, 2015). More Extraverted people are more likely to move in with a partner (Specht et al., 2011), to have children (van Scheppingen et al., 2016), and to enter into romantic relationships (Wagner, Becker, Lüdtke, \& Trautwein, 2015), while more Agreeable people are more likely to become unemployed and less likely to separate from a partner (Specht et al., 2011) or to enter into military service (Jackson, Thoemmes, Jonkmann, Lüdtke, \& Trautwein, 2012). Conscientiousness and Neuroticism, in particular, have been linked to health, both cross-sectionally (e.g., Hampson, 2012) and longitudinally (e.g., Weston et al., 2015). In one study, for example, Conscientiousness predicted the onset of high blood pressure, diabetes, stroke, and arthritis, with Conscientiousness serving as a protective factor against each of these health conditions (Weston et al., 2015).

But there are a number of reasons to interpret the prediction of outcomes from personality with caution. First, although a large number of studies have independently linked similar personality characteristics within similar outcomes and a small number of meta-analyses have tested the robustness of these effects across studies, no study of personality to date has mega-analytically 
examined personality-outcome associations among some of the longest-running and most widely used longitudinal panel studies. Although meta-analyses may be useful for estimating the size of effects, they are limited by (1) the published literature (e.g., Sharpe, 1997), (2) reported test and descriptive statistics (i.e. descriptive statistics and covariance matrices; e.g., Cafri, Kromrey, \& Brannick, 2010), and (3) by the necessity of accounting for different analytical choices made by different teams using indirect statistical means (e.g., Hohn, Slaney, \& Tafreshi, 2019). Thus, the present study goes beyond both basic and meta-analytic studies by using raw data from 10 large (some representative) longitudinal studies. Moreover, all data cleaning and variable choices were made prior to accessing the data and preregistered on the Open Science Framework (https://osf.io/tcysh).

Second, most studies examine cross-sectional group differences among those who have or have not experienced outcomes (i.e. are there mean-level differences in personality between those who have and have not experienced outcomes), making it impossible to tease apart whether personality predicts life events or life events predict personality (i.e. reverse causality). For example, people who are more Extraverted are more likely to have social and enterprising occupational interests (Barrick, Mount, \& Judge, 2001; Larson, Rottinghaus, \& Borgen, 2002), have fewer cardiovascular problems (Miller, Smith, Turner, Guijarro, \& Hallet, 1996), and to start romantic relationships (Wagner et al., 2015). But there is longitudinal evidence that work (e.g., Lüdtke, Roberts, Trautwein, \& Nagy, 2011), chronic illness (e.g., Mueller, Wagner, \& Gerstorf, 2017) and romantic relationships (e.g., Mund \& Neyer, 2014; Neyer, Mund, Zimmermann, \& Wrzus, 2014) may influence personality, which calls into question whether personality influences who experiences life outcomes or vice versa. Without understanding the 
direction of the relationship, reverse causality remains a possible explanation of observed personality-outcome associations.

Third, studies of personality-outcome associations are largely limited to observational crosssectional or longitudinal studies that fail to account for baseline factors that may influence both personality and the likelihood of experiencing an event. Personality has been linked to a number of demographic and background factors, including socioeconomic status (Roberts et al., 2007), cognitive ability (e.g., Moutafi, Furnham, \& Paltiel, 2005), age (e.g., Donnellan \& Lucas, 2008; Soto et al., 2011), parental education (e.g., Sutin, Luchetti, Stephan, Robins, \& Terracciano, 2017), marital satisfaction (e.g., Kelly \& Conley, 1987; Malouff et al., 2010), health (e.g., Hampson, 2012; Roberts et al., 2007), and geographic region (e.g., Rentfrow, Jokela, \& Lamb, 2015), among others. Although most studies control for a small number of these background characteristics, particularly age and gender (e.g., Specht et al., 2011), this is problematic. The small sets of background characteristics do not account for selection bias based on other social, psychological, economic, and demographic characteristics that personality has been linked to. Indeed, in the small number of studies that have accounted for broader ranges of background characteristics (Jackson et al., 2012; Nieß \& Zacher, 2015; van Scheppingen et al., 2016; Wagner et al., 2015), personality-related selection effects have been much more limited. In one study, for example, single young adults were less Extraverted and had lower self-esteem than young adults who entered into romantic relationships (Wagner et al., 2015). After accounting for selection bias through matching, single young adults had higher mean self-esteem than those in relationships. In other words, matching individuals on background characteristics can greatly impact personality-outcome associations-in direction as well as magnitude. Without matching, 
selection effects that are seemingly driven by personality may be driven by the direct or indirect influence of other factors.

Fourth, which background characteristics are controlled for are often somewhat arbitrary, which can result in inconsistencies in personality-outcome associations across studies, even if using the same data sets to test similar or different questions. In other words, one study may control for age and gender and find no effect of personality predicting an outcome, while another study using the same or a different sample may find different results when also controlling for SES. Such inconsistency in which covariates are included can produce inconsistent results and make true hypothesis tests of the robustness of personality prediction difficult. Fifth, unsystematic testing of the boundary conditions of when and for whom personality predicts important outcomes has resulted in little knowledge of their robustness. Indeed, a survey of the literature on essentially any personality-outcome association will reveal that most to all investigations test between zero and three moderators of personality-outcome associations. Some, like age and gender, tend to be included in most that do test boundary conditions, but others, like socioeconomic status, health status (in many distinct forms), marriage status, and many others tend to be represented inconsistently and much less often. The result is that personality appears to predict outcomes in some, but not all investigations, but there is no understanding of what the boundary conditions of such effects are across a wider set of boundary conditions. Thus, there is no understanding of the boundary conditions of when, how, and for whom personality predicts outcomes, which is imperative for understanding why personality prediction occurs and for using it to potentially change negative or create positive outcomes. In the present study, I address concerns about cross-sample heterogeneity, selection bias, reverse causality, arbitrary covariate choice, and the boundary conditions of personality-outcome 
associations by mega-analytically examining selection effects of 14 personality characteristics

(1) in 14 broad outcomes and life events (2) longitudinally (3) while accounting for more than 50 background characteristics in 10 large longitudinal panel studies. In addition, because of the large sample size, both within studies as well as across all of them, I will be able to test important moderators of personality-outcome associations. Doing so will allow me to better estimate personality's unique role in predicting relatively common life experiences and events, as well as its consistency across samples, which I argue will push research toward better understanding the mechanisms through which personality influences the life course.

\subsection{Processes of Personality Prediction}

In addition to a more accurate assessment of the power of personality, as well as the boundary conditions of this predictive ability, accounting for background factors and examining boundary conditions will shed light on the processes by which these associations occur. Traits are thought to influence important life outcomes, like health and relationship satisfaction, through accumulation - that is, traits influence outcomes indirectly through the behaviors and psychological experiences that traits also predict (e.g., Hampson, Edmonds, Goldberg, Dubanoski, \& Hillier, 2015). But to understand how personality might influence the events that people experience through behavior and psychological processes requires an accurate understanding of the relationship. Traits, as they are traditionally considered in trait-outcome associations, are relatively stable patterns of thoughts, beliefs, and behavior that differentiate people from one another (Roberts, Wood, \& Caspi, 2008). This alone is descriptive, describing how people differ from one another on a number of core dimensions rather than why they differ, which means that traits are not good causal candidates for why people engage in certain behaviors. In other words, if personality traits are descriptors for patterns of behaviors, beliefs, 
and thoughts, the link between personality and outcomes is likely found in the behaviors and experiences themselves.

Thus, if the link between traits and outcomes lies in behaviors and experiences, then understanding personality-outcome associations requires an understanding of the processes of behaviors and psychological experiences, not traits. One way to do this is to examine covariates and moderators of personality-outcome associations. If a target covariate, like age or gender, or attenuates, exaggerates, or moderates a personality outcome association, this suggests that developmental processes, culturally specified norms and expectations, or age-graded or genderrelated experiences are critical in both determining both an individual's personality and the outcomes they experience. Thus, examining consequential covariates and moderators is critical to understanding the processes through which personality predicts outcomes. In general, there is much less research examining specific pathways between personality traits and life outcomes than work establishing their connections. Despite this, there have been a number of recent attempts to understand how behavior may mediate between personality traits and outcomes in a few broad domains. Below, I summarize those such attempts in four broad domains of outcomes - health-related, social and interpersonal, work and educational, and societal and civic - that roughly correspond to the 14 life outcomes examined in the present study.

\subsubsection{Health-Related Outcomes}

The present study examines four health-related outcomes: all-cause mortality, major physical health events, major mental health events (e.g., diagnosis of depression), and having a child.1 Of all the outcomes investigated in the present study, the behavioral pathways between personality and health-related outcomes are perhaps the best studied, with a number of literature reviews and meta-analyses devoted to them. 
In the simplest sense, all of the proposed pathways between personality and health-related outcomes incorporate the influence of health-related behaviors and normal aging processes, and many also incorporate educational attainment and social factors, as well. For example, people who are higher in Conscientiousness are less likely to smoke (e.g., Malouff, Thorsteinsson, \& Schutte, 2006; Turiano, Hill, Roberts, Spiro, \& Mroczek, 2012), and people who smoke are more likely to have shorter life spans than those who do not (e.g., Gellert, Schöttker, \& Brenner, 2012; Shavelle, Paculdo, Strauss, \& Kush, 2008). Indeed, there is evidence that smoking does mediate the relationship between Conscientiousness and all-cause mortality, with the direct pathway between Conscientiousness and mortality being largely attenuated when including the indirect path through smoking (Turiano, Hill, Roberts, Spiro, \& Mroczek, 2012).

Similarly, a large number of other health behaviors have been tested as mediators of personalityhealth associations, including diet, exercise, excessive alcohol use, violence, risky sexual behavior, risky driving, and drug use (e.g., Friedman et al., 1995; Hampson, Goldberg, Vogt, \& Dubanoski., 2007; Mroczek, Spiro, \& Turiano, 2009). Conscientiousness, in particular, has been linked to many health behaviors, with Conscientiousness typically negatively predicting negative health behaviors and positively predicting positive health behaviors, but other characteristics, like Locus of Control (e.g., Wurtele, Britcher, \& Saslawsky, 1985) and Optimism (e.g., Kubzansky, Kubzansky, \& Maselko, 2004), have also been reliably positively associated with many of these behaviors. Neuroticism, depression, and negative affect, similarly, are thought to influence health through stress and coping (see Friedman, Kern, Hampson, \& Duckworth, 2014; Hampson, 2012). People who are higher in these characteristics tend to exhibit poor coping behaviors, including health behaviors like excess alcohol use and smoking, and have high levels of stress, all of which are associated with poor health outcomes. 
Health behaviors are thought influence health through accumulation (e.g., Hampson et al., 2007), such that engaging in more positive health behaviors and fewer negative health behaviors over long periods of time has a protective effect on health, while engaging in more negative and fewer positive health behaviors has the opposite effect. Thus, some have investigated the role of both childhood health behaviors and personality on long-term health to test how long the reach of both are (e.g., Friedman, 2000; Friedman et al. 1993, 1995; Hampson, Edmonds, Goldberg, Dubanoski, \& Hillier, 2013; Hampson, Goldberg, Vogt, \& Dubanoski, 2007), finding, for example, that childhood personality shows reliable associations with later health through education, exercise, and smoking (Hampson et al., 2007).

Personality may have a differential relationship with and impact on both outcomes and covariates throughout the lifespan, making age a critical pathway through which personality predicts outcomes. For example, there is well-documented evidence that personality differentially predicts health behaviors throughout the lifespan, with Conscientiousness predicting different health behaviors to different degrees for individuals above and below age 30 (Bogg \& Roberts, 2004). Moreover, at different ages, certain health behaviors may be differentially important for health, with physical activity having a large, cumulative effect across the whole lifespan, nutrition playing its largest role in early childhood, and medication adherence being an important health predictor primarily in older adulthood. Such age differential patterns of personality-outcome associations underlie the importance of investigating moderators of such associations (Hill, Edmonds, \& Jackson, 2019). In the case of medication adherence, for example, a full lifespan sample may show little association between personality and health indicators influenced by medication adherence because emerging (18-25) and young adults (2640) show little association between personality and such outcomes, while middle (40-60) and 
older adults (60+) show stronger associations (see Bogg \& Roberts, 2004). Without explicitly accounting for different personality-outcome associations for different ages, these may appear null. In contrast, a sample with only emerging and young adults would show no association while a middle and older adult population may show strong effects.

Social support and social relationships are also reliably associated with both personality and health. For example, social support has been linked to the Big Five (Hill, Weston, \& Jackson, 2018) as well as a number of other personality characteristics, including depression (e.g., Stice, Ragan, \& Randall, 2004) and self-esteem (e.g., DuBois et al., 2002; Krause, 1987). Moreover, in marriage, some spousal personality characteristics, such Conscientiousness, predict health above and beyond one's own personality (Roberts, Smith, Jackson, \& Edmonds, 2009). For example, in one study of older married couples, partner Conscientiousness had a protective effect health (Roberts et al., 2009). Moreover, this effect was even stronger when both partners were high in Conscientiousness, suggesting an interplay between personal and partner personality in predicting health.

Finally, education and cognitive ability represent another pathway between personality and health. Indeed, cognitive ability and intelligence are reliably associated with concurrent and later health and longevity, with those with lower cognitive ability typically demonstrating worse health outcomes (Hart, et al., 2003; Gottfredson \& Deary, 2004). The protective effect of intelligence on health is perhaps inextricably tied with socioeconomic status, with those with lower intelligence and low SES typically showing the poorest health outcomes (e.g., Hart, et al., 2003; Hart et al., 2005). 
Because education is an important component of achieved SES, one pathway between education and health may be through increased economic and health resources that improve health. However, because education and intelligence are often associated, another pathway through which both intelligence and education are thought to influence health may be through proper utilization of health-related resources (Deary, Whiteman, Starr, Whalley, \& Fox, 2004). Indeed, because important information on health can be complex and even adherence to medication protocols quite complicated, more education and higher intelligence may be associated with better reasoning and problem-solving skills that make utilization and adherence more probable (e.g., Gottfredson \& Deary, 2004).

In sum, health behaviors, social relationships, and education are important pathways through which personality becomes associated with health and longevity. Despite this, the existent evidence suggests that such pathways are complex and differ across personality characteristics and health outcomes, which highlights the importance of rigorous testing of the boundary conditions and directions of such effects.

\subsubsection{Social and Interpersonal Outcomes}

In the present study, I examine four social and interpersonal outcomes: moving in with a partner, marriage, divorce, and having a child move out of one's home. The pathways through which personality may influence each of these outcomes are diverse. Despite this, they share a number of commonalities, including that traits that are associated with more interpersonal, gregarious, and affiliative behaviors have been reliably associated with the start, maintenance, and dissolution of relationships (Ozer \& Benet-Martinez, 2006).

Many social and interpersonal outcomes are normative and age-graded, such that they tend to occur at specific points in the lifespan. Societal expectations that such outcomes occur at certain 
points in the lifespan have been posited to partially account for so-called normative changes toward being more Agreeable and Conscientious and less Neurotic (Neyer \& Lehnart, 2007). However, these personality characteristics also predict social and interpersonal outcomes, often at a greater magnitude than experiencing these events predict personality changes (Neyer, 1999). As a result, societal drives to accomplish age-graded tasks, like starting and maintaining relationships and having children may also underlie why personality characteristics predict social and interpersonal outcomes.

For example, if starting a romantic relationship in early adulthood is a social goal, those who are more Extraverted may have larger social networks through which to meet potential partners because Extraversion is associated with behaviors like going to parties and talking to strangers. Similarly, those who are more Emotionally Stable and more Agreeable may be more likely to initiate a positive relationship with a potential partner because they may be more cooperative, trusting, worry less, and generally exhibit more stable emotions.

Personality also predicts relationship maintenance and dissolution. The general pathway to relationship maintenance (e.g., long-term partnerships, marriage) and dissolution (e.g., divorce, separation) appears to often be through satisfaction (see Solomon \& Jackson, 2014a). Despite this, different personality characteristics may be important at different phases in a relationship, with, for example, one study demonstrating that Agreeableness and Conscientiousness are most predictive of satisfaction for dating partners, while Extraversion is most predictive of satisfaction for married partners (Watson, Hubbard, \& Wiese, 2000). That different personality characteristics predict satisfaction at different phases of relationships suggests that behaviors related to these traits, like cooperativeness and organization, may be more important for dating couples, while social behaviors and dominance may be more important for married couples. 
Personality also appears to have direct effects on relationship dissolution as well as indirect effects through satisfaction (Solomon \& Jackson, 2014a). In one study, for example, higher actor and partner Neuroticism and Openness directly predicted the dissolution of a relationship, while higher actor and partner Neuroticism and Openness and lower Agreeableness and Conscientiousness indirectly predicted relationship dissolution through their association with relationship satisfaction. One reason this may occur is because individuals who are low in Agreeableness tend may engage in negative communication patterns (e.g., Donnellan, Conger, \& Bryant, 2004; Gottman, Coan, Carrere, \& Swanson, 1998) and individuals who are higher in Neuroticism may be more emotionally reactive to conflict and ruminate on it more after (e.g., Bolger \& Schilling, 1991). Moreover, individuals who are lower in Conscientiousness may be more impulsive in ways that could escalate relationship conflict (Robins, Caspi, \& Moffit, 2001).

\subsubsection{Work and Educational Outcomes}

I also examine four work and educational outcomes, including educational attainment, starting a first job, becoming unemployed, and retiring. Of all the examined outcomes, the prediction of work and educational outcomes has perhaps the longest catalogue of empirical studies, with work dating back to the study of will (Webb, 1915) and educational achievement. Given its long history, it is perhaps not surprising that the proposed pathways through which personality predicts both work and educational outcomes is nearly as long.

Despite the myriad of pathways through which personality has been thought to predict work and educational outcomes, many of these can be categorized as pathways through which personality is associated with the capacity to perform, opportunity to perform, and the willingness to perform (Poropat, 2009; Traag, van der Valk, van der Velden, de Vries, \& Wolbers, 2005). 
First, the capacity to perform refers to the skills, knowledge, and intelligence that an individual has, which have rather straightforward links to educational and work outcomes because they are largely necessary for completing educational work, being hired in a job, and performing well in one. Thus, personality's link to educational and work outcomes through capacities are through personality characteristics that govern who gains skills and knowledge. For example, individuals with higher Locus of Control tend to seek intellectual stimulation and be enthusiastic about learning new things (e.g., Deci \& Ryan, 1980). As such, they may be more likely to do better in school and be better workers because these behaviors may push them to gain the knowledge and skills necessary for academic and occupational success. Moreover, individuals who are higher in Conscientiousness and lower in Neuroticism are more likely to continue to pursue goals in the face of setbacks, which may also foster skill development (see Jackson et al., 2009).

Second, the opportunity to perform captures the barriers and environmental constraints that individuals face in educational and work domains, including socioeconomic status (SES), race, and gender. There is ample evidence that each of these are greatly predictive of educational and work outcomes (e.g., Bodovski, 2010; Saifi \& Mehmood, 2011; Watt \& Eccles, 2008). As a result, when considering how opportunities to perform are a pathway between personality and outcomes necessitates considering which personality characteristics allow individuals to experience positive educational- and work-related outcomes and avoid negative ones.

Finally, the willingness to perform captures education- and work-related goals and motivation. The role of goals and motivation in education and work are diverse, ranging from broad goals, like going to school and getting a job, to much more narrow goals, like finishing a project by a deadline or to some set of standards. Despite this, evidence of personality's links to goals is quite consistent, with individuals who are higher in Conscientiousness, Locus of Control, and Self- 
Esteem and lower in Neuroticism and Depression more likely to show initiative, persist in the face of adversity, and to pursue goals to fruition (Willingham, Pollack, \& Lewis, 2002). In addition, Conscientiousness, Extraversion, and Openness have been linked to learning goal orientations (Payne, Youngcourt, \& Beaubien, 2007), which are greatly conducive to building skills necessary for educational and occupational success.

Social relationships and support have also been demonstrated to influence the relationship between personality and work and educational achievement. For educational outcomes, social support is positively related to academic success in adolescents (e.g., Lee \& Smith, 1999). There are multiple pathways through which social support could influence educational outcomes. First, parents and peers may help individuals set goals that help or hinder success (e.g., Cotton \& Wikelund, 1989). Second, parents and peers and may dictate or constrain the behaviors individuals engage in that influence academic outcomes, such as studying or extracurricular activities (Bodovski, 2010; Credé \& Kuncel, 2008). Third, relationship quality and satisfaction may influence overall well-being in ways that enhance or inhibit motivation in different activities (e.g, Etzion, 1984).

There are also multiple pathways through which personality may predict occupational outcomes. For example, spousal personality predicts intrinsic (e.g., satisfaction) and extrinsic (e.g., prestige) occupational success, above and beyond the effect of one's own personality characteristics (Solomon \& Jackson, 2014b). Moreover, relationship satisfaction may also influence work performance and success through its impact on overall well-being.

In sum, personality has a long history of predicting educational and occupational outcomes. Although the pathways between personality and educational and occupational outcomes are 
diverse, they largely center around the capacities, opportunities, and willingness individuals have, each of which have been demonstrated to be related to personality. Finally, personality is critical in social relationships, which, in turn, are critical to both educational and occupational outcomes.

\subsubsection{Societal and Civic Outcomes}

Finally, the remaining two outcomes can be considered as more "societal" outcomes dealing with civic responsibility, including volunteering contact with the criminal justice system. Despite being lumped under the same overarching category, the two societal outcomes considered in the current paper have different pathways through which personality relates to them.

First, for volunteering, Agreeableness and Extraversion are the personality characteristics that are most consistently linked with volunteering. Volunteering and other prosocial behaviors are most often linked to personality through the motivations that individuals have for engaging in them (e.g., Finklestein \& Brannick, 2007). For example, one approach posits six motives for volunteering - career enhancement, learning new skills, social interaction, escape from negative feelings, personal development, and expressing prosocial values - each of which have links to personality (Carlo, Okun, Knight, \& Guzman, 2005; Clary et al., 1998). For example, individuals higher in Extraversion tend to both prefer higher levels of social interaction and to engage in more of it over time (Carlo et al., 2005). Similarly, individuals higher in Agreeableness tend to express more prosocial values and individuals high in Openness tend to value learning new skills (Carlo et al., 2005). Thus, although each of these personality characteristics may predict volunteering behaviors, the pathways through which they do differs.

Second, some attention has been given to the relationship between personality and contact with the criminal justice system (see Bollich, Beck, Jackson, \& Hill, 2020). In this domain, there is an 
acute interest to understand the pathways between personality and criminal behavior in the hopes of developing interventions that may reduce the likelihood of individuals engaging in criminal behavior. Criminal behavior has been most consistently linked to self-control (a facet of Conscientiousness; Bechtold, Cavanagh, Shulman, \& Cauffman, 2014; Burt, Sweeten, \& Simons, 2014), Depression (Chen \& Simons-Morton, 2009; Kofler et al., 2011), Self-Esteem (Donnellan, Trzesniewski, Robins, Moffitt, \& Caspi, 2005; Trzesniewski, Donnellan, Moffitt, Robins, Poulton, \& Caspi, 2006), and Locus of Control (Ahlin, 2014; Blatier, 2000), such that those who are higher in these characteristics are less likely to commit criminal actions. For Conscientiousness, the proposed pathway is because individuals who can constrain their impulses are less likely to engage in illegal impulsive behaviors. For Self-Esteem and Depression, individuals with higher Self-Esteem and lower in Depression are more likely to act aggressively (Dutton \& Karakanta, 2013). Finally, individuals who have lower internal Locus of Control are more likely to engage in criminal behavior. This may be because they perceive their environment as something they cannot control or that works against their advantage, leading them to turn to extralegal actions in order to achieve desired ends.

\subsection{Estimating Personality Predictions}

Despite all of these pathways between personality and health-related, social and interpersonal, work and educational, and societal outcomes, each remains a multiply determined outcome, which makes delineating precise pathways difficult. I use two different methods to disentangle the difficulties in assessing and interpreting previous personality prediction models: propensity score matching and specification curve analysis.

Given that life outcomes cannot be experimentally manipulated and subjective evaluations of life outcomes are often unavailable, research examining life outcomes and personality prediction 
must use alternative methods to improve upon previous work. Using propensity score matching to approximate random assignment of life events is useful in this regard as it allows observational data to mimic the conditions found in experimental designs. Using propensity score matching, individuals can be matched on a number of psychological, social, behavioral, and demographic pathways that may capture some of the pathways through which personality predicts outcomes. For example, in unmatched samples, individuals who are older, exercise less, and smoke are more likely to experience major health events (Hampson, 2007). However, age and health behaviors have been linked to changes in Conscientiousness (Mroczek \& Spiro, 2007). Together, this indicates baseline differences might influence an individual's level on personality, which, in turn, impacts whether the personality characteristic predicts and outcome. Propensity score matching controls for some pathways through which background experiences and characteristics may influence personality and its relationship to outcomes. To do so, background characteristics - excluding the target personality characteristic - are used to derive a propensity score, which is akin to a risk ratio or odds ratio, of how likely they are to experience an outcome. Then, a sample matched on those background characteristics is created by choosing individuals with similar propensity scores but different outcomes until there are no more matches. This creates a smaller subset of the original sample, who are now indirectly matched on the target background characteristics but not personality. Thus, if personality remains associated with the outcome in the matched sample, this is after accounting for the influence of background characteristics on personality. In other words, what remains is a more unbiased estimate of the personality-outcome association.

For example, one study examined how starting a first romantic relationship predicted Big Five personality, self-esteem, depression, and life satisfaction at a later timepoint (Wagner et al., 
2015). Because baseline levels of those characteristics as well as a number of demographic, appearance, and health-related variables may influence who starts a relationship, individuals who were and were not in a relationship at the later timepoint were first matched on those baseline characteristics. Figure 1.1 presents the resulting propensity score balance plot before (open circles) and after (solid circles) propensity score matching. As is clear from the figure, effect size differences between groups were greatly reduced following matching, meaning that when the matched data are used, bias due to baseline differences between groups should be greatly or completely attenuated. Indeed, although single young adults were less Extraverted and had lower Self-Esteem than young adults who entered into romantic relationships, after accounting for selection bias through matching, single young adults had higher mean Self-Esteem than those in relationships (Wagner et al., 2015). In other words, matching individuals on background characteristics can greatly impact personality selection effects on life events. Without matching, selection effects that are seemingly driven by personality may be driven by the direct or indirect influence of other factors. 


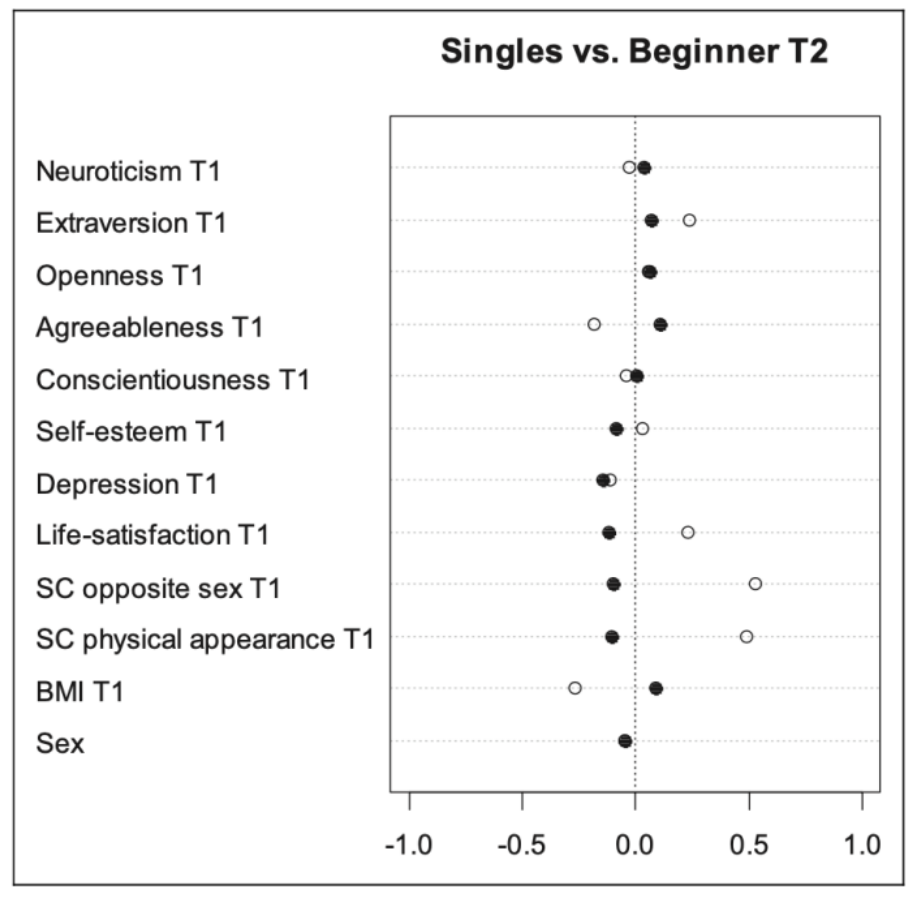

Figure 1.1. Sample standardized mean differences between singles and beginners across baseline measures in matched (filled) and unmatched (unfilled) circles from Wagner et al. (2015).

Although a number of studies have investigated specific pathways, none, to my knowledge, have tested for the robustness these effects, investigating which pathways reliably predict an outcome above and beyond other pathways. Using propensity score matching is a robust method for eliminating baseline differences on large sets of background characteristics. As a result, using propensity score matched samples to examine personality prediction is a very conservative test because any remaining shared variance between personality and outcomes is above and beyond huge sets of other differences that reflect pathways through which the two may have become associated. Moreover, because none have investigated these effects mega-analytically, testing for overall as well as study-specific effects, remaining associations are also those that remain even when controlling for cross-sample differences. Thus, the present study extends previous research on the pathways between personality and outcomes by controlling for selection bias and testing for boundary conditions. 


\subsection{Boundary Conditions}

Understanding the processes through which personality prediction occurs may partially delineate the boundary conditions of when and for whom personality predicts outcomes. However, even seemingly strong theoretical and empirical evidence for an effect may not provide a complete picture of its robustness. In part, this is because the pathways through which personality becomes associated with outcomes is quite heterogeneous. As a result, different investigations tend choose some - but not all - components of proposed pathways when testing personality-outcome associations and are typically not consistent in which pathways are tested.

For example, a review of the relationship between personality characteristics (e.g., hostility, optimism, the Big Five) and mortality (see Table 2 in Roberts et al., 2007) revealed heterogeneity in how such associations were tested. Although the studies were heterogeneous in many ways, perhaps the largest and most obvious was in which covariates (or controls) were included in each study, including age, biological sex, race, blood pressure, smoking, marital status, cohabitation status, physician ratings of health, depression, IQ, education, income, SES, and expected survival, to name just a few. In total, the reported studies included a total of more than 50 unique covariates, with few studies using the same covariates. Although most of these covariates have been theoretically or empirically identified as components of the pathway between personality and mortality, there has been no systematic study of to date how such covariates influence personality-outcome associations - that is, in the boundary conditions of the proposed pathways.

Recently, Simonsohn and colleagues (2015) proposed specification curve analysis as a solution to the effect of publication bias on estimating the robustness of statistical tests (Simonsohn et al., 2015). Specification curve analysis proceeds in three parts: identifying plausible specifications, 
testing all combinations of plausible specifications, and using an inferential permutation-based test to test whether the phenomena is robust under the null of no effect. Each of these stages will be discussed in more detail below. Specification curve analysis has been successfully used, for example, in testing the robustness of birth order effects (Rohrer, Egloff, \& Schmukle, 2017) and how Black-sounding names predict hiring decisions (Simonsohn et al., 2015). But despite its ability to test both the robustness of personality-outcome associations and to identify covariates that have the largest impact on such associations, to date specification curve has been applied in almost no cases within personality psychology.

Specification curve analysis is useful for both testing the overall robustness of personalityoutcome associations when controlling for covariates that have been theoretically and empirically linked to personality or outcomes as well as for delineating which covariates appear to be most consequential in influencing the presence, direction, and magnitude of personalityoutcome associations. Similar to using propensity score matched samples to estimate personality prediction, using specification curve analysis to examine the robustness of personality prediction is very conservative. If a personality characteristic can predict an outcome above and beyond combinations of the covariates identified as likely pathways between the two, then the resulting association is likely the lower bound of the predictive power of personality.

To demonstrate how I will use specification curves to make inferences about both the robustness of personality-outcome associations as well as consequential analytical choices, consider Figure 1.2, which displays a sample specification curve predicting Locus of Control from birth order from Rohrer and colleagues (2017). From the figure, it seems immediately clear that the association between the two is not robust. Despite this, by examining the specification curve in the top part of the figure and the patterns of covariates and operationalizations in the lower part 
of the figure, which have consequences for the presence, direction, and magnitude of the association becomes clear. For example, looking at the left side of the figure, the only specifications with significant effects, all of which were negative, were for siblingships of three in which the age gaps were between 1.5 and 5 years and that used within-family analysis. Examining the right side, in contrast, it becomes clear that the only positive effects were for siblingships of four that used within-family analysis. Indeed, there is clear cusp at the point in the specification curve when within-family analysis was used with siblingships of four. Thus, specification curve is a useful tool for both determining robustness as well as covariates that are consequential to robustness, which in the current example are age gaps, types of analyses, the number of siblings.

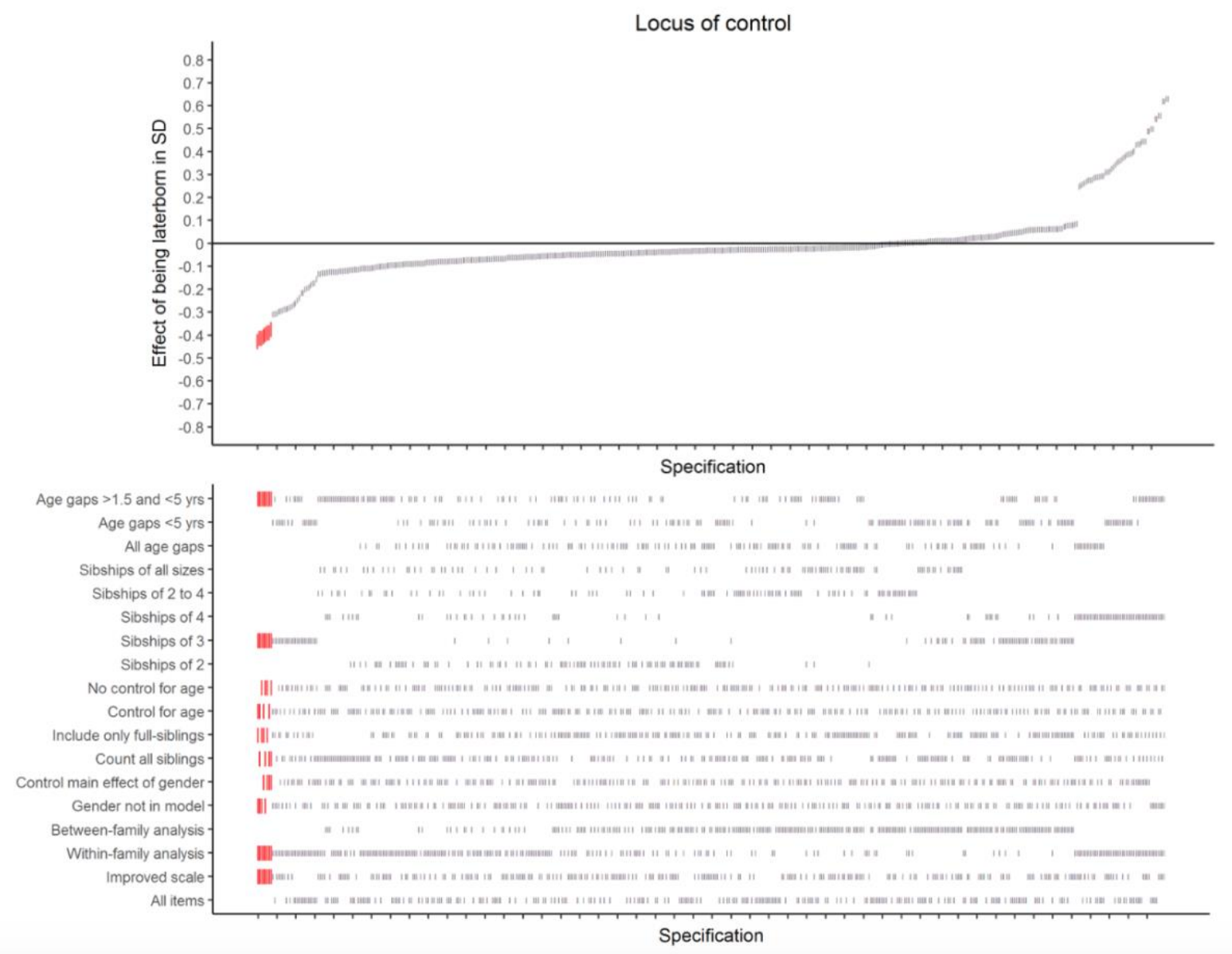


Figure 1.2. Sample specification curve of birth order predicting Locus of Control from Rohrer et al. (2017). The top panel includes the specification curve with points ordered by effect size, while the bottom panel demonstrates which covariates and operationalization were included in each specification. Longer, red lines indicate significant birth order-Locus of Control effects, while shorter, black lines indicate non-significant effects.

\subsection{The Present Study}

Together, the aforementioned evidence suggests that previous investigations of personalityoutcome associations have not adequately accounted for reverse causality and selection bias nor have they examined the boundary conditions of the effects, which has left the robustness conditions of personality-outcome associations unknown. Moreover, previous investigations have not systematically addressed which covariates fundamentally influence personalityoutcome associations or how study-level characteristics may influence them. Using a megaanalytic framework coupled with propensity score matching to control for selection bias specification curve analysis to test boundary conditions, the present study mega-analytically examines the robustness and boundary conditions of personality prediction using 14 personality characteristics to predict 14 life outcomes across eight different person and study-level moderators in 10 longitudinal panel studies. 


\section{Chapter 2: Method}

This study was preregistered on the Open Science Framework (https://osf.io/tcysh). Materials, code, and results are available on GitHub (https://github.com/emoriebeck/selection), the Open Science Framework (https://osf.io/usqzp/), and an R Shiny web application (https://emoriebeck.shinyapps.io/selection).2

\subsection{Participants}

\subsubsection{Add Health}

The National Study of Adolescent to Adult Health (Add Health; Harris \& Udry, 2018) is an ongoing longitudinal study of adolescents in the United States that began as a response to a federal mandate to better understand adolescent health. The data are available online at https://www.icpsr.umich.edu/icpsrweb/DSDR/studies/21600.

The initial sample of participants included approximately 20,000 students who completed at home administrations of the study. Four waves of data collection (1994-1995, 1996, 2001-2002, and 2008) have been completed. The latest release contains data through 2008. Another wave of collection began in 2016 but has not yet been released. More documentation of the data are available at https://www.icpsr.umich.edu/icpsrweb/content/DSDR/add-health-dataguide.html\#intro.

Sample sizes vary by year, from 14,738 (1996) to 20,745 (1994-1995). This provides $99 \%$ power to detect a correlation effect size of $\sim .03$. 


\subsubsection{BHPS}

The British Household Panel Study (BHPS; University of Essex, 2018) is a longitudinal study of households in the United Kingdom. These data are available online, through application, from https://www.iser.essex.ac.uk/bhps/about/latest-release-of-bhps-data.

Participants were recruited from more than 15,000 individuals from approximately 8,000 households in the United Kingdom. Data have been collected annually since 1991 from approximately 10,000 individuals (5,500 households) in Great Britain but expanded to include Scotland and Wales in 1999 and Northern Ireland in 2001. In 2010, the BHPS stopped data collection, but 6,700 of the current 8,000 participants were solicited to become part of the broader Understanding Society study (University of Essex, 2019). Participants can be matched across studies, so I will use additional data on the original BHPS participants from the Understanding Society study for additional waves of outcome data.

Sample sizes vary by year, ranging from 10,264 (1991) to 14419 (2008). This provides 99\% power to detect a zero-order correlation effect size of $\sim .05$, two-tailed at alpha .05 .

\subsubsection{GSOEP}

The German Socioeconomic Panel Study (GSOEP; Socio-Economic Panel, 2017) is an ongoing longitudinal study of Germans collected by the German Institute of Economic Research (DIW Berlin). The data are freely available at https://www.diw.de/soep by application.

Data have been collected annually since 1984 (the latest data release includes data up to 2017). Participants have been recruited from more than 11,000 households, which are nationally representative of private German households. 20,000 individuals are sampled each year, on average. It is critical to note that the GSOEP samples households, not individuals, and the 
households consist of individuals living in both the "old" and "new" federal states (the former West and East Germany), foreigners, and recent immigrants to Germany.

Sample size varies by year, ranging from approximately 10,000 (1989) to 31,000 (2013). This provides $99 \%$ power to detect a zero-order correlation effect size of $\sim .06$, two-tailed at alpha < .05 .

\subsubsection{HILDA}

The Household Income and Labour Dynamics in Australia (HILDA; Wilkins, Laß, Butterworth, \& Vera-Toscano, 2019) study is an ongoing longitudinal study of Australian households. These data are available through application from https://melbourneinstitute.unimelb.edu.au/hilda/fordata-users.

Participants were recruited from more than 17,000 individuals. Data have been collected annually since 2001. The latest data release includes 17 waves of data from 2001 to 2017. More documentation can be found in the HILDA data dictionary at https://www.online.fbe.unimelb.edu.au/HILDAodd/srchSubjectAreas.aspx.

Sample sizes vary by year, ranging from 12,408 (2004) to 17,693 (2016). This provides $99 \%$ power to detect a zero-order correlation effect size of $\sim .03$, two tailed at alpha .05 .

\subsubsection{HRS}

The Health and Retirement Study (HRS; Juster \& Suzman, 1995) is an ongoing longitudinal study of households in the United States. These data are available at https://hrs.isr.umich.edu by creating a free account.

Participants were recruited from more than 35,000 individuals from the financial households of individuals born between 1931 and 1941 in the US. Data have been collected biannually since 
1992. The latest data release includes data up to 2016 . On average, 10,000 individuals are sampled each wave. More information on the HRS can be found at https://hrs.isr.umich.edu/documentation/survey-design, but, in short, the HRS is a nationally representative sample of adults over 50 in the US. It is critical to note that the HRS samples households of the original cohort and follows individuals and their spouses or partners until their death.

Sample size varies by year, ranging from approximately 7,500 (2014) to 15,500 (1992). (https://hrs.isr.umich.edu/sites/default/files/biblio/ResponseRates_2017.pdf). This provides 99\% power to detect a zero-order correlation effect size of $\sim .04$, two-tailed at alpha .05 .

\subsubsection{LISS}

The Longitudinal Studies for the Social sciences (LISS; Scherpenzeel, Das, Ester, \& Kaczmirek, 2010) is an ongoing longitudinal study of households in the Netherlands. These data are online, through application, from https://statements.centerdata.nl/liss-panel-data-statement.

Participants were approximately 8,000 Dutch-speaking individuals permanently residing in the Netherlands from 5,000 households. Data have been collected annually since 2007 . The latest data release includes 11 waves of data from 2008 to 2018. More documentation is available at https://www.dataarchive.lissdata.nl/study_units/view/1.

Sample sizes vary by year, ranging from 5,021 (2018) to 6808 (2008). This provides 99\% power to detect a correlation effect size of $\sim .04$, two-tailed at alpha .05. 


\subsubsection{MIDUS}

The Midlife in the United States (MIDUS; Brim, Ryff, \& Kessler, 2004; Ryff et al., 2012, 2016) study is an ongoing longitudinal study of adults in the United States. These data are available at http://www.icpsr.umich.edu by making a free account.

Participants included more than 10,000 individuals aged 25 or older from the United States. The present study uses data from MIDUS I, II, and III. MIDUS I was collected in 1995-1996.

MIDUS II was the follow-up to MIDUS I and was collected from 2004-2006. MIDUS III was an additional follow-up conducted from 2013-2014. More information can be found at http://midus.wisc.edu/findings/Understanding_Data_Collection_in_MIDUS.pdf.

Sample size varies by wave, with 7,108 (MIDUS I), 4,963 (MIDUS II), 3,294 (MIDUS III). This provides $99 \%$ power to detect a zero-order correlation effect size of $\sim .06$, two-tailed at alpha .05 .

\subsubsection{NLSY}

The Children to Young Adults Study (CNLSY; Bureau of Labor Statistics, 2017) is an offshoot study of the National Longitudinal Study of Youth (NLSY79), which is an ongoing longitudinal, nationally representative study in the United States. These data are available on the National Bureau of Labour Statistics website dedicated to the NLSY studies by creating a free account (https://www.nlsinfo.org/investigator/pages/login).

Participants included more than 12,500 individuals in the United States that began in 1979. The CNLSY includes the biological children of the NLSY79 participants and began in 1986. Children (10 years and older) completed separate inventories from children (or "young adults") aged 15 and above. Mothers of children 10 and below also completed surveys on the children prior to age 10. All participants were interviewed in addition to surveys. 
Sample sizes vary by year, ranging from approximately 1,331 (1979) to 11,530 (2016). This provides $99 \%$ power to detect a zero-order correlation effect size of $\sim .05$.

\subsubsection{SHP}

The Swiss Household Panel Study (SHP; Voorpostel et al., 2016) "Living in Switzerland" is an ongoing longitudinal study of households in Switzerland. These data are available online, through application from https://forsbase.unil.ch/project/study-public-overview/15632/0/.

Participants were recruited from more than 10,000 individuals from the households whose members represent the non-institutional resident population of Switzerland. Data have been collected annually since 1999. The latest data release includes data up to 2018. On average, about 5,000 individuals are sampled at each wave. More documentation can be found at https://forscenter.ch/projects/swiss-household-panel/documentation/, but, in short, the SHP is a nationally representative sample of Swiss citizens.

Sample sizes vary by year, ranging from 5,220 (2003) to 13,295 (2013). This provides $99 \%$ power to detect a zero-order correlation effect size of $\sim .06$, two tailed at alpha .05 .

\subsubsection{WLS}

The Wisconsin Longitudinal Study (WLS) is an ongoing longitudinal study of individuals who graduated from Wisconsin high schools in 1957 and were born between 1937 and 1940 as well as their siblings.

Graduates were randomly recruited from Wisconsin high schools in 1957 and born between 1937 and 1940. In 1977, at least one sibling of the original graduates from 2,100 families were also invited to participate in the study. As such, the study is representative of older, white Americans who have at least a high school education. Graduate data have been collected in in 1957, 1964, 
1975, 1992, 2004, and 2011, and sibling data have been collected in 1977, 1994, 2005, and 2011. Personality data were initially collected in 1992 for graduates and 1994 for siblings. More documentation can be found at https://www.ssc.wisc.edu/wlsresearch/.

Sample sizes vary by wave, from 9,681 (2011) to 10,317 (1957). This provides $99 \%$ power to detect zero-order correlation effect sizes of $\sim .06$, two-tailed at alpha .05.

\subsection{Measures}

In this study, I will test how 14 personality characteristics are associated with 14 life events and outcomes, while controlling for more than 50 background (matching) characteristics (propensity score matching) or covariates and operationalizations (specification curve analysis), testing eight potential moderators of personality predicting such outcomes. For a full overview of which personality, outcome, and moderator measures are available across data sets, see Table 2.1. 
Table 2.1

Personality and Outcome Measures Across Data Sets

\begin{tabular}{|c|c|c|c|c|c|c|c|c|c|c|c|}
\hline & & Add Health & BHPS & GSOEP & HILDA & HRS & LISS & MIDUS & NLSY & SHP & WLS \\
\hline \multirow[t]{14}{*}{ Personality } & Extraversion & $\mathrm{X}$ & $\mathrm{X}$ & $\mathrm{X}$ & $\mathrm{X}$ & $\mathrm{X}$ & $\mathrm{X}$ & $\mathrm{X}$ & $X$ & $\mathrm{X}$ & $\mathrm{X}$ \\
\hline & Agreeableness & $\mathrm{X}$ & $\mathrm{X}$ & $\mathrm{X}$ & $\mathrm{X}$ & $X$ & $\mathrm{X}$ & $\mathrm{X}$ & $\mathrm{X}$ & $X$ & $\mathrm{X}$ \\
\hline & Conscientiousness & $\mathrm{X}$ & $\mathrm{X}$ & $\mathrm{X}$ & $\mathrm{X}$ & $\mathrm{X}$ & $\mathrm{X}$ & $\mathrm{X}$ & $\mathrm{X}$ & $\mathrm{X}$ & $\mathrm{X}$ \\
\hline & Neuroticism & $\mathrm{X}$ & $\mathrm{X}$ & $\mathrm{X}$ & $\mathrm{X}$ & $\mathrm{X}$ & $\mathrm{X}$ & $\mathrm{X}$ & $\mathrm{X}$ & $X$ & $\mathrm{X}$ \\
\hline & Openness to Experience & & $\mathrm{X}$ & $\mathrm{X}$ & $\mathrm{X}$ & $\mathrm{X}$ & $\mathrm{X}$ & $\mathrm{X}$ & $\mathrm{X}$ & $\mathrm{X}$ & $\mathrm{X}$ \\
\hline & Self-Esteem & $\mathrm{X}$ & & $\mathrm{X}$ & & & $\mathrm{X}$ & $\mathrm{X}$ & $\mathrm{X}$ & $\mathrm{X}$ & $\mathrm{X}$ \\
\hline & Optimism / Pessimism & & $\mathrm{X}$ & $\mathrm{X}$ & & $\mathrm{X}$ & & $\mathrm{X}$ & & $\mathrm{X}$ & $\mathrm{X}$ \\
\hline & Satisfaction with Life & & $\mathrm{X}$ & $\mathrm{X}$ & $\mathrm{X}$ & $\mathrm{X}$ & $\mathrm{X}$ & $\mathrm{X}$ & $\mathrm{X}$ & $\mathrm{X}$ & \\
\hline & Positive Affect & $\mathrm{X}$ & & $\mathrm{X}$ & $\mathrm{X}$ & $\mathrm{X}$ & $\mathrm{X}$ & $\mathrm{X}$ & & $\mathrm{X}$ & $\mathrm{X}$ \\
\hline & Negative Affect & $\mathrm{X}$ & & $\mathrm{X}$ & $\mathrm{X}$ & $\mathrm{X}$ & $\mathrm{X}$ & $\mathrm{X}$ & & $\mathrm{X}$ & $\mathrm{X}$ \\
\hline & Locus of Control & $\mathrm{X}$ & $\mathrm{X}$ & $\mathrm{X}$ & $\mathrm{X}$ & $\mathrm{X}$ & & $\mathrm{X}$ & $\mathrm{X}$ & $X$ & $\mathrm{X}$ \\
\hline & Social Support & & $\mathrm{X}$ & $\mathrm{X}$ & & $\mathrm{X}$ & $\mathrm{X}$ & $\mathrm{X}$ & $\mathrm{X}$ & & \\
\hline & IQ & $\mathrm{X}$ & & & $\mathrm{X}$ & $\mathrm{X}$ & $\mathrm{X}$ & $\mathrm{X}$ & $\mathrm{X}$ & & $\mathrm{X}$ \\
\hline & Depression & $\mathrm{X}$ & $\mathrm{X}$ & $\mathrm{X}$ & $\mathrm{X}$ & $\mathrm{X}$ & $\mathrm{X}$ & $\mathrm{X}$ & $\mathrm{X}$ & $\mathrm{X}$ & $\mathrm{X}$ \\
\hline \multirow[t]{14}{*}{ Outcomes } & Marriage & $\mathrm{X}$ & $\mathrm{X}$ & $\mathrm{X}$ & $\mathrm{X}$ & $\mathrm{X}$ & $\mathrm{X}$ & $\mathrm{X}$ & $\mathrm{X}$ & $\mathrm{X}$ & $\mathrm{X}$ \\
\hline & Move in with a partner & $\mathrm{X}$ & $\mathrm{X}$ & $\mathrm{X}$ & $\mathrm{X}$ & & $\mathrm{X}$ & $X$ & $\mathrm{X}$ & $\mathrm{X}$ & \\
\hline & Divorce & $X$ & $\mathrm{X}$ & $X$ & $\mathrm{X}$ & $X$ & $\mathrm{X}$ & $\mathrm{X}$ & $\mathrm{X}$ & $\mathrm{X}$ & $\mathrm{X}$ \\
\hline & Child Birth & $\mathrm{X}$ & $\mathrm{X}$ & $\mathrm{X}$ & $\mathrm{X}$ & & $\mathrm{X}$ & $\mathrm{X}$ & $\mathrm{X}$ & $\mathrm{X}$ & $\mathrm{X}$ \\
\hline & Mortality & $\mathrm{X}$ & $\mathrm{X}$ & $\mathrm{X}$ & $\mathrm{X}$ & $\mathrm{X}$ & & $\mathrm{X}$ & $\mathrm{X}$ & $\mathrm{X}$ & $\mathrm{X}$ \\
\hline & First Job & $\mathrm{X}$ & $\mathrm{X}$ & $\mathrm{X}$ & $\mathrm{X}$ & & $\mathrm{X}$ & $X$ & $\mathrm{X}$ & $\mathrm{X}$ & \\
\hline & Retirement & & $\mathrm{X}$ & $\mathrm{X}$ & $\mathrm{X}$ & $\mathrm{X}$ & $\mathrm{X}$ & $\mathrm{X}$ & & $\mathrm{X}$ & $\mathrm{X}$ \\
\hline & Unemployment & $\mathrm{X}$ & $\mathrm{X}$ & $\mathrm{X}$ & $\mathrm{X}$ & $\mathrm{X}$ & $\mathrm{X}$ & $\mathrm{X}$ & $\mathrm{X}$ & $\mathrm{X}$ & $\mathrm{X}$ \\
\hline & Volunteering & $X$ & $\mathrm{X}$ & $\mathrm{X}$ & $\mathrm{X}$ & $\mathrm{X}$ & $X$ & $\mathrm{X}$ & $\mathrm{X}$ & $\mathrm{X}$ & $\mathrm{X}$ \\
\hline & Child Moves Out & & $\mathrm{X}$ & $\mathrm{X}$ & $\mathrm{X}$ & $\mathrm{X}$ & $\mathrm{X}$ & & $\mathrm{X}$ & $\mathrm{X}$ & \\
\hline & Major Health Event & $\mathrm{X}$ & $\mathrm{X}$ & $\mathrm{X}$ & $\mathrm{X}$ & $X$ & $\mathrm{X}$ & $\mathrm{X}$ & $\mathrm{X}$ & $X$ & $\mathrm{X}$ \\
\hline & Mental Health Event & $\mathrm{X}$ & $\mathrm{X}$ & $\mathrm{X}$ & $\mathrm{X}$ & $X$ & $\mathrm{X}$ & $\mathrm{X}$ & $\mathrm{X}$ & $X$ & $\mathrm{X}$ \\
\hline & Criminality & $\mathrm{X}$ & & & $\mathrm{X}$ & & & $\mathrm{X}$ & $\mathrm{X}$ & & $\mathrm{X}$ \\
\hline & Higher Ed & $\mathrm{X}$ & $X$ & $\mathrm{X}$ & $\mathrm{X}$ & $X$ & $X$ & $\mathrm{X}$ & $X$ & $X$ & $X$ \\
\hline
\end{tabular}




\subsubsection{Personality}

I will examine 14 personality characteristics: The Big Five (Extraversion, Agreeableness, Conscientiousness, Neuroticism, and Openness to Experience), Self-Esteem, Optimism / Pessimism, Subjective Well-being (Satisfaction with Life, Positive Affect, Negative Affect), Locus of Control, Social Support, Depression, and Intelligence / Cognitive Ability. Full information on the scales used for each of these measures for each study is presented Table 2.2. As is clear in Table 2, many of the measures are on different scales, so all personality indicators will be operationalized as Percentages $O$ f the Maximum Possible score (POMP) in the megaanalytic procedure (Cohen, Cohen, Aiken, \& West, 1999). 3 Unlike standardization procedures, that have a mean of zero and unit variance and can be misleading when data are skewed, POMP does not rescale sample variance based on the observed data, which overly relies on deviations from the mean. Instead, POMP relies on the ratio between the difference between a score and the minimum and the maximum and minimum, or

$P O M P=\frac{\text { observed }- \text { minimum }}{\text { maximum-minimum }} * 10$ 
Table 2.2

List of Personality Measures, Scales, and Available Waves Across Studies

\begin{tabular}{|c|c|c|c|}
\hline Measure & Source & Scale & Used (Available) \\
\hline Big 5 Add Health & $\begin{array}{l}6(\mathrm{~N}), 3(\mathrm{E}) \text {, and } 4(\mathrm{C}) \text { item scales (Young \& } \\
\text { Beaujean, 2011) }\end{array}$ & **1 "strongly agree" to 5 "strongly disagree" & $1995(1995,1996,2001)$ \\
\hline BHPS & $\begin{array}{l}15 \text { item BFI-S (Donnellan \& Lucas, 2008; John, } \\
\text { Naumann, \& Soto, 2008) }\end{array}$ & $\begin{array}{l}1 \text { "does not apply at all" to } 7 \text { " applies } \\
\text { perfectly" }\end{array}$ & 2005 (2004) \\
\hline GSOEP & $\begin{array}{l}15 \text { item BFI-S (John, Naumann, \& Soto, 2008, } \\
\text { and Lang, Lüdtke, \& Asendorpf, 2001) }\end{array}$ & $\begin{array}{l}1 \text { "does not apply at all" to } 7 \text { " applies } \\
\text { perfectly" }\end{array}$ & $\begin{array}{l}2005(2005,2009,2013, \\
2017)\end{array}$ \\
\hline HILDA & 30 items from the TDA-40 (Saucier, 1994) & $\begin{array}{l}1 \text { "does not describe me at all" to } 7 \text { "describes } \\
\text { me very well" }\end{array}$ & $\begin{array}{l}2005(2005,2009,2013, \\
2017)\end{array}$ \\
\hline HRS & 25 adjectives (Lachman \& Weaver, 1997) & **1 "a lot" to 4 "not at all" & $\begin{array}{l}2006 / 8(2006 / 8,2010 / 12 \\
2014 / 16)\end{array}$ \\
\hline LISS & 50 items IPIP-50 (Goldberg, 1992) & 1 "very inaccurate" to 5 "very accurate" & $2008(2008-2018)$ \\
\hline MIDUS & 25 adjectives (Lachman \& Weaver, 1997) & **1 "a lot" to 4 "not at all" & $1994(1994,2004,2013)$ \\
\hline NLSY & $\begin{array}{l}10 \text { item TIPI (Gosling, Rentfrow, \& Swann, } \\
\text { 2003) }\end{array}$ & 1 "disagree strongly" to 7 "agree strongly" & $2006(2006-2018)$ \\
\hline SHP & $\begin{array}{l}10 \text { item TIPI (Gosling, Rentfrow, \& Swann, } \\
\text { 2003) }\end{array}$ & 0 "not at all" to 10 "completely" & $2009(2009,2010,2011)$ \\
\hline WLS & $\begin{array}{l}34 \text { items from the "Big Five" inventory (John, } \\
\text { Donahue, \& Kentle, 1991) }\end{array}$ & **1 "agree strongly" to 6 "disagree strongly" & $1992 / 3(1992 / 3,2003 / 4)$ \\
\hline \multirow{2}{*}{$\begin{array}{c}\text { Self-Esteem Add Health } \\
\text { GSOEP }\end{array}$} & 6 items (e.g., "You have a lot of good qualities") & **1 "strongly agree" to 5 "strongly disagree" & $1995(1995,1996,2001)$ \\
\hline & 1 Item (positive attitude toward myself) & 1 "does not apply" to 7 "applies fully" & $\begin{array}{l}2010(2010,2015,2016, \\
2017)\end{array}$ \\
\hline LISS & $\begin{array}{l}\text { 10-item Rosenberg Self-Esteem Scale } \\
\text { (Rosenberg, 1965) }\end{array}$ & 1 "totally disagree" to 7 "totally agree" & $2008(2008-2018)$ \\
\hline MIDUS & 7 items (e.g., "Feel no good at all at times") & **1 "agree strongly" to 7 "disagree strongly" & $2004(2004,2013)$ \\
\hline NLSY & $\begin{array}{l}10 \text { item Rosenberg Self-Esteem Scale } \\
\text { (Rosenberg, 1965) }\end{array}$ & 1 "strongly disagree" to 4 "strongly agree" & $2000(1994-2018)$ \\
\hline SHP & 2 items (uselessness and satisfaction with self) & 0 "not at all" to 10 "completely" & $\begin{array}{l}2009(2009,2012,2015, \\
2018)\end{array}$ \\
\hline WLS & $\begin{array}{l}9 \text { items (e.g., "In general, I feel confident and } \\
\text { positive about myself") }\end{array}$ & **1 "agree strongly" to 6 "disagree strongly" & $1992 / 3(1992 / 3,2003 / 4)$ \\
\hline
\end{tabular}




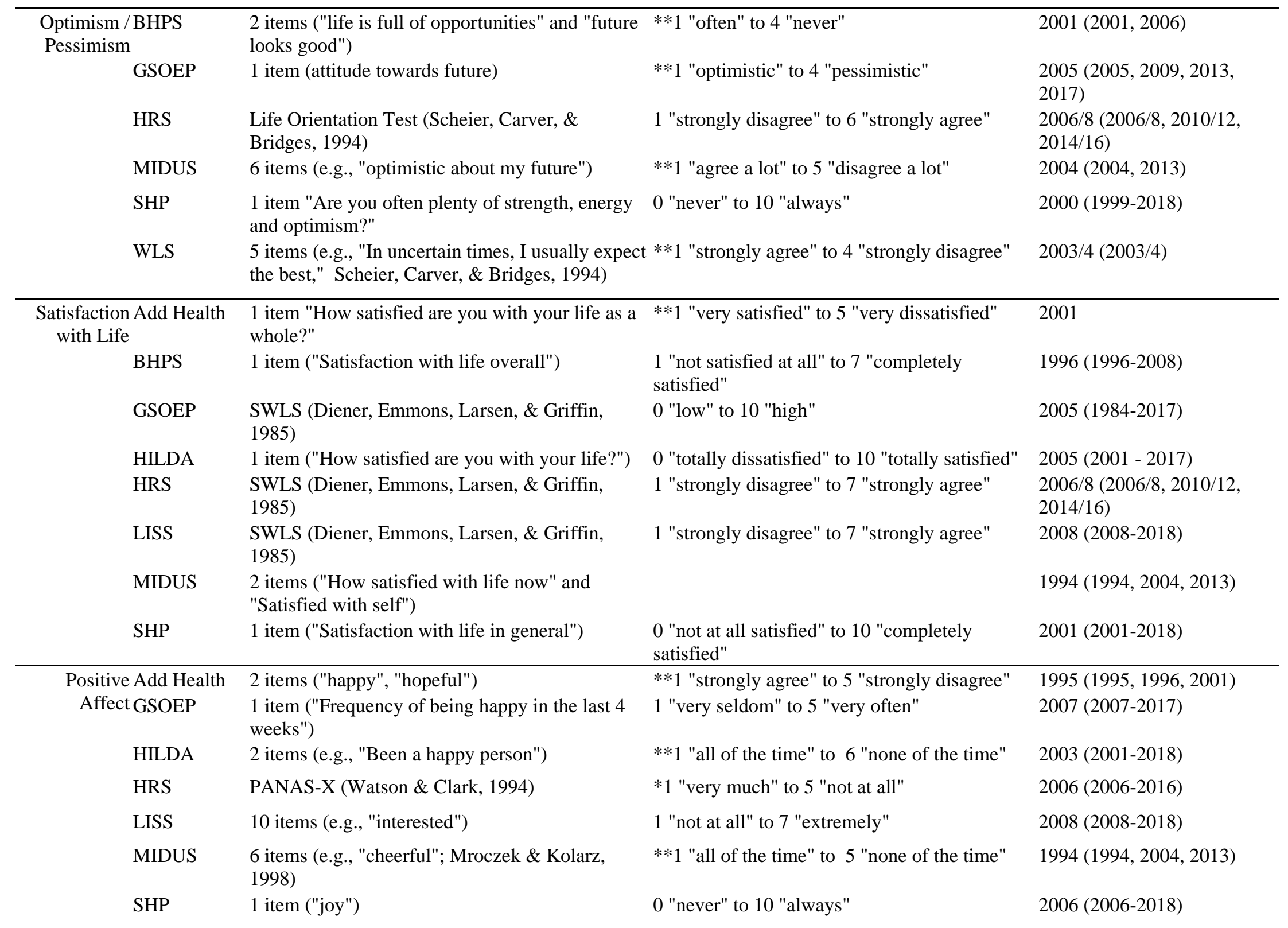


indices (Siblings only; Spielberger, 1980

Spielberger et al., 1970)

\begin{tabular}{|c|c|c|c|}
\hline \multirow{2}{*}{$\begin{array}{l}\text { Negative Add Health } \\
\text { Affect GSOEP }\end{array}$} & 2 items ("fearful", "sad") & $* * 1$ "strongly agree" to 5 "strongly disagree" & $1995(1995,1996,2001)$ \\
\hline & 3 items (angry, sad, worried) & 1 "very seldom" to 5 "very often" & $2007(2007-2017)$ \\
\hline HILDA & 3 items (e.g., "Felt down") & $* * 1$ "all of the time" to 6 "none of the time" & $2003(2001-2018)$ \\
\hline HRS & PANAS-X (Watson \& Clark, 1994) & *1 "very much" to 5 "not at all" & $2006(2016)$ \\
\hline LISS & 10 items (e.g., "distressed") & 1 "not at all" to 7 "extremely" & $2008(2008-2018)$ \\
\hline MIDUS & $\begin{array}{l}6 \text { items (e.g., "nervous"; Mroczek \& Kolarz, } \\
1998)\end{array}$ & $* * 1$ "all of the time" to 5 "none of the time" & $1994(1994,2004,2013)$ \\
\hline SHP & 3 items ("angry", "sad", "worried") & 0 "never" to 10 "always" & $2006(2006-2018)$ \\
\hline WLS & $\begin{array}{l}16 \text { items from the Spielberger anger and anxiety } \\
\text { indices (Siblings only; Spielberger, 1980; } \\
\text { Spielberger et al., 1970) }\end{array}$ & 0 days to 7 days & $1992 / 1993(1992 / 3,2003 / 4)$ \\
\hline $\begin{array}{l}\text { Locus of Add Health } \\
\text { Control }\end{array}$ & $\begin{array}{l}1 \text { item "When you get what you want, it's usually } \\
\text { because you worked hard for it." }\end{array}$ & **1 "strongly agree" to 5 "strongly disagree" & $1995 / 6(1995 / 6)$ \\
\hline BHPS & 7 items (e.g., "Life is full of opportunities") & $* * 1$ "often" to 4 "never" & $2001(2001,2006)$ \\
\hline GSOEP & 8 items (e.g., "No one can escape their destiny" & **1 "agree completely" to 4 "does not apply" & $1994(1994,1995,2013)$ \\
\hline HILDA & Pearlin Mastery Scale (Pearlin \& Schooler, 1978) & 1 "strongly disagree" to 7 "strongly agree" & $\begin{array}{l}2003(2003,2004,2007 \\
2011,2015)\end{array}$ \\
\hline HRS & $\begin{array}{l}10 \text { items (e.g., "What happens in my life is often } \\
\text { beyond my control." Lachman \& Weaver, 1998) }\end{array}$ & 1 "strongly disagree" to 6 "strongly agree" & $2006(2006-2018)$ \\
\hline MIDUS & $\begin{array}{l}12 \text { item Sense of Control Scale (Lachman \& } \\
\text { Weaver, 1998) }\end{array}$ & **1 "agree strongly" to 7 "disagree strongly" & $1994(1994,2004,2013)$ \\
\hline NLSY & Pearlin Mastery Scale (Pearlin \& Schooler, 1978) & 1 "strongly disagree" to 4 "strongly agree" & $2000(1994-2018)$ \\
\hline SHP & $\begin{array}{l}\text { Perceived Constraints subscale from the MIDI } \\
\text { Sense of Control Scale (Lachman \& Weaver, } \\
\text { 1998) }\end{array}$ & 0 "completely disagree" to 10 "agree" & $\begin{array}{l}2009(2009,2012,2015 \\
2018)\end{array}$ \\
\hline WLS & $\begin{array}{l}2 \text { items (e.g., "I have difficulty arranging my life } \\
\text { in a way that is satisfying to me") }\end{array}$ & **1 "agree strongly" to 6 "disagree strongly" & $1992 / 3(1992 / 3,2003 / 4)$ \\
\hline \multirow{2}{*}{$\begin{array}{l}\text { Social BHPS } \\
\text { Support GSOEP }\end{array}$} & 10 items (e.g., "importance of friends") & **1 "daily" to 6 "never" & $2001(2001,2002,2006)$ \\
\hline & $\begin{array}{l}2 \text { items (sum score of how many people support } \\
\text { career and are confidants) }\end{array}$ & $\begin{array}{l}\text { variety of codes indicating relationship of } \\
\text { person }\end{array}$ & $2006(2006,2011,2016)$ \\
\hline
\end{tabular}


HILDA 7 items (e.g. "How much can you rely on them if 1 "Strongly Disagree" to 7 "Strongly Agree" you have a serious problem")

HRS 7 items (e.g., "How much can you rely on them if *1 "A lot" to 4 "Not at all" 2006 (2006-2016) you have a serious problem")

LISS $\quad 12$ items (e.g., "Did you receive any counsel or 1 "no", 2 "once", 3 "several times" 2008 (2008-2017) advice from your father, over the past 3

months?")

MIDUS 24 items (e.g., "Family members/friends/partner $\quad * * 1$ "a lot" to 4 "not at all" care(s) about you")

NLSY 5 items (e.g., "How much can you open up to 1 "not at all" to 5 "a great deal"

$1994(1994,2004,2013)$ relatives if you need to talk about worries") SHP 10 items (practical and emotional support from 0 "not at all" to 10 "a great deal"
colleagues, neighbors, friends, close relatives, and partners)

\begin{tabular}{|c|c|c|c|}
\hline IQ Add Health & 1 Subtest of the WAIS (Picture Vocabulary) & Raw Score & $1995(1995)$ \\
\hline HILDA & $\begin{array}{l}3 \text { Subtests of the WAIS (Digits Backward, } \\
\text { Symbol Digits, and Word Pronunciation) }\end{array}$ & Sum Score & $2012(2012,2017)$ \\
\hline HRS & Vocab, Recall, and Mental Status & Sum Score (range 0 to 45 ) & 1996/8 (1996/8-2010/12) \\
\hline LISS & BSI problems in cogntive functions & T-Score & $2008(2008-2011)$ \\
\hline MIDUS & $\begin{array}{l}6 \text { Subtests of the WAIS (Word Recall (Immediate } \\
\text { and Delayed), Digits Backward, Category } \\
\text { Fluency, Number Series, Backward Counting) }\end{array}$ & Sum Score (range 0 to 185 ) & $2004(2004,2013)$ \\
\hline NLSY & Digit Span, Piat Reading and Math, Word Recall & Raw Score & $2000(1992-2016)$ \\
\hline Depression Add Health & 18 items from the CESD (Radloff, 1977) & $\begin{array}{l}0 \text { "never or rarely" to } 3 \text { "most of the time or all } \\
\text { of the time" }\end{array}$ & $\begin{array}{l}1996(1995,1996,2001, \\
2008)\end{array}$ \\
\hline BHPS & $\begin{array}{l}\text { Mental Health subscale from the SF- } 36 \text { Scale ( } 4 \\
\text { items; e.g., feeling run-down, melancholy) }\end{array}$ & $\begin{array}{l}* * 1 \text { "better than usual" to } 4 \text { "much less than } \\
\text { usual" }\end{array}$ & $1996(1991-2008)$ \\
\hline GSOEP & $\begin{array}{l}\text { Mental Health subscale from the SF-12 Scale (4 } \\
\text { items; e.g., feeling run-down, melancholy, Ware, } \\
\text { Kosinski, \& Keller, 1995) }\end{array}$ & **1 “Always" to 5 "Never" & $2002(2002-2016)$ \\
\hline HILDA & $\begin{array}{l}\text { Mental Health subscale from the SF- } 36 \text { Scale ( } 4 \\
\text { items; e.g., feeling run-down, melancholy) }\end{array}$ & 1 "yes", 2 "no & $2003(2001-2017)$ \\
\hline HRS & $\begin{array}{l}8 \text { items (e.g., "Lose appetite when sad", Kessler, } \\
\text { Mickelson, \& Williams, 1999) }\end{array}$ & $\begin{array}{l}* * 1 \text { "All or almost all of the time" to } 4 \text { "none or } \\
\text { almost none of the time" }\end{array}$ & 1992/4 (1992/4-2012/4) \\
\hline LISS & 5 items (e.g., "I felt very anxious") & 1 "never" to 6 "continuously" & $2008(2008-2018)$ \\
\hline
\end{tabular}


MIDUS

NLSY

Mickelson, \& Williams, 1999)

SHP

1 item "Do you often have negative feelings such 0 "never" to 10 "always"

as having the blues, being desperate, suffering

from anxiety or depression"

WLS Mental Health subscale from the SF-12 Scale (4 0 days to 7 days

items; e.g., feeling run-down, melancholy, Ware,

Kosinski, \& Keller, 1995)
$1994(1994,2004,2013)$

0 "rarely or none of the time/1 day" to 3 "most 2000(1994-2018)

or all of the time/5-7 days"

$2000(1999-2018)$

$1992 / 3(1992 / 3,2003 / 4)$

Note: ** indicates values are all reverse coded such that higher values indicate more likely, frequent, or characteristic on a measure. 


\subsection{Life Events and Outcomes}

I will investigate whether personality predicts 14 life events and outcomes. A full list of outcomes can be seen in Table 2.1. The outcomes chosen are those frequently tested in other studies and most likely to be included in large panel studies. For each outcome, participants reported whether the outcome had occurred in the survey year or years prior or, in some cases, the year an outcome or event first occurred. Responses will be coded as "1" for that event if participants reported experiencing it anytime between the year after the utilized personality measure to the latest available wave and "0" otherwise. Participants who experienced events prior to the first personality measure will be excluded (i.e. coded as "NA").

\subsubsection{Moderators}

In addition to matching for common demographic variables, like age and gender, I will additionally test whether these, as well as race, socioeconomic status (SES; parental education, parental occupational prestige, and gross wages), personality measure reliability, and the interval between personality measurement and the last available outcome measure (i.e. prediction interval) moderate the relationship between personality and outcomes. Because some have suggested that composite measures of SES are not adequate operationalizations of it (e.g., Cirino et al., 2002), the present study will take a tripartite approach to SES, investigating separate measures of parental education, parental occupational prestige, and gross income, which will be tested both as separate moderators of personality-outcome associations. Age will be coded at the time of measured personality. Age, parental occupational prestige, and gross wages will be tested as continuous Level 1 moderators, while race, gender, and parental education will be tested as binary Level 1 moderators. Reliability and prediction interval will be tested as continuous Level 2 moderators. The effect of study will be tested by examining the Level 2 Variance of personality-outcome associations (i.e. the tau matrix). 


\subsubsection{Matching Variables and Specification Curve Covariates}

Matching variables are those to be used in the propensity score analysis to match those who did or did not experience different life events or outcomes. Target variables can be roughly broken down into eight categories: demographics (e.g., sex/gender), activities (e.g., volunteering), financial (e.g., gross wages), household (e.g., number of household members), health (e.g., BMI), psychological (e.g., loneliness), relationship (e.g., marital status), and social (e.g., visits to friends). In order to construct more reliable measures and not exclude participants who did not respond to surveys in the same year as the personality measures (e.g., because some information is only collected at study entrance), matching variables were pooled across time, using all available data from the earliest wave of the study to the year of the utilized personality measure for each person. For numeric and continuous covariates, this was done via averaging. For nominal variables, composites were created using the maximum (e.g., had it ever previously occurred) and mode (e.g., what was the most frequently reported gender). Each of these were preregistered. Cross-study covariates will be operationalized using POMP, with the exception of core variables with meaningful scales (e.g., age, gender), which will be centered or dummy coded on the same scale (e.g., for all studies, gender will be coded as $0=$ male, $1=$ female). The full details of the construction of these variables are available in online codebook (https://osf.io/bdh6w/) and analytic script (https://emoriebeck.github.io/selection/dataCleaning.html).

\subsection{Analytic Plan}

\subsubsection{Study 1: Propensity Score Matched Mega-Analysis of Longitudinal Studies}

Confirmatory analyses will be tested using a series of multilevel Bayesian logistic regression models implemented using the brms (Bürkner, 2017, 2018) package in R (R core team, 2018). I 
used weak priors based on previous effect sizes demonstrated in personality-outcome studies for all fixed effects. However, given the sample sizes in the present model, the data are likely to overwhelm these priors. I used half Cauchy priors for Level 2 variances and LKJ Cholesky covariance priors for Level 2 covariances.

The analysis consists of three main parts, with interim steps to link these together: multiple imputation, propensity score matching, and tests of selection effects using multilevel Bayesian logistic regression models.

First, I used multiple imputation to impute missing data for the matching variables separately for each study. Before doing so, I first created composites of the matching variables up to the year for which I use personality data for each study. I elected to use composites rather than survey responses from the year of personality measures due to irregularities in survey construction and responses that would severely restrict the number of observations. To ensure transparency, I conducted all analyses using the raw data imported directly from the data files obtained from data maintainers for each study, and all steps in creating the composites are documented in an extensive codebook containing the item lists, text, scales, and recoding of all variables for all studies. Importantly, the code used to recode each variable is available in the codebook along with its original scale. Moreover, all steps are documented in files and code shared on the Open Science Framework and GitHub.

The composite matching variables will then be used in multiple imputation and propensity score matching, which requires completely non-missing data. Multiple imputation will be conducted using the mice package (Buuren \& Groothuis-Oudshoorn, 2010) in R. I will impute 5 data sets 
Second, I will use the multiply imputed data to calculate propensity scores for each of the multiply imputed data sets for each outcome, trait, and study combination separately.4 In addition, I will conduct the procedure separately for each individual difference characteristic, such that each propensity score matched set will be matched on all matching variables and the matched sample will be based solely on the population who had both outcome and personality data, making this an extremely conservative test of the relationship between personality and outcomes. Finally, separate propensity score matched sets will also be generated to test each of the Level 1 moderating questions (age, gender, SES, and ethnicity). For Level 2 moderators (reliability and prediction interval), matching sets created for simple personality-outcome associations that include all variables in matching will be used.

The propensity score matching procedure attempts to equate those who did or did not experience an outcome by assigning each person a risk score based on a number of background factors. Then each person who experienced the outcome is matched with someone else in the control group who had a similar "risk" of experiencing the outcome. Matching will be done using the matchit package in $\mathrm{R}$ (Ho, Imai, King, \& Stuart, 2011). Because the sample sizes of the groups of people who experience specific outcomes are much smaller than the individuals who did not experience them, we choose to use propensity score matching rather than propensity score weighting. I will begin by using "nearest neighbor" matching and a ratio of 2 to 1 and a caliper width of $.25 \sigma$ (Guo \& Fraser, 2015) and iteratively increase the ratio for outcomes that were not balanced using these criteria.

Third, I will test for selection effects using a series of multilevel Bayesian logistic regression models using the brms package in R (Bürkner, 2017, 2018). In all models, the "no outcome" group will be considered the reference group. Using matched data sets that did not account for 
personality or moderators at the wave of personality assessment, I will predict outcomes from baseline personality. With the exception of moderator analyses, I will not include additional covariates (e.g., age, gender) in these models because these should be effectively controlled for in the propensity score matching procedure. The basic form of the model is as follows:

Level 1: $Y_{i j}=\beta_{0 j}+\beta_{1 j} * P_{i j}+\varepsilon_{i j}$

Level 2:

$$
\begin{aligned}
& \beta_{0 j}=\gamma_{00}+u_{0 j} \\
& \beta_{1 j}=\gamma_{10}+u_{1 j},
\end{aligned}
$$

where $\gamma_{00}$ is the average log odds of experiencing the outcome across all studies and $\gamma_{10}$ multiple of log odds change associated with a one-unit change in the percentage of the maximum of the possible (POMP) personality score. All results will be presented both as log odds and as odds ratios (OR) with $89 \%$ credible intervals $(\mathrm{CI})$, which have been demonstrated to be more robust than traditional frequentist $95 \%$ levels in Bayesian models with enough posterior samples (Kruschke, 2014; McElreath, 2020). $u_{0 j}$ indicates the difference between the average estimate of $\log$ odds of experiencing an outcome and the estimate for each study (i.e. the study-specific estimate of the log odds of each outcome), and $u_{1 j}$ indicates the difference between the average multiple of log odds associated with a one unit change in POMP personality score and the estimate for each study (i.e. the study-specific estimate of the personality-outcome relationship). Each of these will be presented as forest plots showing both study-specific and average effects.

Moderator analyses will extend the form of the core analyses by additional terms at Level 1 $\left(\beta_{2 j} *\right.$ moderator $_{i j}$ and $\beta_{3 j} * P_{i j} *$ moderator $_{i j}$; age, ethnicity, gender $)$ or Level $2\left(\gamma_{01} *\right.$ 
moderator $_{j}$ and $\gamma_{11} *$ moderator $j$; reliability, prediction interval). For Level 1 moderators, I will include random effects that will capture the study-specific effects for each moderator term (i.e. $u_{2 j}$ and $u_{3 j}$ ). The effect of study will be tested by examining the Level 2 variances of random slopes (i.e. $\tau_{11}, \tau_{22}$, and $\tau_{33}$ ).

\subsubsection{Study 2: Specification Curve Analysis of Longitudinal Studies}

As a second test of the robustness of prospective personality-outcome associations, I will conduct a specification curve analysis for each personality-outcome combination (Simonsohn et al., 2015).

Specification curve analysis is carried out in three main steps. First, the researcher defines the set of reasonable model and variable specifications. Second, the researcher estimates all of these reasonable specifications and represents them using a specification curve. Finally, the researcher constructs an inferential specification curve using join statistical analyses (Simonsohn et al., 2015). Constructing the specification curve in the second step serves both to show the full range of how specifications influence the statistical results as well as which specifications are most consequential for the results, while using the specification curve inferentially in the third step allows the researcher to make a statistical inference about whether the curve is inconsistent with a null hypothesis of no effect of personality on outcomes. This is most simply done with a permutation test in which the consequential variable (in the context of this paper, personality composites) is shuffled. Shuffling the consequential predictor and re-estimating the full set of possible specifications, except now when there is no reason to expect a relationship between predictors and either covariates or outcomes while preserving the relationships between covariates and outcomes, produces a distribution of specification curves under the null of no personality-outcome relationship. 


\section{Defining Specifications}

The first step in specification curve analysis involves defining the set of valid specifications. Because I am testing the relationship between different personality characteristics and outcomes, the set of valid specifications will differ across outcomes. Thus, a unique set of specifications was established for each outcome separately based on (1) covariates used in previous studies to predict those outcomes, (2) other covariates that I identified as plausibly related to each outcome based my literature review of the processes of personality prediction, and (3) relevant moderators used in this study.5 Because the focus is on covariates that may predict the outcome, the same set of covariates will be used to test all personality-outcome associations for each outcome, even when previous work has not linked a covariate to each of the tested personality characteristics. Table 2.3 presents the full set of covariates and operationalizations that will be used for each outcome, as well as the total number of specifications that result from the set of specifications. 
Table 2.3

Specification Curve Analysis Specifications for Each Outcome

Mental Move Child

\begin{tabular}{|c|c|c|c|c|c|c|c|c|c|c|c|c|c|c|c|}
\hline Measure & S T & $\begin{array}{l}\text { Mort- } \\
\text { ality }\end{array}$ & $\begin{array}{r}\text { Health } \\
\text { Event }\end{array}$ & $\begin{array}{c}\text { Health } \\
\text { Event }\end{array}$ & $\begin{array}{l}\text { Child- } \\
\text { birth }\end{array}$ & $\begin{array}{l}\text { in with } \\
\text { Partner }\end{array}$ & $\begin{array}{c}\text { Marr- } \\
\text { iage }\end{array}$ & $\begin{array}{l}\text { Div- } \\
\text { orce }\end{array}$ & $\begin{array}{c}\text { Moves } \\
\text { Out }\end{array}$ & $\begin{array}{c}\text { Higher } \\
\text { Ed }\end{array}$ & $\begin{array}{c}\text { First } \\
\text { Job }\end{array}$ & $\begin{array}{l}\text { Unem- } \\
\text { ployed }\end{array}$ & Retire & $\begin{array}{l}\text { Volun- } \\
\text { teer }\end{array}$ & $\begin{array}{l}\text { Criminal } \\
\text { Behavior }\end{array}$ \\
\hline Age & $\mathrm{C} \mathrm{C}$ & $\mathbf{X}$ & $\mathbf{X}$ & $\mathbf{X}$ & $\mathbf{X}$ & $\mathbf{X}$ & $\mathbf{X}$ & $\mathbf{X}$ & $\mathbf{X}$ & $\mathbf{X}$ & $\mathbf{X}$ & $\mathbf{X}$ & $\mathbf{X}$ & $\mathbf{X}$ & $\mathbf{X}$ \\
\hline Parent Occ. Prestige & C P & $\mathbf{X}$ & $\mathbf{X}$ & $\mathbf{X}$ & $\mathbf{X}$ & $\mathbf{X}$ & $\mathbf{X}$ & $\mathbf{X}$ & $\mathbf{X}$ & $\mathbf{X}$ & $\mathbf{X}$ & $\mathbf{X}$ & $\mathbf{X}$ & $\mathbf{X}$ & $\mathbf{X}$ \\
\hline Parental Education & $\mathrm{B} \mathrm{P}$ & $\mathbf{x}$ & $\mathbf{X}$ & $\mathbf{x}$ & $\mathbf{X}$ & $\mathbf{X}$ & $\mathbf{X}$ & $\mathbf{X}$ & $\mathbf{x}$ & $\mathbf{X}$ & $\mathbf{x}$ & $\mathbf{X}$ & $\mathbf{x}$ & $\mathbf{X}$ & $\mathbf{x}$ \\
\hline Gross Wages & C P & $\mathbf{X}$ & $\mathbf{X}$ & $\mathbf{X}$ & $\mathbf{X}$ & $\mathbf{X}$ & $\mathbf{X}$ & $\mathbf{X}$ & $\mathbf{X}$ & $\mathbf{X}$ & $\mathbf{X}$ & $\mathbf{X}$ & $\mathbf{X}$ & $\mathbf{X}$ & $\mathbf{X}$ \\
\hline Education & N P & $\mathbf{x}$ & $\mathbf{X}$ & $\mathbf{x}$ & $\mathbf{X}$ & $\mathbf{X}$ & $\mathbf{X}$ & $\mathbf{X}$ & $\mathbf{X}$ & & $\mathbf{x}$ & $\mathbf{X}$ & $\mathbf{x}$ & $\mathbf{X}$ & $\mathbf{x}$ \\
\hline Gender & $\mathrm{B} P$ & $\mathbf{X}$ & $\mathbf{X}$ & $\mathbf{X}$ & $\mathbf{X}$ & $\mathbf{X}$ & $\mathbf{X}$ & $\mathbf{X}$ & $\mathbf{X}$ & $\mathbf{X}$ & $\mathbf{x}$ & $\mathbf{X}$ & $\mathbf{x}$ & $\mathbf{X}$ & $\mathbf{X}$ \\
\hline Race & $\mathrm{N} \mathrm{C}$ & $\mathbf{X}$ & $\mathbf{X}$ & $\mathbf{X}$ & $\mathbf{X}$ & $\mathbf{X}$ & $\mathbf{X}$ & $\mathbf{X}$ & $\mathbf{X}$ & $\mathbf{X}$ & $\mathbf{X}$ & $\mathbf{X}$ & $\mathbf{X}$ & $\mathbf{X}$ & $\mathbf{X}$ \\
\hline Disease & $\mathrm{B} \mathrm{C}$ & $\mathbf{X}$ & $\mathbf{X}$ & $\mathbf{X}$ & $\mathbf{X}$ & $\mathbf{X}$ & $\mathbf{X}$ & $\mathbf{X}$ & & $\mathbf{X}$ & $\mathbf{X}$ & $\mathbf{X}$ & $\mathbf{X}$ & $\mathbf{X}$ & $\mathbf{X}$ \\
\hline Self-Rated Health & $\mathrm{B} \mathrm{C}$ & $\mathbf{X}$ & $\mathbf{X}$ & $\mathbf{X}$ & $\mathbf{X}$ & $\mathbf{X}$ & $\mathbf{X}$ & $\mathbf{X}$ & & & & & $\mathbf{X}$ & $\mathbf{X}$ & \\
\hline Smoking & C P & $\mathbf{X}$ & $\mathbf{X}$ & $\mathbf{X}$ & $\mathbf{X}$ & $\mathbf{X}$ & $\mathbf{X}$ & $\mathbf{X}$ & & & & & & & $\mathbf{X}$ \\
\hline Alcohol Consumption & $\mathrm{C} \mathrm{C}$ & $\mathbf{X}$ & $\mathbf{X}$ & $\mathbf{X}$ & & $\mathbf{X}$ & $\mathbf{X}$ & $\mathbf{X}$ & & & & $\mathbf{X}$ & & & \\
\hline Exercise & $\mathrm{C} \mathrm{C}$ & $\mathbf{x}$ & $\mathbf{X}$ & $\mathbf{x}$ & $\mathbf{X}$ & $\mathbf{X}$ & $\mathbf{X}$ & $\mathbf{X}$ & & & & & $\mathbf{x}$ & $\mathbf{X}$ & \\
\hline BMI & $\mathrm{C} \mathrm{C}$ & $\mathbf{X}$ & $\mathbf{X}$ & $\mathbf{X}$ & $\mathbf{X}$ & & & & & & & & $\mathbf{X}$ & & $\mathbf{X}$ \\
\hline Marital Status & $\mathrm{N} \mathrm{C}$ & $\mathbf{X}$ & $\mathbf{X}$ & $\mathbf{X}$ & $\mathbf{X}$ & & & & $\mathbf{X}$ & $\mathbf{X}$ & & $\mathbf{X}$ & $\mathbf{X}$ & & $\mathbf{X}$ \\
\hline Number of Children & $\mathrm{C} \mathrm{C}$ & & & & & & & $\mathbf{X}$ & $\mathbf{X}$ & $\mathbf{X}$ & & & $\mathbf{x}$ & & $\mathbf{X}$ \\
\hline Parental Divorce & $\mathrm{C} \mathrm{C}$ & & & & $\mathbf{X}$ & $\mathbf{X}$ & $\mathbf{X}$ & $\mathbf{X}$ & & $\mathbf{X}$ & $\mathbf{X}$ & & & & $\mathbf{X}$ \\
\hline Functional Limitations & $\mathrm{N} \mathrm{C}$ & $\mathbf{x}$ & $\mathbf{X}$ & $\mathbf{X}$ & $\mathbf{X}$ & & & $\mathbf{X}$ & & & & $\mathbf{X}$ & $\mathbf{x}$ & & \\
\hline Religion & $\mathrm{B} \mathrm{C}$ & $\mathbf{X}$ & & $\mathbf{X}$ & $\mathbf{X}$ & $\mathbf{X}$ & $\mathbf{X}$ & $\mathbf{X}$ & $\mathbf{X}$ & $\mathbf{X}$ & $\mathbf{X}$ & & & $\mathbf{X}$ & \\
\hline
\end{tabular}

Note: Column $\mathrm{S}$ indicates whether variables are continuous (C), binary (B), or nominal (N), while column $\mathrm{T}$ indicates concurrent $(\mathrm{C})$ or prior $(\mathrm{P})$ measurement to personality. 


\section{Defining the specification curve}

The next step in specification curve analysis is to run the model, specifying all combinations of the specifications from the previous step. Once this is done, the target personality-outcome association is extracted from each model and ordered from strongest negative to strongest positive to define the specification curve. As can be seen in Figure 2 in the sample specification curve from Rohrer et al. (2017), a visual representation of which specifications were used in each model is included below the curve. Thus, I will define a total of 196 specification curves (14 personality characteristics x 14 outcomes). Although I could compute separate models for each

study and use the same Bayesian multilevel logistic regression used in propensity score analyses, the number of specifications is so large that this is computationally intractable, even using a high-performance computing center. In addition, because fixed effects (and not Level 2 variances or study-specific effects) are the focus on the specification curve analysis, I will restrict the model to fixed effects maximum likelihood models with a logit link in the fixest package in $R$ that are appropriate for estimating robust fixed effect estimates in clustered data. 6

The basic form of the model is the same as for the propensity score matched mega-analysis, but with additional covariates $\left(\beta_{2 j}\right.$ to $\left.\beta_{p j}\right)$ :

$Y_{i j}=\beta_{0 j}+\beta_{1 j} * P_{i j}+\beta_{2 j} * X_{1 i j}+\cdots+\beta_{p j} * X_{p i j}+\epsilon_{i j}$

where $\beta_{2 j}$ to $\beta_{p j}$ represent main effects with cluster robust standard errors.

\section{Permutation-Based Inferential Test}

The final step in specification curve analysis involves conducting a permutation-based test to determine whether the observed specification curve differs from the null of no relationship between any predictors and the outcome. Thus, the personality variable is shuffled and the 
specification curve procedure from the second step is repeated a large number of times. The observed specification curve can then be plotted against the median permuted curves and the $95 \%$ interval of the permuted curves to demonstrate how the observed curve differs from the null.

Because none of the specifications are independent because all use some overlapping variables, traditional tests that assume independence are not appropriate. Instead, I will base decisions on whether curves differ from the null on three tests: (1) the median overall point estimate within each specification curve, (2) the percentage of specifications that are of the dominant sign, and (3) the percentage of specifications with the dominant sign that are also significant. Each of these results in $p$ value constructed from the number of permutations that meet each criterion divided by the number of permutations. Because there are three tests, I will use a critical value of $.05 / 3=$ .0167 to determine significance. 


\section{Chapter 3: Results}

\subsection{Study 1: Propensity Score Matching}

Table 3.1 presents descriptive statistics of matched and unmatched samples from Studies 1

(Propensity Score Matching) and 2 (Specification Curve Analysis), respectively. Because sample sizes differ slightly across trait, outcome, and study combinations, descriptives are presented as a range across traits for each outcome and study. As is clear from the table, size, age, and gender differ across the matched and unmatched samples. This is particularly true for outcomes that are age-graded (e.g., childbirth) within studies with lifespan samples, which typically indicates that the matching procedure was successful. Tables of descriptives for each trait assessed in each outcome and study available in the online materials on GitHub (https://github.com/emoriebeck/selection/tree/master/results/psm/descriptives), the OSF (https://osf.io/usqzp/), and on the "PSM Descriptives" tab of the R Shiny web application (https://emoriebeck.shinyapps.io/selection).

Table 3.1

Descriptive Statistics of Matched and Raw Samples for Those Who Experienced Outcomes

\begin{tabular}{|c|c|c|c|c|c|c|c|c|}
\hline \multirow[b]{3}{*}{ Study } & \multirow{2}{*}{\multicolumn{2}{|c|}{ Frequency }} & \multicolumn{4}{|c|}{ Age at Baseline } & \multirow{2}{*}{\multicolumn{2}{|c|}{ \% Women }} \\
\hline & & & \multicolumn{2}{|c|}{ M } & \multicolumn{2}{|c|}{ SD } & & \\
\hline & Matched & Raw & Matched & Raw & Matched & Raw & Matched & Raw \\
\hline \multicolumn{9}{|l|}{ Mortality } \\
\hline BHPS & $947-2316(314-811)$ & $7835-16769$ (329-953) & $61.1-69.3$ & $43.8-46.4$ & $15.3-16.4$ & $17.9-18.6$ & $44.0-53.1$ & $53.8-55.4$ \\
\hline HILDA & $1688-6615(538-2534)$ & $10267-39870(554-3059)$ & $59.7-67.6$ & $44.3-44.9$ & $15.5-17.3$ & $17.7-18.8$ & $45.7-48.7$ & $52.7-53.4$ \\
\hline HRS & $7456-8412(3503-5102)$ & $8068-10910(4138-9828)$ & $55.5-70.2$ & $55.5-68.0$ & $4.9-8.7$ & $5.6-10.9$ & $54.3-57.8$ & $53.6-59.3$ \\
\hline MIDUS & $315-2505(120-1041)$ & $745-5802(153-1294)$ & $47.2-55.3$ & $43.2-47.3$ & $10.8-11.6$ & $11.4-13.0$ & 48.9-61.6 & 51.6-64.1 \\
\hline NLSY & $35-243(210-1011)$ & $25-315(570-1639)$ & $26.0-29.7$ & $20.2-29.7$ & $0.7-1.4$ & $0.8-4.9$ & $46.7-100.0$ & $40.0-54.4$ \\
\hline SHP & $437-947(113-294)$ & $6369-6998(114-300)$ & $61.1-68.0$ & $43.1-46.9$ & $14.2-16.2$ & $16.8-18.6$ & $49.1-57.8$ & $43.9-44.8$ \\
\hline WLS & $2084-8766(893-3297)$ & $2912-9872(1053-3492)$ & $53.0-64.3$ & $52.1-63.6$ & $3.3-6.3$ & $4.3-7.4$ & $50.0-51.8$ & $52.9-53.7$ \\
\hline \multicolumn{9}{|c|}{ Major Health Event } \\
\hline Add Health & $399-2224(103-618)$ & $3577-6294(106-623)$ & $16.3-22.1$ & $16.0-21.9$ & $1.5-1.8$ & $1.6-1.8$ & $49.7-54.9$ & $51.7-55.5$ \\
\hline BHPS & $1323-4149(661-2516)$ & $1564-4378(713-2673)$ & $37.4-40.2$ & $38.6-40.4$ & $15.0-16.5$ & $14.9-16.3$ & $58.7-59.3$ & $58.8-60.5$ \\
\hline GSOEP & $915-6673(616-6650)$ & $917-6675$ (617-11610) & $29.0-40.2$ & $29.0-40.4$ & $16.0-20.7$ & $16.1-20.0$ & $50.6-51.7$ & $51.1-52.1$ \\
\hline HILDA & $3260-5054(1483-2808)$ & $3260-6157(1500-3461)$ & $37.4-38.6$ & $37.2-40.0$ & $14.3-15.8$ & $15.6-15.8$ & $51.6-54.9$ & $52.6-54.9$ \\
\hline HRS & $745-871(462-755)$ & $748-850(424-1011)$ & $53.3-59.6$ & $53.2-60.7$ & $6.0-9.5$ & $6.2-10.9$ & $55.6-59.8$ & $55.3-57.8$ \\
\hline LISS & $580-2709$ (201-964) & $1080-4502(199-888)$ & $39.6-46.0$ & $35.7-41.3$ & $12.2-17.2$ & $12.2-16.6$ & $52.2-54.2$ & $50.9-55.5$ \\
\hline MIDUS & $246-2290(172-1562)$ & $258-2318(205-1756)$ & $39.5-41.8$ & $39.6-42.6$ & $9.6-11.5$ & $9.6-11.7$ & $48.5-61.0$ & $48.7-61.6$ \\
\hline NLSY & $147-483(56-130)$ & $381-1818(76-136)$ & $19.2-23.6$ & $13.9-21.9$ & $4.3-5.2$ & $6.4-6.4$ & $53.4-61.2$ & $48.9-48.9$ \\
\hline
\end{tabular}


Table 3.1

Descriptive Statistics of Matched and Raw Samples for Those Who Experienced Outcomes

\begin{tabular}{|c|c|c|c|c|c|c|c|c|}
\hline \multirow[b]{3}{*}{ Study } & \multirow{2}{*}{\multicolumn{2}{|c|}{ Frequency }} & \multicolumn{4}{|c|}{ Age at Baseline } & \multirow{2}{*}{\multicolumn{2}{|c|}{$\%$ Women }} \\
\hline & & & \multicolumn{2}{|c|}{$\mathbf{M}$} & \multicolumn{2}{|c|}{ SD } & & \\
\hline & Matched & Raw & Matched & Raw & Matched & Raw & Matched & Raw \\
\hline SHP & $2004-2983$ (1377-2659) & $2004-2983(1427-3135)$ & $41.2-42.3$ & $42.3-42.5$ & $16.2-17.8$ & $16.4-17.9$ & $45.2-45.9$ & $45.1-45.9$ \\
\hline WLS & $633-2307(632-2307)$ & 635-2308 (1956-7095) & $49.8-62.5$ & $52.1-62.7$ & $4.7-7.5$ & $5.1-7.4$ & $51.1-53.1$ & $51.2-53.0$ \\
\hline \multicolumn{9}{|c|}{ Mental Health Event } \\
\hline Add Health & $938-2396(252-694)$ & $2942-3989(257-698)$ & $15.8-22.0$ & $16.0-22.0$ & $1.6-1.8$ & $1.6-1.8$ & $56.8-63.0$ & $51.3-53.8$ \\
\hline BHPS & $1945-5607(517-1496)$ & $5557-12591(532-1513)$ & $42.7-45.9$ & $42.7-45.4$ & $18.1-19.9$ & $18.2-19.0$ & $57.1-60.8$ & $50.7-52.0$ \\
\hline GSOEP & $2317-6559(587-1769)$ & 9979-21144 (587-1773) & $33.0-38.1$ & $37.0-39.1$ & $14.0-17.5$ & $16.8-19.0$ & $61.9-64.4$ & $51.5-52.7$ \\
\hline HILDA & $5654-6624(2071-3187)$ & $6243-10620(2124-3946)$ & $41.5-44.6$ & $44.3-45.2$ & $16.9-18.4$ & $17.0-19.1$ & $53.5-55.6$ & $51.0-53.8$ \\
\hline HRS & $1927-3508$ (484-879) & $9742-13101(439-843)$ & $55.2-68.0$ & $55.7-68.1$ & $5.6-10.5$ & $5.6-10.9$ & $58.2-62.5$ & $49.8-55.7$ \\
\hline LISS & $734-3624(246-1110)$ & $1554-5887(196-832)$ & $33.4-42.5$ & $37.4-47.5$ & $13.0-18.4$ & $12.7-18.2$ & $61.6-65.6$ & $49.7-54.7$ \\
\hline MIDUS & $728-3060(213-1117)$ & $1451-3272(218-1123)$ & $46.0-47.3$ & $46.7-48.3$ & $12.4-13.2$ & $12.7-13.3$ & $48.6-54.1$ & $46.7-48.2$ \\
\hline NLSY & $684-2592(274-803)$ & $867-4182(284-806)$ & $18.4-21.6$ & $13.9-21.9$ & $4.0-4.6$ & $6.4-6.4$ & $53.9-57.2$ & $48.9-48.9$ \\
\hline SHP & $125-497(32-126)$ & $2145-2346(34-127)$ & $43.6-48.7$ & $44.3-49.9$ & $14.9-17.1$ & $15.0-16.4$ & $18.7-29.9$ & $40.4-41.3$ \\
\hline WLS & $1077-3003(276-754)$ & $3508-11655$ (279-757) & $50.2-61.7$ & $52.0-63.6$ & $4.7-7.2$ & $4.3-7.4$ & $59.2-62.3$ & $53.3-54.0$ \\
\hline \multicolumn{9}{|c|}{ 然 } \\
\hline Add Health & $2478-3643(1288-2429)$ & $65(1295-2720)$ & $16.0-21.8$ & $16.0-21.8$ & $1.6-1.8$ & $1.6-1.8$ & $50.7-51.6$ & $50.6-51.8$ \\
\hline BHPS & $3906-8241(2243-4045)$ & $3909-12688(3789-5089)$ & $40.0-46.2$ & $43.8-46.4$ & $16.2-18.3$ & $17.9-18.6$ & $52.7-54.8$ & $53.8-55.4$ \\
\hline GSOEP & $1711-5249(431-1552)$ & 7296-19319 (432-1552) & $19.7-22.9$ & $36.5-40.5$ & $8.7-14.4$ & $15.7-19.2$ & $50.2-53.3$ & $51.5-53.0$ \\
\hline HILDA & $2328-3307(711-1323)$ & $9050-13291(712-1361)$ & $29.1-31.4$ & $45.0-46.2$ & $11.2-11.9$ & $17.9-19.8$ & $49.7-52.9$ & $52.6-53.1$ \\
\hline LISS & $706-2752(238-918)$ & $1240-3956(203-740)$ & $31.2-37.3$ & $33.2-46.6$ & $12.5-17.4$ & $13.4-20.2$ & $49.2-60.1$ & $51.4-56.8$ \\
\hline MIDUS & $25-694(12-331)$ & $156-951(37-362)$ & $35.3-37.5$ & $37.4-38.6$ & $9.3-11.3$ & $10.6-12.2$ & $44.1-59.5$ & $45.2-50.8$ \\
\hline NLSY & $309-1674(210-1011)$ & $321-1853(570-1639)$ & $17.3-21.6$ & $13.9-21.9$ & $3.4-4.2$ & $6.4-6.4$ & 20.2-21.6 & $48.9-48.9$ \\
\hline SHP & 784-984 (197-279) & $1914-2187$ (200-279) & $29.4-31.8$ & $32.3-33.4$ & $13.2-16.0$ & $16.8-18.3$ & $45.1-50.7$ & $47.5-50.2$ \\
\hline \multicolumn{9}{|c|}{ Move in with a partner } \\
\hline Add Health & $658-2125(480-1563)$ & $658-2125(721-1901)$ & $16.1-21.9$ & $16.2-21.9$ & $1.6-1.8$ & $1.6-1.8$ & $50.8-56.1$ & $50.5-55.2$ \\
\hline BHPS & 2784-6198 (1298-2516) & $5945-13446(1755-2957)$ & $34.8-39.2$ & $43.8-47.0$ & $14.4-15.8$ & $18.1-19.0$ & $49.7-53.1$ & $53.9-55.6$ \\
\hline GSOEP & $1194-4797$ (300-1446) & 7498-19747 (301-1447) & $20.8-24.4$ & $36.5-40.3$ & $11.1-17.1$ & $15.7-19.0$ & $49.4-51.5$ & $51.5-53.0$ \\
\hline HILDA & 499-1482 (127-490) & $2657-6073(127-490)$ & $41.6-44.3$ & $48.7-50.8$ & $13.7-15.9$ & $18.6-19.6$ & $55.1-56.8$ & $56.2-62.5$ \\
\hline LISS & $622-2401(349-1267)$ & $1431-5300(219-730)$ & $26.9-29.8$ & $35.8-45.5$ & $10.1-12.6$ & $12.7-18.8$ & $53.3-59.5$ & $52.1-56.4$ \\
\hline MIDUS & $143-170(40-45)$ & $6093-6883(47-52)$ & $37.9-39.0$ & $46.6-47.2$ & $11.0-12.5$ & $12.9-12.9$ & $47.0-57.6$ & $51.8-52.7$ \\
\hline NLSY & 319-2001 (293-1399) & $326-2168(645-1663)$ & $17.2-20.6$ & $13.9-21.9$ & $3.3-4.1$ & $6.4-6.4$ & $45.8-47.8$ & $48.9-48.9$ \\
\hline SHP & $1152-1352(418-571)$ & $1622-1783(419-589)$ & $26.9-30.4$ & $36.6-37.8$ & $14.7-15.7$ & $20.5-23.0$ & $45.4-48.2$ & $41.4-43.5$ \\
\hline \multicolumn{9}{|l|}{ Marriage } \\
\hline Add Health & $2555-3476(1291-2307)$ & $2680-3516(1307-2654)$ & $15.9-21.8$ & $16.0-21.7$ & $1.6-1.8$ & $1.6-1.8$ & $50.8-52.1$ & $51.6-52.2$ \\
\hline BHPS & 2096-4784 (793-1665) & $5984-8989(819-1699)$ & $33.3-35.2$ & $41.5-45.9$ & $14.1-15.7$ & $18.1-19.1$ & $48.8-51.5$ & $53.4-55.3$ \\
\hline GSOEP & $2272-5320(576-1557)$ & 8301-19709 (576-1557) & $20.0-25.5$ & $36.8-39.7$ & $10.9-16.3$ & $16.3-19.3$ & $48.3-52.8$ & $50.9-52.1$ \\
\hline HILDA & $2208-4466(621-1407)$ & $9269-13736(621-1407)$ & $33.7-35.5$ & $44.5-45.4$ & $14.7-15.1$ & $17.7-19.4$ & $51.2-52.7$ & $53.0-53.6$ \\
\hline LISS & $563-2270(176-668)$ & $1569-5767(124-434)$ & $26.9-29.1$ & $35.8-45.2$ & $9.7-12.1$ & $12.6-18.7$ & $58.6-62.0$ & $51.9-56.2$ \\
\hline MIDUS & $383-492(179-220)$ & $539-699(197-225)$ & $34.5-35.6$ & $37.2-37.9$ & $9.2-10.2$ & $11.6-12.0$ & $46.5-49.0$ & $48.2-50.1$ \\
\hline NLSY & $669-3108(405-1358)$ & $694-3862(483-1365)$ & $18.1-22.1$ & $13.9-21.9$ & $3.9-4.4$ & $6.4-6.4$ & $47.2-50.8$ & $48.9-48.9$ \\
\hline SHP & $717-1380(185-352)$ & $5794-6213(187-353)$ & $40.5-44.6$ & $42.6-46.0$ & $11.8-12.5$ & $17.0-19.0$ & $39.6-45.7$ & $44.9-45.4$ \\
\hline WLS & $78-228(41-225)$ & $166-239(178-3382)$ & $50.4-61.0$ & $51.4-61.6$ & $6.4-8.0$ & 7.3-7.6 & $48.7-54.8$ & $48.3-53.0$ \\
\hline \multicolumn{9}{|l|}{ Divorce } \\
\hline Add Health & $207-314(55-85)$ & $3775-4789(60-89)$ & $16.8-22.9$ & $15.9-21.9$ & $1.4-1.7$ & $1.6-1.8$ & $52.5-58.2$ & $53.9-54.1$ \\
\hline BHPS & $563-1863(151-474)$ & 7216-15887 (160-481) & $40.4-45.3$ & $43.5-45.9$ & $14.4-17.1$ & $18.3-19.0$ & $58.0-63.6$ & $52.9-54.3$ \\
\hline GSOEP & $652-2592(164-656)$ & $7871-21631$ (167-657) & $26.2-31.9$ & $36.5-39.2$ & $9.8-14.5$ & $15.7-19.2$ & $54.0-59.5$ & $51.5-53.0$ \\
\hline HILDA & $806-2084(202-521)$ & $10571-15973(202-521)$ & $37.6-42.5$ & $44.5-44.8$ & $13.1-14.3$ & $17.7-19.0$ & $53.6-58.5$ & $52.7-53.2$ \\
\hline HRS & $595-1498(151-387)$ & 10934-15594 (147-376) & $52.6-62.9$ & $55.7-68.3$ & $6.7-10.2$ & $5.8-11.0$ & $53.6-60.1$ & $52.0-57.9$ \\
\hline LISS & 276-1134 (111-402) & $1713-6587(63-241)$ & $36.6-41.9$ & $36.5-45.8$ & $12.1-17.3$ & $12.7-18.6$ & $57.4-64.2$ & $50.2-55.6$ \\
\hline MIDUS & $99-1353(31-348)$ & $596-5584(47-353)$ & $39.0-43.3$ & $43.2-47.7$ & $10.2-11.1$ & $12.0-13.4$ & $54.8-66.9$ & $49.9-64.5$ \\
\hline
\end{tabular}


Table 3.1

Descriptive Statistics of Matched and Raw Samples for Those Who Experienced Outcomes

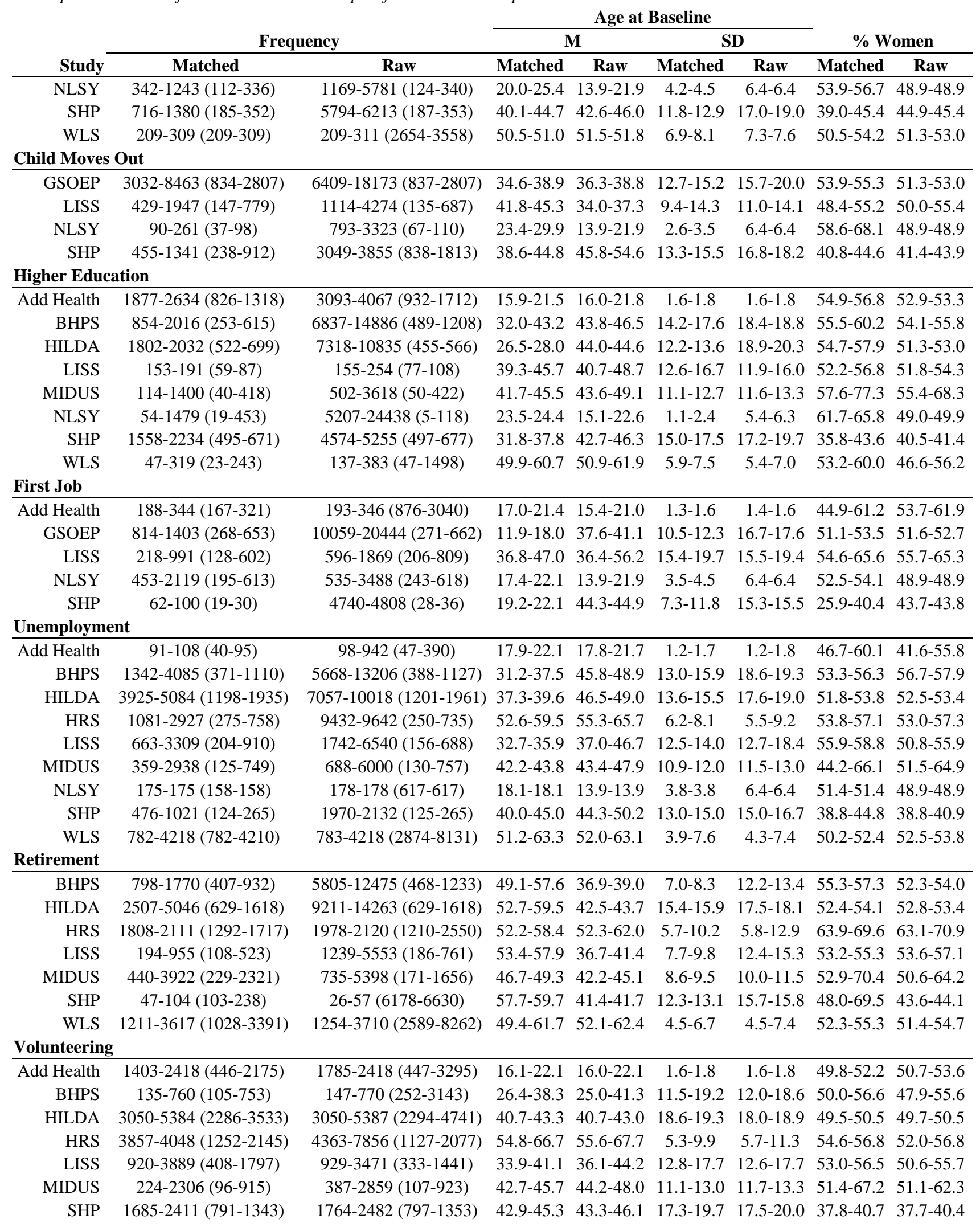


Table 3.1

Descriptive Statistics of Matched and Raw Samples for Those Who Experienced Outcomes

\begin{tabular}{|c|c|c|c|c|c|c|c|c|}
\hline \multirow[b]{3}{*}{ Study } & \multirow{2}{*}{\multicolumn{2}{|c|}{ Frequency }} & \multicolumn{4}{|c|}{ Age at Baseline } & & \\
\hline & & & \multicolumn{2}{|c|}{$\mathbf{M}$} & \multicolumn{2}{|c|}{ SD } & \multicolumn{2}{|c|}{ \% Women } \\
\hline & Matched & Raw & Matched & Raw & Matched & Raw & Matched & Raw \\
\hline WLS & $95-528(94-523)$ & $98-531(608-3841)$ & $52.1-62.5$ & $51.8-62.2$ & $5.2-8.2$ & $6.4-7.5$ & $52.4-60.5$ & $51.5-55.0$ \\
\hline \multicolumn{9}{|l|}{ Criminality } \\
\hline Add Health & $40-138(140-523)$ & 49-141 (4737-6385) & $15.8-21.8$ & $16.0-21.9$ & $1.6-1.8$ & $1.6-1.8$ & $16.3-24.3$ & $51.7-53.9$ \\
\hline HILDA & $42-120(157-468)$ & $42-120(11152-16430)$ & $37.3-41.1$ & $44.3-44.7$ & $16.6-18.8$ & $17.6-18.8$ & $31.2-38.7$ & $53.0-53.5$ \\
\hline MIDUS & $42-269(132-1037)$ & $48-270(850-6826)$ & $42.2-44.1$ & $43.2-47.5$ & $9.9-12.1$ & $11.4-13.0$ & $27.3-55.2$ & $51.6-64.1$ \\
\hline NLSY & $208-460(511-1517)$ & $240-464(931-4850)$ & $17.8-21.2$ & $13.9-21.9$ & $3.6-4.5$ & $6.4-6.4$ & $33.2-42.5$ & $48.9-48.9$ \\
\hline
\end{tabular}

Note. All results presented as a range. Frequency = Experienced (Did not Experience); $\mathrm{M}=$ Mean age at baseline; SD = Standard deviation of age at baseline

\subsubsection{Propensity Score Matching Balance}

Before running propensity score matched personality prediction models, I first examined whether the propensity score matching procedure successfully matched those who did and did not experience outcomes. As a reminder, propensity score matching was carried out for each study (10), outcome (14), trait (14), moderator (8), and imputation, which resulted in a huge number of total matching results, figures, and tables. Figure 3.1 presents a sample balance plot demonstrating the balance (in Cohen's $d$ terms) for all continuous matching variables between those who did or did not get divorced and had Conscientiousness data at baseline. As is clear from the figure, across studies, the magnitude of Cohen's $d$ was greatly reduced in the matched (filled-in circles) versus the unmatched (unfilled circles) samples. The results were similar across other trait and outcome combinations, the full results of which are available in the online materials and the web application (see the "Balance Tables" tab). Moreover, the online materials contain a total of 51,520 tables that also demonstrate matching on categorical variables (https://github.com/emoriebeck/selection/tree/master/results/psm/bal_tabs). 
Outcome $=$ Divorce, Conscientiousness Set, No Moderation

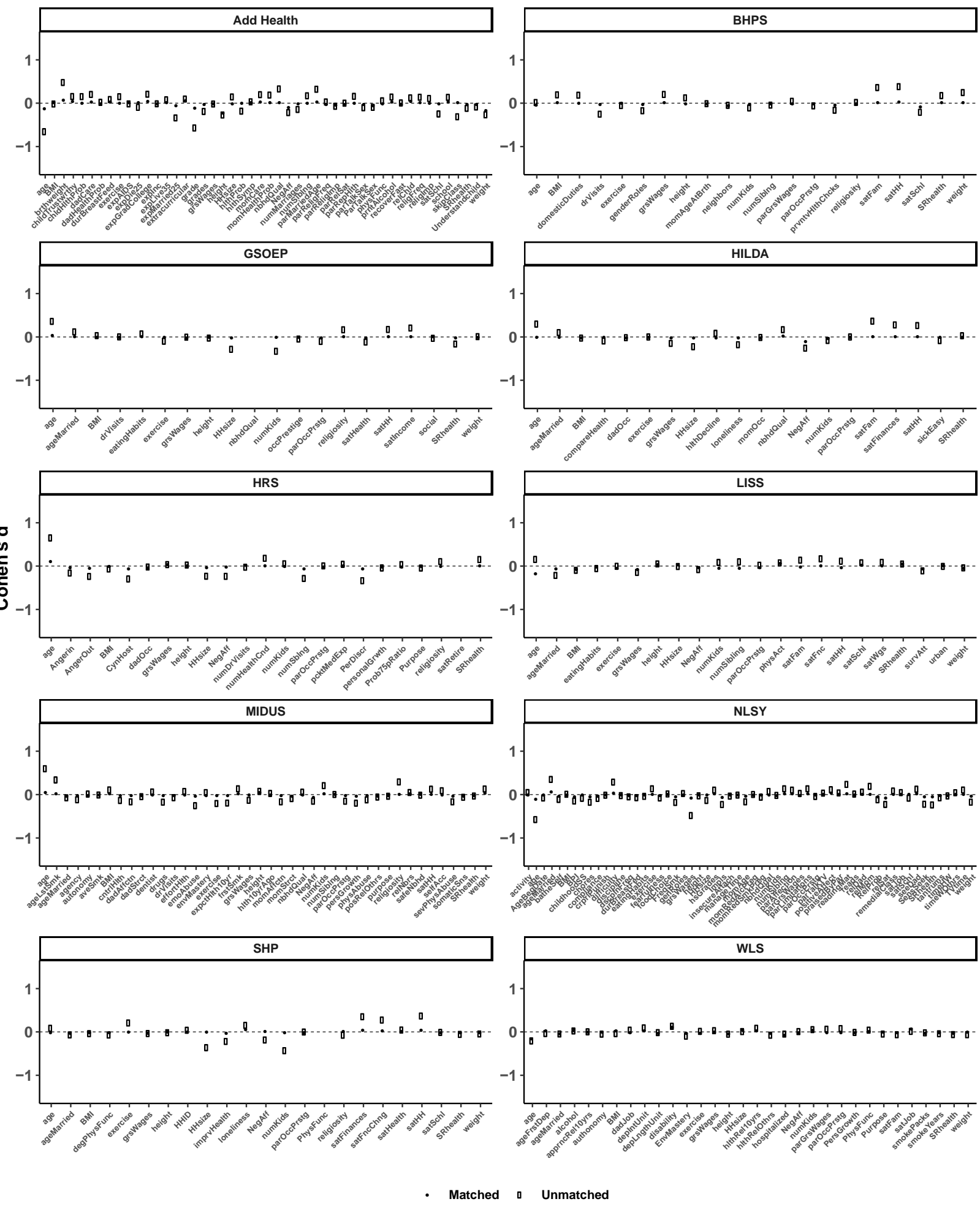

Figure 3.1. Balance plots of mean-level differences (Cohen's $d$ ) of continuous variables between those who did or did not experience divorce in the matched (filled-in points) and unmatched 
(unfilled points) samples of those with Conscientiousness data in each study. Continuous variables used for matching are on the x-axis, Cohen's $d$ values are on the y-axis, and each panel represents a different study.

\subsubsection{Matched Personality-Outcome Associations}

First, to test the robustness of personality-outcome associations when controlling for (half of)

reverse causality and selection bias, I ran a series of Bayesian logistic MLM's predicting outcomes from personality in the samples matched on all background characteristics. Table 3.2 presents overall $\left(\gamma_{10}\right)$ and study-specific $\left(\beta_{1 j}\right)$ effects for each trait-outcome association. Figure 3.2 presents a forest plot for fixed effects $\left(\gamma_{10}\right)$ of personality-outcome associations for all traits and outcomes, and Table 3.3 presents summaries of Level 2 random slopes $\left(\tau_{11}\right)$ for all Traits and Outcomes. In both the table and figure, estimates with wider Bayesian credible intervals (error bars in Figure 3.2) indicate that fewer studies were available to test a specific traitoutcome association. Additional figures with overall and study-specific effects, as well as Level 2 variances for moderators, for each trait and outcome are available in the online materials as well as visually depicted in the online web application. All parameter estimates below will include the average estimate across samples and the $89 \%$ credible interval for the fixed effect $\left(\gamma_{10}\right)$ as well as the average estimate across samples and the $89 \%$ credible interval for Level 2 standard deviation of personality-outcome associations $\left(\tau_{11}\right)$ or moderators of personalityoutcome associations $\left(\tau_{22}\right.$ and $\left.\tau_{33}\right)$. 
Table 3.2

Mega-Analytic and Study-Specific Personality-Outcome Associations in Matched Samples

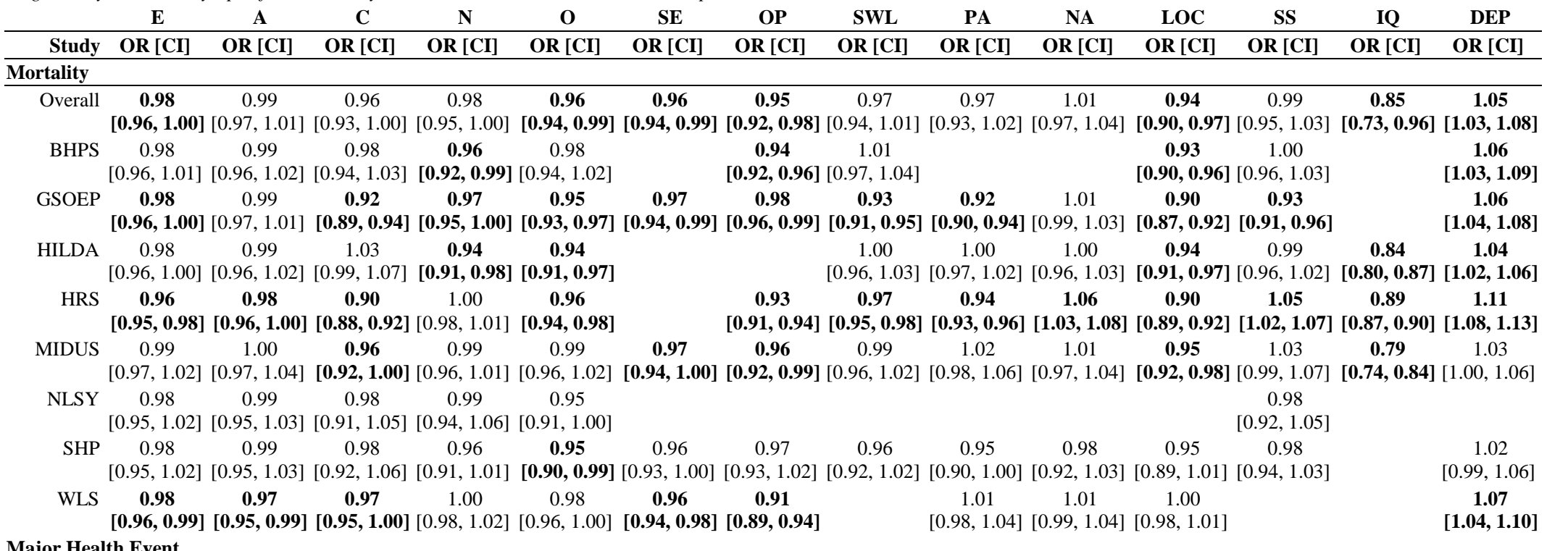

\begin{tabular}{|c|c|c|c|c|c|c|c|c|c|c|c|c|c|c|}
\hline & & & & & & & & 1.0 & & & & & & \\
\hline & {$[0.9]$} & [ & & [ & & {$[0.96$} & {$[0$.} & ] $[0.97,1.03]$ & {$[0.97$} & .97 & ] $[0.96,1.02]$ & & & \\
\hline Id Health & $\begin{array}{c}0.99 \\
{[0.95,1.03]}\end{array}$ & $\begin{array}{c}1.02 \\
{[0.98,1.07]}\end{array}$ & $\begin{array}{c}1.02 \\
{[0.98,1.07]}\end{array}$ & $\begin{array}{c}1.01 \\
{[0.99,1.04]}\end{array}$ & & $\begin{array}{c}1.00 \\
{[0.95,1.06]}\end{array}$ & & $\begin{array}{c}0.98 \\
{[0.94,1.01]}\end{array}$ & $\begin{array}{c}1.02 \\
{[0.97,1.07]}\end{array}$ & $\begin{array}{c}1.00 \\
{[0.94,1.07]}\end{array}$ & $\begin{array}{c}1.01 \\
{[0.94,1.08]}\end{array}$ & & $\begin{array}{c}0.98 \\
{[0.93,1.04]}\end{array}$ & $\begin{array}{c}1.03 \\
{[0.95,1.12]}\end{array}$ \\
\hline $\mathrm{BH}$ & $\begin{array}{c}0.98 \\
{[0.95,1.00]}\end{array}$ & $\begin{array}{c}1.03 \\
{[1.00,1.05]}\end{array}$ & $\begin{array}{c}1.02 \\
{[0.99,1.05]}\end{array}$ & $\begin{array}{c}1.01 \\
{[1.00,1.03]}\end{array}$ & $\begin{array}{c}0.99 \\
{[0.97,1.02]}\end{array}$ & & $\begin{array}{c}0.94 \\
{[0.92,0.96]}\end{array}$ & $\begin{array}{c}0.99 \\
{[0.97,1.02]}\end{array}$ & & & $\begin{array}{c}0.94 \\
{[0.92,0.97]}\end{array}$ & $\begin{array}{c}1.05 \\
{[1.01,1.09]}\end{array}$ & & $\begin{array}{c}1.02 \\
{[0.99,1.06]}\end{array}$ \\
\hline GSOEP & $\begin{array}{c}1.00 \\
{[0.98,1.02]}\end{array}$ & $\begin{array}{c}1.03 \\
{[1.01,1.05]}\end{array}$ & $\begin{array}{c}1.03 \\
{[1.01,1.06]}\end{array}$ & $\begin{array}{c}1.01 \\
{[0.99,1.02]}\end{array}$ & $\begin{array}{c}1.02 \\
{[1.00,1.04]}\end{array}$ & & $\begin{array}{c}1.00 \\
{[0.99,1.02]}\end{array}$ & $\begin{array}{c}1.07 \\
{[1.04,1.10]}\end{array}$ & $\begin{array}{c}1.01 \\
{[0.98,1.03]}\end{array}$ & $\begin{array}{c}0.97 \\
{[0.94,0.99]}\end{array}$ & $\begin{array}{c}1.04 \\
{[0.99,1.09]}\end{array}$ & $\begin{array}{c}1.00 \\
{[0.99,1.02]}\end{array}$ & & $\begin{array}{r}0 . \\
{[0.94}\end{array}$ \\
\hline HILD & $\begin{array}{c}0.98 \\
{[0.96,1.00]}\end{array}$ & $\begin{array}{c}1.03 \\
{[1.00,1.05]}\end{array}$ & $\begin{array}{c}1.01 \\
{[0.98,1.03]}\end{array}$ & $\begin{array}{c}1.01 \\
{[0.99,1.02]}\end{array}$ & $\begin{array}{c}1.02 \\
{[1.00,1.04]}\end{array}$ & & & $\begin{array}{c}0.97 \\
{[0.95,1.00]}\end{array}$ & $\begin{array}{c}0.95 \\
{[0.93,0.97]}\end{array}$ & 1.02, & $\begin{array}{c}0.96 \\
{[0.94,0.98]}\end{array}$ & $\begin{array}{r}0 . \\
{[0.93}\end{array}$ & ] $\begin{array}{r}1 . \\
{[0.99}\end{array}$ & $\begin{array}{r}1 \\
{[1.04}\end{array}$ \\
\hline HRS & $\begin{array}{c}0.99 \\
{[0.96,1.01]}\end{array}$ & $\begin{array}{c}1.00 \\
{[0.96,1.03]}\end{array}$ & $\begin{array}{c}0.99 \\
{[0.94,1.03]}\end{array}$ & $\begin{array}{c}1.01 \\
{[1.00,1.04]}\end{array}$ & $\begin{array}{c}1.00 \\
{[0.96,1.02]}\end{array}$ & & $\begin{array}{c}0.97 \\
0.94,1.00]\end{array}$ & $\begin{array}{c}0.98 \\
{[0.95,1.02]}\end{array}$ & $\begin{array}{r}0 \\
{[0.93}\end{array}$ & $2.07]$ & $\begin{array}{c}0.99 \\
{[0.96,1.03]}\end{array}$ & $\begin{array}{r}0 . \\
{[0.95}\end{array}$ & $\begin{array}{r}1 \\
{[1.03}\end{array}$ & $\begin{array}{r}1 \\
{[0.96}\end{array}$ \\
\hline L & $\begin{array}{c}0.99 \\
{[0.96,1.01]}\end{array}$ & $\begin{array}{c}1.06 \\
{[1.02,1.11]}\end{array}$ & $\begin{array}{c}1.03 \\
{[1.00,1.06]}\end{array}$ & 1.02 & $\begin{array}{c}1.02 \\
{[0.99,1.05]}\end{array}$ & $\begin{array}{r}0 . \\
{[0.96}\end{array}$ & & $\begin{array}{c}0.98 \\
{[0.94,1.02]}\end{array}$ & $\begin{array}{c}1.04 \\
{[1.00,1.07]}\end{array}$ & $\begin{array}{c}0.99 \\
{[0.96,1.03]}\end{array}$ & & $\begin{array}{c}0.96 \\
{[0.92,0.99]}\end{array}$ & $\begin{array}{l}3 \\
1.07]\end{array}$ & $\begin{array}{r}1 \\
{[1.02}\end{array}$ \\
\hline IDUS & $\begin{array}{c}0.99 \\
{[0.97,1.01]}\end{array}$ & $\begin{array}{c}1.03 \\
{[1.00,1.05]}\end{array}$ & $\begin{array}{c}1.05 \\
{[1.01,1.09]}\end{array}$ & $\begin{array}{c}1.01 \\
{[0.99,1.02]}\end{array}$ & $\begin{array}{c}0.99 \\
{[0.96,1.01]}\end{array}$ & $\begin{array}{c}1.00 \\
{[0.96,1.05]}\end{array}$ & $\begin{array}{c}0.96 \\
{[0.92,1.02]}\end{array}$ & $\begin{array}{c}1.03 \\
{[1.00,1.06]}\end{array}$ & $\begin{array}{c}0.98 \\
{[0.95,1.00]}\end{array}$ & $\begin{array}{c}0.98 \\
{[0.95,1.02]}\end{array}$ & $\begin{array}{c}0.99 \\
{[0.96,1.02]}\end{array}$ & $\begin{array}{c}1.00 \\
{[0.97,1.04]}\end{array}$ & $\begin{array}{r}1 . \\
{[1.03}\end{array}$ & $\begin{array}{c}1.00 \\
{[0.95,1.05]}\end{array}$ \\
\hline NLSY & $\begin{array}{c}0.99 \\
{[0.96,1.03]}\end{array}$ & $\begin{array}{c}1.02 \\
{[0.96,1.06]}\end{array}$ & $\begin{array}{c}1.02 \\
{[0.97,1.06]}\end{array}$ & $\begin{array}{c}1.02 \\
{[0.99,1.04]}\end{array}$ & $\begin{array}{c}0.99 \\
{[0.95,1.03]}\end{array}$ & $\begin{array}{c}0.99 \\
{[0.94,1.05]}\end{array}$ & & & & & $\begin{array}{c}0.98 \\
{[0.91,1.04]}\end{array}$ & $\begin{array}{c}0.99 \\
{[0.93,1.06]}\end{array}$ & $\begin{array}{r}1 \\
{[0.98}\end{array}$ & $\begin{array}{c}1.04 \\
{[0.97,1.11]}\end{array}$ \\
\hline SHP & $\begin{array}{c}1.02 \\
{[0.99,1.05]}\end{array}$ & $\begin{array}{c}1.02 \\
{[0.99,1.05]}\end{array}$ & $\begin{array}{c}1.02 \\
{[0.99,1.05]}\end{array}$ & $\begin{array}{c}1.01 \\
{[1.00,1.03]}\end{array}$ & $\begin{array}{c}1.00 \\
{[0.98,1.02]}\end{array}$ & $\begin{array}{c}0.99 \\
{[0.96,1.02]}\end{array}$ & $\begin{array}{c}0.97 \\
{[0.95,0.99]}\end{array}$ & $\begin{array}{c}1.00 \\
{[0.95,1.04]}\end{array}$ & $\begin{array}{c}1.00 \\
{[0.97,1.0}\end{array}$ & $\begin{array}{c}0.97 \\
{[0.94,1.00]}\end{array}$ & $\begin{array}{c}0.99 \\
\text { ] }[0.97,1.01]\end{array}$ & $\begin{array}{c}\mathbf{0 . 9 1} \\
{[0.88,0.93]}\end{array}$ & & $\begin{array}{c}1.04 \\
{[1.02,1.06]}\end{array}$ \\
\hline LS & $\begin{array}{c}0.99 \\
{[0.96,1.0}\end{array}$ & $\begin{array}{c}1.02 \\
.99,1.04]\end{array}$ & $\begin{array}{c}1.01 \\
{[0.97,1.04]}\end{array}$ & $\begin{array}{c}1.02 \\
{[1.00,1.05]}\end{array}$ & $\begin{array}{c}1.00 \\
{[0.97,1.02]}\end{array}$ & $\begin{array}{c}0.95 \\
{[0.92,0.99]}\end{array}$ & $\begin{array}{c}0.96 \\
{[0.94,0.99]}\end{array}$ & & $\begin{array}{c}0.98 \\
{[0.95,1.02]}\end{array}$ & $\begin{array}{c}1.08 \\
{[1.03,1.13]}\end{array}$ & $\begin{array}{c}0.98 \\
{[0.95,1.01]}\end{array}$ & & & $\begin{array}{c}1.03 \\
{[0.99,1.07}\end{array}$ \\
\hline
\end{tabular}


Table 3.2

Mega-Analytic and Study-Specific Personality-Outcome Associations in Matched Samples

\begin{tabular}{|c|c|c|c|c|c|c|c|c|c|c|c|c|c|c|}
\hline & $\mathbf{E}$ & A & C & $\mathbf{N}$ & O & SE & OP & SWL & PA & NA & LOC & SS & IQ & DEP \\
\hline Study & OR [CI] & OR [CI] & OR [CI] & OR [CI] & OR [CI] & $\mathrm{OR}[\mathrm{CI}]$ & OR [CI] & OR [CI] & OR [CI] & OR [CI] & OR [CI] & OR [CI] & OR [CI] & OR [CI] \\
\hline \multicolumn{15}{|c|}{ Mental Health Event } \\
\hline all & $\begin{array}{c}0.98 \\
{[0.96,1.00]}\end{array}$ & $\begin{array}{c}1.01 \\
{[0.98,1.05]}\end{array}$ & $\begin{array}{c}0.97 \\
{[0.94,0.99]}\end{array}$ & $\begin{array}{c}1.15 \\
{[1.10,1.20]}\end{array}$ & $\begin{array}{c}1.05 \\
{[1.02,1.07]}\end{array}$ & $\begin{array}{c}0.91 \\
{[0.87,0.96]}\end{array}$ & $\begin{array}{c}0.95 \\
{[0.93,0.98]}\end{array}$ & $\begin{array}{c}0.91 \\
{[0.86,0.96]}\end{array}$ & $\begin{array}{c}0.92 \\
{[0.86,0.97]}\end{array}$ & $\begin{array}{c}1.17 \\
{[1.03,1.31]}\end{array}$ & $\begin{array}{c}0.94 \\
{[0.89,0.99]}\end{array}$ & $\begin{array}{c}0.96 \\
{[0.91,1.02]}\end{array}$ & $\begin{array}{c}1.01 \\
{[0.99,1.05]}\end{array}$ & $\begin{array}{c}1.14 \\
{[1.10,1.18]}\end{array}$ \\
\hline dd Health & $\begin{array}{c}0.99 \\
{[0.96,1.03]}\end{array}$ & $\begin{array}{c}1.07 \\
{[1.04,1.11]}\end{array}$ & $\begin{array}{c}0.98 \\
{[0.95,1.01]}\end{array}$ & $\begin{array}{c}1.12 \\
{[1.07,1.17]}\end{array}$ & & $\begin{array}{c}0.92 \\
{[0.88,0.96]}\end{array}$ & & $\begin{array}{c}0.90 \\
{[0.86,0.95]}\end{array}$ & $\begin{array}{c}1.00 \\
{[0.97,1.02]}\end{array}$ & $\begin{array}{c}1.13 \\
{[1.09,1.18]}\end{array}$ & $\begin{array}{c}0.94 \\
{[0.89,0.98]}\end{array}$ & & $\begin{array}{c}1.01 \\
{[0.98,1.04]}\end{array}$ & $\begin{array}{c}1.11 \\
{[1.05,1.16]}\end{array}$ \\
\hline BHPS & $\begin{array}{c}0.99 \\
{[0.96,1.02]}\end{array}$ & $\begin{array}{c}1.00 \\
{[0.96,1.04]}\end{array}$ & $\begin{array}{c}0.99 \\
{[0.95,1.02]}\end{array}$ & $\begin{array}{c}1.14 \\
{[1.10,1.18]}\end{array}$ & $\begin{array}{c}1.04 \\
{[1.01,1.07]}\end{array}$ & & $\begin{array}{c}0.94 \\
{[0.92,0.96]}\end{array}$ & $\begin{array}{c}0.91 \\
{[0.89,0.94]}\end{array}$ & & & $\begin{array}{c}0.87 \\
{[0.84,0.89]}\end{array}$ & $\begin{array}{c}0.97 \\
{[0.94,1.01]}\end{array}$ & & $\begin{array}{c}1.24 \\
{[1.19,1.28]}\end{array}$ \\
\hline GSOEP & $\begin{array}{c}0.96 \\
{[0.93,0.98]}\end{array}$ & $\begin{array}{c}0.99 \\
{[0.96,1.02]}\end{array}$ & $\begin{array}{c}\mathbf{0 . 9 7} \\
{[\mathbf{0 . 9 5}, 1.00]}\end{array}$ & $\begin{array}{c}1.19 \\
{[1.16,1.22]}\end{array}$ & $\begin{array}{c}1.04 \\
{[1.02,1.07]}\end{array}$ & $\begin{array}{c}0.90 \\
{[0.88,0.92]}\end{array}$ & $\begin{array}{c}0.94 \\
{[0.93,0.96]}\end{array}$ & $\begin{array}{c}0.92 \\
{[0.90,0.95]}\end{array}$ & $\begin{array}{c}0.93 \\
{[0.91,0.95]}\end{array}$ & $\begin{array}{c}1.21 \\
{[1.18,1.23]}\end{array}$ & $\begin{array}{c}1.01 \\
{[0.96,1.06]}\end{array}$ & $\begin{array}{c}1.00 \\
{[0.98,1.02]}\end{array}$ & & $\begin{array}{c}1.16 \\
{[1.13,1.18]}\end{array}$ \\
\hline HILDA & $\begin{array}{c}0.95 \\
{[0.93,0.97]}\end{array}$ & $\begin{array}{c}0.98 \\
{[0.95,1.00]}\end{array}$ & $\begin{array}{c}0.88 \\
{[0.86,0.90]}\end{array}$ & $\begin{array}{c}1.31 \\
{[1.28,1.34]}\end{array}$ & $\begin{array}{c}1.09 \\
{[1.07,1.12]}\end{array}$ & & & $\begin{array}{c}0.80 \\
{[0.78,0.82]}\end{array}$ & $\begin{array}{c}0.75 \\
{[0.73,0.76]}\end{array}$ & $\begin{array}{c}1.60 \\
{[1.56,1.64]}\end{array}$ & $\begin{array}{c}0.78 \\
{[0.76,0.80]}\end{array}$ & $\begin{array}{c}0.79 \\
{[0.78,0.81]}\end{array}$ & $\begin{array}{c}1.00 \\
{[0.98,1.02]}\end{array}$ & $\begin{array}{c}1.18 \\
{[1.16,1.19]}\end{array}$ \\
\hline HRS & $\begin{array}{c}1.00 \\
{[0.98,1.03]}\end{array}$ & $\begin{array}{c}1.03 \\
{[1.00,1.07]}\end{array}$ & $\begin{array}{c}0.98 \\
{[0.95,1.01]}\end{array}$ & $\begin{array}{c}1.16 \\
{[1.13,1.20]}\end{array}$ & $\begin{array}{c}1.00 \\
{[0.97,1.04]}\end{array}$ & & $\begin{array}{c}0.95 \\
{[0.93,0.97]}\end{array}$ & $\begin{array}{c}0.95 \\
{[0.93,0.98]}\end{array}$ & $\begin{array}{c}0.90 \\
{[0.88,0.93]}\end{array}$ & $\begin{array}{c}1.17 \\
{[1.13,1.21]}\end{array}$ & $\begin{array}{c}0.96 \\
{[0.93,0.99]}\end{array}$ & $\begin{array}{c}0.93 \\
{[0.90,0.97]}\end{array}$ & $\begin{array}{c}1.00 \\
{[0.97,1.03]}\end{array}$ & $\begin{array}{c}1.13 \\
{[1.06,1.19]}\end{array}$ \\
\hline LISS & $\begin{array}{c}0.98 \\
{[0.95,1.00]}\end{array}$ & $\begin{array}{c}1.09 \\
{[1.05,1.14]}\end{array}$ & $\begin{array}{c}0.97 \\
{[0.95,1.00]}\end{array}$ & $\begin{array}{c}1.19 \\
{[1.15,1.23]}\end{array}$ & $\begin{array}{c}1.06 \\
{[1.02,1.09]}\end{array}$ & $\begin{array}{c}0.81 \\
{[0.78,0.85]}\end{array}$ & & $\begin{array}{c}0.84 \\
{[0.81,0.88]}\end{array}$ & $\begin{array}{c}0.93 \\
{[0.90,0.96]}\end{array}$ & $\begin{array}{c}1.07 \\
{[1.04,1.10]}\end{array}$ & & $\begin{array}{c}1.02 \\
{[0.99,1.05]}\end{array}$ & $\begin{array}{c}1.02 \\
{[0.99,1.06]}\end{array}$ & $\begin{array}{c}1.11 \\
{[1.07,1.14]}\end{array}$ \\
\hline MIDUS & $\begin{array}{c}0.99 \\
{[0.97,1.02]}\end{array}$ & $\begin{array}{c}0.99 \\
{[0.95,1.02]}\end{array}$ & $\begin{array}{c}0.97 \\
{[0.93,1.01]}\end{array}$ & $\begin{array}{c}1.13 \\
{[1.10,1.16]}\end{array}$ & $\begin{array}{c}1.02 \\
{[0.99,1.06]}\end{array}$ & $\begin{array}{c}0.94 \\
{[0.89,1.00]}\end{array}$ & $\begin{array}{c}0.96 \\
{[0.93,1.01]}\end{array}$ & $\begin{array}{c}0.97 \\
{[0.94,1.01]}\end{array}$ & $\begin{array}{c}0.91 \\
{[0.88,0.95]}\end{array}$ & $\begin{array}{c}1.20 \\
{[1.13,1.26]}\end{array}$ & $\begin{array}{c}0.96 \\
{[0.93,0.99]}\end{array}$ & $\begin{array}{c}0.94 \\
{[0.90,0.97]}\end{array}$ & $\begin{array}{c}1.01 \\
{[0.98,1.07]}\end{array}$ & \\
\hline NLSY & $\begin{array}{c}1.00 \\
{[0.97,1.03]}\end{array}$ & $\begin{array}{c}1.01 \\
{[0.98,1.05]}\end{array}$ & $\begin{array}{c}0.96 \\
{[0.93,0.98]}\end{array}$ & $\begin{array}{c}1.08 \\
{[1.05,1.11]}\end{array}$ & $\begin{array}{c}1.04 \\
{[1.01,1.07]}\end{array}$ & $\begin{array}{c}0.94 \\
{[0.88,1.00]}\end{array}$ & & & & & $\begin{array}{c}0.95 \\
{[0.89,1.01]}\end{array}$ & $\begin{array}{c}1.01 \\
{[0.96,1.07]}\end{array}$ & $\begin{array}{c}1.01 \\
{[0.98,1.04]}\end{array}$ & $\begin{array}{c}1.13 \\
{[1.08,1.19]}\end{array}$ \\
\hline SHP & $\begin{array}{r}0.98 \\
{[0.94,1.02]}\end{array}$ & $\begin{array}{c}1.01 \\
{[0.93,1.09]}\end{array}$ & $\begin{array}{c}0.99 \\
{[0.94,1.06]}\end{array}$ & $\begin{array}{c}1.10 \\
{[1.00,1.20]}\end{array}$ & $\begin{array}{c}1.05 \\
{[1.00,1.11]}\end{array}$ & $\begin{array}{c}0.94 \\
{[0.86,1.04]}\end{array}$ & $\begin{array}{c}0.96 \\
0.93,1.00]\end{array}$ & $\begin{array}{c}0.97 \\
{[0.89,1.07]}\end{array}$ & $\begin{array}{c}0.96 \\
{[0.86,1.08]}\end{array}$ & $\begin{array}{c}1.02 \\
{[0.91,1.14]}\end{array}$ & $\begin{array}{c}1.02 \\
{[0.92,1.13]}\end{array}$ & $\begin{array}{c}1.03 \\
{[0.95,1.12]}\end{array}$ & & $\begin{array}{c}1.11 \\
{[1.05,1.17]}\end{array}$ \\
\hline WLS & $\begin{array}{c}0.98 \\
{[0.94,1.01]}\end{array}$ & $\begin{array}{c}0.97 \\
{[0.92,1.0}\end{array}$ & $\begin{array}{c}0.97 \\
{[0.94,1.00]}\end{array}$ & $\begin{array}{c}1.08 \\
{[1.04,1.12]}\end{array}$ & $\begin{array}{c}1.08 \\
{[1.04,1.13]}\end{array}$ & $\begin{array}{c}0.92 \\
{[0.88,0.96]}\end{array}$ & $\begin{array}{c}\mathbf{0 . 9 3} \\
{[0.88,0.96}\end{array}$ & & $\begin{array}{c}0.97 \\
{[0.93,1.01]}\end{array}$ & $\begin{array}{c}1.09 \\
{[1.05,1.14]}\end{array}$ & $\begin{array}{c}0.98 \\
{[0.95,1.02]}\end{array}$ & & & $\begin{array}{c}1.12 \\
{[1.07,1.17]}\end{array}$ \\
\hline erall & $\begin{array}{c}1.03 \\
{[1.02,1.05]}\end{array}$ & $\begin{array}{c}1.01 \\
{[0.99,1.04]}\end{array}$ & $\begin{array}{c}1.03 \\
{[1.00,1.07]}\end{array}$ & $\begin{array}{c}1.00 \\
{[0.98,1.02]}\end{array}$ & $\begin{array}{c}0.98 \\
{[0.96,1.00]}\end{array}$ & $\begin{array}{c}1.01 \\
{[0.97,1.05]}\end{array}$ & $\begin{array}{c}1.01 \\
{[0.96,1.05]}\end{array}$ & $\begin{array}{c}1.06 \\
{[1.02,1.09]}\end{array}$ & $\begin{array}{c}1.04 \\
{[1.01,1.08]}\end{array}$ & $\begin{array}{c}1.01 \\
{[0.97,1.05]}\end{array}$ & $\begin{array}{c}1.06 \\
{[1.03,1.09]}\end{array}$ & $\begin{array}{c}1.02 \\
{[0.97,1.07]}\end{array}$ & $\begin{array}{c}1.00 \\
{[0.91,1.10]}\end{array}$ & $\begin{array}{c}1.02 \\
{[0.98,1.06]}\end{array}$ \\
\hline dd Health & $\begin{array}{c}1.03 \\
{[1.02,1.06]}\end{array}$ & $\begin{array}{c}1.00 \\
{[0.98,1.02]}\end{array}$ & $\begin{array}{c}1.00 \\
{[0.97,1.02]}\end{array}$ & $\begin{array}{c}1.02 \\
{[1.00,1.05]}\end{array}$ & & $\begin{array}{c}0.98 \\
{[0.95,1.01]}\end{array}$ & & $\begin{array}{c}1.05 \\
{[1.02,1.07]}\end{array}$ & $\begin{array}{c}1.02 \\
{[1.01,1.04]}\end{array}$ & $\begin{array}{c}1.05 \\
{[1.02,1.08]}\end{array}$ & $\begin{array}{c}1.03 \\
{[1.00,1.06]}\end{array}$ & & $\begin{array}{c}0.91 \\
{[0.87,0.94]}\end{array}$ & $\begin{array}{c}1.10 \\
{[1.06,1.15]}\end{array}$ \\
\hline BHPS & $\begin{array}{c}1.03 \\
{[1.02,1.04]}\end{array}$ & $\begin{array}{c}1.00 \\
{[0.99,1.0}\end{array}$ & $\begin{array}{c}0.99 \\
{[0.97,1.00]}\end{array}$ & $\begin{array}{c}0.98 \\
{[0.97,1.00]}\end{array}$ & $\begin{array}{c}0.98 \\
{[0.96,0.99]}\end{array}$ & & $\begin{array}{c}1.01 \\
{[1.00,1.02]}\end{array}$ & $\begin{array}{c}1.03 \\
{[1.01,1.05]}\end{array}$ & & & $\begin{array}{c}1.06 \\
{[1.04,1.07]}\end{array}$ & $\begin{array}{c}1.05 \\
{[1.02,1.07]}\end{array}$ & & $\begin{array}{c}1.02 \\
{[0.99,1.04]}\end{array}$ \\
\hline GSOEP & $\begin{array}{c}1.02 \\
{[1.00,1.04]}\end{array}$ & $\begin{array}{c}1.02 \\
{[1.00,1.05]}\end{array}$ & $\begin{array}{c}1.05 \\
{[1.01,1.08]}\end{array}$ & $\begin{array}{c}1.01 \\
{[0.99,1.04]}\end{array}$ & $\begin{array}{c}0.97 \\
{[0.94,0.99]}\end{array}$ & $\begin{array}{c}1.02 \\
{[0.98,1.06]}\end{array}$ & $\begin{array}{c}1.02 \\
{[1.00,1.04]}\end{array}$ & $\begin{array}{c}1.06 \\
{[1.03,1.10]}\end{array}$ & $\begin{array}{c}1.10 \\
{[1.06,1.14]}\end{array}$ & $\begin{array}{c}1.01 \\
98,1.04]\end{array}$ & $\begin{array}{c}1.06 \\
{[1.04,1.10]}\end{array}$ & $\begin{array}{c}1.02 \\
{[1.00,1.04]}\end{array}$ & & $\begin{array}{c}1.00 \\
{[0.98,1.03]}\end{array}$ \\
\hline HILDA & $\begin{array}{c}1.04 \\
{[1.02,1.06]}\end{array}$ & $\begin{array}{c}1.01 \\
{[0.99,1.04]}\end{array}$ & $\begin{array}{c}1.03 \\
{[1.00,1.06]}\end{array}$ & $\begin{array}{c}1.00 \\
{[0.98,1.03]}\end{array}$ & $\begin{array}{c}0.97 \\
{[0.94,0.99]}\end{array}$ & & & $\begin{array}{c}1.04 \\
{[1.01,1.08]}\end{array}$ & $\begin{array}{c}1.02 \\
{[1.00,1.05]}\end{array}$ & $\begin{array}{c}0.98 \\
{[0.95,1.01]}\end{array}$ & $\begin{array}{c}1.08 \\
{[1.05,1.11]}\end{array}$ & $\begin{array}{c}1.09 \\
{[1.06,1.13]}\end{array}$ & $\begin{array}{c}1.05 \\
{[1.01,1.09]}\end{array}$ & $\begin{array}{c}0.99 \\
{[0.97,1.01]}\end{array}$ \\
\hline LISS & $\begin{array}{c}1.03 \\
{[1.01,1.05]}\end{array}$ & $\begin{array}{c}1.03 \\
{[1.00,1.08]}\end{array}$ & $\begin{array}{c}1.06 \\
{[1.03,1.10]}\end{array}$ & $\begin{array}{c}1.01 \\
{[0.98,1.04]}\end{array}$ & $\begin{array}{c}0.99 \\
{[0.96,1.04]}\end{array}$ & $\begin{array}{c}1.04 \\
{[1.00,1.09]}\end{array}$ & & $\begin{array}{c}1.09 \\
{[1.04,1.15]}\end{array}$ & $\begin{array}{c}1.03 \\
{[1.00,1.07]}\end{array}$ & $\begin{array}{c}1.03 \\
{[1.00,1.06]}\end{array}$ & & $\begin{array}{c}0.95 \\
{[0.92,0.99]}\end{array}$ & 0.99 & $\begin{array}{c}0.98 \\
0.95,1.02]\end{array}$ \\
\hline MIDUS & $\begin{array}{c}1.03 \\
{[1.01,1.05]}\end{array}$ & $\begin{array}{c}1.00 \\
{[0.96,1.03]}\end{array}$ & $\begin{array}{c}1.02 \\
{[0.97,1.08]}\end{array}$ & $\begin{array}{c}0.99 \\
{[0.95,1.02]}\end{array}$ & $\begin{array}{c}0.98 \\
{[0.95,1.02]}\end{array}$ & & & $\begin{array}{c}1.09 \\
{[1.04,1.16]}\end{array}$ & $\begin{array}{c}1.06 \\
{[1.01,1.12]}\end{array}$ & $\begin{array}{c}1.00 \\
{[0.95,1.05]}\end{array}$ & $\begin{array}{c}1.07 \\
{[1.03,1.11]}\end{array}$ & $\begin{array}{c}1.07 \\
{[1.00,1.14]}\end{array}$ & & \\
\hline NLSY & $\begin{array}{c}1.03 \\
{[1.02,1.05]}\end{array}$ & $\begin{array}{c}1.02 \\
{[0.99,1.05]}\end{array}$ & $\begin{array}{c}1.03 \\
{[1.00,1.07]}\end{array}$ & $\begin{array}{c}0.99 \\
{[0.96,1.01]}\end{array}$ & $\begin{array}{c}0.99 \\
{[0.96,1.02]}\end{array}$ & $\begin{array}{c}0.99 \\
{[0.93,1.04]}\end{array}$ & & & & & $\begin{array}{c}1.01 \\
{[0.96,1.06]}\end{array}$ & $\begin{array}{c}0.96 \\
{[0.91,1.01]}\end{array}$ & $\begin{array}{c}1.06 \\
{[1.01,1.1}\end{array}$ & $\begin{array}{c}1.00 \\
{[0.94,1.06]}\end{array}$ \\
\hline SHP & $\begin{array}{c}1.03 \\
{[1.01,1.06]}\end{array}$ & $\begin{array}{c}1.02 \\
{[0.99,1.07]}\end{array}$ & $\begin{array}{c}1.09 \\
{[1.04,1.16]}\end{array}$ & $\begin{array}{c}0.98 \\
{[0.94,1.02]}\end{array}$ & $\begin{array}{c}0.98 \\
{[0.95,1.01]}\end{array}$ & $\begin{array}{c}1.02 \\
{[0.97,1.0}\end{array}$ & $\begin{array}{c}1.00 \\
94,1.0\end{array}$ & $\begin{array}{l}1.03 \\
96,1.0\end{array}$ & $\begin{array}{c}1.03 \\
97,1.0\end{array}$ & $\begin{array}{c}1.01 \\
97,1.06\end{array}$ & 1.11 & 1.02 & & $\begin{array}{c}1.03 \\
{[0.97,1.09]}\end{array}$ \\
\hline
\end{tabular}


Table 3.2

Mega-Analytic and Study-Specific Personality-Outcome Associations in Matched Samples

\begin{tabular}{|c|c|c|c|c|c|c|c|c|c|c|c|c|c|c|}
\hline & $\mathbf{E}$ & $\mathbf{A}$ & $\mathrm{C}$ & $\mathbf{N}$ & O & SE & OP & SWL & PA & NA & LOC & SS & IQ & DEP \\
\hline Study & OR [CI] & OR [CI] & OR [CI] & OR [CI] & OR [CI] & OR [CI] & OR [CI] & OR [CI] & OR [CI] & OR [CI] & OR [CI] & OR [CI] & OR [CI] & OR [CI] \\
\hline \multicolumn{15}{|c|}{ Move in with a partner } \\
\hline Overall & 1.06 & & & & 1.07 & 1.00 & 1.0 & 1.0 & 1.04 & $1.0 \mathrm{~J}$ & 1. & & 1. & \\
\hline & {$[1.03,1.08]$} & {$[0.99,1.04]$} & {$[0.99,1.03]$} & {$[1.00,1.05]$} & {$[1.01,1.06]$} & {$[0.95,1.06]$} & {$[1.01,1.12]$} & {$[0.96,1.05]$} & {$[1.00,1.08]$} & {$[1.00,1.06]$} & 6] $[0.99,1.05]$ & {$[1.00,1.12]$} & {$[0.90,1.15]$} & {$[0.97,1.07]$} \\
\hline dd Health & 1.04 & 1.01 & 1.01 & 1.04 & & 0.98 & & 0.90 & 1.03 & 1.02 & 1.00 & & 0.98 & 1.07 \\
\hline BHPS & 1.06 & 1.01 & 1.01 & 1.02 & 1.04 & & 1.0 & 1.02 & & & 1.03 & 1.0 & & $\mathbf{0}$. \\
\hline & {$[1.04,1.08]$} & {$[0.99,1.03]$} & {$[0.99,1.02]$} & {$[1.01,1.04]$} & {$[1.02,1.06]$} & & {$[1.03,1.07]$} & {$[0.99,1.04]$} & & & {$[1.01,1.05]$} & {$[0.99,1.04]$} & & {$[0.92,0.98]$} \\
\hline GSOEP & $\begin{array}{c}1.08 \\
{[1.05,1.12]}\end{array}$ & $\begin{array}{c}1.03 \\
{[1.00,1.06]}\end{array}$ & $\begin{array}{c}1.01 \\
{[0.99,1.03]}\end{array}$ & $\begin{array}{c}1.02 \\
{[1.00,1.05]}\end{array}$ & $\begin{array}{c}1.04 \\
{[1.01,1.06]}\end{array}$ & $\begin{array}{c}1.04 \\
{[0.99,1.09]}\end{array}$ & $\begin{array}{c}1.04 \\
{[1.01,1.06]}\end{array}$ & $\begin{array}{c}1.01 \\
{[0.98,1.04]}\end{array}$ & $\begin{array}{c}1.05 \\
{[1.02,1.09}\end{array}$ & $\begin{array}{c}1.04 \\
{[1.02,1.08]}\end{array}$ & $\begin{array}{c}1.01 \\
{[0.97,1.04]}\end{array}$ & $\begin{array}{c}1.03 \\
{[1.01,1.06]}\end{array}$ & & $\begin{array}{c}1.05 \\
{[1.03,1.08]}\end{array}$ \\
\hline HILDA & $\begin{array}{c}1.06 \\
{[1.02,1.10]}\end{array}$ & $\begin{array}{c}1.02 \\
{[0.99,1.06]}\end{array}$ & $\begin{array}{c}1.01 \\
{[0.98,1.04]}\end{array}$ & $\begin{array}{c}1.02 \\
{[0.98,1.05]}\end{array}$ & $\begin{array}{c}1.03 \\
{[0.99,1.06]}\end{array}$ & & & $\begin{array}{c}1.00 \\
{[0.95,1.05]}\end{array}$ & $\begin{array}{c}1.01 \\
{[0.97,1.05]}\end{array}$ & $\begin{array}{c}1.03 \\
{[1.00,1.05]}\end{array}$ & $\begin{array}{c}1.02 \\
{[0.99,1.06]}\end{array}$ & $\begin{array}{c}1.02 \\
{[0.98,1.07]}\end{array}$ & $\begin{array}{c}1.03 \\
{[0.95,1.11]}\end{array}$ & $\begin{array}{c}1.00 \\
{[0.98,1.03]}\end{array}$ \\
\hline LISS & $\begin{array}{c}1.02 \\
{[0.98,1.06]}\end{array}$ & $\begin{array}{c}1.02 \\
{[1.00,1.06]}\end{array}$ & $\begin{array}{c}1.01 \\
{[0.99,1.03]}\end{array}$ & $\begin{array}{c}1.05 \\
{[1.02,1.09]}\end{array}$ & $\begin{array}{c}1.03 \\
{[1.00,1.06]}\end{array}$ & $\begin{array}{c}0.96 \\
{[0.92,1.00]}\end{array}$ & & $\begin{array}{c}1.02 \\
{[0.98,1.06]}\end{array}$ & $\begin{array}{c}1.00 \\
{[0.97,1.03]}\end{array}$ & $\begin{array}{c}1.03 \\
{[1.00,1.05]}\end{array}$ & & $\begin{array}{c}1.18 \\
{[1.14,1.22]}\end{array}$ & $\begin{array}{c}0.95 \\
{[0.91,1.00]}\end{array}$ & $\begin{array}{c}1.10 \\
{[1.05,1.14]}\end{array}$ \\
\hline MIDUS & & & & & & & & $\begin{array}{c}1.03 \\
{[0.95,1.13]}\end{array}$ & $\begin{array}{c}1.04 \\
{[0.98,1.12]}\end{array}$ & $\begin{array}{c}1.04 \\
{[1.00,1.08]}\end{array}$ & $\begin{array}{c}1.02 \\
{[0.96,1.07]}\end{array}$ & & & \\
\hline NLSY & $\begin{array}{c}1.05 \\
{[1.03,1.08]}\end{array}$ & $\begin{array}{c}1.00 \\
{[0.97,1.02]}\end{array}$ & $\begin{array}{c}1.01 \\
{[0.98,1.03]}\end{array}$ & $\begin{array}{c}1.02 \\
{[0.99,1.04]}\end{array}$ & $\begin{array}{c}1.05 \\
{[1.02,1.09]}\end{array}$ & $\begin{array}{c}1.02 \\
{[0.95,1.10]}\end{array}$ & & & & & $\begin{array}{c}1.02 \\
{[0.96,1.07]}\end{array}$ & $\begin{array}{c}1.05 \\
{[1.02,1.08]}\end{array}$ & $\begin{array}{c}1.13 \\
{[1.09,1.17]}\end{array}$ & $\begin{array}{c}0.97 \\
{[0.91,1.04]}\end{array}$ \\
\hline SHP & $\begin{array}{c}1.07 \\
{[1.04,1.12]}\end{array}$ & $\begin{array}{c}1.01 \\
{[0.98,1.05]}\end{array}$ & $\begin{array}{c}1.02 \\
{[0.99,1.05]}\end{array}$ & $\begin{array}{c}1.02 \\
{[0.98,1.05]}\end{array}$ & $\begin{array}{c}1.02 \\
{[0.99,1.05]}\end{array}$ & $\begin{array}{c}1.01 \\
{[0.97,1.06]}\end{array}$ & $\begin{array}{c}1.04 \\
{[1.01,1.08]}\end{array}$ & $\begin{array}{c}1.04 \\
{[0.99,1.10]}\end{array}$ & $\begin{array}{c}1.08 \\
{[1.02,1.16]}\end{array}$ & $\begin{array}{c}1.03 \\
{[0.99,1.06]}\end{array}$ & $\begin{array}{c}1.04 \\
{[1.01,1.09]}\end{array}$ & $\begin{array}{c}1.04 \\
{[1.00,1.09]}\end{array}$ & & $\begin{array}{c}1.01 \\
{[0.97,1.05]}\end{array}$ \\
\hline \multicolumn{15}{|l|}{ Iarriage } \\
\hline 11 & $\begin{array}{c}1.03 \\
{[1.01,1.07]}\end{array}$ & $\begin{array}{c}1.04 \\
{[1.02,1.06]}\end{array}$ & $\begin{array}{c}1.04 \\
{[1.01,1.06]}\end{array}$ & $\begin{array}{c}1.01 \\
{[0.99,1.03]}\end{array}$ & $\begin{array}{c}1.02 \\
{[0.99,1.05]}\end{array}$ & $\begin{array}{c}0.98 \\
{[0.95,1.01]}\end{array}$ & $\begin{array}{c}1.02 \\
{[0.95,1.11]}\end{array}$ & $\begin{array}{c}1.02 \\
{[0.94,1.10]}\end{array}$ & $\begin{array}{c}1.00 \\
{[0.96,1.05]}\end{array}$ & $\begin{array}{c}1.02 \\
{[0.98,1.04]}\end{array}$ & $\begin{array}{c}1.05 \\
{[1.03,1.08]}\end{array}$ & $\begin{array}{c}1.04 \\
{[1.01,1.07]}\end{array}$ & $\begin{array}{c}1.10 \\
{[1.01,1.21]}\end{array}$ & $\begin{array}{c}0.99 \\
{[0.95,1.02]}\end{array}$ \\
\hline dd Health & $\begin{array}{c}1.06 \\
{[1.03,1.09]}\end{array}$ & $\begin{array}{c}1.02 \\
{[1.00,1.04]}\end{array}$ & $\begin{array}{c}0.99 \\
{[0.96,1.02]}\end{array}$ & $\begin{array}{c}1.01 \\
{[0.99,1.04]}\end{array}$ & & $\begin{array}{c}0.99 \\
{[0.96,1.01]}\end{array}$ & & $\begin{array}{c}1.13 \\
{[1.10,1.16]}\end{array}$ & $\begin{array}{c}0.97 \\
{[0.95,0.99]}\end{array}$ & $\begin{array}{c}1.02 \\
{[1.00,1.04]}\end{array}$ & $\begin{array}{c}1.07 \\
{[1.04,1.10]}\end{array}$ & & $\begin{array}{c}1.14 \\
{[1.11,1.17]}\end{array}$ & $\begin{array}{c}0.97 \\
{[0.94,1.01]}\end{array}$ \\
\hline BHPS & $\begin{array}{c}1.02 \\
{[0.99,1.04]}\end{array}$ & $\begin{array}{c}1.05 \\
{[1.03,1.08]}\end{array}$ & $\begin{array}{c}1.07 \\
{[1.04,1.10]}\end{array}$ & $\begin{array}{c}1.00 \\
{[0.98,1.02]}\end{array}$ & $\begin{array}{c}1.02 \\
{[1.00,1.04]}\end{array}$ & & $\begin{array}{c}1.05 \\
{[1.03,1.07]}\end{array}$ & $\begin{array}{c}1.03 \\
{[1.01,1.06]}\end{array}$ & & & $\begin{array}{c}1.05 \\
{[1.03,1.08]}\end{array}$ & $\begin{array}{c}1.03 \\
{[1.01,1.06]}\end{array}$ & & $\begin{array}{c}0.94 \\
{[0.91,0.97]}\end{array}$ \\
\hline GSOEP & $\begin{array}{c}1.02 \\
{[0.99,1.04]}\end{array}$ & $\begin{array}{c}1.03 \\
{[1.01,1.06]}\end{array}$ & $\begin{array}{c}1.05 \\
{[1.02,1.08]}\end{array}$ & $\begin{array}{c}1.02 \\
{[1.00,1.04]}\end{array}$ & $\begin{array}{c}1.03 \\
{[1.01,1.06]}\end{array}$ & $\begin{array}{c}0.98 \\
{[0.95,1.00]}\end{array}$ & $\begin{array}{c}1.01 \\
{[0.99,1.03]}\end{array}$ & $\begin{array}{c}1.03 \\
{[1.00,1.06]}\end{array}$ & $\begin{array}{c}1.08 \\
{[1.05,1.11]}\end{array}$ & $\begin{array}{c}1.04 \\
{[1.01,1.07]}\end{array}$ & $\begin{array}{c}1.05 \\
{[1.02,1.08]}\end{array}$ & $\begin{array}{c}1.02 \\
{[1.00,1.04]}\end{array}$ & & $\begin{array}{c}1.02 \\
{[1.00,1.04]}\end{array}$ \\
\hline HILDA & $\begin{array}{c}1.02 \\
{[1.00,1.05]}\end{array}$ & $\begin{array}{c}1.04 \\
{[1.02,1.07]}\end{array}$ & $\begin{array}{c}1.04 \\
{[1.01,1.07]}\end{array}$ & $\begin{array}{c}1.02 \\
{[1.00,1.05]}\end{array}$ & $\begin{array}{c}1.04 \\
{[1.01,1.07]}\end{array}$ & & & $\begin{array}{c}1.01 \\
{[0.97,1.04]}\end{array}$ & $\begin{array}{c}1.02 \\
{[1.00,1.05]}\end{array}$ & $\begin{array}{c}1.02 \\
{[0.99,1.04]}\end{array}$ & $\begin{array}{c}1.04 \\
{[1.01,1.06]}\end{array}$ & $\begin{array}{c}1.05 \\
{[1.02,1.08]}\end{array}$ & $\begin{array}{c}1.04 \\
{[1.01,1.08]}\end{array}$ & $\begin{array}{c}0.99 \\
{[0.98,1.01]}\end{array}$ \\
\hline LISS & $\begin{array}{c}1.00 \\
{[0.96,1.03]}\end{array}$ & $\begin{array}{c}1.04 \\
{[1.01,1.07]}\end{array}$ & $\begin{array}{c}1.04 \\
{[1.00,1.08]}\end{array}$ & $\begin{array}{c}1.03 \\
{[1.00,1.07]}\end{array}$ & $\begin{array}{c}1.03 \\
{[1.00,1.07]}\end{array}$ & $\begin{array}{c}0.97 \\
{[0.94,1.00]}\end{array}$ & & $\begin{array}{c}1.05 \\
{[1.00,1.11]}\end{array}$ & $\begin{array}{c}0.97 \\
{[0.93,1.01]}\end{array}$ & $\begin{array}{c}1.01 \\
{[0.98,1.04]}\end{array}$ & & $\begin{array}{c}1.06 \\
{[1.02,1.10]}\end{array}$ & $\begin{array}{c}1.04 \\
{[0.99,1.09]}\end{array}$ & $\begin{array}{c}1.02 \\
{[0.99,1.06]}\end{array}$ \\
\hline MIDUS & $\begin{array}{c}1.03 \\
{[1.00,1.07]}\end{array}$ & $\begin{array}{c}1.02 \\
{[0.97,1.05]}\end{array}$ & $\begin{array}{c}1.04 \\
{[0.99,1.09]}\end{array}$ & $\begin{array}{c}1.00 \\
{[0.97,1.03]}\end{array}$ & $\begin{array}{c}1.03 \\
{[0.99,1.09]}\end{array}$ & & & $\begin{array}{c}1.08 \\
{[1.02,1.15]}\end{array}$ & $\begin{array}{c}1.03 \\
{[0.97,1.10]}\end{array}$ & $\begin{array}{c}0.99 \\
{[0.91,1.04]}\end{array}$ & $\begin{array}{c}1.07 \\
{[1.03,1.14]}\end{array}$ & $\begin{array}{c}1.08 \\
{[1.02,1.17]}\end{array}$ & & \\
\hline NLSY & $\begin{array}{c}1.03 \\
{[1.01,1.05]}\end{array}$ & $\begin{array}{c}1.04 \\
{[1.02,1.07]}\end{array}$ & $\begin{array}{c}1.02 \\
{[0.99,1.04]}\end{array}$ & $\begin{array}{c}0.99 \\
{[0.97,1.02]}\end{array}$ & $\begin{array}{c}1.01 \\
{[0.98,1.03]}\end{array}$ & $\begin{array}{c}0.99 \\
{[0.96,1.03]}\end{array}$ & & & & & $\begin{array}{c}1.06 \\
{[1.02,1.10]}\end{array}$ & $\begin{array}{c}1.02 \\
{[0.98,1.05]}\end{array}$ & $\begin{array}{c}1.17 \\
{[1.13,1.22]}\end{array}$ & $\begin{array}{c}0.97 \\
{[0.92,1.01]}\end{array}$ \\
\hline SHP & $\begin{array}{c}1.03 \\
{[0.99,1.08]}\end{array}$ & $\begin{array}{c}1.04 \\
{[1.01,1.08]}\end{array}$ & $\begin{array}{c}1.04 \\
{[1.00,1.09]}\end{array}$ & $\begin{array}{c}1.01 \\
{[0.98,1.05]}\end{array}$ & $\begin{array}{c}1.05 \\
{[1.01,1.10]}\end{array}$ & $\begin{array}{c}0.97 \\
{[0.94,1.01]}\end{array}$ & $\begin{array}{c}0.98 \\
{[0.94,1.02]}\end{array}$ & $\begin{array}{c}0.84 \\
{[0.73,0.95]}\end{array}$ & $\begin{array}{c}0.98 \\
{[0.91,1.05]}\end{array}$ & $\begin{array}{c}1.04 \\
{[1.00,1.09]}\end{array}$ & $\begin{array}{c}1.03 \\
{[0.99,1.07]}\end{array}$ & $\begin{array}{c}1.01 \\
{[0.96,1.05]}\end{array}$ & & $\begin{array}{c}1.05 \\
{[1.01,1.10]}\end{array}$ \\
\hline WLS & $\begin{array}{c}1.10 \\
{[1.03,1.19]}\end{array}$ & $\begin{array}{c}1.04 \\
{[1.00,1.10]}\end{array}$ & $\begin{array}{c}1.03 \\
{[0.97,1.11]}\end{array}$ & $\begin{array}{c}1.01 \\
{[0.96,1.07]}\end{array}$ & $\begin{array}{c}0.95 \\
{[0.87,1.03]}\end{array}$ & $\begin{array}{c}1.00 \\
{[0.96,1.07]}\end{array}$ & & & $\begin{array}{c}0.98 \\
{[0.92,1.05]}\end{array}$ & $\begin{array}{c}1.01 \\
{[0.93,1.07]}\end{array}$ & $\begin{array}{c}1.05 \\
{[0.99,1.11]}\end{array}$ & & & $\begin{array}{c}0.94 \\
{[0.86,1.01]}\end{array}$ \\
\hline vorce & & & & & & & & & & & & & & \\
\hline
\end{tabular}


Table 3.2

Mega-Analytic and Study-Specific Personality-Outcome Associations in Matched Samples

\begin{tabular}{|c|c|c|c|c|c|c|c|c|c|c|c|c|c|c|}
\hline & $\mathbf{E}$ & $\mathbf{A}$ & $\mathrm{C}$ & $\mathbf{N}$ & O & SE & OP & SWL & PA & NA & LOC & SS & IQ & DEP \\
\hline Study & OR [CI] & OR [CI] & OR [CI] & OR [CI] & OR [CI] & OR [CI] & OR [CI] & OR [CI] & OR [CI] & OR [CI] & OR [CI] & OR [CI] & OR [CI] & OR [CI] \\
\hline Overall & $\begin{array}{c}1.03 \\
{[1.00,1.06]}\end{array}$ & $\begin{array}{c}1.05 \\
{[1.02,1.09]}\end{array}$ & $\begin{array}{c}1.04 \\
{[1.01,1.06]}\end{array}$ & $\begin{array}{c}1.01 \\
{[0.98,1.03]}\end{array}$ & $\begin{array}{c}1.03 \\
{[1.00,1.06]}\end{array}$ & $\begin{array}{c}0.98 \\
{[0.93,1.02]}\end{array}$ & $\begin{array}{c}0.99 \\
{[0.96,1.02]}\end{array}$ & $\begin{array}{c}0.91 \\
{[0.89,0.94]}\end{array}$ & $\begin{array}{c}0.98 \\
{[0.96,1.01]}\end{array}$ & $\begin{array}{c}1.05 \\
{[1.01,1.07]}\end{array}$ & $\begin{array}{c}0.99 \\
{[0.96,1.01]}\end{array}$ & $\begin{array}{c}0.97 \\
{[0.95,0.99]}\end{array}$ & $\begin{array}{c}0.99 \\
{[0.95,1.05]}\end{array}$ & $\begin{array}{c}1.03 \\
{[0.99,1.07]}\end{array}$ \\
\hline Add Health & $\begin{array}{c}1.03 \\
{[0.98,1.10]}\end{array}$ & $\begin{array}{c}1.05 \\
{[1.00,1.10]}\end{array}$ & $\begin{array}{c}1.04 \\
{[1.00,1.08]}\end{array}$ & $\begin{array}{c}1.00 \\
{[0.96,1.04]}\end{array}$ & & $\begin{array}{c}0.98 \\
{[0.92,1.04]}\end{array}$ & & $\begin{array}{c}0.92 \\
{[0.89,0.96]}\end{array}$ & $\begin{array}{c}0.98 \\
{[0.95,1.01]}\end{array}$ & $\begin{array}{c}1.05 \\
{[1.01,1.10]}\end{array}$ & $\begin{array}{c}0.99 \\
{[0.95,1.03]}\end{array}$ & & $\begin{array}{c}1.01 \\
{[0.95,1.11]}\end{array}$ & $\begin{array}{c}1.03 \\
{[0.95,1.10]}\end{array}$ \\
\hline BHPS & $\begin{array}{c}1.03 \\
{[0.98,1.09]}\end{array}$ & $\begin{array}{c}1.05 \\
{[1.01,1.11]}\end{array}$ & $\begin{array}{c}1.03 \\
{[0.99,1.06]}\end{array}$ & $\begin{array}{c}0.99 \\
{[0.95,1.03]}\end{array}$ & $\begin{array}{c}1.04 \\
{[1.00,1.07]}\end{array}$ & & $\begin{array}{c}0.96 \\
{[0.93,1.00]}\end{array}$ & $\begin{array}{c}0.93 \\
{[0.90,0.95]}\end{array}$ & & & $\begin{array}{c}0.96 \\
{[0.92,1.00]}\end{array}$ & $\begin{array}{c}0.97 \\
{[0.94,1.00]}\end{array}$ & & $\begin{array}{c}1.06 \\
{[1.02,1.11]}\end{array}$ \\
\hline GSOEP & $\begin{array}{c}1.04 \\
{[1.00,1.08]}\end{array}$ & $\begin{array}{c}1.01 \\
{[0.96,1.05]}\end{array}$ & $\begin{array}{c}1.03 \\
{[0.99,1.06]}\end{array}$ & $\begin{array}{c}1.01 \\
{[0.99,1.05]}\end{array}$ & $\begin{array}{c}1.04 \\
{[1.01,1.08]}\end{array}$ & $\begin{array}{c}1.00 \\
{[0.95,1.06]}\end{array}$ & $\begin{array}{c}1.00 \\
{[0.97,1.04]}\end{array}$ & $\begin{array}{c}0.91 \\
{[0.88,0.94]}\end{array}$ & $\begin{array}{c}0.98 \\
{[0.95,1.00]}\end{array}$ & $\begin{array}{c}1.06 \\
{[1.03,1.10]}\end{array}$ & $\begin{array}{c}0.99 \\
{[0.95,1.02]}\end{array}$ & $\begin{array}{c}0.97 \\
{[0.95,1.00]}\end{array}$ & & $\begin{array}{c}1.11 \\
{[1.07,1.15]}\end{array}$ \\
\hline HILDA & $\begin{array}{c}1.03 \\
{[0.99,1.06]}\end{array}$ & $\begin{array}{c}1.06 \\
{[1.01,1.11]}\end{array}$ & $\begin{array}{c}1.05 \\
{[1.01,1.09]}\end{array}$ & $\begin{array}{c}0.99 \\
{[0.95,1.02]}\end{array}$ & $\begin{array}{c}1.05 \\
{[1.02,1.09]}\end{array}$ & & & $\begin{array}{c}0.91 \\
{[0.88,0.94]}\end{array}$ & $\begin{array}{c}0.98 \\
{[0.95,1.00]}\end{array}$ & $\begin{array}{c}1.05 \\
{[1.02,1.08]}\end{array}$ & $\begin{array}{c}0.99 \\
{[0.96,1.02]}\end{array}$ & $\begin{array}{c}0.98 \\
{[0.95,1.01]}\end{array}$ & $\begin{array}{c}0.97 \\
{[0.92,1.02]}\end{array}$ & $\begin{array}{c}1.03 \\
{[1.01,1.05]}\end{array}$ \\
\hline HRS & $\begin{array}{c}1.04 \\
{[1.01,1.09]}\end{array}$ & $\begin{array}{c}1.04 \\
{[1.01,1.08]}\end{array}$ & $\begin{array}{c}1.04 \\
{[1.00,1.07]}\end{array}$ & $\begin{array}{c}1.00 \\
{[0.97,1.03]}\end{array}$ & $\begin{array}{l}1.05 \\
{[1.02,1.09]}\end{array}$ & & $\begin{array}{c}1.00 \\
{[0.97,1.05]}\end{array}$ & $\begin{array}{c}0.91 \\
{[0.88,0.93]}\end{array}$ & $\begin{array}{c}0.98 \\
{[0.95,1.00]}\end{array}$ & $\begin{array}{c}1.04 \\
{[0.99,1.07]}\end{array}$ & $\begin{array}{c}0.99 \\
{[0.96,1.03]}\end{array}$ & $\begin{array}{c}0.96 \\
{[0.93,0.99]}\end{array}$ & $\begin{array}{c}1.01 \\
{[0.96,1.08]}\end{array}$ & $\begin{array}{c}1.05 \\
{[0.99,1.11]}\end{array}$ \\
\hline LISS & $\begin{array}{c}0.98 \\
{[0.93,1.03]}\end{array}$ & $\begin{array}{c}1.09 \\
{[1.04,1.14]}\end{array}$ & $\begin{array}{c}1.05 \\
{[1.01,1.09]}\end{array}$ & $\begin{array}{c}1.03 \\
{[0.99,1.07]}\end{array}$ & $\begin{array}{c}1.02 \\
{[0.99,1.06]}\end{array}$ & $\begin{array}{c}0.94 \\
{[0.88,0.99]}\end{array}$ & & $\begin{array}{c}0.92 \\
{[0.87,0.96]}\end{array}$ & $\begin{array}{c}0.99 \\
{[0.96,1.02]}\end{array}$ & $\begin{array}{c}1.06 \\
{[1.02,1.10]}\end{array}$ & & $\begin{array}{c}0.96 \\
{[0.92,0.99]}\end{array}$ & $\begin{array}{c}0.96 \\
{[0.90,1.02]}\end{array}$ & $\begin{array}{c}1.04 \\
{[1.00,1.09]}\end{array}$ \\
\hline MIDUS & $\begin{array}{c}1.01 \\
{[0.96,1.04]}\end{array}$ & $\begin{array}{c}1.02 \\
{[0.97,1.06]}\end{array}$ & $\begin{array}{c}1.02 \\
{[0.98,1.05]}\end{array}$ & $\begin{array}{c}1.01 \\
{[0.98,1.04]}\end{array}$ & $\begin{array}{c}1.04 \\
{[1.00,1.07]}\end{array}$ & $\begin{array}{c}0.98 \\
{[0.93,1.04]}\end{array}$ & $\begin{array}{c}1.00 \\
{[0.96,1.06]}\end{array}$ & $\begin{array}{c}0.93 \\
{[0.90,0.96]}\end{array}$ & $\begin{array}{c}0.98 \\
{[0.95,1.00]}\end{array}$ & $\begin{array}{c}1.04 \\
{[1.00,1.08]}\end{array}$ & $\begin{array}{c}0.99 \\
{[0.96,1.02]}\end{array}$ & $\begin{array}{c}0.97 \\
{[0.94,1.00]}\end{array}$ & $\begin{array}{c}1.00 \\
{[0.94,1.08]}\end{array}$ & $\begin{array}{c}1.00 \\
{[0.91,1.08]}\end{array}$ \\
\hline NLSY & $\begin{array}{c}1.01 \\
{[0.97,1.04]}\end{array}$ & $\begin{array}{c}1.05 \\
{[1.02,1.09]}\end{array}$ & $\begin{array}{c}1.03 \\
{[1.00,1.06]}\end{array}$ & $\begin{array}{c}0.99 \\
{[0.95,1.02]}\end{array}$ & $\begin{array}{c}1.03 \\
{[0.99,1.07]}\end{array}$ & $\begin{array}{c}0.98 \\
{[0.92,1.05]}\end{array}$ & & & & & $\begin{array}{c}0.99 \\
{[0.95,1.03]}\end{array}$ & $\begin{array}{c}0.97 \\
{[0.94,1.00]}\end{array}$ & $\begin{array}{c}1.00 \\
{[0.94,1.08]}\end{array}$ & $\begin{array}{c}1.02 \\
{[0.96,1.08]}\end{array}$ \\
\hline SHP & $\begin{array}{c}1.05 \\
{[1.00,1.11]}\end{array}$ & $\begin{array}{c}1.05 \\
{[1.00,1.11]}\end{array}$ & $\begin{array}{c}1.03 \\
{[1.00,1.07]}\end{array}$ & $\begin{array}{c}1.00 \\
{[0.97,1.04]}\end{array}$ & $\begin{array}{c}1.05 \\
{[1.01,1.09]}\end{array}$ & $\begin{array}{c}0.98 \\
{[0.93,1.04]}\end{array}$ & $\begin{array}{c}0.98 \\
{[0.94,1.01]}\end{array}$ & $\begin{array}{c}0.89 \\
{[0.83,0.93]}\end{array}$ & $\begin{array}{c}0.98 \\
{[0.95,1.01]}\end{array}$ & $\begin{array}{c}1.06 \\
{[1.02,1.11]}\end{array}$ & $\begin{array}{c}0.99 \\
{[0.96,1.03]}\end{array}$ & $\begin{array}{c}0.97 \\
{[0.94,1.00]}\end{array}$ & & $\begin{array}{c}1.07 \\
{[1.03,1.11]}\end{array}$ \\
\hline WLS & $\begin{array}{c}1.06 \\
{[0.98,1.16]}\end{array}$ & $\begin{array}{c}1.11 \\
{[1.03,1.21]}\end{array}$ & $\begin{array}{c}1.06 \\
{[1.00,1.13]}\end{array}$ & $\begin{array}{c}1.04 \\
{[0.98,1.12]}\end{array}$ & $\begin{array}{c}0.96 \\
{[0.87,1.04]}\end{array}$ & $\begin{array}{c}0.98 \\
{[0.89,1.08]}\end{array}$ & & & $\begin{array}{c}1.00 \\
{[0.96,1.08]}\end{array}$ & $\begin{array}{c}1.02 \\
{[0.92,1.09]}\end{array}$ & $\begin{array}{c}0.98 \\
{[0.93,1.04]}\end{array}$ & & & $\begin{array}{c}0.93 \\
{[0.84,1.03]}\end{array}$ \\
\hline
\end{tabular}

Child Moves Out

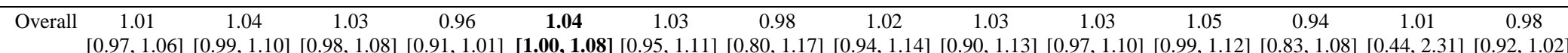

$[0.98,1.03][0.98,1.03][\mathbf{1 . 0 2}, \mathbf{1 . 0 8}][0.98,1.02][\mathbf{1 . 0 1}, \mathbf{1 . 0 6}][0.95,1.01][\mathbf{0 . 9 6}, \mathbf{1 . 0 0}][0.97,1.01][1.00,1.04][0.99,1.04][\mathbf{1 . 0 2}, \mathbf{1 . 0 8}][1.00,1.03] \quad[0.98,1.02]$

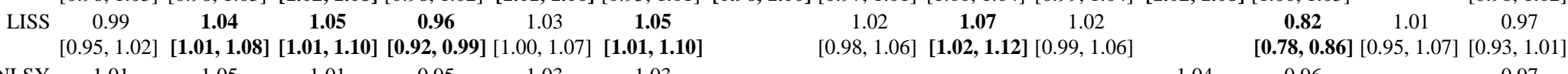
$\begin{array}{lllllll}\text { NLSY } & 1.01 & 1.05 & 1.01 & 0.95 & 1.03 & 1.03\end{array}$ $[0.96,1.07][1.00,1.11][0.94,1.07][0.89,1.01][0.98,1.06][0.96,1.11]$

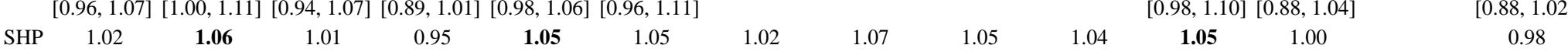
$[0.97,1.09][\mathbf{1 . 0 0}, \mathbf{1 . 1 2}][0.94,1.07][0.89,1.00][\mathbf{1 . 0 0}, \mathbf{1 . 1 0}][0.99,1.10][0.98,1.08][0.98,1.17][0.99,1.11][1.00,1.09][\mathbf{1 . 0 1}, \mathbf{1 . 1 0}][0.95,1.05] \quad[0.95,1.01]$

Higher Education

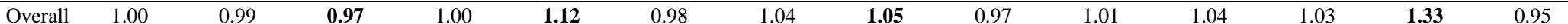
$[0.97,1.05][0.95,1.04][\mathbf{0 . 9 5}, \mathbf{1 . 0 0}][0.98,1.03][\mathbf{1 . 0 3}, \mathbf{1 . 2 3}][0.94,1.03][0.90,1.16][\mathbf{1 . 0 1}, \mathbf{1 . 1 0}][0.94,1.02][0.97,1.05][0.99,1.09][0.99,1.08][\mathbf{1 . 0 2}, \mathbf{1 . 7 5}][0.90,1.01]$ $\begin{array}{llll}\mathbf{1 . 0 6} & 0.98 & 1.00 & 1.02\end{array}$

$\begin{array}{lccc}1.09 & 0.92 & 0.96 & 1.03\end{array}$

1.720 .87

$\begin{array}{ccccc}\text { Add Health } & 1.02 & \mathbf{1 . 0 6} & 0.98 & 1.00 \\ & {[0.99,1.05]} & {[\mathbf{1 . 0 3}, \mathbf{1 . 0 9}]} & {[0.95,1.00]} & {[0.98,1.02]}\end{array}$

$[0.98,1.07]$

$[1.06,1.12][0.90,0.95][0.93,1.00][1.00,1.07]$

$[1.62,1.83][0.83,0.90]$ BHPS $\mathbf{1 . 1 4} 1.02$

$[\mathbf{1 . 0 6}, \mathbf{1 . 1 7}][0.95,1.04]$ 0.94

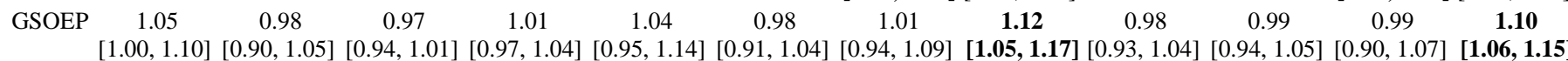
$[0.89,1.00]$ $0.89,0.98$ 
Table 3.2

Mega-Analytic and Study-Specific Personality-Outcome Associations in Matched Samples

\begin{tabular}{|c|c|c|c|c|c|c|c|c|c|c|c|c|c|c|}
\hline & $\mathbf{E}$ & A & C & $\mathbf{N}$ & O & SE & OP & SWL & PA & NA & LOC & SS & IQ & DEP \\
\hline Study & OR [CI] & OR [CI $]$ & OR [CI] & OR [CI] & OR [CI $]$ & OR [CI] & OR [CI] & OR [CI] & OR [CI] & OR [CI] & OR [CI] & OR [CI] & OR [CI] & OR [CI] \\
\hline HILDA & $\begin{array}{c}1.00 \\
{[0.96,1.04]}\end{array}$ & $\begin{array}{c}1.02 \\
{[0.98,1.06]}\end{array}$ & $\begin{array}{c}0.96 \\
{[0.94,0.99]}\end{array}$ & $\begin{array}{c}1.00 \\
{[0.98,1.03]}\end{array}$ & $\begin{array}{c}1.19 \\
{[1.13,1.24]}\end{array}$ & & & $\begin{array}{c}1.04 \\
{[1.00,1.07}\end{array}$ & $\begin{array}{c}0.97 \\
{[0.94,1.00]}\end{array}$ & $\begin{array}{c}1.02 \\
{[0.99,1.06]}\end{array}$ & $\begin{array}{c}1.04 \\
{[1.00,1.08]}\end{array}$ & $\begin{array}{c}1.05 \\
{[1.02,1.09]}\end{array}$ & $\begin{array}{c}1.21 \\
{[1.15,1.28]}\end{array}$ & $\begin{array}{c}1.02 \\
{[1.00,1.05]}\end{array}$ \\
\hline LISS & $\begin{array}{c}1.00 \\
{[0.95,1.05]}\end{array}$ & $\begin{array}{c}0.98 \\
0.92,1.05]\end{array}$ & $\begin{array}{c}0.97 \\
0.94,1.01]\end{array}$ & $\begin{array}{c}1.00 \\
{[0.97,1.03]}\end{array}$ & $\begin{array}{c}1.28 \\
{[1.15,1.45]}\end{array}$ & $\begin{array}{c}1.00 \\
{[0.94,1.06]}\end{array}$ & & $\begin{array}{c}1.07 \\
{[1.02,1.13}\end{array}$ & $\begin{array}{c}0.99 \\
{[0.93,1.07]}\end{array}$ & $\begin{array}{c}1.02 \\
{[0.97,1.08]}\end{array}$ & & $\begin{array}{c}1.06 \\
{[1.00,1.13]}\end{array}$ & & $\begin{array}{c}1.01 \\
{[0.90,1.12]}\end{array}$ \\
\hline MIDUS & 0.97 & 0.97 & 0.97 & 1.01 & 1.04 & 0.98 & 1.07 & 1.01 & 0.96 & 1.03 & 1.02 & 1.00 & 1.09 & 0.96 \\
\hline
\end{tabular}

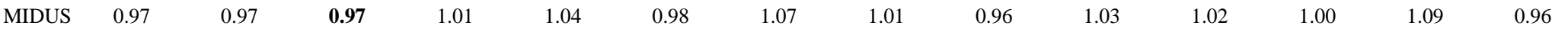

$[0.94,1.00][0.93,1.02][\mathbf{0 . 9 3}, \mathbf{1 . 0 0}][0.98,1.04][0.99,1.09][0.92,1.04][0.99,1.15][0.98,1.04][0.92,1.00][0.98,1.08][0.96,1.07][0.96,1.04][0.96,1.25][0.88,1.05]$

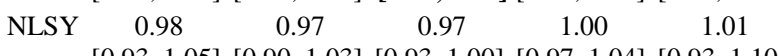
$[0.93,1.05][0.90,1.03][0.93,1.00][0.97,1.04][0.93,1.10]$

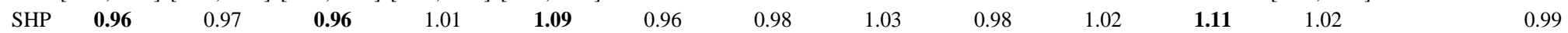

$[\mathbf{0 . 9 3}, \mathbf{1 . 0 0}][0.92,1.01][\mathbf{0 . 9 3}, \mathbf{0 . 9 9}][0.98,1.04][\mathbf{1 . 0 5}, \mathbf{1 . 1 4}][0.92,1.01][0.94,1.02][0.99,1.08][0.94,1.03][0.98,1.06][\mathbf{1 . 0 7}, \mathbf{1 . 1 6}][0.98,1.05] \quad[0.96,1.03]$

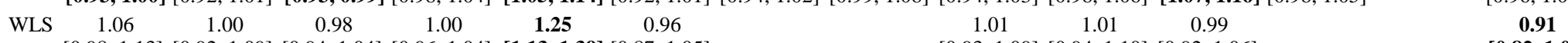
$[0.98,1.13][0.92,1.09][0.94,1.04][0.96,1.04][\mathbf{1 . 1 3}, \mathbf{1 . 3 9}][0.87,1.05] \quad[0.93,1.09][0.94,1.10][0.92,1.06] \quad[\mathbf{0 . 8 2}, \mathbf{1 . 0 0}]$

First Jo

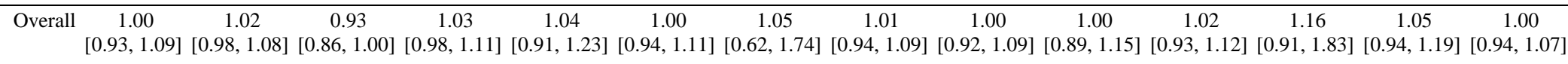

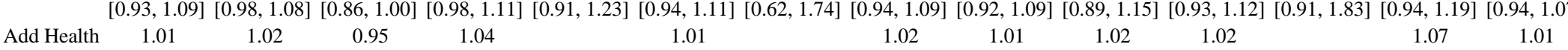

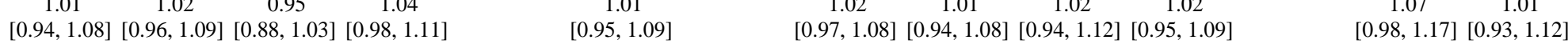

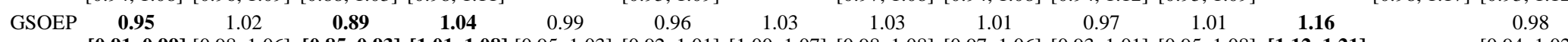

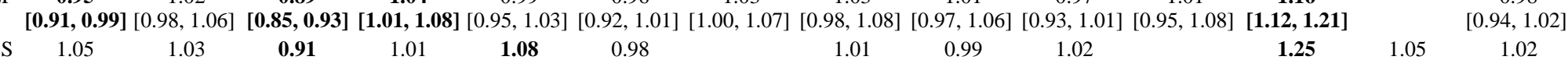

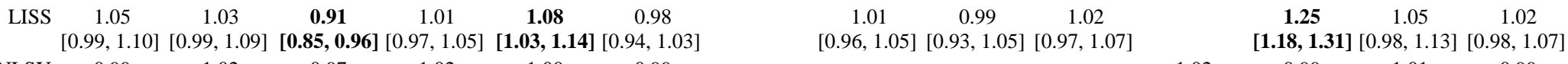
$\begin{array}{lllllllllll}\text { NLSY } & 0.99 & 1.02 & 0.97 & 1.02 & 1.00 & 0.99 & 1.02 & 0.99 & 1.01 & 0.99\end{array}$ $[0.96,1.02][0.99,1.06][0.94,1.01][0.99,1.05][0.96,1.04][0.94,1.06] \quad[0.96,1.09][0.95,1.04][0.96,1.05][0.94,1.05]$ Unemployment

\begin{tabular}{|c|c|c|c|c|c|c|c|c|c|c|c|c|c|c|}
\hline Overall & $\begin{array}{c}0.99 \\
{[0.97,1.01]}\end{array}$ & $\begin{array}{c}1.00 \\
{[0.98,1.02]}\end{array}$ & $\begin{array}{c}0.97 \\
{[0.94,1.01]}\end{array}$ & $\begin{array}{c}1.03 \\
{[1.02,1.05]}\end{array}$ & $\begin{array}{c}1.03 \\
{[1.01,1.05]}\end{array}$ & $\begin{array}{c}0.95 \\
{[0.91,0.99]}\end{array}$ & $\begin{array}{c}0.97 \\
{[0.95,1.00]}\end{array}$ & $\begin{array}{c}0.95 \\
{[0.92,0.97]}\end{array}$ & $\begin{array}{c}0.98 \\
{[0.95,1.01]}\end{array}$ & $\begin{array}{c}1.04 \\
{[1.01,1.07]}\end{array}$ & $\begin{array}{c}0.96 \\
{[0.95,0.97]}\end{array}$ & $\begin{array}{c}0.97 \\
{[0.93,1.00]}\end{array}$ & $\begin{array}{c}1.07 \\
{[1.01,1.15}\end{array}$ & $\begin{array}{c}1.02 \\
{[0.99,1.05]}\end{array}$ \\
\hline Health & $\begin{array}{c}0.97 \\
{[0.93,1.02]}\end{array}$ & $\begin{array}{c}1.00 \\
{[0.96,1.05]}\end{array}$ & $\begin{array}{c}0.97 \\
{[0.90,1.06]}\end{array}$ & $\begin{array}{c}1.04 \\
{[1.00,1.09]}\end{array}$ & & $\begin{array}{c}0.96 \\
{[0.91,1.06]}\end{array}$ & & & $\begin{array}{c}0.95 \\
{[0.89,1.01]}\end{array}$ & $\begin{array}{c}1.01 \\
{[0.94,1.07]}\end{array}$ & $\begin{array}{c}0.96 \\
{[0.94,0.99]}\end{array}$ & & $\begin{array}{c}1.14 \\
{[1.06,1.23]}\end{array}$ & $\begin{array}{c}0.98 \\
{[0.92,1.05]}\end{array}$ \\
\hline BHPS & $\begin{array}{c}1.01 \\
{[0.98,1.04]}\end{array}$ & $\begin{array}{c}0.99 \\
{[0.96,1.02]}\end{array}$ & $\begin{array}{c}0.96 \\
{[0.92,1.00]}\end{array}$ & $\begin{array}{c}1.02 \\
{[0.99,1.04]}\end{array}$ & $\begin{array}{c}1.04 \\
{[1.01,1.07]}\end{array}$ & & $\begin{array}{c}0.98 \\
{[0.96,1.00]}\end{array}$ & $\begin{array}{c}0.96 \\
{[0.94,0.99]}\end{array}$ & & & $\begin{array}{c}0.96 \\
{[0.94,0.98]}\end{array}$ & $\begin{array}{c}0.96 \\
{[0.92,0.99]}\end{array}$ & & $\begin{array}{c}1.02 \\
{[0.98,1.05]}\end{array}$ \\
\hline GSOEP & $\begin{array}{c}0.99 \\
{[0.97,1.01]}\end{array}$ & $\begin{array}{c}0.99 \\
{[0.97,1.02]}\end{array}$ & $\begin{array}{c}0.96 \\
{[0.93,0.99]}\end{array}$ & $\begin{array}{c}1.03 \\
{[1.01,1.05]}\end{array}$ & $\begin{array}{c}1.05 \\
{[1.03,1.07]}\end{array}$ & $\begin{array}{c}0.95 \\
{[0.92,0.98]}\end{array}$ & $\begin{array}{c}0.99 \\
{[0.97,1.01]}\end{array}$ & $\begin{array}{c}0.93 \\
{[0.91,0.96}\end{array}$ & $\begin{array}{c}1.00 \\
{[0.97,1.02]}\end{array}$ & $\begin{array}{c}1.07 \\
{[1.04,1.10]}\end{array}$ & $\begin{array}{c}0.96 \\
{[0.94,0.97]}\end{array}$ & $\begin{array}{c}1.04 \\
{[1.02,1.06]}\end{array}$ & & $\begin{array}{c}1.03 \\
{[1.01,1.05]}\end{array}$ \\
\hline HILDA & $\begin{array}{c}1.01 \\
{[0.99,1.04]}\end{array}$ & $\begin{array}{c}0.99 \\
{[0.96,1.01]}\end{array}$ & $\begin{array}{c}\mathbf{0 . 9 1} \\
{[0.88,0.93]}\end{array}$ & $\begin{array}{c}1.05 \\
{[1.03,1.08]}\end{array}$ & $\begin{array}{c}1.05 \\
{[1.02,1.07]}\end{array}$ & & & $\begin{array}{c}0.96 \\
{[0.94,0.99]}\end{array}$ & $\begin{array}{c}0.95 \\
{[0.93,0.97]}\end{array}$ & $\begin{array}{c}1.07 \\
{[1.04,1.09]}\end{array}$ & $\begin{array}{c}0.96 \\
{[0.95,0.98]}\end{array}$ & $\begin{array}{c}0.97 \\
{[0.94,0.99]}\end{array}$ & $\begin{array}{c}1.02 \\
{[0.99,1.05]}\end{array}$ & $\begin{array}{c}1.03 \\
{[1.02,1.04]}\end{array}$ \\
\hline HRS & $\begin{array}{c}1.00 \\
{[0.97,1.03]}\end{array}$ & $\begin{array}{c}1.02 \\
{[0.99,1.06]}\end{array}$ & $\begin{array}{c}1.03 \\
{[0.99,1.08]}\end{array}$ & $\begin{array}{c}1.04 \\
{[1.02,1.07]}\end{array}$ & $\begin{array}{c}1.03 \\
{[1.00,1.06]}\end{array}$ & & $\begin{array}{c}0.98 \\
{[0.95,1.00]}\end{array}$ & $\begin{array}{c}0.95 \\
{[0.93,0.97]}\end{array}$ & $\begin{array}{c}0.97 \\
{[0.94,1.00]}\end{array}$ & $\begin{array}{c}1.05 \\
{[1.02,1.08]}\end{array}$ & $\begin{array}{c}0.96 \\
{[0.95,0.99]}\end{array}$ & $\begin{array}{c}0.94 \\
{[0.90,0.98]}\end{array}$ & $\begin{array}{c}1.03 \\
{[0.98,1.07]}\end{array}$ & $\begin{array}{c}1.07 \\
{[1.02,1.14]}\end{array}$ \\
\hline LISS & $\begin{array}{c}0.98 \\
{[0.95,1.00]}\end{array}$ & $\begin{array}{c}1.01 \\
{[0.98,1.04]}\end{array}$ & $\begin{array}{c}0.99 \\
{[0.95,1.03]}\end{array}$ & $\begin{array}{c}1.04 \\
{[1.01,1.06]}\end{array}$ & $\begin{array}{c}1.03 \\
{[0.99,1.06]}\end{array}$ & $\begin{array}{c}0.95 \\
{[0.92,0.98]}\end{array}$ & & $\begin{array}{c}0.94 \\
{[0.91,0.96]}\end{array}$ & $\begin{array}{c}1.02 \\
{[0.98,1.06]}\end{array}$ & $\begin{array}{c}1.04 \\
{[1.01,1.07]}\end{array}$ & & $\begin{array}{c}1.00 \\
{[0.97,1.03]}\end{array}$ & $\begin{array}{c}1.06 \\
{[1.02,1.10]}\end{array}$ & $\begin{array}{c}1.06 \\
{[1.03,1.10]}\end{array}$ \\
\hline MIDUS & $\begin{array}{c}1.00 \\
{[0.97,1.02]}\end{array}$ & $\begin{array}{c}1.00 \\
{[0.97,1.02]}\end{array}$ & $\begin{array}{c}0.97 \\
{[0.93,1.01]}\end{array}$ & $\begin{array}{c}1.02 \\
{[1.00,1.05]}\end{array}$ & $\begin{array}{c}1.04 \\
{[1.01,1.07]}\end{array}$ & $\begin{array}{c}0.96 \\
{[0.92,1.02]}\end{array}$ & $\begin{array}{c}0.98 \\
{[0.95,1.02]}\end{array}$ & $\begin{array}{c}0.95 \\
{[0.93,0.97]}\end{array}$ & $\begin{array}{c}0.96 \\
{[0.93,0.99]}\end{array}$ & $\begin{array}{c}1.05 \\
{[1.02,1.08]}\end{array}$ & $\begin{array}{c}0.96 \\
{[0.93,0.97]}\end{array}$ & $\begin{array}{c}0.94 \\
{[0.90,0.98]}\end{array}$ & $\begin{array}{c}1.04 \\
{[0.99,1.11]}\end{array}$ & $\begin{array}{c}1.03 \\
{[0.98,1.08]}\end{array}$ \\
\hline NLSY & & & & & & $\begin{array}{c}0.94 \\
{[0.89,1.01]}\end{array}$ & & & & & $\begin{array}{c}0.96 \\
{[0.94,0.99]}\end{array}$ & & $\begin{array}{c}1.17 \\
{[1.10,1.26]}\end{array}$ & $\begin{array}{c}0.97 \\
{[0.92,1.02]}\end{array}$ \\
\hline
\end{tabular}


Table 3.2

Mega-Analytic and Study-Specific Personality-Outcome Associations in Matched Samples

\begin{tabular}{|c|c|c|c|c|c|c|c|c|c|c|c|c|c|c|}
\hline & $\mathbf{E}$ & A & C & $\mathbf{N}$ & O & SE & OP & SWL & PA & NA & LOC & SS & IQ & DEP \\
\hline udy & $\mathrm{R}[\mathrm{CI}]$ & OR [CI] & OR [CI] & OR [CI] & OR [CI] & OR [CI] & OR $[\mathrm{CI}]$ & OR $[\mathrm{CI}]$ & OR [CI] & OR [CI] & OR $[\mathrm{CI}]$ & OR $[\mathrm{CI}]$ & OR [CI] & OR [CI $]$ \\
\hline & $\begin{array}{c}0.98 \\
{[0.93,1.01]}\end{array}$ & $\begin{array}{c}0.99 \\
{[0.93,1.02]}\end{array}$ & $\begin{array}{c}0.98 \\
{[0.92,1.04]}\end{array}$ & $\begin{array}{c}1.03 \\
{[0.98,1.06]}\end{array}$ & $\begin{array}{c}1.03 \\
{[0.99,1.07]}\end{array}$ & $\begin{array}{c}0.95 \\
{[0.90,1.00]}\end{array}$ & $\begin{array}{c}0.98 \\
{[0.95,1.01]}\end{array}$ & $\begin{array}{c}0.93 \\
{[0.88,0.96]}\end{array}$ & $\begin{array}{c}0.96 \\
{[0.90,1.01]}\end{array}$ & $\begin{array}{c}1.08 \\
{[1.03,1.14]}\end{array}$ & $\begin{array}{c}0.96 \\
{[0.94,0.98]}\end{array}$ & $\begin{array}{c}0.95 \\
{[0.90,1.00]}\end{array}$ & & $\begin{array}{c}1.03 \\
{[1.00,1.07]}\end{array}$ \\
\hline$v_{v}$ & $\begin{array}{c}0.97 \\
{[0.95,0.99}\end{array}$ & $\begin{array}{c}1.00 \\
{[0.98,1.03]}\end{array}$ & $\begin{array}{c}1.00 \\
{[0.97,1.03]}\end{array}$ & $\begin{array}{c}1.03 \\
{[1.01,1.05}\end{array}$ & $\begin{array}{c}0.98 \\
{[0.96,1.01]}\end{array}$ & $\begin{array}{c}0.91 \\
{[0.88,0.93}\end{array}$ & $\begin{array}{c}0.94 \\
{[0.90,0.99]}\end{array}$ & & $\begin{array}{c}1.01 \\
{[0.98,1.04]}\end{array}$ & $\begin{array}{c}0.98 \\
{[0.94,1.02]}\end{array}$ & $\begin{array}{c}0.96 \\
{[0.94,0.97]}\end{array}$ & & & $\begin{array}{c}0.97 \\
{[0.93,1.01]}\end{array}$ \\
\hline
\end{tabular}

\section{Retirement}

\begin{tabular}{|c|c|c|c|c|c|c|c|c|c|c|c|c|c|}
\hline Overall & 0.99 & 1.02 & 1.01 & 1.00 & 0.98 & 1.00 & 1.00 & 1.03 & 1.01 & 0.99 & 0.98 & 1.01 & 1.01 \\
\hline & {$[0.98,1.01]$} & {$[1.00,1.03]$} & {$[0.99,1.03]$} & ] $[0.97,1.02]$ & ] $[0.96,1.00]$ & {$[0.95,1.05]$} & {$[0.97,1.03]$} & {$[1.00,1.06]$} & {$[0.99,1.03]$} & {$[0.97,1.02]$} & {$[0.95,1.02]$} & {$[0.95,1.08][0.90,1.13]$} & ] $[0.98,1.03]$ \\
\hline BHPS & $\begin{array}{c}1.00 \\
{[0.97,1.03]}\end{array}$ & $\begin{array}{c}1.02 \\
{[0.99,1.04]}\end{array}$ & $\begin{array}{c}1.00 \\
{[0.97,1.03}\end{array}$ & $\begin{array}{c}0.99 \\
{[0.96,1.02]}\end{array}$ & $\begin{array}{c}0.98 \\
][0.95,1.01]\end{array}$ & & $\begin{array}{c}0.99 \\
{[0.97,1.01]}\end{array}$ & $\begin{array}{c}1.02 \\
{[0.99,1.05]}\end{array}$ & & & $\begin{array}{c}1.00 \\
{[0.97,1.04]}\end{array}$ & $\begin{array}{c}1.05 \\
{[0.99,1.12]}\end{array}$ & $\begin{array}{c}1.03 \\
{[0.99,1.08]}\end{array}$ \\
\hline GSOEP & $\begin{array}{c}1.00 \\
{[0.98,1.02}\end{array}$ & $\begin{array}{c}1.01 \\
0.99,1.0\end{array}$ & $\begin{array}{c}1.01 \\
{[0.98,1.0}\end{array}$ & $\begin{array}{c}1.02 \\
{[0.99,1.05]}\end{array}$ & $\begin{array}{c}1.01 \\
{[0.98,1.04]}\end{array}$ & $\begin{array}{c}1.00 \\
{[0.97,1.02]}\end{array}$ & $\begin{array}{c}0.98 \\
{[0.96,1.00]}\end{array}$ & $\begin{array}{c}1.00 \\
{[0.98,1.03]}\end{array}$ & $\begin{array}{c}0.99 \\
{[0.96,1.01]}\end{array}$ & $\begin{array}{c}1.00 \\
{[0.98,1.03]}\end{array}$ & $\begin{array}{c}0.95 \\
{[0.91,0.98}\end{array}$ & $\begin{array}{c}\mathbf{0 . 9 2} \\
{[0.89,0.94]}\end{array}$ & $\begin{array}{c}1.01 \\
{[0.99,1.03]}\end{array}$ \\
\hline
\end{tabular}

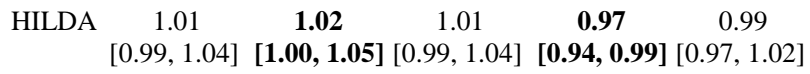

$\begin{array}{llllll}\text { HRS } & 0.99 & 1.01 & 1.00 & 1.01 & \mathbf{0 . 9 7}\end{array}$

$[0.97,1.02][0.99,1.03][0.97,1.02][0.99,1.04][\mathbf{0 . 9 5}, \mathbf{1 . 0 0}]$

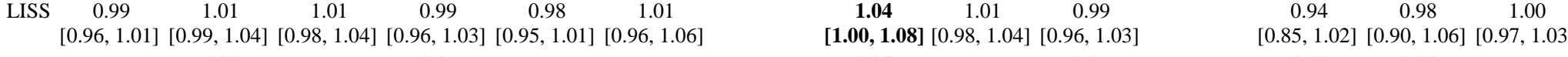

[1.00, 1.06] $[1.00,1.04][0.96,1.01][0.97,1.02][0.97,1.02][0.99,1.08][0.99,1.01]$

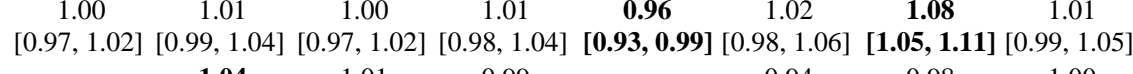

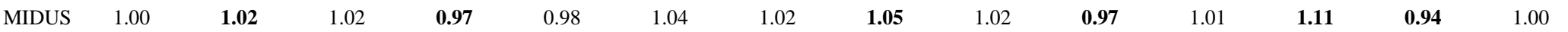

$[0.98,1.02][\mathbf{1 . 0 0}, \mathbf{1 . 0 4}][1.00,1.05][\mathbf{0 . 9 4 , 0 . 9 9}][0.96,1.01][0.99,1.08][0.98,1.06][\mathbf{1 . 0 3}, \mathbf{1 . 0 9}][1.00,1.05][\mathbf{0 . 9 3}, \mathbf{1 . 0 0}][0.98,1.03][\mathbf{1 . 0 7}, \mathbf{1 . 1 5}][\mathbf{0 . 8 9 , 0 . 9 9}][0.97,1.04]$ SHP 1.01

$\begin{array}{llllllll}\text { WLS } & \mathbf{0 . 9 7} & 1.01 & 1.01 & 1.02 & \mathbf{0 . 9 6} & \mathbf{0 . 9 7} & 1.01\end{array}$ $[\mathbf{0 . 9 5}, \mathbf{1 . 0 0}][0.99,1.03][0.99,1.03][1.00,1.04][\mathbf{0 . 9 3}, \mathbf{0 . 9 9}][\mathbf{0 . 9 4}, \mathbf{1 . 0 0}][0.98,1.04]$

$\begin{array}{lrr}1.02 & 0.99 \quad 1.00\end{array}$

0.99 Volunteering

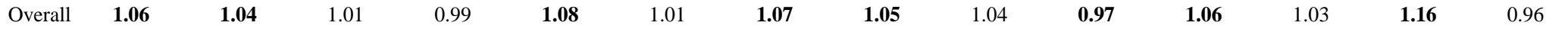
$[\mathbf{1 . 0 3}, \mathbf{1 . 0 9}][\mathbf{1 . 0 1}, \mathbf{1 . 0 6}][0.97,1.05][0.97,1.00][\mathbf{1 . 0 5}, \mathbf{1 . 1 1}][0.95,1.05][\mathbf{1 . 0 2}, \mathbf{1 . 1 3}][\mathbf{1 . 0 3}, \mathbf{1 . 0 8}][1.00,1.09][\mathbf{0 . 9 4}, \mathbf{1 . 0 0}][\mathbf{1 . 0 2}, \mathbf{1 . 0 9}][0.99,1.08][\mathbf{1 . 0 6}, \mathbf{1 . 2 7}][0.92,1.00]$

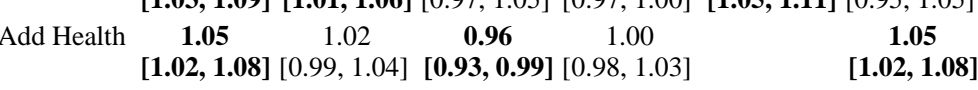
$\begin{array}{llll}1.05 & 0.94 & 0.97 & \mathbf{1 . 0 6}\end{array}$ $1.30 \quad 0.92$ $\begin{array}{lllllll}\text { BHPS } & 1.02 & 1.03 & 0.98 & 0.99 & 1.05 & 1.02\end{array}$ $[0.93,1.08][0.98,1.07][0.91,1.05][0.96,1.01][0.96,1.10]$

$\begin{array}{lllllll}\text { HILDA } & \mathbf{1 . 0 7} & \mathbf{1 . 0 3} & 1.00 & 0.99 & \mathbf{1 . 0 8} & {[0.99,1.06]}\end{array}$ $[\mathbf{1 . 0 4}, \mathbf{1 . 0 9}][\mathbf{1 . 0 0}, \mathbf{1 . 0 5}][0.97,1.03][0.97,1.00][\mathbf{1 . 0 5}, \mathbf{1 . 1 0}]$

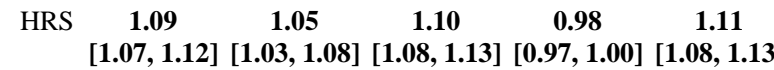

$\begin{array}{lllllll}\text { LISS } & \mathbf{1 . 0 6} & \mathbf{1 . 0 6} & 1.00 & 0.99 & \mathbf{1 . 0 9} & 1.01\end{array}$ $[1.04,1.09][1.03,1.09][0.97,1.03][0.97,1.00][1.07,1.12][0.98,1.04]$ $\left[\begin{array}{cc}1.01,1.08] & \mathbf{0 . 9 2}, \mathbf{0 . 9 6}][0.95,1.00] \\ {[1.02} & 1.02\end{array}\right.$ $[1.25,1.36][0.89,0.96]$

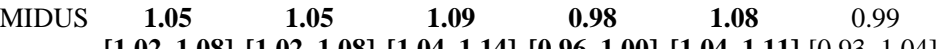
$\left.\begin{array}{ccccccc}1.05 & 1.04 & 0.95 & 1.08 & 1.06 & 1.12 & 0.96 \\ {[1.02,1.07]} & {[1.02,1.06]} & {[0.93,0.97]} & {[1.06,1.10]} & {[1.04,1.09]} & {[1.09,1.14]} & {[0.95,0.98}\end{array}\right]$ $[1.10,1.15][1.04,1.08][1.09,1.14][0.94,0.98][1.07,1.12][0.95,1.00][1.08,1.14][0.90,0.97]$ $\begin{array}{llllllll}1.07 & 1.06 & 1.03 & 0.96 & 1.07 & 1.08 & 1.25 & 1.00\end{array}$ SHP $11.02,1.08][1.02,1.08][1.04,1.14][0.96,1.00][1.04,1.11][0.93,1.04][1.00,1.13][1.04,1.09][0.99,1.06][0.92,1.00][1.03,1.11][1.03,1.14][1.15,1.38][0.93,1.07]$

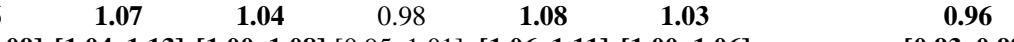

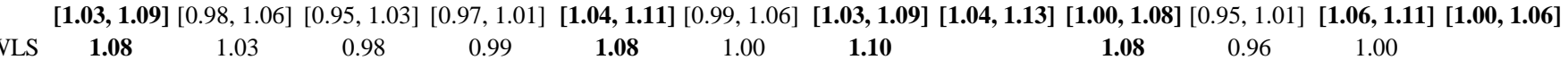
$[0.93,0.98]$

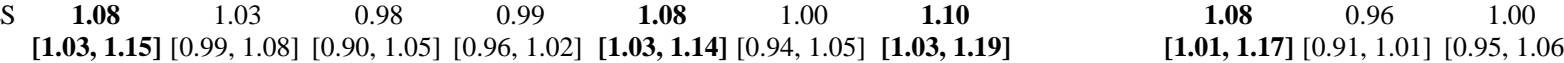


Table 3.2

Mega-Analytic and Study-Specific Personality-Outcome Associations in Matched Samples

\begin{tabular}{|c|c|c|c|c|c|c|c|c|c|c|c|c|c|c|}
\hline & $\mathbf{E}$ & A & C & $\mathbf{N}$ & O & SE & OP & SWL & PA & NA & LOC & SS & IQ & DEP \\
\hline Study & OR [CI] & OR [CI] & OR $[\mathrm{CI}]$ & OR [CI] & OR [CI] & OR [CI] & OR [CI] & OR [CI] & OR [CI] & OR [CI] & OR $[\mathrm{CI}]$ & OR [CI] & OR $[\mathrm{CI}]$ & OR [CI] \\
\hline \multicolumn{15}{|l|}{ Criminality } \\
\hline \multirow[t]{2}{*}{ Overall } & 1.00 & 0.95 & 0.96 & 1.01 & 1.03 & 0.97 & 1.06 & 0.95 & 1.03 & 1.01 & 0.95 & 0.97 & 0.97 & 1.03 \\
\hline & {$[0.96,1.04]$} & {$[0.92,0.99]$} & {$[0.93,1.00]$} & {$[0.96,1.06]$} & {$[0.99,1.09]$} & {$[0.90,1.05]$} & {$[0.81,1.50]$} & {$[0.89,1.00]$} & {$[0.96,1.10]$} & {$[0.93,1.08]$} & {$[0.90,1.01]$} & {$[0.83,1.08]$} & {$[0.91,1.03]$} & {$[0.98,1.09]$} \\
\hline \multirow[t]{2}{*}{ Add Health } & 1.00 & 0.96 & 0.97 & 1.01 & & 0.96 & & 0.93 & 1.04 & 0.98 & 0.96 & & 0.96 & 1.03 \\
\hline & {$[0.95,1.05]$} & {$[0.92,1.01]$} & {$[0.92,1.01]$} & {$[0.96,1.07]$} & & {$[0.90,1.03]$} & & {$[0.87,0.98]$} & {$[0.99,1.10]$} & {$[0.88,1.05]$} & {$[0.90,1.03]$} & & {$[0.91,1.02]$} & {$[0.96,1.10]$} \\
\hline \multirow[t]{2}{*}{ HILDA } & 1.00 & 0.94 & 0.96 & 1.01 & 1.03 & & & 0.95 & 1.03 & 1.02 & 0.93 & 0.97 & 0.95 & 1.03 \\
\hline & {$[0.95,1.04]$} & {$[0.88,0.98]$} & {$[0.91,1.00]$} & {$[0.96,1.06]$} & {$[0.97,1.08]$} & & & {$[0.91,1.01]$} & {$[0.98,1.08]$} & {$[0.96,1.08]$} & {$[0.87,0.99]$} & {$[0.90,1.03]$} & {$[0.88,1.01]$} & {$[1.00,1.07]$} \\
\hline \multirow[t]{2}{*}{ MIDUS } & 1.00 & 0.95 & 0.96 & 1.00 & 1.03 & 0.97 & 1.04 & 0.95 & 1.02 & 1.02 & 0.96 & 0.97 & 0.96 & 1.06 \\
\hline & {$[0.97,1.03]$} & {$[0.92,0.99]$} & {$[0.93,1.00]$} & {$[0.96,1.04]$} & {$[0.99,1.08]$} & {$[0.90,1.04]$} & {$[0.92,1.17]$} & {$[0.92,1.00]$} & {$[0.97,1.07]$} & {$[0.96,1.08]$} & {$[0.91,1.02]$} & {$[0.89,1.04]$} & {$[0.89,1.02]$} & {$[0.99,1.16]$} \\
\hline \multirow[t]{2}{*}{ NLSY } & 1.01 & 0.96 & 0.97 & 1.03 & 1.04 & 1.00 & & & & & 0.98 & 1.03 & 0.99 & 1.01 \\
\hline & {$[0.98,1.04]$} & {$[0.93,0.99]$} & {$[0.94,1.00]$} & {$[0.99,1.07]$} & {$[1.00,1.08]$} & {$[0.94,1.07]$} & & & & & {$[0.92,1.04]$} & {$[0.98,1.08]$} & {$[0.95,1.03]$} & {$[0.95,1.07]$} \\
\hline \multirow[t]{2}{*}{ WLS } & 1.00 & 0.95 & 0.96 & 1.01 & 1.04 & 0.96 & 1.01 & & & 1.01 & 0.94 & & & 1.03 \\
\hline & {$[0.96$,} & 91 & 91,1 & 07 & {$[0.99,1.1]$} & 87, & $86,1.16]$ & & & {$[0.92$,} & {$[0.87$} & & & {$[0.96,1.12]$} \\
\hline
\end{tabular}

$O R=$ Odds Ratio; $C I=89 \%$ Bayesian Credible Interval. Bold indicates model terms whose $89 \% \mathrm{CI}$ of log odds did not overlap with 0. 


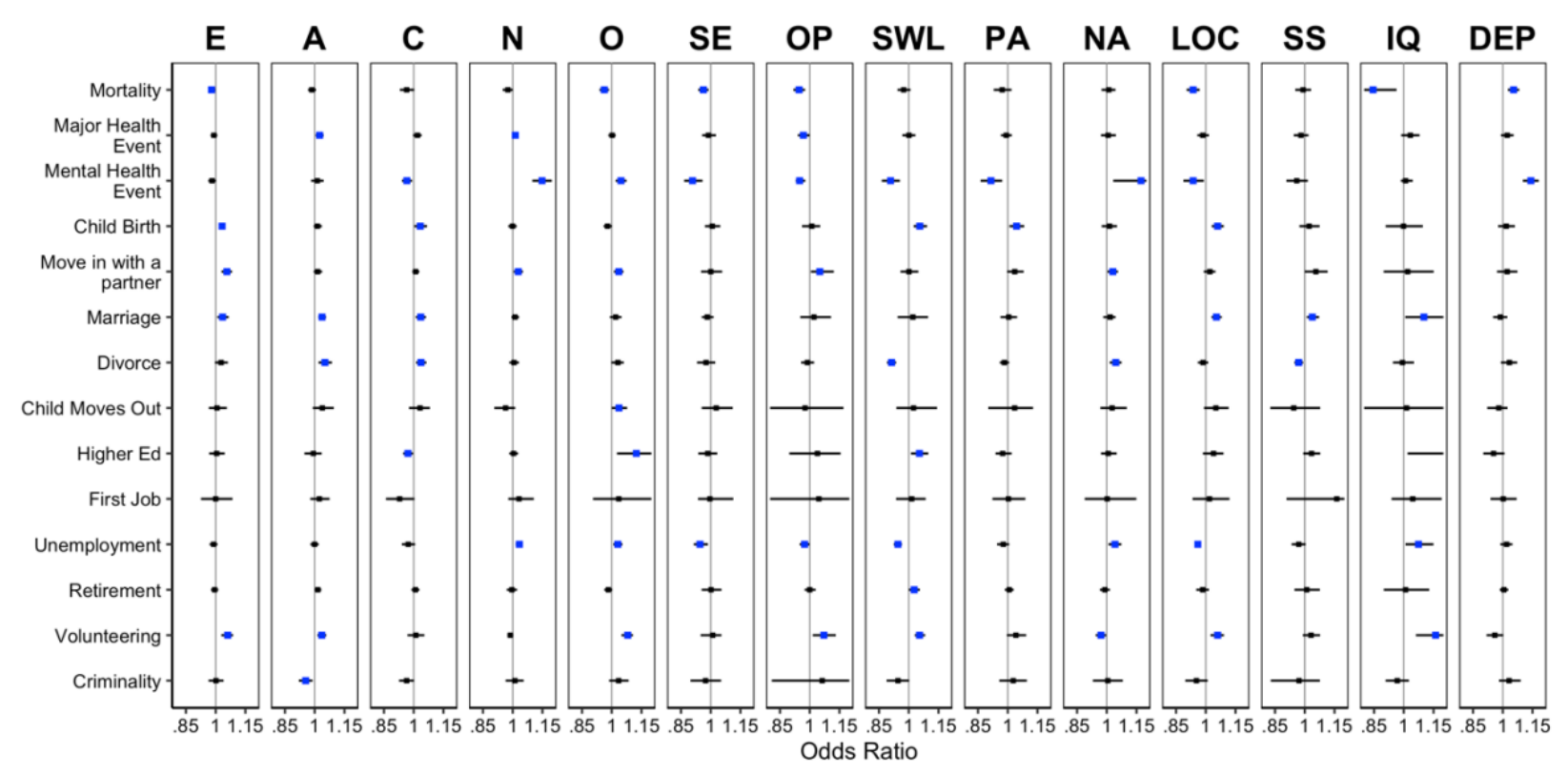

Figure 3.2. Odd ratios fixed $\left(\gamma_{10}\right)$ effects of personality characteristics on outcomes (dots) following propensity score matching. Blue squares represent effects whose $89 \%$ Bayesian Credible intervals of log odds did not overlap with 0 , indicating reliable effects. Rows represent different outcomes, while columns represent different personality characteristics. 
Table 3.3

Level 2 Standard Deviations of Personality-Outcome Associations in Matched Samples

\begin{tabular}{|c|c|c|c|c|c|c|c|c|c|c|c|c|c|c|}
\hline & $\mathbf{E}$ & $\mathbf{A}$ & C & $\mathbf{N}$ & $\mathbf{O}$ & SE & OP & SWL & PA & NA & LOC & SS & IQ & DEP \\
\hline Outcome & $\tau_{11}[\mathrm{CI}]$ & $\tau_{11}[\mathrm{CI}]$ & $\tau_{11}[\mathrm{CI}]$ & $\tau_{11}[\mathrm{CI}]$ & $\tau_{11}[\mathrm{CI}]$ & $\tau_{11}[\mathrm{CI}]$ & $\tau_{11}[\mathrm{CI}]$ & $\tau_{11}[\mathrm{CI}]$ & $\tau_{11}[\mathrm{CI}]$ & $\tau_{11}[\mathrm{CI}]$ & $\tau_{11}[\mathrm{CI}]$ & $\tau_{11}[\mathrm{CI}]$ & $\tau_{11}[\mathrm{CI}]$ & $\tau_{11}[\mathrm{CI}]$ \\
\hline \multirow{4}{*}{ Major Health Event } & .02 & .02 & .06 & .04 & .03 & .02 & .04 & .04 & .06 & .05 & .05 & .06 & .20 & .04 \\
\hline & {$[.002, .04]$} & {$[.002, .04]$} & {$[.03, .09]$} & {$[.010, .07]$} & {$[.009, .07]$} & {$[.002, .07]$} & {$[.02, .08]$} & {$[.02, .08]$} & {$[.03, .12]$} & {$[.02, .10]$} & {$[.03, .09]$} & {$[.03, .10]$} & {$[.04, .59]$} & {$[.02, .07]$} \\
\hline & .02 & .03 & .03 & .01 & .02 & .04 & .04 & .05 & .04 & .06 & .04 & .06 & .06 & .05 \\
\hline & {$[.004, .04]$} & {$[.003, .06]$} & {$[.004, .06]$} & {$[.001, .03]$} & {$[.004, .05]$} & {$[.005, .08]$} & {$[.02, .08]$} & {$[.03, .09]$} & {$[.02, .07]$} & {$[.03, .10]$} & {$[.02, .08]$} & {$[.03, .10]$} & {$[.01, .12]$} & {$[.03, .08]$} \\
\hline \multirow[t]{2}{*}{ Mental Health Event } & .03 & .05 & .04 & .08 & .04 & .07 & .02 & .08 & 10 & .19 & .09 & .09 & .02 & .06 \\
\hline & {$[.01, .05]$} & {$[.03, .08]$} & {$[.03, .07]$} & {$[.05, .12]$} & {$[.02, .07]$} & {$[.04, .12]$} & {$[.002, .06]$} & {$[.05, .13]$} & {$[.06, .15]$} & {$[.11, .32]$} & {$[.06, .14]$} & {$[.06, .14]$} & {$[.002, .08]$} & {$[.03, .10]$} \\
\hline \multirow[t]{2}{*}{ Child Birth } & .01 & .02 & .05 & .03 & .02 & .04 & .04 & .04 & .05 & .05 & .04 & .07 & .11 & .06 \\
\hline & {$[.001, .03]$} & {$[.003, .05]$} & {$[.02, .08]$} & {$[.008, .06]$} & {$[.002, .05]$} & {$[.007, .09]$} & {$[.002, .13]$} & {$[.009, .09]$} & {$[.02, .09]$} & {$[.01, .10]$} & {$[.01, .07]$} & {$[.04, .13]$} & {$[.05, .22]$} & {$[.03, .12]$} \\
\hline \multirow{2}{*}{ Move in with a partner } & .03 & .02 & .01 & .03 & .02 & .06 & .04 & .06 & .05 & .02 & .03 & .08 & .14 & .08 \\
\hline & {$[.007, .06]$} & {$[.003, .05]$} & {$[.001, .04]$} & {$[.003, .06]$} & {$[.002, .06]$} & {$[.01, .13]$} & {$[.002, .16]$} & {$[.03, .11]$} & {$[.009, .11]$} & {$[.002, .06]$} & {$[.003, .07]$} & {$[.04, .14]$} & {$[.05, .30]$} & {$[.04, .14]$} \\
\hline \multirow[t]{2}{*}{ Marriage } & .04 & .02 & .04 & .02 & .04 & .03 & .09 & .11 & .06 & .03 & .03 & .04 & .11 & .05 \\
\hline & {$[.01, .08]$} & {$[.004, .05]$} & {$[.02, .06]$} & {$[.004, .05]$} & {$[.006, .08]$} & {$[.002, .08]$} & {$[.02, .29]$} & {$[.05, .20]$} & {$[.03, .11]$} & {$[.002, .09]$} & {$[.003, .07]$} & {$[.007, .09]$} & {$[.04, .22]$} & {$[.03, .10]$} \\
\hline \multirow[t]{2}{*}{ Divorce } & .04 & .05 & .03 & .03 & .04 & .05 & .03 & .03 & .02 & .03 & .02 & .02 & .04 & .06 \\
\hline & {$[.01, .08]$} & {$[.01, .08]$} & {$[.003, .06]$} & {$[.003, .07]$} & {$[.005, .08]$} & {$[.006, .10]$} & {$[.002, .08]$} & {$[.003, .07]$} & {$[.002, .05]$} & {$[.003, .07]$} & {$[.002, .06]$} & {$[.001, .04]$} & {$[.004, .11]$} & {$[.03, .11]$} \\
\hline \multirow[t]{2}{*}{ Child Moves Out } & .05 & .05 & .05 & .06 & .03 & .08 & .20 & .10 & .11 & .06 & .05 & .16 & .68 & .05 \\
\hline & {$[.003, .13]$} & {$[.008, .13]$} & {$[.004, .13]$} & {$[.01, .14]$} & {$[.002, .10]$} & {$[.02, .18]$} & {$[.01, .59]$} & {$[.009, .27]$} & {$[.008, .43]$} & {$[.003, .20]$} & {$[.002, .15]$} & {$[.07, .33]$} & {$[.05,1.75]$} & {$[.004, .16]$} \\
\hline \multirow[t]{2}{*}{ Higher Ed } & .05 & .06 & .02 & .02 & .13 & .05 & .12 & .05 & .05 & .05 & .07 & .05 & .29 & .08 \\
\hline & {$[.02, .10]$} & {$[.02, .11]$} & {$[.002, .05]$} & {$[.001, .04]$} & {$[.06, .24]$} & {$[.01, .11]$} & {$[.05, .32]$} & {$[.02, .10]$} & {$[.02, .11]$} & {$[.01, .10]$} & {$[.03, .13]$} & {$[.02, .10]$} & {$[.13, .55]$} & {$[.04, .14]$} \\
\hline \multirow[t]{2}{*}{ First Job } & .09 & .04 & .08 & .06 & .14 & .06 & .49 & .06 & .06 & .12 & .07 & .28 & .11 & .07 \\
\hline & {$[.02, .21]$} & {$[.003, .11]$} & {$[.03, .19]$} & {$[.003, .19]$} & {$[.03, .40]$} & {$[.004, .20]$} & {$[.04,1.33]$} & {$[.004, .18]$} & {$[.004, .21]$} & {$[.009, .38]$} & {$[.004, .23]$} & {$[.08, .80]$} & {$[.007, .33]$} & {$[.006, .19]$} \\
\hline \multirow[t]{2}{*}{ Unemployment } & .03 & .02 & .05 & .02 & .03 & .04 & .03 & .03 & .05 & .05 & .01 & .05 & .09 & .05 \\
\hline & {$[.005, .05]$} & {$[.002, .06]$} & {$[.03, .09]$} & {$[.002, .05]$} & {$[.01, .05]$} & {$[.010, .09]$} & $.004, .06]$ & {$[.004, .06]$} & {$[.02, .09]$} & {$[.02, .08]$} & {$[.001, .03]$} & {$[.03, .09]$} & {$[.03, .18]$} & {$[.02, .08]$} \\
\hline \multirow[t]{2}{*}{ Retirement } & .02 & .01 & .02 & .04 & .03 & .05 & .03 & .03 & .03 & .03 & .04 & .09 & .13 & .02 \\
\hline & {$[.003, .04]$} & {$[.001, .03]$} & {$[.001, .05]$} & {$[.02, .07]$} & {$[.005, .05]$} & {$[.01, .13]$} & {$[.005, .07]$} & {$[.008, .07]$} & {$[.003, .06]$} & {$[.003, .07]$} & {$[.01, .09]$} & {$[.05, .16]$} & {$[.04, .29]$} & {$[.002, .06]$} \\
\hline \multirow[t]{2}{*}{ Volunteering } & .04 & .03 & .07 & .02 & .03 & .05 & .07 & .03 & .07 & .04 & .04 & .06 & .12 & .06 \\
\hline & {$[.006, .08]$} & {$[.006, .05]$} & {$[.04, .11]$} & {$[.001, .04]$} & {$[.004, .08]$} & {$[.007, .12]$} & {$[.03, .14]$} & {$[.002, .07]$} & {$[.04, .12]$} & {$[.01, .07]$} & {$[.02, .08]$} & {$[.03, .11]$} & {$[.06, .22]$} & {$[.03, .12]$} \\
\hline \multirow[t]{2}{*}{ Criminality } & .02 & .02 & .02 & .04 & .03 & .06 & .26 & .05 & .06 & .07 & .05 & .13 & .05 & 04 \\
\hline & 07 & P? & & 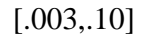 & & & 1 & & & & & & & \\
\hline
\end{tabular}


Overall, personality-outcome associations were relatively robust, even following propensity score matching, with $32.65 \%$ of all tested mega-analytic fixed effects of personality on outcomes being reliable at the $89 \%$ Credible level, which has been demonstrated to be more robust than traditional frequentist 95\% levels in Bayesian models with enough posterior samples (Kruschke, 2014; McElreath, 2020). Indeed, each of the 14 personality characteristics predicted at least one outcome, and each of the 14 outcomes, with the exception of starting a first job, was predicted by at least one personality characteristic. Despite this, there was some variability in how predictive personality characteristics were and in how predictable outcomes were. For example, Openness to Experience and Satisfaction with Life each predicted seven outcomes, which were largely non-overlapping. In contrast, Positive Affect (childbirth, mental health event), Depression (mortality, mental health event), and Social Support (marriage, divorce) predicted just two outcomes. For outcomes, mental health events were predicted by 10 personality characteristics, while retirement (Satisfaction with Life; OR $=1.03 ; 89 \%$ CI $[1.00,1.06], \tau_{11}=03 ; 89 \% \mathrm{CI}$ $[.008, .07])$, contact with the criminal justice system (Agreeableness; OR $=.95 ; 89 \%$ CI [.92, $\left..99] ; \tau_{11}=.02 ; 89 \% \mathrm{CI}[.002, .07]\right)$, and a child moving out of one's home (Openness; OR = $1.04 ; 89 \%$ CI $[1.00,1.08] ; \tau_{11}=.03 ; 89 \%$ CI $\left.[.002, .10]\right)$ were predicted by just one personality characteristic.

Most of the reliable trait-outcome associations were expected based on results from prior studies. For example, Openness (OR $\left.=1.12,89 \% \mathrm{CI}[1.02,1.23] ; \tau_{11}=.13 ; 89 \% \mathrm{CI}[.06, .24]\right)$ and Intelligence $\left(\mathrm{OR}=1.33,89 \% \mathrm{CI}[1.02,1.75] ; \tau_{11}=.29 ; 89 \% \mathrm{CI}[.13, .55]\right)$ predicted higher odds of receiving a college degree or higher, Social Support predicted lower odds of divorce $(\mathrm{OR}=$ $.97,89 \%$ CI $[.95, .99] ; \tau_{11}=.02 ; 89 \%$ CI $\left.[.001, .04]\right)$, and Optimism $(\mathrm{OR}=.95,89 \%$ CI [.92, $\left..98] ; \tau_{11}=.04 ; 89 \% \mathrm{CI}[.02, .08]\right)$, Intelligence $\left(\mathrm{OR}=.85,89 \% \mathrm{CI}[.73, .96] ; \tau_{11}=.20 ; 89 \% \mathrm{CI}\right.$ 
$[.04, .59])$, and Openness (OR $=.96 ; 95 \%$ CI $[.94, .99] ; \tau_{11}=.03 ; 89 \%$ CI $\left.[.009, .07]\right)$ predicted lower odds of mortality. Despite this, some of the observed associations were unexpected, with Agreeableness predicting higher (rather than lower) odds of divorce (OR = .97, 89\% CI [.94,.99]; $\left.\tau_{11}=.05 ; 89 \% \mathrm{CI}[.01, .08]\right)$ and a major health event $\left(\mathrm{OR}=1.02,89 \% \mathrm{CI}[1.00,1.04] ; \tau_{11}=\right.$ $.03 ; 89 \% \mathrm{CI}[.003, .06])$ and Intelligence predicting higher odds of unemployment $(\mathrm{OR}=1.07$, $89 \%$ CI $[1.01,1.15] ; \tau_{11}=.09 ; 89 \%$ CI $\left.[.03, .18]\right)$.

However, a number of expected associations were notably absent. Conscientiousness $(\mathrm{OR}=.96$; $89 \%$ CI $[.93,1.00] ; \tau_{11}=.06 ; 89 \%$ CI $\left.[.03, .09]\right)$, Agreeableness (OR = .99; 89\% CI [.97, 1.01]; $\tau_{11}=.02 ; 89 \%$ CI $\left.[.002, .04]\right)$, Neuroticism (OR $=.98 ; 89 \%$ CI $[.95,1.00] ; \tau_{11}=.04 ; 89 \%$ CI $[.01, .07])$, and Negative Affect $\left(\mathrm{OR}=1.01 ; 89 \% \mathrm{CI}[.97,1.04] ; \tau_{11}=.05 ; 89 \%\right.$ CI $\left.[.02, .10]\right)$, for example, did not predict mortality despite seemingly robust previous evidence of their links. In addition, Conscientiousness did not predict major health events $(\mathrm{OR}=1.02 ; 89 \% \mathrm{CI}[1.00$, 1.04]; $\tau_{11}=.03 ; 89 \%$ CI $\left.[.004, .06]\right)$. However, as is clear in Figure 3.3, which presents the overall and study-specific associations of all 14 personality characteristics with mortality, there is considerable variability across studies in Conscientiousness-mortality associations, suggesting that there may be important study-level characteristics that moderate this finding. Although Conscientiousness did not predict mortality $\left(\mathrm{OR}=.97,89 \% \mathrm{CI}[.93,1.02] ; \tau_{11}=.06 ; 89 \% \mathrm{CI}\right.$ $[.03, .09])$, a number of other personality characteristics did, both at the mega-analytic and studyspecific levels. Specifically, Extraversion $\left(\mathrm{OR}=.98,89 \%\right.$ CI $[.96,1.00] ; \tau_{11}=.02 ; 89 \%$ CI $[.002$, $.04])$, Openness $\left(\mathrm{OR}=.96,89 \%\right.$ CI $[.94, .99] ; \tau_{11}=.03 ; 89 \%$ CI $\left.[.009, .07]\right)$, Self-Esteem $(\mathrm{OR}=$ $.96,89 \%$ CI $[.94, .99] ; \tau_{11}=.02 ; 89 \%$ CI $\left.[.002, .07]\right)$, Optimism $\left(\mathrm{OR}=.95,89 \%\right.$ CI $[.92, .98] ; \tau_{11}$ $=.04 ; 89 \% \mathrm{CI}[.02, .08])$, Locus of Control $\left(\mathrm{OR}=.94,89 \% \mathrm{CI}[.90, .97] ; \tau_{11}=.05 ; 89 \% \mathrm{CI}[.03\right.$, $.09])$, and Intelligence $\left(\mathrm{OR}=.85,89 \% \mathrm{CI}[.73, .96] ; \tau_{11}=.20 ; 89 \% \mathrm{CI}[.04, .59]\right)$ all 
demonstrated a protective effect of personality on mortality, with higher levels of each characteristic being associated with lower odds of mortality across studies. Only higher levels of Depression suggested an increase in mortality risk $\left(\mathrm{OR}=1.05,89 \% \mathrm{CI}[1.03,1.08] ; \tau_{11}=.04\right.$; $89 \%$ CI $[.02, .07])$.

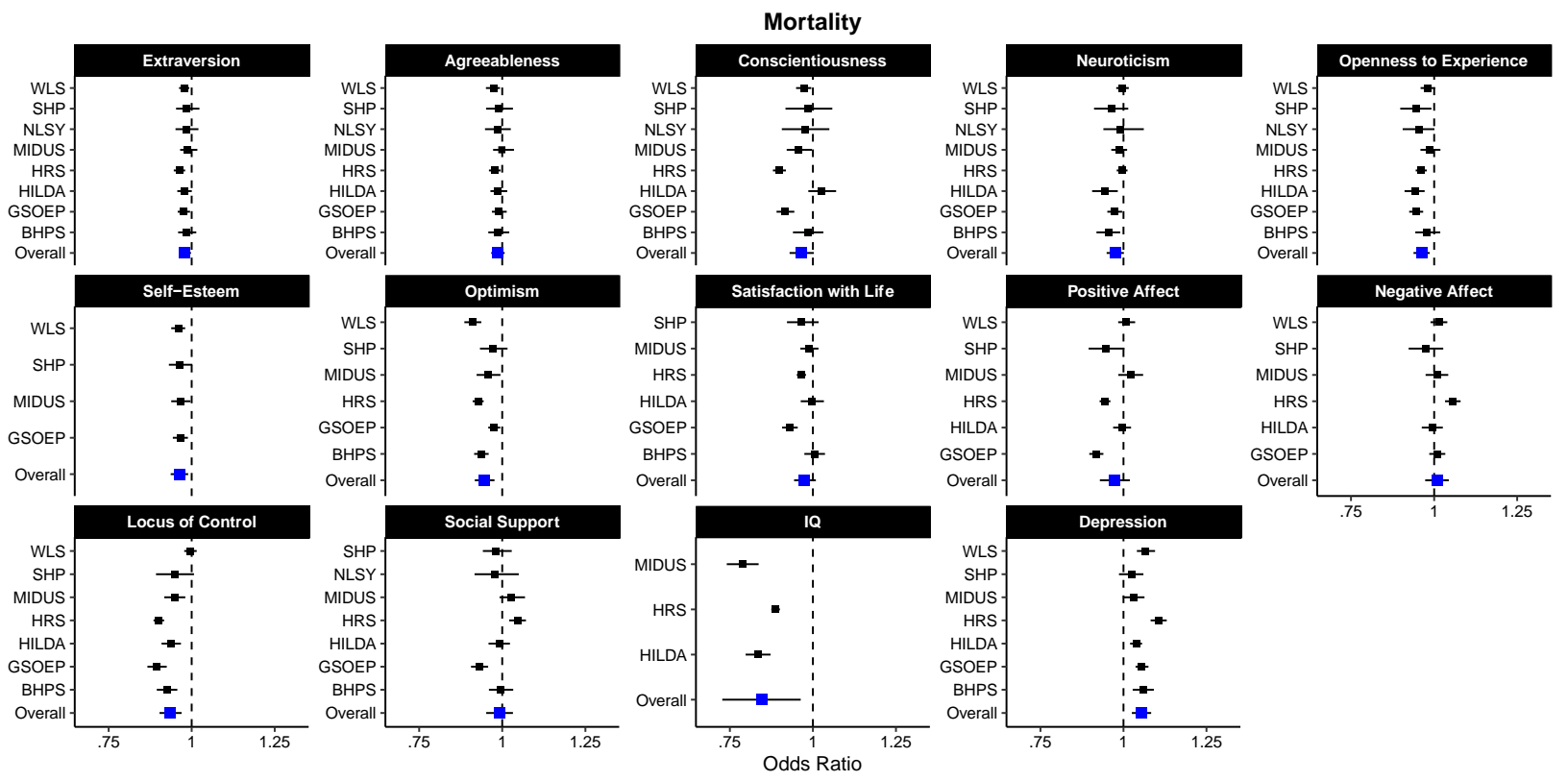

Figure 3.3. Odds ratios of fixed $\left(\gamma_{10}\right)$ and study-specific $\left(\beta_{1 j}\right)$ effects of personality characteristics on mortality (dots) following propensity score matching. Error bars represent $89 \%$ Bayesian Credible Intervals around each effect in the pooled models. Error bars that do not overlap with 1 are considered reliable effects of personality on mortality.

Despite this, with the exception of IQ's protective effect on mortality, not all study-specific effects of these characteristics predicting mortality demonstrated a robust effect (see Figure 3.3).

For example, Optimism suggested a protective effect on mortality for five (BHPS, GSOEP, HRS, MIDUS, and WLS) of the six (SHP) studies used to test the association, while Openness suggested a protective effect for only four (GSOEP, HILDA, HRS, and SHP) of the eight studies (BHPS, MIDUS, NLSY, and WLS) used to test the association. Moreover, even though Conscientiousness did not exhibit a mega-analytic effect on mortality, four (GSOEP, HRS, 
MIDUS, and WLS) of the eight (BHPS, HILDA, NLSY, and SHP) tested studies showed links between it and mortality. In one case, different studies significantly predicted mortality from Social Support in opposite directions, with HRS data suggesting that Social Support was associated with higher odds of mortality while GSOEP data suggested that Social Support had a protective effect on mortality.

\subsubsection{Moderators of Matched Personality-Outcome Associations}

Next, I tested a series of key moderators - age, gender, socioeconomic status (parental education, parental occupational prestige, and gross income), race/ethnicity, scale reliability, and prediction interval - in samples matched on all background characteristics but the target moderator. The mega-analytic moderator results of all trait-outcome associations are presented in Table 3.4. Study-specific results and simple effects plots for all moderator results are available in the online materials and on the web application. Overall, the presence of moderators of personalityoutcome associations $(6.70 \%)$ was much more modest than the presence of main effects of personality-outcome associations (32.65\%), suggesting that personality prediction is relatively robust across the eight tested moderators in this study. 
Table 3.4

Fixed Effect Moderators of Personality-Outcome Associations

\begin{tabular}{|c|c|c|c|c|c|c|c|c|c|c|c|c|c|c|}
\hline & $\mathbf{E}$ & $\mathbf{A}$ & $\mathrm{C}$ & $\mathbf{N}$ & $\mathbf{O}$ & SE & OP & SWL & PA & NA & LOC & SS & IQ & DEP \\
\hline Term & OR [CI] & OR [CI] & OR [CI] & OR [CI] & OR [CI] & OR [CI] & OR [CI] & OR [CI] & OR [CI] & OR [CI] & OR [CI] & OR [CI] & OR [CI] & OR [CI] \\
\hline \multicolumn{15}{|l|}{ Mortality } \\
\hline Age & $\begin{array}{c}1.00 \\
{[1.00,1.00]}\end{array}$ & $\begin{array}{c}1.00 \\
{[1.00,1.00]}\end{array}$ & $\begin{array}{c}1.00 \\
{[1.00,1.00]}\end{array}$ & $\begin{array}{c}1.00 \\
{[1.00,1.00]}\end{array}$ & $\begin{array}{c}1.00 \\
{[1.00,1.00]}\end{array}$ & $\begin{array}{c}1.00 \\
{[1.00,1.00]}\end{array}$ & $\begin{array}{c}1.00 \\
{[1.00,1.00]}\end{array}$ & $\begin{array}{c}1.00 \\
{[1.00,1.00]}\end{array}$ & $\begin{array}{c}1.00 \\
{[1.00,1.00]}\end{array}$ & $\begin{array}{c}1.00 \\
{[1.00,1.00]}\end{array}$ & $\begin{array}{c}1.00 \\
{[1.00,1.00]}\end{array}$ & $\begin{array}{c}1.00 \\
{[1.00,1.00]}\end{array}$ & $\begin{array}{c}1.00 \\
{[0.99,1.02]}\end{array}$ & $\begin{array}{c}1.00 \\
{[0.99,1.00]}\end{array}$ \\
\hline $\begin{array}{r}\text { Gender } \\
\text { (Female v Male) }\end{array}$ & $\begin{array}{c}0.96 \\
{[0.93,0.99]}\end{array}$ & $\begin{array}{c}0.95 \\
{[0.92,0.99]}\end{array}$ & $\begin{array}{c}0.96 \\
{[0.93,0.99]}\end{array}$ & $\begin{array}{c}0.99 \\
{[0.96,1.02]}\end{array}$ & $\begin{array}{c}0.98 \\
{[0.95,1.01]}\end{array}$ & $\begin{array}{c}1.00 \\
{[0.94,1.05]}\end{array}$ & $\begin{array}{c}0.99 \\
{[0.97,1.01]}\end{array}$ & $\begin{array}{c}1.01 \\
{[0.98,1.04]}\end{array}$ & $\begin{array}{c}0.97 \\
{[0.95,1.00]}\end{array}$ & $\begin{array}{c}1.02 \\
{[0.98,1.05]}\end{array}$ & $\begin{array}{c}0.99 \\
{[0.97,1.01]}\end{array}$ & $\begin{array}{c}1.00 \\
{[0.97,1.04]}\end{array}$ & $\begin{array}{c}0.96 \\
{[0.89,1.06]}\end{array}$ & $\begin{array}{c}1.01 \\
{[0.99,1.04]}\end{array}$ \\
\hline $\begin{array}{c}\text { Prediction } \\
\text { Interval }\end{array}$ & $\begin{array}{c}1.00 \\
{[1.00,1.01]}\end{array}$ & $\begin{array}{c}1.00 \\
{[0.99,1.01]}\end{array}$ & $\begin{array}{c}1.00 \\
{[0.99,1.02]}\end{array}$ & $\begin{array}{c}1.00 \\
{[0.99,1.01]}\end{array}$ & $\begin{array}{c}1.01 \\
{[1.00,1.01]}\end{array}$ & $\begin{array}{c}1.00 \\
{[0.99,1.01]}\end{array}$ & $\begin{array}{c}1.00 \\
{[0.99,1.02]}\end{array}$ & $\begin{array}{c}1.00 \\
{[0.99,1.02]}\end{array}$ & $\begin{array}{c}1.01 \\
{[1.00,1.02]}\end{array}$ & $\begin{array}{c}1.00 \\
{[0.99,1.01]}\end{array}$ & $\begin{array}{c}1.00 \\
{[0.99,1.01]}\end{array}$ & $\begin{array}{c}1.00 \\
{[0.97,1.01]}\end{array}$ & $\begin{array}{c}1.00 \\
{[0.91,1.10]}\end{array}$ & $\begin{array}{c}1.00 \\
{[0.99,1.02]}\end{array}$ \\
\hline $\begin{array}{r}\text { Race } \\
\text { (Black v White) }\end{array}$ & $\begin{array}{c}1.03 \\
{[0.92,1.13]}\end{array}$ & $\begin{array}{c}1.07 \\
{[0.97,1.17]}\end{array}$ & $\begin{array}{c}1.05 \\
{[0.96,1.15]}\end{array}$ & $\begin{array}{c}1.01 \\
{[0.86,1.22]}\end{array}$ & $\begin{array}{c}1.00 \\
{[0.91,1.08]}\end{array}$ & $\begin{array}{c}0.95 \\
{[0.58,1.60]}\end{array}$ & $\begin{array}{c}1.01 \\
{[0.91,1.12]}\end{array}$ & $\begin{array}{c}1.03 \\
{[0.91,1.16]}\end{array}$ & $\begin{array}{c}1.08 \\
{[0.93,1.26]}\end{array}$ & $\begin{array}{c}1.01 \\
{[0.79,1.35]}\end{array}$ & $\begin{array}{c}0.97 \\
{[0.85,1.08]}\end{array}$ & $\begin{array}{c}1.06 \\
{[0.96,1.16]}\end{array}$ & $\begin{array}{c}1.04 \\
{[0.54,1.83]}\end{array}$ & $\begin{array}{c}1.01 \\
{[0.85,1.23]}\end{array}$ \\
\hline $\begin{array}{r}\text { Race } \\
\text { (Other v White) }\end{array}$ & $\begin{array}{c}1.02 \\
{[0.86,1.28]}\end{array}$ & $\begin{array}{c}1.03 \\
{[0.87,1.31]}\end{array}$ & $\begin{array}{c}1.09 \\
{[0.93,1.31]}\end{array}$ & $\begin{array}{c}1.13 \\
{[0.93,1.71]}\end{array}$ & $\begin{array}{c}1.05 \\
{[0.88,1.32]}\end{array}$ & $\begin{array}{c}1.36 \\
{[.10,49.25]}\end{array}$ & $\begin{array}{c}1.02 \\
{[0.54,2.57]}\end{array}$ & $\begin{array}{c}0.87 \\
{[0.50,1.33]}\end{array}$ & $\begin{array}{c}1.14 \\
{[0.62,2.45]}\end{array}$ & $\begin{array}{c}1.18 \\
{[0.60,2.97]}\end{array}$ & $\begin{array}{c}1.16 \\
{[0.83,1.95]}\end{array}$ & $\begin{array}{c}1.05 \\
{[0.87,1.38]}\end{array}$ & $\begin{array}{c}1.04 \\
{[0.31,3.68]}\end{array}$ & $\begin{array}{c}1.16 \\
{[0.61,2.60]}\end{array}$ \\
\hline Reliability & $\begin{array}{c}0.97 \\
{[0.83,1.14]}\end{array}$ & $\begin{array}{c}0.98 \\
.88,1.09]\end{array}$ & $\begin{array}{c}1.05 \\
{[0.79,1.39]}\end{array}$ & $\begin{array}{l}0.87 \\
.65,1.15]\end{array}$ & $\begin{array}{c}1.02 \\
{[0.87,1.21]}\end{array}$ & $\begin{array}{c}0.78 \\
0.10,5.25]\end{array}$ & $\begin{array}{c}1.03 \\
{[0.16,6.42}\end{array}$ & $\begin{array}{c}0.95 \\
{[0.43,1.89]}\end{array}$ & $\begin{array}{c}0.94 \\
{[0.22,3.54]}\end{array}$ & $\begin{array}{c}1.14 \\
{[0.47,2.74]}\end{array}$ & $\begin{array}{c}0.88 \\
{[0.66,1.20]}\end{array}$ & $\begin{array}{c}1.17 \\
{[1.05,1.31]}\end{array}$ & $\begin{array}{c}1.08 \\
{[0.24,6.62]}\end{array}$ & \\
\hline
\end{tabular}

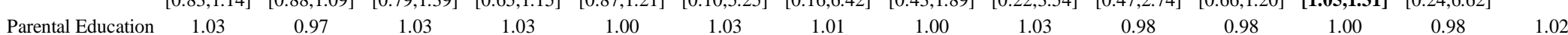

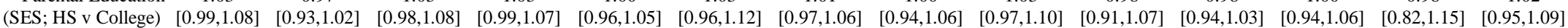

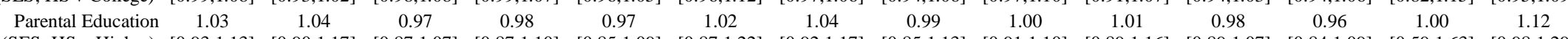

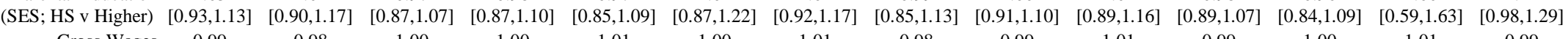

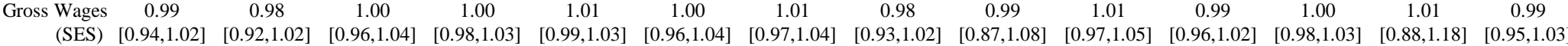

$\begin{array}{lllllllllllllll}\text { Parental Occupational } & \mathbf{1 . 0 1} & 1.00 & 1.00 & 1.00 & 1.00 & 1.01 & 1.00 & 1.01 & 1.00 & 1.00 & 1.00 & 1.00 & 0.99 & 1.00\end{array}$

Prestige (SES) $[\mathbf{1 . 0 0 , 1 . 0 1}][0.99,1.01][0.99,1.01] \quad[0.99,1.01] \quad[0.99,1.01] \quad[0.99,1.02] \quad[1.00,1.01] \quad[1.00,1.02] \quad[0.99,1.01] \quad[0.99,1.01] \quad[1.00,1.01] \quad[0.99,1.01] \quad[0.97,1.02] \quad[0.99,1.00]$ Major Health Event

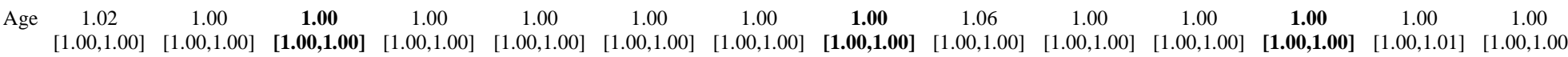

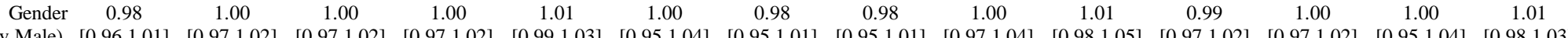
(Female v Male) $[0.96,1.01] \quad[0.97,1.021$

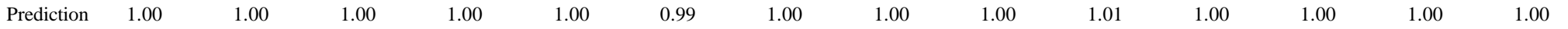
Interval $[0.99,1.00][0.99,1.01] \quad[0.99,1.01][1.00,1.00] \quad[0.99,1.00] \quad[0.98,1.01] \quad[0.99,1.01] \quad[0.99,1.01] \quad[0.99,1.00] \quad[1.00,1.02] \quad[0.99,1.01] \quad[0.99,1.01] \quad[0.97,1.01] \quad[0.99,1.01]$

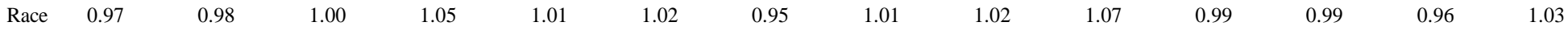
$\begin{array}{llllllllllllllllllll}\text { (Black v White) } & {[0.91,1.04]} & {[0.92,1.05]} & {[0.94,1.07]} & {[0.98,1.12]} & {[0.94,1.08]} & {[0.90,1.15]} & {[0.86,1.05]} & {[0.96,1.07]} & {[0.95,1.10]} & {[0.98,1.17]} & {[0.92,1.06]} & {[0.92,1.07]} & {[0.84,1.08]} & {[0.95,1.11]}\end{array}$

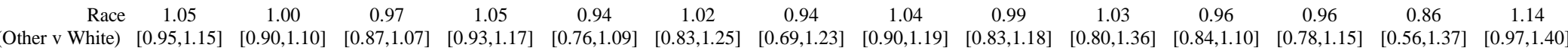

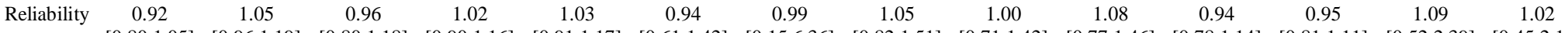
$\begin{array}{ccccccccccccccc}{[0.80,1.05]} & {[0.96,1.19]} & {[0.80,1.18]} & {[0.90,1.16]} & {[0.91,1.17]} & {[0.61,1.42]} & {[0.15,6.36]} & {[0.82,1.51]} & {[0.71,1.42]} & {[0.77,1.46]} & {[0.78,1.14]} & {[0.81,1.11]} & {[0.52,2.39]} & {[0.45,2.16}\end{array}$

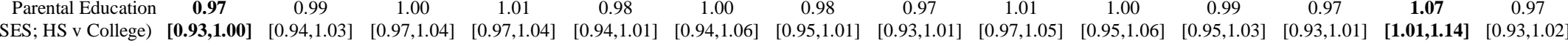

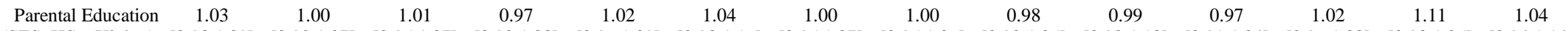

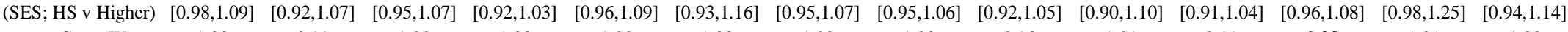
$\begin{array}{llllllllllllllll}\text { Gross Wages } & 1.00 & 0.99 & 1.00 & 1.00 & 1.00 & 1.00 & 1.00 & 1.00 & 0.98 & 1.01 & 0.99 & \mathbf{0 . 9 8} & 1.01 & 1.00\end{array}$

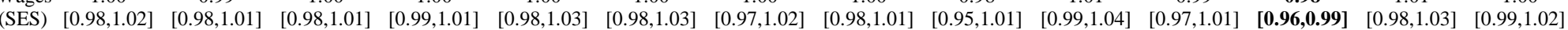

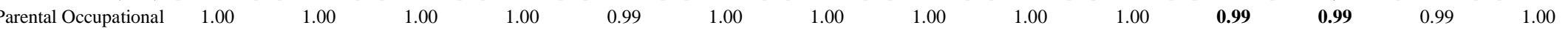

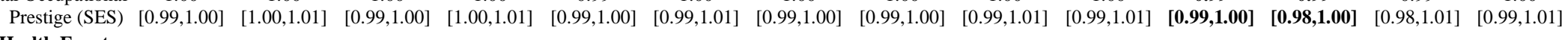
Mental Health Event

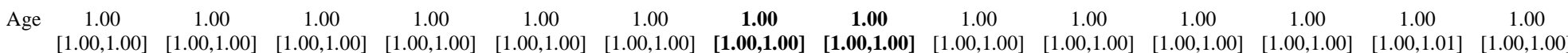


Table 3.4

Fixed Effect Moderators of Personality-Outcome Associations

\begin{tabular}{|c|c|c|c|c|c|c|c|c|c|c|c|c|c|c|}
\hline & $\mathbf{E}$ & A & C & $\mathbf{N}$ & $\mathbf{O}$ & SE & OP & SWL & PA & NA & LOC & SS & IQ & DEP \\
\hline Term & OR [CI] & OR [CI] & OR [CI] & {$[\mathrm{CI}]$} & [CI] & I] & {$[\mathrm{CI}]$} & OR [CI] & {$[\mathrm{CI}]$} & {$[\mathrm{CI}]$} & OR [CI] & {$[\mathrm{CI}]$} & {$[\mathrm{CI}]$} & OR [CI] \\
\hline $\begin{array}{r}\text { Gender } \\
\text { (Female v Male) }\end{array}$ & $\begin{array}{c}1.02 \\
{[0.99,1.04]}\end{array}$ & $\begin{array}{c}0.99 \\
{[0.96,1.01]}\end{array}$ & $\begin{array}{c}1.01 \\
{[0.99,1.04]}\end{array}$ & $\begin{array}{c}0.99 \\
{[0.97,1.02]}\end{array}$ & $\begin{array}{c}1.03 \\
{[1.00,1.05]}\end{array}$ & $\begin{array}{c}1.02 \\
{[0.98,1.06]}\end{array}$ & $\begin{array}{c}1.01 \\
{[0.97,1.06]}\end{array}$ & $\begin{array}{c}1.00 \\
{[0.97,1.03]}\end{array}$ & $\begin{array}{c}1.00 \\
{[0.97,1.02]}\end{array}$ & $\begin{array}{c}0.97 \\
{[0.94,1.00]}\end{array}$ & $\begin{array}{c}1.03 \\
{[1.00,1.06]}\end{array}$ & $\begin{array}{c}1.00 \\
{[0.97,1.04]}\end{array}$ & $\begin{array}{c}1.06 \\
{[1.01,1.12]}\end{array}$ & $\begin{array}{c}0.97 \\
{[0.94,1.00]}\end{array}$ \\
\hline $\begin{array}{c}\text { Prediction } \\
\text { Interval }\end{array}$ & $\begin{array}{c}1.00 \\
{[0.99,1.01]}\end{array}$ & $\begin{array}{c}0.99 \\
{[0.98,1.00]}\end{array}$ & $\begin{array}{c}1.00 \\
{[0.99,1.01]}\end{array}$ & $\begin{array}{c}1.00 \\
{[0.98,1.01]}\end{array}$ & $\begin{array}{c}1.00 \\
{[0.99,1.01]}\end{array}$ & $\begin{array}{c}1.00 \\
{[0.99,1.02]}\end{array}$ & $\begin{array}{c}1.00 \\
{[0.99,1.01]}\end{array}$ & & $\begin{array}{c}1.00 \\
{[0.98,1.02]}\end{array}$ & $\begin{array}{c}1.01 \\
{[0.97,1.04]}\end{array}$ & $\begin{array}{c}1.00 \\
{[0.99,1.01]}\end{array}$ & $\begin{array}{c}1.00 \\
{[0.99,1.01]}\end{array}$ & $\begin{array}{c}1.00 \\
{[0.99,1.01]}\end{array}$ & $\begin{array}{c}1.00 \\
{[1.00,1.01]}\end{array}$ \\
\hline $\begin{array}{r}\text { Race } \\
\text { (Black v White) }\end{array}$ & $\begin{array}{c}1.03 \\
{[0.98,1.09]}\end{array}$ & $\begin{array}{c}0.97 \\
{[0.91,1.03]}\end{array}$ & $\begin{array}{c}1.04 \\
{[0.99,1.10]}\end{array}$ & $\begin{array}{c}0.99 \\
{[0.93,1.05]}\end{array}$ & $\begin{array}{c}1.01 \\
{[0.94,1.08]}\end{array}$ & $\begin{array}{c}1.03 \\
{[0.91,1.18]}\end{array}$ & $\begin{array}{c}1.03 \\
{[0.93,1.14]}\end{array}$ & $\begin{array}{c}0.98 \\
{[0.92,1.03]}\end{array}$ & $\begin{array}{c}1.02 \\
{[0.94,1.10]}\end{array}$ & $\begin{array}{c}0.98 \\
{[0.88,1.13]}\end{array}$ & $\begin{array}{c}1.06 \\
{[0.99,1.14]}\end{array}$ & $\begin{array}{c}1.00 \\
{[0.93,1.08]}\end{array}$ & $\begin{array}{c}0.98 \\
{[0.89,1.10]}\end{array}$ & $\begin{array}{c}0.92 \\
{[0.83,1.02]}\end{array}$ \\
\hline $\begin{array}{r}\text { Race } \\
\text { (Other v White) }\end{array}$ & $\begin{array}{c}0.97 \\
{[0.91,1.05]}\end{array}$ & $\begin{array}{c}0.97 \\
{[0.90,1.04]}\end{array}$ & $\begin{array}{c}0.99 \\
{[0.91,1.07]}\end{array}$ & $\begin{array}{c}0.91 \\
{[0.83,0.99]}\end{array}$ & $\begin{array}{c}0.99 \\
{[0.88,1.10]}\end{array}$ & $\begin{array}{c}0.94 \\
{[0.72,1.24]}\end{array}$ & $\begin{array}{c}1.03 \\
{[0.74,1.51]}\end{array}$ & $\begin{array}{c}0.97 \\
{[0.81,1.13]}\end{array}$ & $\begin{array}{c}1.10 \\
{[0.80,1.78]}\end{array}$ & $\begin{array}{c}0.91 \\
{[0.62,1.27]}\end{array}$ & $\begin{array}{c}1.05 \\
{[0.94,1.17]}\end{array}$ & $\begin{array}{c}0.93 \\
{[0.82,1.06]}\end{array}$ & $\begin{array}{c}1.02 \\
{[0.64,1.46]}\end{array}$ & $\begin{array}{c}1.04 \\
{[0.90,1.22]}\end{array}$ \\
\hline Reliability & $\begin{array}{c}0.93 \\
{[0.83,1.05]}\end{array}$ & $\begin{array}{c}1.02 \\
{[0.90,1.16]}\end{array}$ & $\begin{array}{c}0.87 \\
{[0.72,1.05]}\end{array}$ & $\begin{array}{c}1.28 \\
{[0.97,1.67]}\end{array}$ & $\begin{array}{c}0.97 \\
{[0.84,1.13]}\end{array}$ & $\begin{array}{c}0.77 \\
{[0.44,1.44]}\end{array}$ & $\begin{array}{c}1.13 \\
{[0.16,7.56]}\end{array}$ & $\begin{array}{c}0.87 \\
{[0.65,1.17]}\end{array}$ & $\begin{array}{c}0.90 \\
{[0.49,1.60]}\end{array}$ & $\begin{array}{c}1.13 \\
{[0.46,2.76]}\end{array}$ & $\begin{array}{c}0.96 \\
{[0.77,1.23]}\end{array}$ & $\begin{array}{c}0.94 \\
{[0.78,1.14]}\end{array}$ & $\begin{array}{c}0.99 \\
{[0.42,1.87]}\end{array}$ & $\begin{array}{c}1.27 \\
{[0.62,2.48]}\end{array}$ \\
\hline $\begin{array}{l}\text { Parental Education } \\
\text { (SES; HS v College) }\end{array}$ & $\begin{array}{c}0.99 \\
{[0.96,1.02]}\end{array}$ & $\begin{array}{c}1.03 \\
{[0.99,1.07]}\end{array}$ & $\begin{array}{c}1.01 \\
{[0.98,1.04]}\end{array}$ & $\begin{array}{c}1.00 \\
{[0.97,1.04]}\end{array}$ & $\begin{array}{c}0.99 \\
{[0.95,1.03]}\end{array}$ & $\begin{array}{c}0.97 \\
{[0.91,1.03]}\end{array}$ & $\begin{array}{c}0.97 \\
{[0.94,1.01]}\end{array}$ & $\begin{array}{c}0.98 \\
{[0.94,1.01]}\end{array}$ & $\begin{array}{c}1.01 \\
{[0.97,1.04]}\end{array}$ & $\begin{array}{c}1.05 \\
{[0.99,1.12]}\end{array}$ & $\begin{array}{c}0.97 \\
{[0.93,1.01]}\end{array}$ & $\begin{array}{c}0.97 \\
{[0.94,1.01]}\end{array}$ & $\begin{array}{c}0.98 \\
{[0.94,1.03]}\end{array}$ & $\begin{array}{c}0.96 \\
{[0.91,1.01]}\end{array}$ \\
\hline $\begin{array}{c}\text { Parental Education } \\
\text { (SES; HS v Higher) }\end{array}$ & $\begin{array}{c}1.03 \\
{[0.98,1.08]}\end{array}$ & $\begin{array}{c}1.02 \\
{[0.97,1.08]}\end{array}$ & $\begin{array}{c}1.02 \\
{[0.98,1.07]}\end{array}$ & $\begin{array}{c}0.98 \\
{[0.92,1.03]}\end{array}$ & $\begin{array}{c}1.06 \\
{[1.00,1.12]}\end{array}$ & $\begin{array}{c}0.99 \\
{[0.90,1.09]}\end{array}$ & $\begin{array}{c}0.95 \\
{[0.87,1.03]}\end{array}$ & $\begin{array}{c}0.99 \\
{[0.93,1.06]}\end{array}$ & $\begin{array}{c}1.07 \\
{[1.00,1.15]}\end{array}$ & $\begin{array}{c}1.00 \\
{[0.91,1.10]}\end{array}$ & $\begin{array}{c}0.99 \\
{[0.93,1.06]}\end{array}$ & $\begin{array}{c}1.03 \\
{[0.97,1.09]}\end{array}$ & $\begin{array}{c}0.98 \\
{[0.90,1.08]}\end{array}$ & $\begin{array}{c}0.94 \\
{[0.86,1.03]}\end{array}$ \\
\hline $\begin{array}{c}\text { Gross Wages } \\
\text { (SES) }\end{array}$ & $\begin{array}{c}0.99 \\
{[0.98,1.01]}\end{array}$ & $\begin{array}{c}1.00 \\
{[0.99,1.01]}\end{array}$ & $\begin{array}{c}0.99 \\
{[0.98,1.01]}\end{array}$ & $\begin{array}{c}1.01 \\
{[1.00,1.03]}\end{array}$ & $\begin{array}{c}1.01 \\
{[1.00,1.02]}\end{array}$ & $\begin{array}{c}1.00 \\
{[0.98,1.02]}\end{array}$ & $\begin{array}{c}0.99 \\
{[0.96,1.01]}\end{array}$ & $\begin{array}{c}1.00 \\
{[0.98,1.01]}\end{array}$ & $\begin{array}{c}1.00 \\
{[0.99,1.02]}\end{array}$ & $\begin{array}{c}1.00 \\
{[0.98,1.02]}\end{array}$ & $\begin{array}{c}0.98 \\
{[0.97,1.00]}\end{array}$ & $\begin{array}{c}1.01 \\
{[0.99,1.02]}\end{array}$ & $\begin{array}{c}1.03 \\
{[1.00,1.05]}\end{array}$ & $\begin{array}{c}1.02 \\
{[1.00,1.03]}\end{array}$ \\
\hline $\begin{array}{l}\text { Parental Occupational } \\
\text { Prestige (SES) } \\
\text { Childbirth }\end{array}$ & $\begin{array}{c}1.00 \\
{[1.00,1.01]}\end{array}$ & $\begin{array}{l}.001 \\
.00,1.02]\end{array}$ & $\begin{array}{c}1.00 \\
0.99,1.01]\end{array}$ & $\begin{array}{c}1.00 \\
.99,1.01]\end{array}$ & $\begin{array}{c}1.00 \\
.99,1.01]\end{array}$ & $\begin{array}{c}0.99 \\
{[0.98,1.00]}\end{array}$ & $\begin{array}{c}1.00 \\
0.99,1.01]\end{array}$ & $\begin{array}{c}0.99 \\
0.98,1.00]\end{array}$ & $\begin{array}{c}0.99 \\
{[0.98,1.00]}\end{array}$ & $\begin{array}{c}1.00 \\
{[0.99,1.02]}\end{array}$ & $\begin{array}{c}1.00 \\
{[0.99,1.01]}\end{array}$ & $\begin{array}{c}1.00 \\
{[0.99,1.00]}\end{array}$ & $\begin{array}{c}1.01 \\
{[1.00,1.02]}\end{array}$ & $\begin{array}{c}1.00 \\
1.00,1.01]\end{array}$ \\
\hline A & $\begin{array}{c}1.00 \\
{[1.00,1.01]}\end{array}$ & $\begin{array}{c}1.00 \\
{[1.00,1.00]}\end{array}$ & $\begin{array}{c}1.00 \\
{[0.99,1.00]}\end{array}$ & $\begin{array}{c}1.00 \\
{[1.00,1.00]}\end{array}$ & $\begin{array}{c}1.00 \\
{[1.00,1.00]}\end{array}$ & $\begin{array}{c}1.00 \\
{[0.99,1.01]}\end{array}$ & $\begin{array}{c}1.00 \\
{[0.99,1.01]}\end{array}$ & $\begin{array}{c}1.00 \\
{[0.99,1.01]}\end{array}$ & {$[1.00,1.00]$} & $\begin{array}{c}1.00 \\
{[0.99,1.01]}\end{array}$ & $\begin{array}{c}1.00 \\
{[1.00,1.01]}\end{array}$ & $\begin{array}{c}1.00 \\
{[1.00,1.01]}\end{array}$ & {$[0.98,1.06]$} & $\begin{array}{c}1.00 \\
{[0.99,1.00]}\end{array}$ \\
\hline $\begin{array}{r}\text { Gender } \\
\text { (Female v Male) }\end{array}$ & $\begin{array}{c}0.98 \\
{[0.96,1.01]}\end{array}$ & $\begin{array}{c}0.99 \\
{[0.96,1.02]}\end{array}$ & $\begin{array}{c}0.97 \\
{[0.94,1.00]}\end{array}$ & $\begin{array}{c}1.04 \\
{[1.01,1.06]}\end{array}$ & $\begin{array}{c}1.01 \\
{[0.98,1.04]}\end{array}$ & $\begin{array}{c}0.97 \\
{[0.91,1.03]}\end{array}$ & $\begin{array}{c}1.00 \\
{[0.93,1.07]}\end{array}$ & $\begin{array}{c}1.01 \\
{[0.98,1.06]}\end{array}$ & $\begin{array}{c}1.00 \\
{[0.96,1.04]}\end{array}$ & $\begin{array}{c}1.02 \\
{[0.97,1.07]}\end{array}$ & $\begin{array}{c}0.99 \\
{[0.96,1.03]}\end{array}$ & $\begin{array}{c}1.03 \\
{[0.99,1.07]}\end{array}$ & $\begin{array}{c}0.94 \\
{[0.87,1.02]}\end{array}$ & $\begin{array}{c}1.01 \\
{[0.95,1.08]}\end{array}$ \\
\hline $\begin{array}{c}\text { Prediction } \\
\text { Interval }\end{array}$ & $\begin{array}{c}1.00 \\
{[0.99,1.00]}\end{array}$ & $\begin{array}{c}0.99 \\
{[0.98,0.99]}\end{array}$ & $\begin{array}{c}0.99 \\
{[0.98,1.00]}\end{array}$ & $\begin{array}{c}1.00 \\
{[0.99,1.01]}\end{array}$ & $\begin{array}{c}1.00 \\
{[0.99,1.00]}\end{array}$ & $\begin{array}{c}0.99 \\
{[0.98,1.00]}\end{array}$ & $\begin{array}{c}1.00 \\
{[0.94,1.07]}\end{array}$ & $\begin{array}{c}1.00 \\
{[0.99,1.01]}\end{array}$ & $\begin{array}{c}1.00 \\
{[0.98,1.02]}\end{array}$ & $\begin{array}{c}0.99 \\
{[0.98,1.01]}\end{array}$ & $\begin{array}{c}1.00 \\
{[0.99,1.01]}\end{array}$ & $\begin{array}{c}1.01 \\
{[1.00,1.02]}\end{array}$ & $\begin{array}{c}0.99 \\
{[0.92,1.06]}\end{array}$ & $\begin{array}{c}1.00 \\
{[0.98,1.02]}\end{array}$ \\
\hline $\begin{array}{r}\text { Race } \\
\text { (Black v White) }\end{array}$ & $\begin{array}{c}1.05 \\
{[0.98,1.11]}\end{array}$ & $\begin{array}{c}1.03 \\
{[0.96,1.09]}\end{array}$ & $\begin{array}{c}1.03 \\
{[0.96,1.09]}\end{array}$ & $\begin{array}{c}0.97 \\
{[0.91,1.03]}\end{array}$ & $\begin{array}{c}1.06 \\
{[0.98,1.15]}\end{array}$ & $\begin{array}{c}1.03 \\
{[0.91,1.16]}\end{array}$ & $\begin{array}{c}0.95 \\
{[0.52,1.60]}\end{array}$ & $\begin{array}{c}1.00 \\
{[0.93,1.08]}\end{array}$ & $\begin{array}{c}1.00 \\
{[0.89,1.12]}\end{array}$ & $\begin{array}{c}1.01 \\
{[0.87,1.17]}\end{array}$ & $\begin{array}{c}0.98 \\
{[0.90,1.06]}\end{array}$ & $\begin{array}{c}0.96 \\
{[0.87,1.04]}\end{array}$ & $\begin{array}{c}1.20 \\
{[0.63,2.30]}\end{array}$ & $\begin{array}{c}0.92 \\
{[0.83,1.03]}\end{array}$ \\
\hline $\begin{array}{r}\text { Race } \\
\text { (Other v White) }\end{array}$ & $\begin{array}{c}1.04 \\
{[0.91,1.15]}\end{array}$ & $\begin{array}{c}1.00 \\
{[0.91,1.08]}\end{array}$ & $\begin{array}{c}0.99 \\
{[0.88,1.07]}\end{array}$ & $\begin{array}{c}1.02 \\
{[0.90,1.23]}\end{array}$ & $\begin{array}{c}0.96 \\
{[0.75,1.18]}\end{array}$ & $\begin{array}{c}1.02 \\
{[0.79,1.31]}\end{array}$ & $\begin{array}{c}1.23 \\
{[0.63,2.26]}\end{array}$ & $\begin{array}{c}0.96 \\
{[0.80,1.18]}\end{array}$ & $\begin{array}{c}0.70 \\
{[0.18,2.04]}\end{array}$ & $\begin{array}{c}0.70 \\
{[0.16,2.14]}\end{array}$ & $\begin{array}{c}0.93 \\
{[0.81,1.04]}\end{array}$ & $\begin{array}{c}0.95 \\
{[0.78,1.17]}\end{array}$ & $\begin{array}{c}1.09 \\
{[0.36,3.20]}\end{array}$ & $\begin{array}{c}0.96 \\
{[0.72,1.23]}\end{array}$ \\
\hline Reliability & $\begin{array}{c}1.00 \\
{[0.91,1.11]}\end{array}$ & $\begin{array}{c}0.96 \\
{[0.88,1.04]}\end{array}$ & $\begin{array}{c}0.93 \\
{[0.75,1.13]}\end{array}$ & $\begin{array}{c}1.07 \\
{[0.92,1.25]}\end{array}$ & $\begin{array}{c}0.99 \\
{[0.89,1.12]}\end{array}$ & $\begin{array}{c}0.93 \\
{[0.34,1.61]}\end{array}$ & $\begin{array}{c}0.95 \\
{[0.06,15.25]}\end{array}$ & $\begin{array}{c}1.13 \\
{[0.89,1.46]}\end{array}$ & $\begin{array}{c}1.10 \\
{[0.66,1.91]}\end{array}$ & $\begin{array}{c}0.89 \\
{[0.69,1.18]}\end{array}$ & $\begin{array}{c}1.04 \\
{[0.90,1.18]}\end{array}$ & $\begin{array}{c}1.02 \\
{[0.84,1.25]}\end{array}$ & $\begin{array}{c}1.20 \\
{[0.25,8.51]}\end{array}$ & $\begin{array}{c}1.37 \\
{[0.61,2.95]}\end{array}$ \\
\hline $\begin{array}{l}\text { Parental Education } \\
\text { (SES; HS v College) }\end{array}$ & $\begin{array}{c}0.98 \\
{[0.93,1.02]}\end{array}$ & $\begin{array}{c}1.00 \\
{[0.96,1.04]}\end{array}$ & $\begin{array}{c}1.07 \\
{[1.03,1.11]}\end{array}$ & $\begin{array}{c}1.00 \\
{[0.97,1.04]}\end{array}$ & $\begin{array}{c}0.97 \\
{[0.94,1.01]}\end{array}$ & $\begin{array}{c}1.01 \\
{[0.94,1.08]}\end{array}$ & $\begin{array}{c}1.01 \\
{[0.94,1.09]}\end{array}$ & $\begin{array}{c}1.00 \\
{[0.95,1.05]}\end{array}$ & $\begin{array}{c}1.02 \\
{[0.96,1.09]}\end{array}$ & $\begin{array}{c}0.99 \\
{[0.88,1.11]}\end{array}$ & $\begin{array}{c}1.01 \\
{[0.96,1.06]}\end{array}$ & $\begin{array}{c}0.91 \\
{[0.80,1.02]}\end{array}$ & $\begin{array}{c}0.94 \\
{[0.84,1.04]}\end{array}$ & $\begin{array}{c}1.02 \\
{[0.95,1.09]}\end{array}$ \\
\hline $\begin{array}{l}\text { Parental Education } \\
\text { (SES; HS v Higher) }\end{array}$ & $\begin{array}{c}0.92 \\
{[0.87,0.98]}\end{array}$ & $\begin{array}{c}0.98 \\
{[0.92,1.05]}\end{array}$ & $\begin{array}{c}1.07 \\
{[0.99,1.15]}\end{array}$ & $\begin{array}{c}1.02 \\
{[0.96,1.10]}\end{array}$ & $\begin{array}{c}0.91 \\
{[0.85,0.98]}\end{array}$ & $\begin{array}{c}1.02 \\
{[0.90,1.16]}\end{array}$ & $\begin{array}{c}0.98 \\
{[0.75,1.29]}\end{array}$ & $\begin{array}{c}0.99 \\
{[0.91,1.07]}\end{array}$ & $\begin{array}{c}0.93 \\
{[0.79,1.11]}\end{array}$ & $\begin{array}{c}1.02 \\
{[0.89,1.19]}\end{array}$ & $\begin{array}{c}0.99 \\
{[0.90,1.08]}\end{array}$ & $\begin{array}{c}\mathbf{0 . 8 8} \\
{[0.80,0.96]}\end{array}$ & $\begin{array}{c}1.23 \\
{[0.68,3.02]}\end{array}$ & $\begin{array}{c}0.97 \\
{[0.87,1.08]}\end{array}$ \\
\hline $\begin{array}{r}\text { Gross Wages } \\
\text { (SES) }\end{array}$ & $\begin{array}{c}0.99 \\
{[0.97,1.01]}\end{array}$ & $\begin{array}{c}0.99 \\
{[0.95,1.01]}\end{array}$ & $\begin{array}{c}1.00 \\
{[0.98,1.03]}\end{array}$ & $\begin{array}{c}0.99 \\
{[0.96,1.01]}\end{array}$ & $\begin{array}{c}1.00 \\
{[0.98,1.03]}\end{array}$ & $\begin{array}{c}0.98 \\
{[0.94,1.03]}\end{array}$ & $\begin{array}{c}1.01 \\
{[0.93,1.11]}\end{array}$ & $\begin{array}{c}0.97 \\
{[0.93,1.00]}\end{array}$ & $\begin{array}{c}0.99 \\
{[0.95,1.01]}\end{array}$ & $\begin{array}{c}1.03 \\
{[0.98,1.08]}\end{array}$ & $\begin{array}{c}1.00 \\
{[0.98,1.03]}\end{array}$ & $\begin{array}{c}0.98 \\
{[0.94,1.02]}\end{array}$ & $\begin{array}{c}0.97 \\
{[0.82,1.11]}\end{array}$ & $\begin{array}{c}1.00 \\
{[0.98,1.04]}\end{array}$ \\
\hline $\begin{array}{l}\text { Parental Occupational } \\
\text { Prestige (SES) }\end{array}$ & $\begin{array}{c}1.00 \\
{[1.00,1.01]}\end{array}$ & $\begin{array}{c}1.00 \\
{[0.99,1.00]}\end{array}$ & $\begin{array}{c}1.01 \\
{[1.00,1.01]}\end{array}$ & $\begin{array}{c}1.01 \\
{[1.00,1.01]}\end{array}$ & $\begin{array}{c}1.00 \\
{[0.99,1.01]}\end{array}$ & $\begin{array}{c}1.00 \\
{[0.98,1.02]}\end{array}$ & $\begin{array}{c}1.01 \\
{[0.99,1.02]}\end{array}$ & $\begin{array}{c}1.00 \\
{[0.99,1.01]}\end{array}$ & $\begin{array}{c}1.00 \\
{[0.99,1.01]}\end{array}$ & $\begin{array}{c}1.01 \\
{[0.99,1.02]}\end{array}$ & $\begin{array}{c}1.01 \\
{[1.00,1.02]}\end{array}$ & $\begin{array}{c}1.01 \\
{[0.99,1.02]}\end{array}$ & $\begin{array}{c}1.01 \\
{[0.99,1.04]}\end{array}$ & $\begin{array}{c}1.00 \\
{[0.98,1.01]}\end{array}$ \\
\hline \multicolumn{15}{|l|}{ Move in with a Partner } \\
\hline Age & $\begin{array}{c}1.00 \\
{[1.00,1.00]}\end{array}$ & $\begin{array}{c}1.00 \\
{[0.99,1.00]}\end{array}$ & $\begin{array}{c}1.00 \\
{[0.99,1.00]}\end{array}$ & $\begin{array}{c}1.00 \\
{[1.00,1.00]}\end{array}$ & $\begin{array}{c}1.00 \\
{[1.00,1.00]}\end{array}$ & $\begin{array}{c}1.00 \\
{[1.00,1.01]}\end{array}$ & $\begin{array}{c}0.98 \\
{[0.98,1.00]}\end{array}$ & $\begin{array}{c}1.00 \\
{[0.99,1.00]}\end{array}$ & $\begin{array}{c}1.01 \\
{[1.00,1.01]}\end{array}$ & $\begin{array}{c}1.00 \\
{[1.00,1.00]}\end{array}$ & $\begin{array}{c}1.00 \\
{[1.00,1.00]}\end{array}$ & $\begin{array}{c}1.00 \\
{[1.00,1.00]}\end{array}$ & $\begin{array}{c}1.01 \\
{[1.00,1.02]}\end{array}$ & $\begin{array}{c}1.00 \\
{[1.00,1.00]}\end{array}$ \\
\hline Gender & 0.99 & $\begin{array}{c}0.97 \\
94,1.0\end{array}$ & $\begin{array}{c}1.00 \\
.97,1.0\end{array}$ & $\begin{array}{c}1.06 \\
.00,1.1\end{array}$ & $\begin{array}{c}0.95 \\
.91,0.9\end{array}$ & $\begin{array}{c}0.91 \\
.86,0.9\end{array}$ & $\begin{array}{c}1.01 \\
.96,1.0\end{array}$ & $\begin{array}{c}0.98 \\
.93,1.0\end{array}$ & $\begin{array}{c}1.00 \\
.94,1.0\end{array}$ & $\begin{array}{c}1.07 \\
.01,1.1\end{array}$ & $\begin{array}{c}0.97 \\
93,1.0\end{array}$ & $\begin{array}{c}1.05 \\
00,1.1\end{array}$ & $\begin{array}{l}1.02 \\
91,1.1\end{array}$ & $\begin{array}{c}1.06 \\
02,1.1\end{array}$ \\
\hline
\end{tabular}




\begin{tabular}{|c|c|c|c|c|c|c|c|c|c|c|c|c|c|c|}
\hline & $\mathbf{E}$ & A & C & $\mathbf{N}$ & $\mathbf{O}$ & SE & OP & SWL & PA & $\mathbf{N A}$ & LOC & SS & IQ & DEP \\
\hline Term & OR [CI] & OR [CI] & OR [CI] & OR [CI] & OR [CI] & $\mathrm{R}[\mathrm{CI}]$ & OR $[\mathrm{CI}]$ & OR $[\mathrm{CI}]$ & OR $[\mathrm{CI}]$ & OR [CI] & $\mathrm{R}[\mathrm{CI}]$ & $\mathrm{R}[\mathrm{CI}]$ & OR [CI] & OR [CI] \\
\hline $\begin{array}{c}\text { Prediction } \\
\text { Interval }\end{array}$ & $\begin{array}{r}1.00 \\
{[0.98,1.0}\end{array}$ & 100 & 099 & 1] & 2] & 3] & $\begin{array}{r}1 .( \\
{[0.85,}\end{array}$ & .00 & 2] & 1. & $\begin{array}{l}1.00 \\
.99,1.00]\end{array}$ & $\begin{array}{c}0.99 \\
{[0.98,1.00]}\end{array}$ & $\begin{array}{r}1 . \\
{[0.94}\end{array}$ & $\begin{array}{c}0.99 \\
{[0.98,1.00]}\end{array}$ \\
\hline $\begin{array}{r}\text { Race } \\
\text { (Black v White) }\end{array}$ & $\begin{array}{c}0.98 \\
{[0.91,1.06]}\end{array}$ & $\begin{array}{c}0.97 \\
{[0.90,1.05]}\end{array}$ & $\begin{array}{c}0.97 \\
{[0.90,1.06]}\end{array}$ & $\begin{array}{c}1.01 \\
{[0.93,1.10]}\end{array}$ & $\begin{array}{c}0.98 \\
{[0.89,1.09]}\end{array}$ & $\begin{array}{c}1.04 \\
{[0.90,1.19]}\end{array}$ & $\begin{array}{c}0.95 \\
{[0.59,1.51]}\end{array}$ & $\begin{array}{c}1.05 \\
{[0.95,1.15]}\end{array}$ & $\begin{array}{c}0.95 \\
{[0.81,1.12]}\end{array}$ & $\begin{array}{c}0.97 \\
{[0.80,1.19]}\end{array}$ & $\begin{array}{c}1.01 \\
{[0.89,1.14]}\end{array}$ & $\begin{array}{c}1.10 \\
{[1.01,1.20]}\end{array}$ & $\begin{array}{c}1.29 \\
{[0.64,2.56]}\end{array}$ & $\begin{array}{c}0.95 \\
{[0.83,1.08]}\end{array}$ \\
\hline $\begin{array}{r}\text { Race } \\
\text { (Other v White) }\end{array}$ & $\begin{array}{c}1.00 \\
{[0.91,1.10]}\end{array}$ & $\begin{array}{l}0.99 \\
0.89,1.08]\end{array}$ & $\begin{array}{l}1.00 \\
.90,1.10]\end{array}$ & $\begin{array}{c}0.99 \\
{[0.85,1.17]}\end{array}$ & $\begin{array}{c}0.98 \\
{[0.78,1.17]}\end{array}$ & $\begin{array}{c}1.02 \\
{[0.88,1.18]}\end{array}$ & $\begin{array}{c}0.58 \\
{[0.11,1.95]}\end{array}$ & $\begin{array}{c}0.96 \\
{[0.77,1.14]}\end{array}$ & $\begin{array}{c}0.78 \\
{[0.31,1.64]}\end{array}$ & $\begin{array}{c}0.69 \\
{[0.15,1.59]}\end{array}$ & $\begin{array}{c}1.01 \\
{[0.89,1.15]}\end{array}$ & $\begin{array}{c}0.97 \\
{[0.62,1.55]}\end{array}$ & $\begin{array}{c}1.06 \\
{[0.35,3.12]}\end{array}$ & $\begin{array}{c}0.99 \\
{[0.73,1.39]}\end{array}$ \\
\hline Reliability & $\begin{array}{c}0.96 \\
{[0.81,1.13]}\end{array}$ & $\begin{array}{l}1.09 \\
.99,1.19]\end{array}$ & $\begin{array}{c}0.96 \\
0.79,1.14]\end{array}$ & $\begin{array}{c}1.12 \\
{[0.94,1.33]}\end{array}$ & $\begin{array}{c}0.99 \\
{[0.81,1.44]}\end{array}$ & $\begin{array}{c}0.93 \\
{[0.36,2.58]}\end{array}$ & $\begin{array}{c}0.97 \\
{[0.06,17.00]}\end{array}$ & $\begin{array}{c}0.97 \\
{[0.83,1.15]}\end{array}$ & $\begin{array}{c}0.92 \\
{[0.43,2.07]}\end{array}$ & $\begin{array}{c}1.05 \\
{[0.75,1.48]}\end{array}$ & $\begin{array}{c}1.03 \\
{[0.87,1.21]}\end{array}$ & $\begin{array}{c}1.02 \\
{[0.81,1.27]}\end{array}$ & $\begin{array}{c}1.14 \\
{[0.16,7.71]}\end{array}$ & $\begin{array}{c}0.98 \\
{[0.32,3.13]}\end{array}$ \\
\hline $\begin{array}{l}\text { Parental Education } \\
\text { (SES; HS v College) }\end{array}$ & $\begin{array}{c}0.99 \\
{[0.95,1.04]}\end{array}$ & $\begin{array}{c}0.99 \\
.94,1.04]\end{array}$ & $\begin{array}{l}1.01 \\
.93,1.08]\end{array}$ & $\begin{array}{c}1.00 \\
{[0.96,1.05]}\end{array}$ & $\begin{array}{c}0.99 \\
{[0.90,1.06]}\end{array}$ & $\begin{array}{c}0.96 \\
0.84,1.09]\end{array}$ & $\begin{array}{c}1.00 \\
0.93,1.07]\end{array}$ & $\begin{array}{c}0.97 \\
{[0.93,1.01]}\end{array}$ & $\begin{array}{c}0.96 \\
{[0.84,1.08]}\end{array}$ & $\begin{array}{c}1.06 \\
{[0.93,1.24]}\end{array}$ & $\begin{array}{c}0.96 \\
{[0.89,1.02]}\end{array}$ & $\begin{array}{c}1.04 \\
{[0.99,1.09]}\end{array}$ & $\begin{array}{c}0.90 \\
{[0.80,1.03]}\end{array}$ & $\begin{array}{c}1.01 \\
{[0.94,1.08]}\end{array}$ \\
\hline $\begin{array}{l}\text { Parental Education } \\
\text { (SES; HS v Higher) }\end{array}$ & $\begin{array}{c}0.99 \\
{[0.92,1.06]}\end{array}$ & $\begin{array}{c}0.96 \\
0.89,1.03]\end{array}$ & $\begin{array}{l}1.05 \\
.97,1.14]\end{array}$ & $\begin{array}{c}0.97 \\
{[0.90,1.04]}\end{array}$ & $\begin{array}{c}1.01 \\
{[0.92,1.10]}\end{array}$ & $\begin{array}{c}0.96 \\
{[0.82,1.12]}\end{array}$ & $\begin{array}{c}0.96 \\
{[0.71,1.28]}\end{array}$ & $\begin{array}{c}1.04 \\
{[0.96,1.13]}\end{array}$ & $\begin{array}{c}1.05 \\
{[0.93,1.19]}\end{array}$ & $\begin{array}{c}1.02 \\
{[0.82,1.25]}\end{array}$ & $\begin{array}{c}0.98 \\
{[0.88,1.08]}\end{array}$ & $\begin{array}{c}1.05 \\
{[0.94,1.19]}\end{array}$ & $\begin{array}{c}0.92 \\
{[0.74,1.14]}\end{array}$ & $\begin{array}{c}0.98 \\
{[0.84,1.12]}\end{array}$ \\
\hline $\begin{array}{c}\text { Gross Wages } \\
\text { (SES) }\end{array}$ & $\begin{array}{c}1.00 \\
{[0.98,1.02]}\end{array}$ & $\begin{array}{c}1.00 \\
{[0.98,1.03]}\end{array}$ & $\begin{array}{l}1.02 \\
.00,1.04]\end{array}$ & $\begin{array}{c}0.98 \\
{[0.96,1.01]}\end{array}$ & $\begin{array}{c}1.02 \\
{[1.00,1.04]}\end{array}$ & $\begin{array}{c}1.04 \\
{[0.99,1.08]}\end{array}$ & $\begin{array}{c}0.97 \\
{[0.92,1.03]}\end{array}$ & $\begin{array}{c}0.99 \\
{[0.96,1.01]}\end{array}$ & $\begin{array}{c}1.00 \\
{[0.97,1.02]}\end{array}$ & $\begin{array}{r}1 . \\
{[0.97}\end{array}$ & $1]$ & $\begin{array}{r}0 . \\
{[0.97}\end{array}$ & $\begin{array}{r}1 . \\
{[0.97}\end{array}$ & $\begin{array}{r}1 . \\
{[0.98}\end{array}$ \\
\hline $\begin{array}{c}\text { Parental Occupational } \\
\text { Prestige (SES) }\end{array}$ & $\begin{array}{c}1.00 \\
{[0.99,1.01]}\end{array}$ & $\begin{array}{c}1.00 \\
0.99,1.01]\end{array}$ & $\begin{array}{l}1.01 \\
\text { l.00,1.02] }\end{array}$ & $\begin{array}{c}1.00 \\
1.00,1.01]\end{array}$ & $\begin{array}{c}1.01 \\
{[1.00,1.01]}\end{array}$ & $\begin{array}{c}1.03 \\
{[1.01,1.05]}\end{array}$ & $\begin{array}{c}1.00 \\
0.99,1.02]\end{array}$ & $\begin{array}{c}1.01 \\
{[1.00,1.02]}\end{array}$ & $\begin{array}{c}1.01 \\
{[1.00,1.02]}\end{array}$ & $\begin{array}{c}1.00 \\
{[0.99,1.02]}\end{array}$ & $\begin{array}{c}1.00 \\
{[0.99,1.01]}\end{array}$ & $\begin{array}{c}1.00 \\
{[0.99,1.01]}\end{array}$ & $\begin{array}{c}1.01 \\
{[0.96,1.05]}\end{array}$ & $\begin{array}{c}1.01 \\
{[1.00,1.02]}\end{array}$ \\
\hline \multicolumn{15}{|l|}{ 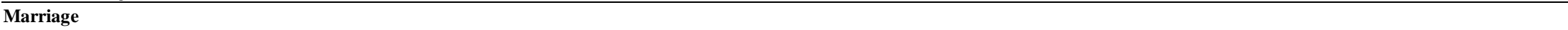 } \\
\hline Age & {$[1.00$,} & {$[0.99$,} & $.99,1.00]$ & 00] & $\begin{array}{c}1.00 \\
{[1.00,1.00]}\end{array}$ & $\begin{array}{l}1.00 \\
1.00,1.01]\end{array}$ & $\begin{array}{c}1.00 \\
{[0.99,1.01]}\end{array}$ & $\begin{array}{c}1.00 \\
{[1.00,1.00]}\end{array}$ & {$[1.00,1.00]$} & $\begin{array}{r}1.0 \\
{[1.00,}\end{array}$ & {$[0.99,1.01]$} & {$[1.00,1.00]$} & $\begin{array}{c}1.00 \\
{[0.99,1.02]}\end{array}$ & {$[0.99,1.00]$} \\
\hline $\begin{array}{r}\text { Gender } \\
\text { (Female v Male) }\end{array}$ & $\begin{array}{c}0.98 \\
{[0.94,1.01]}\end{array}$ & $\begin{array}{c}0.99 \\
0.96,1.02]\end{array}$ & $\begin{array}{l}0.98 \\
.96,1.01]\end{array}$ & $\begin{array}{c}1.04 \\
{[1.01,1.06]}\end{array}$ & $\begin{array}{c}0.98 \\
{[0.94,1.01]}\end{array}$ & $\begin{array}{c}0.98 \\
{[0.94,1.02]}\end{array}$ & $\begin{array}{c}0.97 \\
{[0.88,1.03]}\end{array}$ & $\begin{array}{r}0.9 \\
{[0.95,}\end{array}$ & $\begin{array}{r}0 . \\
{[0.95}\end{array}$ & $\begin{array}{r}1 . \\
{[0.96}\end{array}$ & $\begin{array}{r}0.9 \\
{[0.95}\end{array}$ & $\begin{array}{r}1 . \\
{[0.97}\end{array}$ & $\begin{array}{r}0 \\
{[0.89}\end{array}$ & $\begin{array}{r}1 \\
{[0.96}\end{array}$ \\
\hline & $\begin{array}{c}1.00 \\
{[0.99,1.02]}\end{array}$ & $\begin{array}{c}1.00 \\
{[0.99,1.00]}\end{array}$ & $\begin{array}{l}1.00 \\
.99,1.01]\end{array}$ & $\begin{array}{r}1 . \\
0.99\end{array}$ & $\begin{array}{c}1.00 \\
0.99,1.01]\end{array}$ & $\begin{array}{c}1.00 \\
1.00,1.01]\end{array}$ & $\begin{array}{c}1.00 \\
{[0.97,1.03]}\end{array}$ & $\begin{array}{c}0.99 \\
{[0.97,1.01]}\end{array}$ & $\begin{array}{r}1 .( \\
{[0.98,}\end{array}$ & $\begin{array}{r}0 . \\
{[0.98,}\end{array}$ & $\begin{array}{r}1.0 \\
{[1.00,}\end{array}$ & {$[0.99,1.01]$} & {$[0.96$,} & $\begin{array}{r}0 . \\
{[0.98}\end{array}$ \\
\hline $\begin{array}{r}\text { Race } \\
\text { (Black v White) }\end{array}$ & $\begin{array}{c}0.99 \\
{[0.92,1.06]}\end{array}$ & $\begin{array}{r}0.9 \\
0.92,\end{array}$ & $\begin{array}{l}1.01 \\
.96,1.07]\end{array}$ & $\begin{array}{r}1 . \\
{[0.99}\end{array}$ & $\begin{array}{c}0.95 \\
{[0.87,1.04]}\end{array}$ & $\begin{array}{c}1.00 \\
{[0.89,1.11]}\end{array}$ & $\begin{array}{c}0.91 \\
{[0.57,1.53]}\end{array}$ & $\begin{array}{c}1.03 \\
{[0.95,1.13]}\end{array}$ & $\begin{array}{r}0.9 \\
{[0.86}\end{array}$ & $\begin{array}{r}1.0 \\
{[0.87}\end{array}$ & $\begin{array}{c}0.99 \\
{[0.91,1.07]}\end{array}$ & $\begin{array}{r}1 . \\
{[0.94,}\end{array}$ & $\begin{array}{r}0.9 \\
{[0.46,}\end{array}$ & $\begin{array}{r}0.9 \\
{[0.85,}\end{array}$ \\
\hline $\begin{array}{r}\text { Race } \\
\text { Other v White) }\end{array}$ & $\begin{array}{c}1.04 \\
{[0.94,1.19]}\end{array}$ & $\begin{array}{l}1.00 \\
.91,1.14]\end{array}$ & $\begin{array}{r}1.0 \\
.92,\end{array}$ & $\begin{array}{r}1 . \\
0.90\end{array}$ & $\begin{array}{c}1.01 \\
{[0.84,1.24]}\end{array}$ & $\begin{array}{c}1.00 \\
{[0.87,1.19]}\end{array}$ & $\begin{array}{c}1.17 \\
{[0.57,4.61]}\end{array}$ & $\begin{array}{c}1.03 \\
{[0.80,1.38]}\end{array}$ & $\begin{array}{c}1.05 \\
{[0.68,1.69]}\end{array}$ & $\begin{array}{c}0.95 \\
{[0.54,1.60]}\end{array}$ & $\begin{array}{c}0.98 \\
{[0.84,1.17]}\end{array}$ & $\begin{array}{c}0.93 \\
{[0.79,1.11]}\end{array}$ & $\begin{array}{c}1.26 \\
{[0.42,5.89]}\end{array}$ & $\begin{array}{c}0.98 \\
{[0.76,1.40]}\end{array}$ \\
\hline Reliability & $\begin{array}{c}0.96 \\
{[0.76,1.19]}\end{array}$ & $\begin{array}{c}0.98 \\
{[0.89,1.08]}\end{array}$ & $\begin{array}{c}0.99 \\
0.80,1.24]\end{array}$ & $\begin{array}{c}1.12 \\
{[0.98,1.27]}\end{array}$ & $\begin{array}{c}1.05 \\
{[0.92,1.18]}\end{array}$ & $\begin{array}{c}0.92 \\
{[0.34,1.92]}\end{array}$ & $\begin{array}{c}1.16 \\
{[0.08,14.13]}\end{array}$ & $\begin{array}{c}1.43 \\
{[0.84,2.39]}\end{array}$ & $\begin{array}{c}1.09 \\
{[0.63,1.89]}\end{array}$ & $\begin{array}{c}0.86 \\
{[0.58,1.21]}\end{array}$ & $\begin{array}{c}0.99 \\
{[0.84,1.20]}\end{array}$ & $\begin{array}{c}1.06 \\
{[0.92,1.22]}\end{array}$ & $\begin{array}{c}1.27 \\
{[0.15,10.68]}\end{array}$ & $\begin{array}{c}0.82 \\
{[0.46,1.69]}\end{array}$ \\
\hline $\begin{array}{l}\text { Parental Education } \\
\text { (SES; HS v College) }\end{array}$ & $\begin{array}{c}0.98 \\
{[0.94,1.02]}\end{array}$ & $\begin{array}{c}1.01 \\
0.97,1.05]\end{array}$ & $\begin{array}{c}1.00 \\
0.96,1.04]\end{array}$ & $\begin{array}{c}0.97 \\
{[0.94,1.00]}\end{array}$ & $\begin{array}{c}0.96 \\
{[0.92,1.00]}\end{array}$ & $\begin{array}{c}0.97 \\
{[0.92,1.02]}\end{array}$ & $\begin{array}{c}1.01 \\
{[0.90,1.11]}\end{array}$ & $\begin{array}{c}1.03 \\
{[0.98,1.08]}\end{array}$ & $\begin{array}{c}0.97 \\
{[0.87,1.06]}\end{array}$ & $\begin{array}{c}0.91 \\
{[0.85,0.97]}\end{array}$ & $\begin{array}{c}1.03 \\
{[0.98,1.09]}\end{array}$ & $\begin{array}{c}0.97 \\
{[0.93,1.02]}\end{array}$ & $\begin{array}{c}0.93 \\
{[0.86,1.01]}\end{array}$ & $\begin{array}{c}0.96 \\
{[0.91,1.01]}\end{array}$ \\
\hline $\begin{array}{l}\text { Parental Education } \\
\text { (SES; HS v Higher) }\end{array}$ & $\begin{array}{c}0.98 \\
{[0.93,1.04]}\end{array}$ & $\begin{array}{c}1.03 \\
{[0.95,1.11]}\end{array}$ & $\begin{array}{c}1.00 \\
0.93,1.06]\end{array}$ & $\begin{array}{c}0.99 \\
{[0.93,1.04]}\end{array}$ & $\begin{array}{c}0.91 \\
{[0.84,0.98]}\end{array}$ & $\begin{array}{c}1.06 \\
{[0.94,1.18]}\end{array}$ & $\begin{array}{c}1.01 \\
{[0.74,1.37]}\end{array}$ & $\begin{array}{c}1.02 \\
{[0.89,1.14]}\end{array}$ & $\begin{array}{c}1.00 \\
{[0.93,1.08]}\end{array}$ & $\begin{array}{c}0.95 \\
{[0.78,1.10]}\end{array}$ & $\begin{array}{c}1.01 \\
{[0.94,1.10]}\end{array}$ & $\begin{array}{c}1.01 \\
{[0.94,1.09]}\end{array}$ & $\begin{array}{c}0.97 \\
{[0.71,1.27]}\end{array}$ & $\begin{array}{c}0.93 \\
{[0.83,1.04]}\end{array}$ \\
\hline $\begin{array}{c}\text { Gross Wages } \\
\text { (SES) }\end{array}$ & $\begin{array}{c}1.00 \\
{[0.99,1.02]}\end{array}$ & $\begin{array}{l}1.00 \\
.98,1.02]\end{array}$ & $\begin{array}{c}1.00 \\
.98,1.01]\end{array}$ & $\begin{array}{c}1.00 \\
{[0.99,1.02]}\end{array}$ & $\begin{array}{c}0.98 \\
{[0.97,1.00]}\end{array}$ & $\begin{array}{c}1.01 \\
{[0.98,1.04]}\end{array}$ & $\begin{array}{c}0.98 \\
{[0.93,1.03]}\end{array}$ & $\begin{array}{c}0.98 \\
{[0.96,1.01]}\end{array}$ & $\begin{array}{c}1.00 \\
{[0.98,1.02]}\end{array}$ & $\begin{array}{c}0.99 \\
{[0.97,1.02]}\end{array}$ & $\begin{array}{c}1.00 \\
{[0.99,1.02]}\end{array}$ & $\begin{array}{c}1.01 \\
{[0.99,1.03]}\end{array}$ & $\begin{array}{c}0.99 \\
{[0.96,1.03]}\end{array}$ & $\begin{array}{c}0.99 \\
{[0.97,1.02]}\end{array}$ \\
\hline $\begin{array}{c}\text { Parental Occupational } \\
\text { Prestige (SES) }\end{array}$ & $\begin{array}{r}1.0 \\
{[0.99,1}\end{array}$ & 1] & 1 & 0] & $\begin{array}{r}1.0 \\
.99\end{array}$ & $\begin{array}{c}1.0 \\
.99,\end{array}$ & & 03] & & $\begin{array}{c}0.99 \\
{[0.98,1.00]}\end{array}$ & $\begin{array}{r}1.0 \\
{[1.00,}\end{array}$ & $\begin{array}{c}1.00 \\
{[0.99,1.01]}\end{array}$ & $\begin{array}{c}1.00 \\
{[0.98,1.03]}\end{array}$ & $\begin{array}{c}1.00 \\
0.99,1.01]\end{array}$ \\
\hline \multicolumn{15}{|l|}{ Divorce } \\
\hline Age & $\begin{array}{r}1 \\
{[1.00}\end{array}$ & $\begin{array}{l}1.0 \\
00,\end{array}$ & , & S & $\begin{array}{r}1.0 \\
{[1.00,}\end{array}$ & $\begin{array}{r}1 .( \\
{[0.99}\end{array}$ & $\begin{array}{r}1.0 \\
{[1.00,}\end{array}$ & 1. & $\begin{array}{r}1.0 \\
{[1.00,}\end{array}$ & $\begin{array}{r}1.0 \\
{[1.00,}\end{array}$ & $\begin{array}{r}1 .( \\
{[1.00,}\end{array}$ & [1.00, & {$[0.99$, } & $\begin{array}{r}1.0 \\
{[1.00,}\end{array}$ \\
\hline $\begin{array}{l}\text { Gender } \\
\text { emale v Male) }\end{array}$ & $\begin{array}{c}1.00 \\
{[0.96,1.04]}\end{array}$ & $\begin{array}{c}1.00 \\
{[0.96,1.05]}\end{array}$ & $\begin{array}{c}1.01 \\
{[0.97,1.05]}\end{array}$ & $\begin{array}{c}1.03 \\
{[0.99,1.07]}\end{array}$ & $\begin{array}{c}1.01 \\
{[0.97,1.05]}\end{array}$ & $\begin{array}{c}0.99 \\
{[0.93,1.05]}\end{array}$ & $\begin{array}{c}0.96 \\
{[0.92,1.01]}\end{array}$ & $\begin{array}{c}0.99 \\
{[0.95,1.03]}\end{array}$ & $\begin{array}{c}0.99 \\
{[0.95,1.04]}\end{array}$ & $\begin{array}{c}0.99 \\
{[0.95,1.04]}\end{array}$ & $\begin{array}{c}0.97 \\
{[0.92,1.01]}\end{array}$ & $\begin{array}{c}1.02 \\
{[0.97,1.06]}\end{array}$ & $\begin{array}{c}1.04 \\
{[0.97,1.12]}\end{array}$ & $\begin{array}{c}0.98 \\
0.94,1.02]\end{array}$ \\
\hline $\begin{array}{l}\text { Prediction } \\
\text { Interval }\end{array}$ & $\begin{array}{c}1.00 \\
{[0.99,1.01]}\end{array}$ & $\begin{array}{c}1.00 \\
{[0.99,1.01]}\end{array}$ & $\begin{array}{c}1.00 \\
{[0.99,1.00]}\end{array}$ & $\begin{array}{c}1.00 \\
{[0.99,1.01]}\end{array}$ & $\begin{array}{c}0.99 \\
{[0.98,1.00]}\end{array}$ & $\begin{array}{c}1.00 \\
{[0.99,1.01]}\end{array}$ & $\begin{array}{c}0.99 \\
{[0.98,0.99]}\end{array}$ & $\begin{array}{c}1.00 \\
{[1.00,1.01]}\end{array}$ & $\begin{array}{c}1.00 \\
{[0.99,1.01]}\end{array}$ & $\begin{array}{c}0.99 \\
{[0.99,1.00]}\end{array}$ & $\begin{array}{c}1.00 \\
{[0.99,1.00]}\end{array}$ & $\begin{array}{c}1.00 \\
{[1.00,1.01]}\end{array}$ & $\begin{array}{c}1.01 \\
{[0.99,1.02]}\end{array}$ & $\begin{array}{c}1.00 \\
{[0.99,1.01]}\end{array}$ \\
\hline
\end{tabular}


Table 3.4

Fixed Effect Moderators of Personality-Outcome Associations

\begin{tabular}{llllllllllllllll}
\hline E & A & C & N & O & SE & OP & SWL & PA & NA & LOC & SS & IQ & DEP \\
\hline
\end{tabular}

\begin{tabular}{rccccccccccccccc} 
& & $\mathbf{E}$ & $\mathbf{A}$ & $\mathbf{C}$ & $\mathbf{N}$ & $\mathbf{O}$ & $\mathbf{S E}$ & $\mathbf{O P}$ & $\mathbf{S W L}$ & PA & NA & LOC & SS & IQ & DEP \\
\hline Term & OR [CI] & OR [CI] & OR [CI] & OR [CI] & OR [CI] & OR [CI] & OR [CI] & OR [CI] & OR [CI] & OR [CI] & OR [CI] & OR [CI] & OR [CI] & OR [CI] \\
\hline Race & 0.95 & 1.01 & 0.99 & 0.94 & 0.98 & 0.99 & 1.02 & 0.98 & 1.01 & 0.94 & 1.06 & 1.10 & 0.98 & $\mathbf{0 . 8 4}$
\end{tabular}

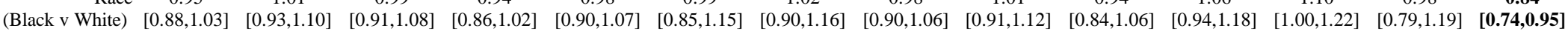

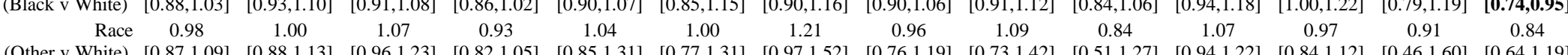

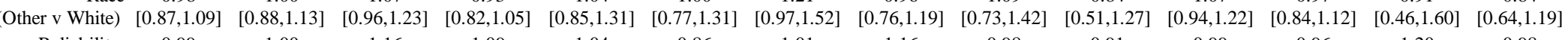

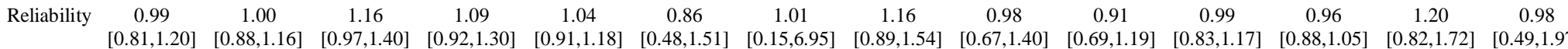

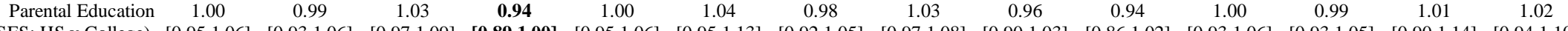

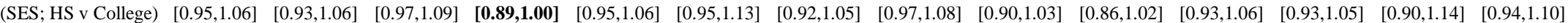

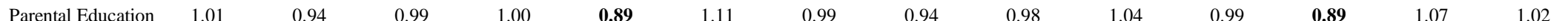

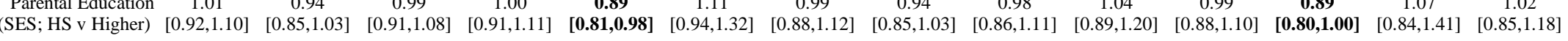

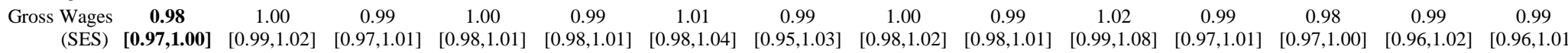

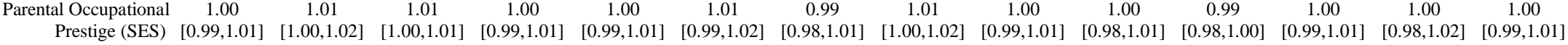
Child Moves Out

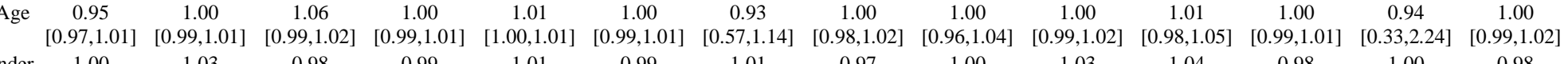

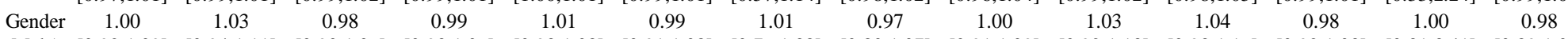
$\begin{array}{llllllllllllllllll}\text { (Female v Male) } & {[0.92,1.09]} & {[0.94,1.11]} & {[0.90,1.06]} & {[0.93,1.06]} & {[0.93,1.08]} & {[0.91,1.08]} & {[0.76,1.38]} & {[0.80,1.07]} & {[0.91,1.09]} & {[0.92,1.13]} & {[0.93,1.16]} & {[0.92,1.03]} & {[0.31,3.41]} & {[0.89,1.07]}\end{array}$

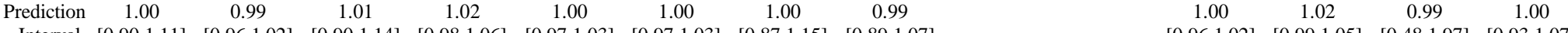
$\begin{array}{cccccccccccccc}\text { Race } & 1.03 & 1.01 & 1.00 & 0.96 & 0.95 & 1.17 & 0.97 & 1.02 & 0.99 & 0.98 & 1.13 & 1.05 & 0.94 \\ \text { (Black v White) } & {[0.79,1.35]} & {[0.71,1.42]} & {[0.71,1.40]} & {[0.65,1.36]} & {[0.72,1.29]} & {[0.86,1.60]} & {[0.26,5.30]} & {[0.36,2.17]} & {[0.49,1.98]} & {[0.48,2.01]} & {[0.57,2.21]} & {[0.78,1.41]} & {[0.65,1.34]}\end{array}$

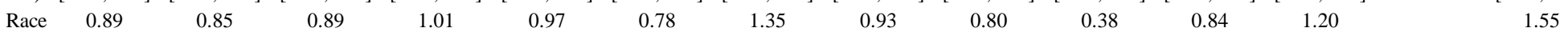
$\begin{array}{llllllllllllllll}(\text { Other v White) } & {[0.38,1.76]} & {[0.31,2.02]} & {[0.33,2.00]} & {[0.43,2.06]} & {[0.47,1.82]} & {[0.29,1.74]} & {[0.28,5.98]} & {[0.22,3.62]} & {[0.08,5.35]} & {[0.02,3.92]} & {[0.36,1.73]} & {[0.68,2.25]} & 0.03 & 0.53,7.26]\end{array}$ $\begin{array}{ccccccccccccc}\text { Reliability } & 0.89 & 0.94 & 1.40 & 1.05 & 1.03 & 1.07 & 0.93 & 1.11 & 1.02 & 0.92 & 0.50 \\ & {[0.64,1.23]} & {[0.69,1.31]} & {[0.96,2.04]} & {[0.71,1.63]} & {[0.79,1.35]} & {[0.54,2.11]} & {[0.73,1.18]} & {[0.09,12.38]} & {[0.39,2.76]} & {[0.40,2.61]} & {[0.54,1.38]} & {[0.27,7.02]}\end{array}$

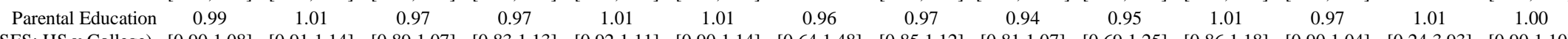
$\begin{array}{lllllllllllllll}(\mathrm{SES} ; \mathrm{HS} \text { v College) } & {[0.90,1.08]} & {[0.91,1.14]} & {[0.89,1.07]} & {[0.83,1.13]} & {[0.92,1.11]} & {[0.90,1.14]} & {[0.64,1.48]} & {[0.85,1.12]} & {[0.81,1.07]} & {[0.69,1.25]} & {[0.86,1.18]} & {[0.90,1.04]} & {[0.24,3.93]} & {[0.90,1.10]}\end{array}$ $\begin{array}{ccccccccccccccc}\text { Parental Education } & 0.95 & 0.94 & 1.08 & 0.98 & 0.95 & 1.03 & 0.97 & 1.04 & 0.98 & 0.67 & 0.94 & 0.90 & 0.34 & 0.94 \\ \text { (SES; HS v Higher) } & {[0.67,1.32]} & {[0.69,1.25]} & {[0.84,1.39]} & {[0.70,1.33]} & {[0.76,1.19]} & {[0.76,1.42]} & {[0.29,3.24]} & {[0.61,1.67]} & {[0.57,1.70]} & {[0.20,1.98]} & {[0.53,1.78]} & {[0.64,1.18]} & {[0.00,19.45]} & {[0.54,1.44]}\end{array}$

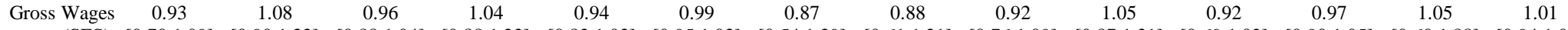
$\begin{array}{llllllllllllllllllllll}\text { (SES) } & {[0.70,1.09]} & {[0.90,1.33]} & {[0.88,1.04]} & {[0.88,1.23]} & {[0.83,1.03]} & {[0.95,1.03]} & {[0.54,1.39]} & {[0.61,1.21]} & {[0.76,1.09]} & {[0.87,1.31]} & {[0.69,1.02]} & {[0.90,1.05]} & {[0.60,1.88]} & {[0.94,1.07]}\end{array}$

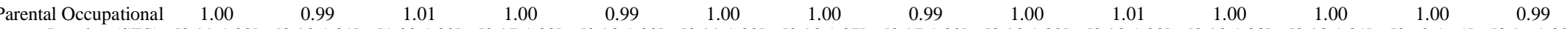
$\begin{array}{lllllllllllllll}\text { Prestige (SES) } & {[0.99,1.02]} & {[0.98,1.01]} & {[1.00,1.02]} & {[0.97,1.02]} & {[0.98,1.00]} & {[0.99,1.02]} & {[0.93,1.07]} & {[0.97,1.02]} & {[0.98,1.02]} & {[0.98,1.03]} & {[0.98,1.03]} & {[0.98,1.01]} & {[0.62,1.61]} & {[0.96,1.02]}\end{array}$

\section{Higher Education}

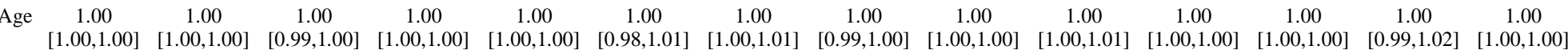

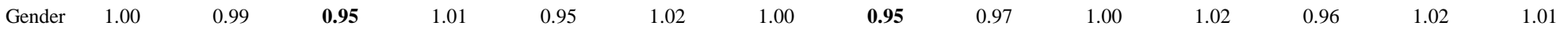

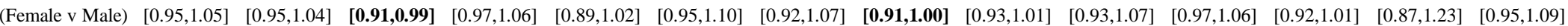

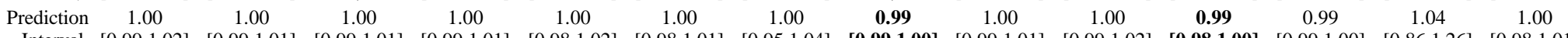

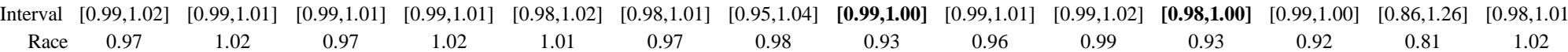
$\begin{array}{llllllllllllllll}\text { (Black v White) } & {[0.88,1.07]} & {[0.92,1.14]} & {[0.88,1.08]} & {[0.92,1.13]} & {[0.88,1.16]} & {[0.84,1.12]} & {[0.79,1.22]} & {[0.84,1.04]} & {[0.88,1.06]} & {[0.87,1.14]} & {[0.82,1.06]} & {[0.81,1.06]} & {[0.47,1.53]} & {[0.89,1.19}\end{array}$ 


\begin{tabular}{|c|c|c|c|c|c|c|c|c|c|c|c|c|c|c|}
\hline & $\mathbf{E}$ & $\mathbf{A}$ & $\mathrm{C}$ & $\mathbf{N}$ & $\mathbf{O}$ & SE & OP & SWL & PA & NA & LOC & SS & IQ & DEP \\
\hline Term & OR [CI] & OR [CI] & OR [CI] & OR [CI] & OR $[\mathrm{CI}]$ & OR $[\mathrm{CI}]$ & OR [CI] & OR [CI $]$ & [CI] & [CI] & OR [CI] & [CI] & OR $[\mathrm{CI}]$ & OR [CI] \\
\hline $\begin{array}{r}\text { Race } \\
\text { (Other v White) }\end{array}$ & $\begin{array}{c}1.09 \\
{[0.96,1.25]}\end{array}$ & $\begin{array}{c}1.08 \\
{[0.92,1.26]}\end{array}$ & $\begin{array}{c}1.00 \\
{[0.87,1.14]}\end{array}$ & $\begin{array}{c}1.03 \\
{[0.87,1.34]}\end{array}$ & $\begin{array}{c}0.99 \\
{[0.59,1.59]}\end{array}$ & $\begin{array}{c}0.95 \\
{[0.67,1.48]}\end{array}$ & $\begin{array}{c}1.12 \\
{[0.58,2.21]}\end{array}$ & $\begin{array}{c}1.03 \\
{[0.84,1.29]}\end{array}$ & $\begin{array}{c}1.10 \\
{[0.67,2.37]}\end{array}$ & $\begin{array}{c}1.01 \\
{[0.61,1.65]}\end{array}$ & $\begin{array}{c}0.97 \\
{[0.77,1.28]}\end{array}$ & $\begin{array}{c}0.96 \\
{[0.55,1.38]}\end{array}$ & $\begin{array}{c}1.06 \\
{[0.33,3.83]}\end{array}$ & $\begin{array}{c}0.94 \\
{[0.56,1.62]}\end{array}$ \\
\hline Reliability & $\begin{array}{c}1.05 \\
{[0.81,1.39]}\end{array}$ & $\begin{array}{c}1.08 \\
{[0.91,1.28]}\end{array}$ & $\begin{array}{c}1.03 \\
{[0.83,1.31]}\end{array}$ & $\begin{array}{c}0.96 \\
{[0.77,1.21]}\end{array}$ & $\begin{array}{c}1.20 \\
{[0.81,1.80]}\end{array}$ & $\begin{array}{c}1.29 \\
{[0.69,2.28]}\end{array}$ & $\begin{array}{c}0.86 \\
{[0.07,9.31]}\end{array}$ & $\begin{array}{c}1.03 \\
{[0.52,2.10]}\end{array}$ & $\begin{array}{c}1.25 \\
{[0.68,2.31]}\end{array}$ & $\begin{array}{c}1.29 \\
{[0.94,1.76]}\end{array}$ & $\begin{array}{c}0.97 \\
{[0.75,1.23]}\end{array}$ & $\begin{array}{c}0.89 \\
{[0.76,1.04]}\end{array}$ & $\begin{array}{c}0.88 \\
{[0.08,11.03]}\end{array}$ & $\begin{array}{c}0.50 \\
{[0.11,2.51]}\end{array}$ \\
\hline $\begin{array}{l}\text { Parental Education } \\
\text { (SES; HS v College) }\end{array}$ & $\begin{array}{c}0.99 \\
{[0.92,1.07]}\end{array}$ & $\begin{array}{c}1.00 \\
{[0.92,1.09]}\end{array}$ & $\begin{array}{c}1.03 \\
{[0.96,1.10]}\end{array}$ & $\begin{array}{c}1.01 \\
0.95,1.08]\end{array}$ & $\begin{array}{c}0.97 \\
{[0.88,1.09]}\end{array}$ & $\begin{array}{c}1.00 \\
{[0.91,1.10]}\end{array}$ & $\begin{array}{c}0.98 \\
{[0.90,1.07]}\end{array}$ & $\begin{array}{c}1.08 \\
{[0.98,1.23]}\end{array}$ & $\begin{array}{c}1.03 \\
{[0.93,1.14]}\end{array}$ & $\begin{array}{c}1.04 \\
{[0.94,1.18]}\end{array}$ & $\begin{array}{c}0.96 \\
{[0.90,1.03]}\end{array}$ & $\begin{array}{c}1.01 \\
{[0.93,1.10]}\end{array}$ & $\begin{array}{c}1.00 \\
{[0.82,1.24]}\end{array}$ & $\begin{array}{c}0.99 \\
{[0.89,1.11]}\end{array}$ \\
\hline $\begin{array}{r}\text { Parental Education } \\
\text { (SES; HS v Higher) }\end{array}$ & $\begin{array}{c}1.09 \\
{[0.98,1.24]}\end{array}$ & $\begin{array}{c}1.02 \\
{[0.91,1.15]}\end{array}$ & $\begin{array}{c}1.05 \\
{[0.92,1.21]}\end{array}$ & $\begin{array}{c}1.03 \\
{[0.92,1.15]}\end{array}$ & $\begin{array}{c}1.01 \\
{[0.83,1.25]}\end{array}$ & $\begin{array}{c}1.05 \\
{[0.91,1.23]}\end{array}$ & $\begin{array}{c}0.92 \\
{[0.74,1.11]}\end{array}$ & $\begin{array}{c}1.09 \\
{[0.93,1.29]}\end{array}$ & $\begin{array}{c}1.04 \\
{[0.87,1.27]}\end{array}$ & $\begin{array}{c}1.06 \\
{[0.88,1.33]}\end{array}$ & $\begin{array}{c}0.96 \\
{[0.86,1.08]}\end{array}$ & $\begin{array}{c}0.96 \\
{[0.84,1.10]}\end{array}$ & $\begin{array}{c}1.06 \\
{[0.60,1.74]}\end{array}$ & $\begin{array}{c}0.91 \\
{[0.77,1.08]}\end{array}$ \\
\hline $\begin{array}{c}\text { Gross Wages } \\
\text { (SES) }\end{array}$ & $\begin{array}{c}1.01 \\
{[0.98,1.03]}\end{array}$ & $\begin{array}{c}1.00 \\
{[0.97,1.05]}\end{array}$ & $\begin{array}{c}0.99 \\
{[0.95,1.02]}\end{array}$ & $\begin{array}{c}1.01 \\
0.99,1.04]\end{array}$ & $\begin{array}{c}1.00 \\
{[0.98,1.02]}\end{array}$ & $\begin{array}{c}1.02 \\
{[0.95,1.09]}\end{array}$ & $\begin{array}{c}0.96 \\
{[0.91,1.01]}\end{array}$ & $\begin{array}{c}1.01 \\
{[0.97,1.04]}\end{array}$ & $\begin{array}{c}0.98 \\
{[0.94,1.02]}\end{array}$ & $\begin{array}{c}0.98 \\
{[0.94,1.01]}\end{array}$ & $\begin{array}{c}0.99 \\
{[0.95,1.04]}\end{array}$ & $\begin{array}{c}0.99 \\
{[0.97,1.02]}\end{array}$ & $\begin{array}{c}0.98 \\
{[0.86,1.17]}\end{array}$ & $\begin{array}{c}1.00 \\
{[0.96,1.04]}\end{array}$ \\
\hline $\begin{array}{r}\text { Parental Occupational } \\
\text { Prestige (SES) }\end{array}$ & $\begin{array}{c}1.00 \\
{[0.99,1.01]}\end{array}$ & $\begin{array}{c}1.00 \\
{[0.98,1.01]}\end{array}$ & $\begin{array}{c}1.00 \\
{[0.99,1.01]}\end{array}$ & $\begin{array}{c}1.00 \\
{[0.98,1.01]}\end{array}$ & $\begin{array}{c}1.00 \\
{[0.99,1.02]}\end{array}$ & $\begin{array}{c}0.99 \\
{[0.97,1.02]}\end{array}$ & $\begin{array}{c}0.99 \\
{[0.95,1.02]}\end{array}$ & $\begin{array}{c}0.99 \\
{[0.97,1.02]}\end{array}$ & $\begin{array}{c}1.00 \\
{[0.99,1.02]}\end{array}$ & $\begin{array}{c}1.00 \\
0.98,1.01]\end{array}$ & $\begin{array}{c}0.99 \\
{[0.98,1.01]}\end{array}$ & $\begin{array}{c}1.01 \\
{[1.00,1.02]}\end{array}$ & $\begin{array}{c}0.97 \\
{[0.84,1.13]}\end{array}$ & $\begin{array}{c}0.99 \\
{[0.98,1.01]}\end{array}$ \\
\hline just Joh & {$[0.99,1.01]$} & $\begin{array}{c}1.00 \\
{[0.98,1.01]}\end{array}$ & $\begin{array}{c}1.00 \\
{[0.99,1.01]}\end{array}$ & {$[0.99,1.00]$} & {$[0.98,1.01]$} & {$[0.98,1.01]$} & {$[0.53,2.16]$} & {$[0.94,1.04]$} & $\begin{array}{c}1.00 \\
{[0.97,1.02]}\end{array}$ & $\begin{array}{c}1.00 \\
0.97,1.03]\end{array}$ & {$[0.95,1.04]$} & {$[0.99,1.02]$} & {$[0.94,1.11]$} & {$[0.94,1.04]$} \\
\hline $\begin{array}{r}\text { Gender } \\
\text { (Female v Male) }\end{array}$ & $\begin{array}{c}1.02 \\
{[0.95,1.09]}\end{array}$ & $\begin{array}{c}0.97 \\
{[0.91,1.04]}\end{array}$ & $\begin{array}{c}1.03 \\
{[0.97,1.10]}\end{array}$ & $\begin{array}{c}1.00 \\
{[0.94,1.06]}\end{array}$ & $\begin{array}{c}0.96 \\
{[0.88,1.04]}\end{array}$ & $\begin{array}{c}1.03 \\
{[0.95,1.12]}\end{array}$ & $\begin{array}{c}1.01 \\
{[0.38,2.73]}\end{array}$ & $\begin{array}{c}1.00 \\
{[0.92,1.09]}\end{array}$ & $\begin{array}{c}0.94 \\
{[0.84,1.05]}\end{array}$ & $\begin{array}{c}1.04 \\
{[0.88,1.27]}\end{array}$ & $\begin{array}{c}0.95 \\
{[0.84,1.09]}\end{array}$ & $\begin{array}{c}0.99 \\
{[0.83,1.19]}\end{array}$ & $\begin{array}{c}1.06 \\
{[0.93,1.21]}\end{array}$ & $\begin{array}{c}1.01 \\
{[0.89,1.17]}\end{array}$ \\
\hline $\begin{array}{c}\text { Prediction } \\
\text { Interval }\end{array}$ & $\begin{array}{c}0.98 \\
{[0.86,1.12]}\end{array}$ & $\begin{array}{c}0.99 \\
{[0.95,1.03]}\end{array}$ & $\begin{array}{c}1.01 \\
{[0.87,1.19]}\end{array}$ & $\begin{array}{c}1.01 \\
{[0.94,1.06]}\end{array}$ & $\begin{array}{c}0.97 \\
{[0.86,1.12]}\end{array}$ & $\begin{array}{c}1.01 \\
{[0.99,1.03]}\end{array}$ & $\begin{array}{c}1.04 \\
{[0.90,1.17]}\end{array}$ & $\begin{array}{c}1.00 \\
{[0.90,1.06]}\end{array}$ & $\begin{array}{c}1.01 \\
{[0.93,1.11]}\end{array}$ & $\begin{array}{c}1.00 \\
{[0.90,1.13]}\end{array}$ & $\begin{array}{c}1.00 \\
{[0.97,1.04]}\end{array}$ & $\begin{array}{c}0.99 \\
{[0.81,1.23]}\end{array}$ & $\begin{array}{c}1.00 \\
{[0.86,1.18]}\end{array}$ & $\begin{array}{c}0.99 \\
{[0.91,1.08]}\end{array}$ \\
\hline $\begin{array}{r}\text { Race } \\
\text { (Black v White) }\end{array}$ & $\begin{array}{c}0.97 \\
{[0.81,1.18]}\end{array}$ & $\begin{array}{c}0.96 \\
0.77,1.17]\end{array}$ & $\begin{array}{c}1.02 \\
{[0.80,1.31]}\end{array}$ & $\begin{array}{c}0.95 \\
{[0.77,1.24]}\end{array}$ & $\begin{array}{c}1.08 \\
{[0.54,2.30]}\end{array}$ & $\begin{array}{c}0.88 \\
{[0.71,1.10]}\end{array}$ & & $\begin{array}{c}0.84 \\
{[0.42,1.67]}\end{array}$ & $\begin{array}{c}1.16 \\
{[0.57,2.28]}\end{array}$ & $\begin{array}{c}1.11 \\
{[0.52,2.30]}\end{array}$ & $\begin{array}{c}0.91 \\
{[0.56,1.52]}\end{array}$ & $\begin{array}{c}1.10 \\
{[0.59,2.21]}\end{array}$ & $\begin{array}{c}0.88 \\
{[0.44,1.84]}\end{array}$ & $\begin{array}{c}1.01 \\
{[0.77,1.31]}\end{array}$ \\
\hline $\begin{array}{r}\text { Race } \\
\text { (Other v White) }\end{array}$ & $\begin{array}{c}1.00 \\
{[0.70,1.48]}\end{array}$ & $\begin{array}{c}0.90 \\
{[0.62,1.31]}\end{array}$ & $\begin{array}{c}1.00 \\
{[0.64,1.50]}\end{array}$ & $\begin{array}{c}0.91 \\
0.54,1.37]\end{array}$ & $\begin{array}{c}1.00 \\
{[0.39,2.65]}\end{array}$ & $\begin{array}{c}1.00 \\
{[0.69,1.42]}\end{array}$ & & $\begin{array}{c}0.94 \\
{[0.30,3.12]}\end{array}$ & $\begin{array}{c}1.01 \\
{[0.26,3.87]}\end{array}$ & $\begin{array}{c}1.02 \\
0.25,3.99]\end{array}$ & $\begin{array}{c}1.03 \\
{[0.65,1.75]}\end{array}$ & $\begin{array}{c}1.11 \\
{[0.44,2.98]}\end{array}$ & $\begin{array}{c}0.86 \\
{[0.29,2.81]}\end{array}$ & $\begin{array}{c}1.09 \\
{[0.67,1.90]}\end{array}$ \\
\hline Reliability & $\begin{array}{c}1.09 \\
{[0.46,2.55]}\end{array}$ & $\begin{array}{c}1.00 \\
{[0.60,1.64]}\end{array}$ & $\begin{array}{c}0.92 \\
{[0.33,3.00]}\end{array}$ & $\begin{array}{c}1.06 \\
{[0.41,2.98]}\end{array}$ & $\begin{array}{c}1.11 \\
{[0.53,2.53]}\end{array}$ & $\begin{array}{c}0.77 \\
{[0.10,8.28]}\end{array}$ & & $\begin{array}{c}1.07 \\
{[.11,10.67]}\end{array}$ & $\begin{array}{c}0.97 \\
{[0.14,7.26]}\end{array}$ & $\begin{array}{c}1.02 \\
{[0.19,5.00]}\end{array}$ & $\begin{array}{c}1.08 \\
{[0.28,3.63]}\end{array}$ & $\begin{array}{c}0.95 \\
{[0.31,3.40]}\end{array}$ & $\begin{array}{c}1.02 \\
{[0.06,17.57]}\end{array}$ & $\begin{array}{c}0.99 \\
{[0.21,4.65]}\end{array}$ \\
\hline $\begin{array}{l}\text { Parental Education } \\
\text { (SES; HS v College) }\end{array}$ & $\begin{array}{c}1.06 \\
{[0.93,1.23]}\end{array}$ & $\begin{array}{c}1.10 \\
{[0.91,1.36]}\end{array}$ & $\begin{array}{c}1.12 \\
{[0.97,1.26]}\end{array}$ & $\begin{array}{c}1.07 \\
0.94,1.23]\end{array}$ & $\begin{array}{c}1.02 \\
{[0.80,1.34]}\end{array}$ & $\begin{array}{c}1.03 \\
{[0.90,1.17]}\end{array}$ & $\begin{array}{c}1.01 \\
{[0.34,3.16]}\end{array}$ & $\begin{array}{c}0.99 \\
{[0.81,1.21]}\end{array}$ & $\begin{array}{c}0.99 \\
{[0.83,1.19]}\end{array}$ & $\begin{array}{c}1.01 \\
{[0.76,1.34]}\end{array}$ & $\begin{array}{c}1.16 \\
{[0.96,1.44]}\end{array}$ & $\begin{array}{c}0.91 \\
{[0.75,1.09]}\end{array}$ & $\begin{array}{c}0.98 \\
{[0.79,1.22]}\end{array}$ & $\begin{array}{c}0.95 \\
{[0.85,1.07]}\end{array}$ \\
\hline $\begin{array}{r}\text { Parental Education } \\
\text { (SES; HS v Higher) }\end{array}$ & $\begin{array}{c}1.05 \\
{[0.88,1.31]}\end{array}$ & $\begin{array}{c}1.02 \\
{[0.87,1.23]}\end{array}$ & $\begin{array}{c}1.19 \\
{[0.98,1.58]}\end{array}$ & $\begin{array}{c}0.98 \\
0.82,1.16]\end{array}$ & $\begin{array}{c}1.00 \\
{[0.77,1.38]}\end{array}$ & $\begin{array}{c}1.01 \\
{[0.86,1.20]}\end{array}$ & $\begin{array}{c}0.98 \\
{[0.27,3.88]}\end{array}$ & $\begin{array}{c}0.96 \\
{[0.70,1.40]}\end{array}$ & $\begin{array}{c}1.03 \\
{[0.78,1.42]}\end{array}$ & $\begin{array}{c}1.07 \\
{[0.69,1.76]}\end{array}$ & $\begin{array}{c}1.04 \\
{[0.82,1.32]}\end{array}$ & $\begin{array}{c}1.14 \\
{[0.72,2.20]}\end{array}$ & $\begin{array}{c}1.16 \\
{[0.76,2.07]}\end{array}$ & $\begin{array}{c}1.08 \\
{[0.80,1.63]}\end{array}$ \\
\hline $\begin{array}{c}\text { Gross Wages } \\
\text { (SES) }\end{array}$ & $\begin{array}{c}1.00 \\
{[0.96,1.06]}\end{array}$ & $\begin{array}{c}1.01 \\
{[0.96,1.09]}\end{array}$ & $\begin{array}{c}0.97 \\
{[0.90,1.02]}\end{array}$ & $\begin{array}{c}1.02 \\
0.97,1.07]\end{array}$ & $\begin{array}{c}0.99 \\
{[0.90,1.09]}\end{array}$ & $\begin{array}{c}1.00 \\
{[0.95,1.05]}\end{array}$ & $\begin{array}{c}1.04 \\
{[0.56,1.99]}\end{array}$ & $\begin{array}{c}1.00 \\
{[0.93,1.07]}\end{array}$ & $\begin{array}{c}0.98 \\
{[0.88,1.09]}\end{array}$ & $\begin{array}{c}1.06 \\
{[0.85,1.38]}\end{array}$ & $\begin{array}{c}1.04 \\
{[0.95,1.14]}\end{array}$ & $\begin{array}{c}0.98 \\
{[0.89,1.08]}\end{array}$ & $\begin{array}{c}1.01 \\
{[0.94,1.09]}\end{array}$ & $\begin{array}{c}1.01 \\
{[0.95,1.08]}\end{array}$ \\
\hline $\begin{array}{r}\text { Parental Occupational } \\
\text { Prestige (SES) }\end{array}$ & $\begin{array}{c}0.99 \\
{[0.96,1.01]}\end{array}$ & $\begin{array}{c}1.00 \\
{[0.98,1.02]}\end{array}$ & $\begin{array}{c}1.00 \\
{[0.98,1.03]}\end{array}$ & $\begin{array}{c}1.01 \\
0.98,1.03]\end{array}$ & $\begin{array}{c}1.00 \\
{[0.97,1.04]}\end{array}$ & $\begin{array}{c}0.99 \\
{[0.95,1.03]}\end{array}$ & $\begin{array}{c}1.02 \\
{[0.76,1.46]}\end{array}$ & $\begin{array}{c}0.98 \\
{[0.89,1.08]}\end{array}$ & $\begin{array}{c}0.99 \\
{[0.90,1.08]}\end{array}$ & $\begin{array}{c}1.03 \\
0.88,1.19]\end{array}$ & $\begin{array}{c}1.01 \\
{[0.91,1.12]}\end{array}$ & $\begin{array}{c}1.00 \\
{[0.97,1.04]}\end{array}$ & $\begin{array}{c}1.01 \\
{[0.88,1.17]}\end{array}$ & $\begin{array}{c}1.00 \\
{[0.97,1.03]}\end{array}$ \\
\hline Age & $\begin{array}{c}1.00 \\
{[1.00,1.00]}\end{array}$ & $\begin{array}{c}1.00 \\
1.00,1.00]\end{array}$ & $\begin{array}{c}1.00 \\
{[1.00,1.01]}\end{array}$ & $\begin{array}{l}1.00 \\
.00,1.00]\end{array}$ & {$[1.00,1.00]$} & $\begin{array}{c}1.00 \\
{[1.00,1.00]}\end{array}$ & $\begin{array}{c}1.00 \\
{[1.00,1.01]}\end{array}$ & $\begin{array}{c}1.00 \\
{[1.00,1.00]}\end{array}$ & {$[1.00,1.00]$} & $\begin{array}{c}1.00 \\
1.00,1.00]\end{array}$ & {$[1.00,1.00]$} & {$[1.00,1.00]$} & $\begin{array}{c}1.00 \\
{[1.00,1.01]}\end{array}$ & $\begin{array}{c}1.00 \\
{[1.00,1.00]}\end{array}$ \\
\hline $\begin{array}{r}\text { Gender } \\
\text { (Female v Male) }\end{array}$ & $\begin{array}{c}0.99 \\
{[0.96,1.01]}\end{array}$ & $\begin{array}{c}1.01 \\
{[0.98,1.04]}\end{array}$ & $\begin{array}{c}1.00 \\
{[0.97,1.03]}\end{array}$ & $\begin{array}{c}1.03 \\
{[1.00,1.06]}\end{array}$ & $\begin{array}{c}1.01 \\
{[0.98,1.04]}\end{array}$ & $\begin{array}{c}1.01 \\
{[0.97,1.06]}\end{array}$ & $\begin{array}{c}1.02 \\
{[0.99,1.05]}\end{array}$ & $\begin{array}{c}1.01 \\
{[0.98,1.04]}\end{array}$ & $\begin{array}{c}0.98 \\
{[0.93,1.02]}\end{array}$ & $\begin{array}{c}1.03 \\
{[0.99,1.06]}\end{array}$ & $\begin{array}{c}1.02 \\
{[1.00,1.05]}\end{array}$ & $\begin{array}{c}1.00 \\
{[0.97,1.03]}\end{array}$ & $\begin{array}{c}1.00 \\
{[0.94,1.06]}\end{array}$ & $\begin{array}{c}0.97 \\
{[0.94,1.00]}\end{array}$ \\
\hline $\begin{array}{c}\text { Prediction } \\
\text { Interval }\end{array}$ & $\begin{array}{r}1.00 \\
{[0.99,1.01]}\end{array}$ & $\begin{array}{c}1.00 \\
{[0.99,1.01]}\end{array}$ & $\begin{array}{c}1.00 \\
{[0.99,1.01]}\end{array}$ & $\begin{array}{c}1.00 \\
{[0.99,1.00]}\end{array}$ & $\begin{array}{c}1.00 \\
{[0.99,1.00]}\end{array}$ & $\begin{array}{c}1.00 \\
{[0.99,1.01]}\end{array}$ & $\begin{array}{c}1.00 \\
{[0.99,1.02]}\end{array}$ & $\begin{array}{c}1.00 \\
{[0.99,1.01]}\end{array}$ & $\begin{array}{c}1.00 \\
{[0.98,1.01]}\end{array}$ & $\begin{array}{c}1.00 \\
{[0.99,1.00]}\end{array}$ & $\begin{array}{c}1.00 \\
{[0.99,1.00]}\end{array}$ & $\begin{array}{c}0.99 \\
{[0.99,1.00]}\end{array}$ & $\begin{array}{c}1.01 \\
{[0.99,1.03]}\end{array}$ & $\begin{array}{c}1.00 \\
{[0.99,1.01]}\end{array}$ \\
\hline $\begin{array}{r}\text { Race } \\
\text { (Black v White) }\end{array}$ & $\begin{array}{c}1.05 \\
0.97,1.14]\end{array}$ & $\begin{array}{c}1.05 \\
{[0.96,1.16]}\end{array}$ & $\begin{array}{c}1.05 \\
{[0.94,1.18]}\end{array}$ & $\begin{array}{c}1.06 \\
{[0.97,1.16]}\end{array}$ & $\begin{array}{c}1.03 \\
{[0.93,1.16]}\end{array}$ & $\begin{array}{c}1.05 \\
{[0.88,1.24]}\end{array}$ & $\begin{array}{c}0.96 \\
{[0.85,1.08]}\end{array}$ & $\begin{array}{c}0.99 \\
{[0.92,1.06]}\end{array}$ & $\begin{array}{c}1.11 \\
{[1.00,1.24]}\end{array}$ & $\begin{array}{c}0.95 \\
{[0.83,1.08]}\end{array}$ & $\begin{array}{c}1.01 \\
{[0.93,1.10]}\end{array}$ & $\begin{array}{c}1.01 \\
{[0.92,1.10]}\end{array}$ & $\begin{array}{c}1.02 \\
{[0.89,1.17]}\end{array}$ & $\begin{array}{c}1.00 \\
{[0.89,1.12]}\end{array}$ \\
\hline $\begin{array}{r}\text { Race } \\
\text { (Other v White) }\end{array}$ & $\begin{array}{c}0.97 \\
{[0.81,1.15]}\end{array}$ & $\begin{array}{c}1.03 \\
{[0.86,1.23]}\end{array}$ & $\begin{array}{c}1.09 \\
{[0.90,1.33]}\end{array}$ & $\begin{array}{c}1.06 \\
{[0.86,1.38]}\end{array}$ & $\begin{array}{c}0.84 \\
{[0.57,1.17]}\end{array}$ & $\begin{array}{c}0.83 \\
{[0.59,1.12]}\end{array}$ & $\begin{array}{c}0.90 \\
{[0.53,1.32]}\end{array}$ & $\begin{array}{c}0.99 \\
{[0.59,1.38]}\end{array}$ & $\begin{array}{c}1.05 \\
{[0.84,1.28]}\end{array}$ & $\begin{array}{c}0.94 \\
{[0.70,1.22]}\end{array}$ & $\begin{array}{c}1.06 \\
{[0.92,1.20]}\end{array}$ & $\begin{array}{c}0.86 \\
{[0.37,1.37]}\end{array}$ & $\begin{array}{c}1.06 \\
{[0.65,1.81]}\end{array}$ & $\begin{array}{c}1.04 \\
{[0.87,1.24]}\end{array}$ \\
\hline
\end{tabular}


Table 3.4

Fixed Effect Moderators of Personality-Outcome Associations

\begin{tabular}{|c|c|c|c|c|c|c|c|c|c|c|c|c|c|c|}
\hline & $\mathbf{E}$ & $\mathbf{A}$ & C & $\mathbf{N}$ & $\mathbf{O}$ & SE & OP & SWL & PA & $\sqrt{A}$ & LOC & SS & IQ & DEP \\
\hline Term & $\mathrm{R}[\mathrm{C}$ & & 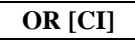 & & 1 & 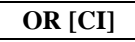 & 1 & $1]$ & & & ( & I] & I] & CI] \\
\hline iability & 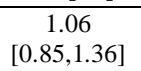 & & & 1 & {$[0.0$} & & & & & & & & & \\
\hline (SES; Hs & {$[0.93$,} & 6] & & $1+2$ & $\begin{array}{r}0 \\
{[0.91}\end{array}$ & 0 & & & & & & & & \\
\hline & & & & & & & & & & & & & & \\
\hline $\begin{array}{c}\text { Gross Wages } \\
\text { (SES) }\end{array}$ & {$[0.97,1.00]$} & $.90,1.01]$ & $0.70,1.01]$ & $\begin{array}{c}1.00 \\
{[0.99,1.01]}\end{array}$ & $\begin{array}{c}0.99 \\
{[0.98,1.01]}\end{array}$ & $\begin{array}{c}1.01 \\
{[0.99,1.03]}\end{array}$ & $\begin{array}{c}0.98 \\
{[0.94,1.01]}\end{array}$ & $\begin{array}{c}1.00 \\
{[0.98,1.02]}\end{array}$ & $\begin{array}{c}1.00 \\
{[0.98,1.01]}\end{array}$ & $\begin{array}{c}1.00 \\
{[0.98,1.02]}\end{array}$ & $\begin{array}{c}1.00 \\
{[0.98,1.01]}\end{array}$ & $\begin{array}{c}1.00 \\
{[0.99,1.02]}\end{array}$ & & {$[0.99,1.0$} \\
\hline $\begin{array}{c}\text { ental Occupational } \\
\text { Prestige (SES) }\end{array}$ & {$[0.99,1.00]$} & $\begin{array}{c}1.01 \\
1.00,1.01]\end{array}$ & $\begin{array}{c}1.01 \\
.00,1.02]\end{array}$ & $\begin{array}{c}1.01 \\
{[1.00,1.01]}\end{array}$ & $\begin{array}{c}0.99 \\
{[0.99,1.00]}\end{array}$ & $\begin{array}{c}0.99 \\
{[0.99,1.00]}\end{array}$ & $\begin{array}{c}1.00 \\
{[0.99,1.01]}\end{array}$ & $\begin{array}{c}1.00 \\
0.99,1.01]\end{array}$ & $\begin{array}{c}0.99 \\
{[0.98,1.00]}\end{array}$ & $\begin{array}{c}1.00 \\
{[0.99,1.01]}\end{array}$ & $\begin{array}{c}1.00 \\
{[0.99,1.00]}\end{array}$ & $\begin{array}{c}1.00 \\
{[0.99,1.00]}\end{array}$ & $\begin{array}{c}0.99 \\
0.98,1.00]\end{array}$ & $\begin{array}{c}1.00 \\
1.00,1.0\end{array}$ \\
\hline
\end{tabular}
Retirement

$\begin{array}{cccccccccccccccc} & \text { Occupational } & 1.00 & 1.01 & 1.01 & 1.01 & 0.99 & 0.99 & 1.00 & 1.00 & \mathbf{0 . 9 9} & 1.00 & 1.00 & 1.00 & 0.99 & 1.00 \\ \text { Prestige (SES) } & {[0.99,1.00]} & {[1.00,1.01]} & {[1.00,1.02]} & {[1.00,1.01]} & {[0.99,1.00]} & {[0.99,1.00]} & {[0.99,1.01]} & {[0.99,1.01]} & {[\mathbf{0 . 9 8 , 1 . 0 0 ]}} & {[0.99,1.01]} & {[0.99,1.00]} & {[0.99,1.00]} & {[0.98,1.00]} & {[1.00,1.01]}\end{array}$

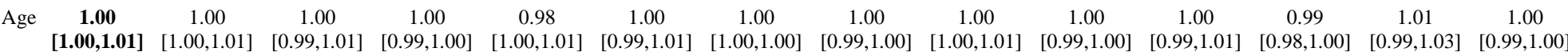

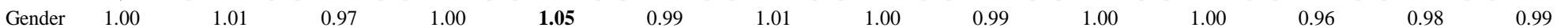

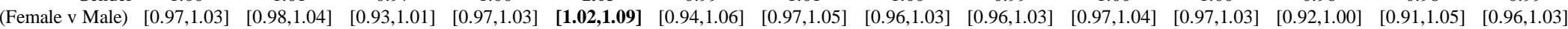

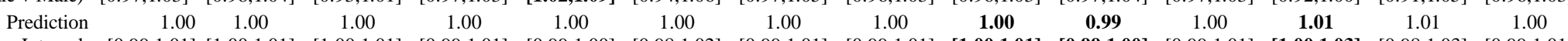

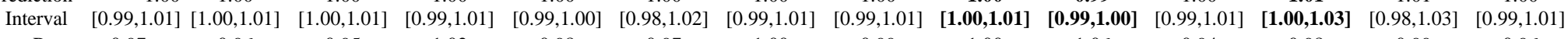

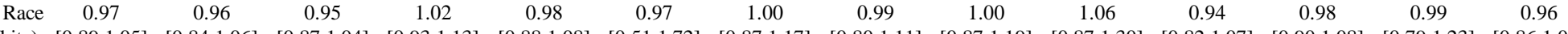
$\begin{array}{lllllllllllllllllll}\text { (Black v White) } & {[0.89,1.05]} & {[0.84,1.06]} & {[0.87,1.04]} & {[0.93,1.13]} & {[0.88,1.08]} & {[0.51,1.72]} & {[0.87,1.17]} & {[0.80,1.11]} & {[0.87,1.19]} & {[0.87,1.30]} & {[0.82,1.07]} & {[0.90,1.08]} & {[0.79,1.23]} & {[0.86,1.06]}\end{array}$

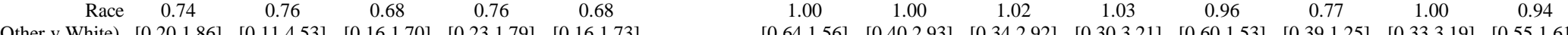
[0.60,1.53] $[0.39,1.25] \quad[0.33,3.19] \quad[0.55,1.61]$

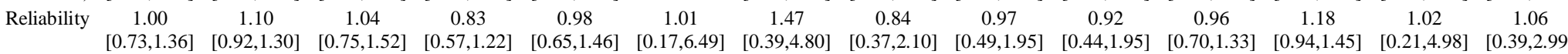
$\begin{array}{cccccccccccccc}{[0.73,1.36]} & {[0.92,1.30]} & {[0.75,1.52]} & {[0.57,1.22]} & {[0.65,1.46]} & {[0.17,6.49]} & {[0.39,4.80]} & {[0.37,2.10]} & {[0.49,1.95]} & {[0.44,1.95]} & {[0.70,1.33]} & {[0.94,1.45]} & {[0.21,4.98]} & {[0.39,2.99} \\ 0.97 & 1.01 & \mathbf{1 . 0 6} & 0.99 & 1.01 & 0.97 & 0.97 & 1.04 & \mathbf{1 . 0 5} & 0.96 & 1.02 & \mathbf{0 . 9 3} & 1.04 & 0.97\end{array}$ $\begin{array}{ccccccccccccccccc}\text { Parental Education } & 0.97 & 1.01 & \mathbf{1 . 0 6} & 0.99 & 1.01 & 0.97 & 0.97 & 1.04 & \mathbf{1 . 0 5} & 0.96 & 1.02 & \mathbf{0 . 9 3} & 1.04 & 0.97 \\ \text { (SES; HS v College) } & {[0.94,1.01]} & {[0.97,1.06]} & \mathbf{[ 1 . 0 0 , 1 . 1 1}] & {[0.95,1.03]} & {[0.97,1.06]} & {[0.91,1.03]} & {[0.93,1.01]} & {[0.99,1.09]} & {[\mathbf{1 . 0 1 , 1 . 1 0}]} & {[0.89,1.02]} & {[0.98,1.07]} & {[\mathbf{0 . 8 8 , 0 . 9 9}]} & {[0.91,1.19]} & {[0.90,1.04]}\end{array}$

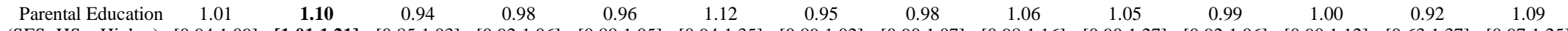

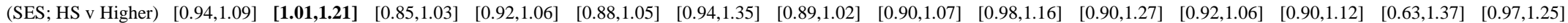
$\begin{array}{lllllllllllllll}\text { Gross Wages } & \mathbf{0 . 9 8} & 1.00 & 1.01 & 0.99 & \mathbf{0 . 9 8} & 0.98 & 1.00 & 1.02 & 1.00 & 0.95 & 1.00 & 1.01 & 0.98 & 0.99\end{array}$

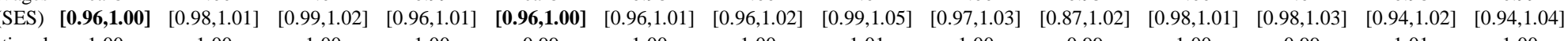

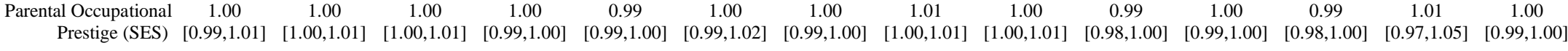
Volunteering

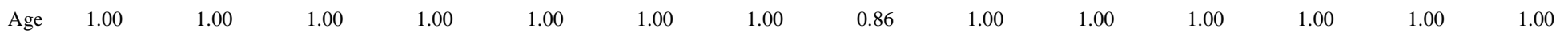
$\begin{array}{lllllllllllllllllll} & {[1.00,1.00]} & {[1.00,1.00]} & {[1.00,1.00]} & {[1.00,1.00]} & {[1.00,1.00]} & {[1.00,1.00]} & {[1.00,1.00]} & {[1.00,1.00]} & {[1.00,1.00]} & {[1.00,1.00]} & {[1.00,1.00]} & {[0.99,1.00]} & {[1.00,1.00]} & {[1.00,1.00]}\end{array}$ $\begin{array}{cccccccccccccccccccc}\text { Gender } & 1.02 & 1.00 & 0.98 & 0.98 & 1.03 & 0.98 & 1.03 & 1.01 & 1.00 & \mathbf{0 . 9 6} & 1.00 & 1.01 & 1.02 & 0.99 \\ \text { (Female v Male) } & {[0.99,1.06]} & {[0.97,1.02]} & {[0.95,1.01]} & {[0.95,1.00]} & {[0.99,1.07]} & {[0.93,1.03]} & {[0.98,1.08]} & {[0.98,1.04]} & {[0.97,1.03]} & {[\mathbf{0 . 9 4}, \mathbf{0 . 9 9}]} & {[0.97,1.04]} & {[0.98,1.05]} & {[0.98,1.07]} & {[0.95,1.03]}\end{array}$

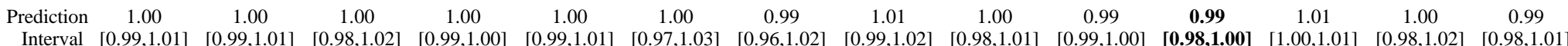

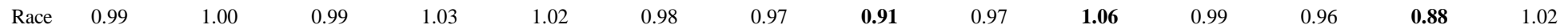

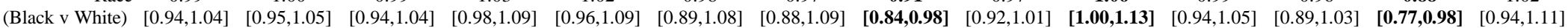

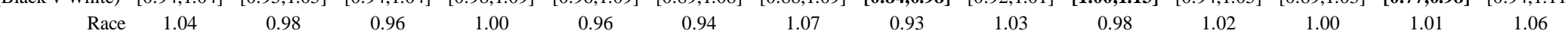
$\begin{array}{llllllllllllllllll}\text { Other v White) } & {[0.92,1.17]} & {[0.85,1.08]} & {[0.82,1.08]} & {[0.85,1.12]} & {[0.31,1.36]} & {[0.64,1.41]} & {[0.79,1.55]} & {[0.81,1.09]} & {[0.93,1.14]} & {[0.85,1.15]} & {[0.91,1.16]} & {[0.67,1.44]} & {[0.73,1.73]} & {[0.82,1.52]}\end{array}$

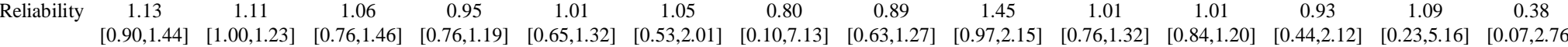


Table 3.4

Fixed Effect Moderators of Personality-Outcome Associations

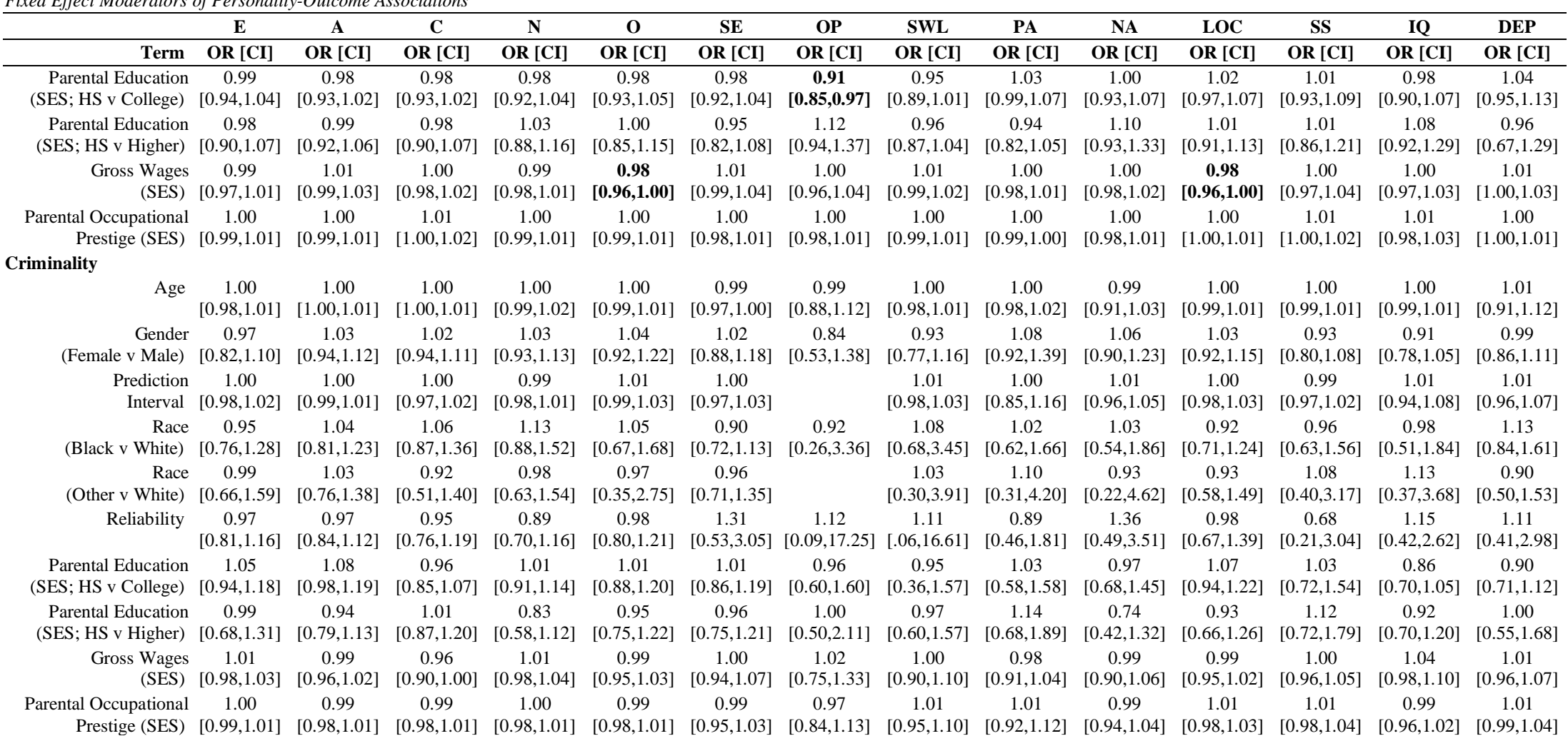

Note. OR $=$ Odds Ratio; $C I=89 \%$ Bayesian Credible Interval. Bold indicates model terms whose $89 \% \mathrm{CI}$ of log odds did not overlap with 0 . Binary variables were dummy coded such that the label to the right of the ' $v$ ' indicates the reference group. Missing cells indicate cases in which the available studies lacked moderator variables. 
As is clear from the table, the most consistent moderator of trait-outcome associations was parental education, which moderated $11.20 \%$ (high school or below versus either 2/4-year college, $8.16 \%$; degree or beyond 4 years of college, $4.08 \%$ ) of associations, followed by age $(10.20 \%)$ and gender (9.18\%). In contrast, the least consistent moderators were race, which moderated 3.57\% (white versus Black, 3.06\%; white versus other; .51\%) of associations, and scale reliability, which moderated $1.02 \%$ of associations. Simple effects of all moderators whose $89 \%$ credible intervals did not overlap with 0 for age, gender, and parental education moderation are presented in Figures 3.4, 3.5, and 3.6, respectively.

Somewhat surprisingly, age-graded events, like mortality, experiencing major health events, retiring, and starting a first job, that tend to occur in relatively small intervals throughout the lifespan were not often moderated by age. Indeed, major health events, for example, were only moderated by age for Conscientiousness $\left(\mathrm{OR}=1.002,89 \% \mathrm{CI}[1.001,1.003] ; \tau_{22}=.001 ; 89 \%\right.$ CI $[.000, .003])$, Satisfaction with Life $\left(\mathrm{OR}=1.002,89 \%\right.$ CI $[1.001,1.004] ; \tau_{22}=.0 \mathrm{r} ; 89 \% \mathrm{CI}$ $[.02, .07])$, and Social Support $\left(\mathrm{OR}=1.002,89 \%\right.$ CI $[1.001,1.003] ; \tau_{22}=.001 ; 89 \%$ CI $[.000$, .003]), such that individuals who had higher than average age in each sample and had higher scores on each personality characteristic had higher odds of experiencing a major health event than younger individuals (see Figure 3.4). 


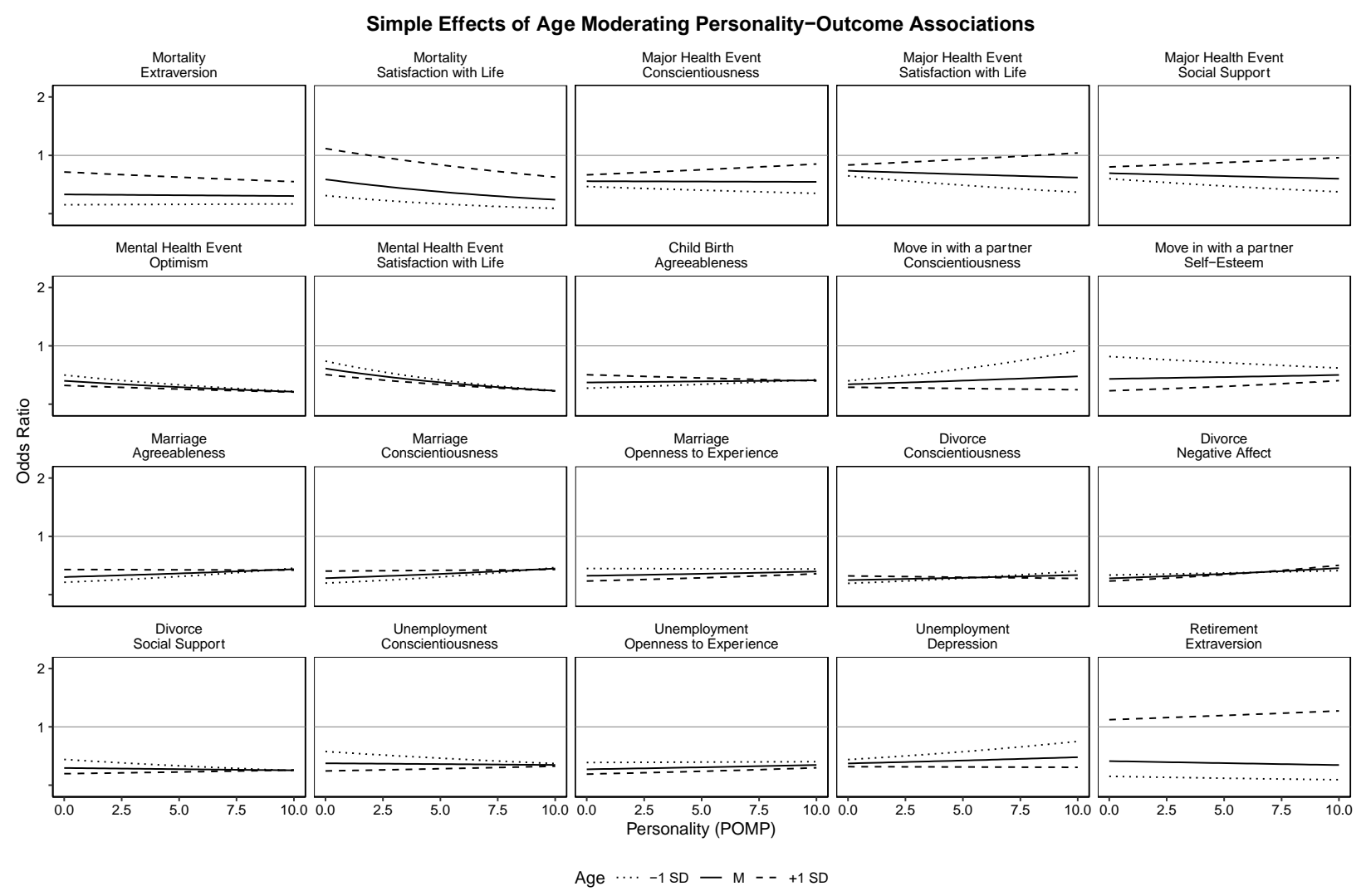

Figure 3.4. Simple effects of all personality-outcome associations that were reliably moderated by age. Each panel indicates a separate personality-outcome association in terms of the odds ratio associated with a particular personality score for different age groups. Solid lines represent within-study-centered average age (i.e. 0), while dashed and dotted lines represent individuals in each study $1 \mathrm{SD}$ above or below the study-centered average age, respectively. Shaded regions represent the $89 \%$ credible interval around the fitted estimates. Personality characteristics are presented as Percentage of Maximum Possible (POMP), which ranges from 0-10 for each study, such that 10 represents the maximum possible score, while 0 represents the minimum possible score. 


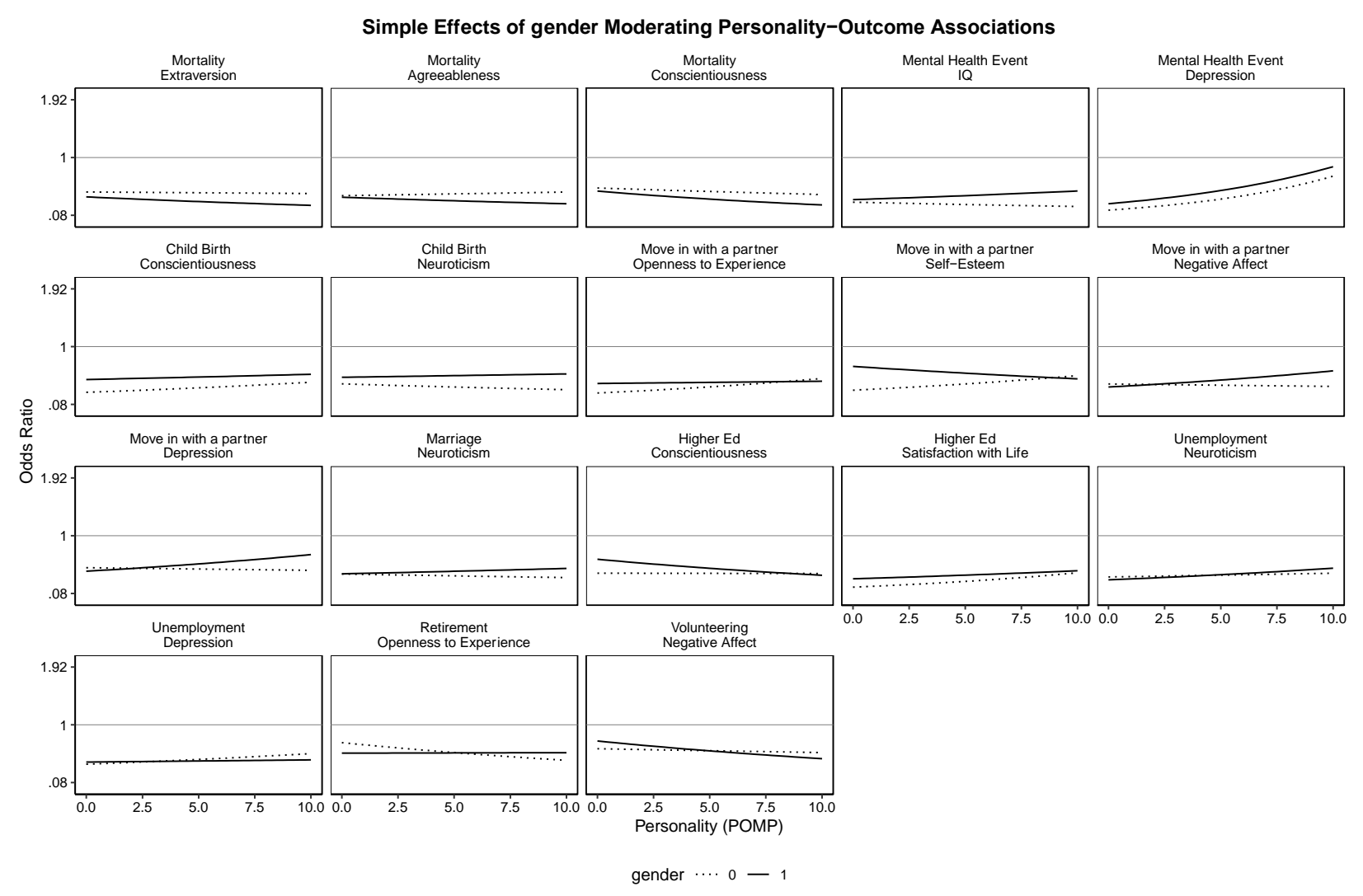

Figure 3.5. Simple effects of all personality-outcome associations that were reliably moderated by gender $(0=$ male, $1=$ female $)$. Each panel indicates a separate personality-outcome association in terms of the odds ratio associated with a particular personality score for different gender groups. Dotted lines represent individuals who identified as male, while solid lines represent individuals who identified as female. Shaded regions represent the $89 \%$ credible interval around the fitted estimates. Personality characteristics are presented as Percentage of Maximum Possible (POMP), which ranges from 0-10 for each study, such that 10 represents the 
maximum possible score, while 0 represents the minimum possible score.

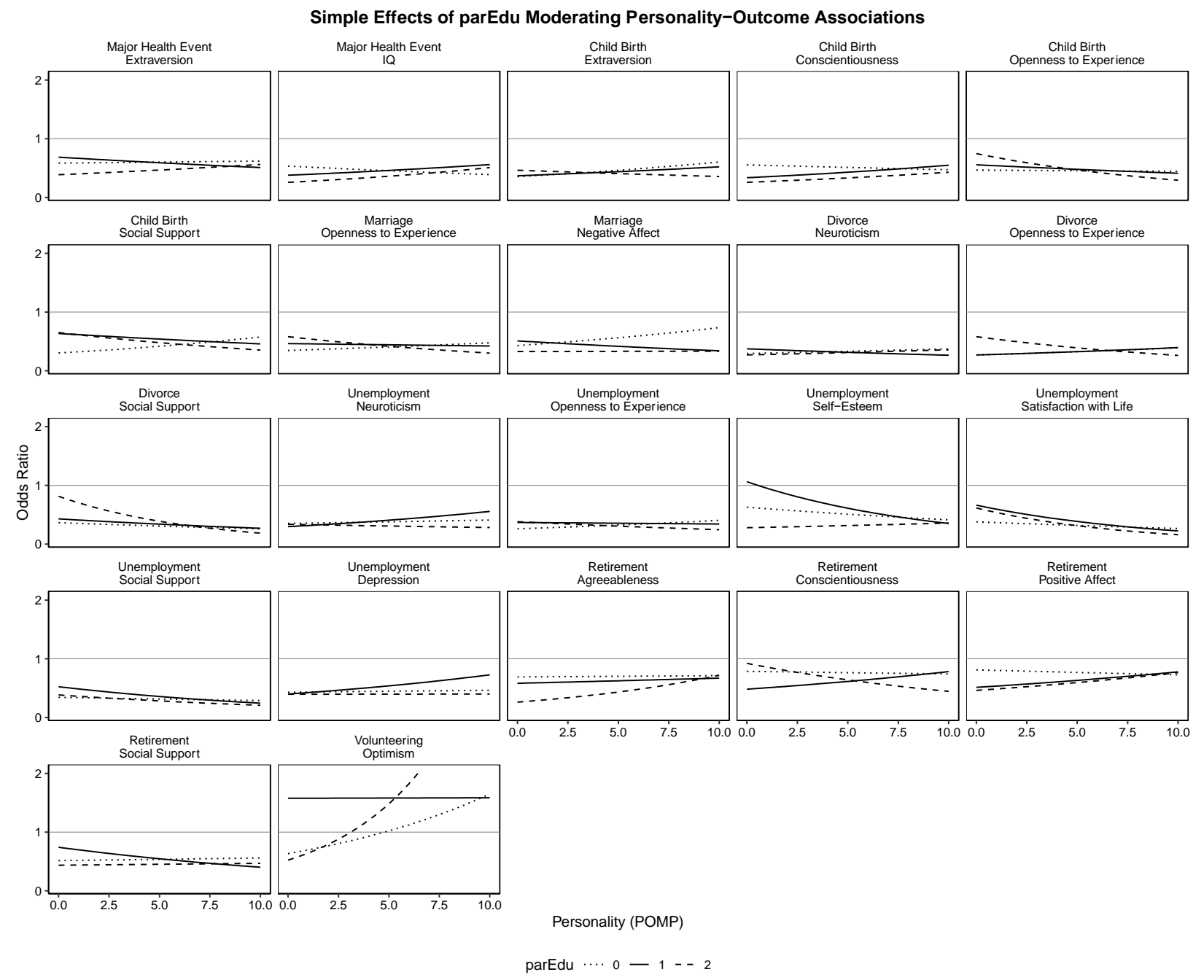

Figure 3.6. Simple effects of all personality-outcome associations that were reliably moderated by parental education ( $0=$ high school or less, $1=$ college, $2=$ beyond college). Each panel indicates a separate personality-outcome association in terms of the odds ratio associated with a particular personality score for different levels of parental education. groups. Dotted lines represent those who parents had less than a college degree, while solid and dashed lines represent individuals in each study whose parents had a college degree or beyond a college degree, respectively. Shaded regions represent the $89 \%$ credible interval around the fitted estimates. Personality characteristics are presented as Percentage of Maximum Possible (POMP), which ranges from 0-10 for each study, such that 10 represents the maximum possible score, while 0 represents the minimum possible score. The scale on each panel have been constrained to be the same. As a result, unreliable effects, like the Optimism-volunteering effect for non-Black people of color, appear exaggerated. 
Despite this, moderators performed differently across traits and outcomes. Indeed, age and parental education, which were the two most frequent moderators, only moderated four of the same personality-outcome associations, which is a small subset of the total number of associations each moderated. Both moderated the relationships between Depression and Openness and unemployment, Openness and marriage, and Social Support and divorce, with, for example, those who have little social support and are older or whose parents had less education showing a greater protective effect than those who were younger or whose parents had more education (see Figures 3.4 and 3.5).

Moreover, some outcomes' associations with personality were more often moderated overall. For example, personality-unemployment associations were the most frequently moderated by any of tested moderators $(13.39 \%)$, while personality-education associations were the least frequently moderated $(3.57 \%)$. In addition to being one of the most frequent moderators overall, parental education (high school versus college) was the most frequent moderator of personalityunemployment associations, moderating the association between Neuroticism (OR $=1.05 ; 89 \%$ CI $[1.01,1.09] ; \tau_{22}=.03 ; 89 \%$ CI $\left.[.002, .07]\right)$, Openness $\left(\mathrm{OR}=.94 ; 95 \%\right.$ UI $[.91, .99] ; \tau_{22}=$ $.02 ; 89 \%$ CI $[.003, .06])$, Self-Esteem $\left(\mathrm{OR}=.93 ; 89 \%\right.$ CI $[.89, .98] ; \tau_{22}=.02 ; 89 \%$ CI $[.002$, $.07])$, Satisfaction with Life $\left(\mathrm{OR}=.93 ; 89 \%\right.$ CI $[.88, .98] ; \tau_{22}=.04 ; 89 \%$ CI $\left.[.003, .10]\right)$, Social Support $\left(\mathrm{OR}=.94 ; 89 \%\right.$ CI $[.89,1.00] ; \tau_{22}=.05 ; 89 \%$ CI $\left.[.003, .13]\right)$, and Depression $(\mathrm{OR}=$ $.05 ; 89 \%$ CI $[1.01,1.10] ; \tau_{22}=.03 ; 89 \%$ CI $\left.[.002, .07]\right)$. In other words, as is seen in Figure 3.7, which presents the simple effects of reliable moderators of personality-outcome associations, with the exception of Neuroticism, higher parental educational was protective against unemployment, particularly at higher levels of each characteristic. 
Similarly, some traits were more frequently moderated across events. Social Support was the most frequently moderated personality characteristic (12.50\%), despite having the smallest number of personality-outcome associations, while Optimism was the least frequently moderated trait $(2.68 \%)$. Social Support-outcome associations were also most frequently moderated by parental education, moderating the relationship between Social Support and childbirth (ORbeyond college $=.88 ; 89 \%$ CI $[.80, .96] ; \tau_{33 \text { beyond college }}=.08 ; 89 \%$ CI $\left.[.005, .24]\right)$, divorce (ORbeyond college $\left.=.89 ; 89 \% \mathrm{CI}[.80,1.00] ; \tau_{33 \text { beyond college }}=.05 ; 89 \% \mathrm{CI}[.004, .13]\right)$, unemployment $\left(\mathrm{OR}\right.$ college $=.94 ; 89 \% \mathrm{CI}[.89,1.00] ; \tau_{22}$ college $\left.=.05 ; 89 \% \mathrm{CI}[.003, .13]\right)$, and retirement $\left(\mathrm{OR}\right.$ college $\left.=.93 ; 89 \% \mathrm{CI}[.88, .99] ; \tau_{22 \text { college }}=.03 ; 89 \% \mathrm{CI}[.002, .11]\right)$.

Because of the mega-analytic framework of this study, it is the first to be able to examine the moderating effects of scale reliability and the interval between personality and outcome measurement. Reliability moderated only two (1.02\%) personality-outcome associations, between Social Support and mortality $(\mathrm{OR}=1.17,89 \% \mathrm{CI}[1.05,1.31])$ and unemployment (OR $=.88,89 \% \mathrm{CI}[.80, .97])$. In contrast, prediction interval moderated a larger percentage of personality-outcome associations although there does not appear to be a pattern in which outcomes or personality characteristics were most frequently moderated (see Figure 8). Moreover, there does not appear to be a clear pattern than in whether longer or shorter prediction intervals attenuated or exaggerated the personality-outcome associations. For example, for moving in with a partner, shorter intervals attenuated the effect at high levels of Depression and Social Support, while for childbirth, longer intervals attenuated the effect at low levels of Agreeableness, Conscientiousness, and Social Support. Thus, although the internal consistency of the scales used in each study had little impact on the robustness of those associations, the 
length of the period of time over which personality predicted outcomes appeared to have a larger effect on personality-outcome associations.

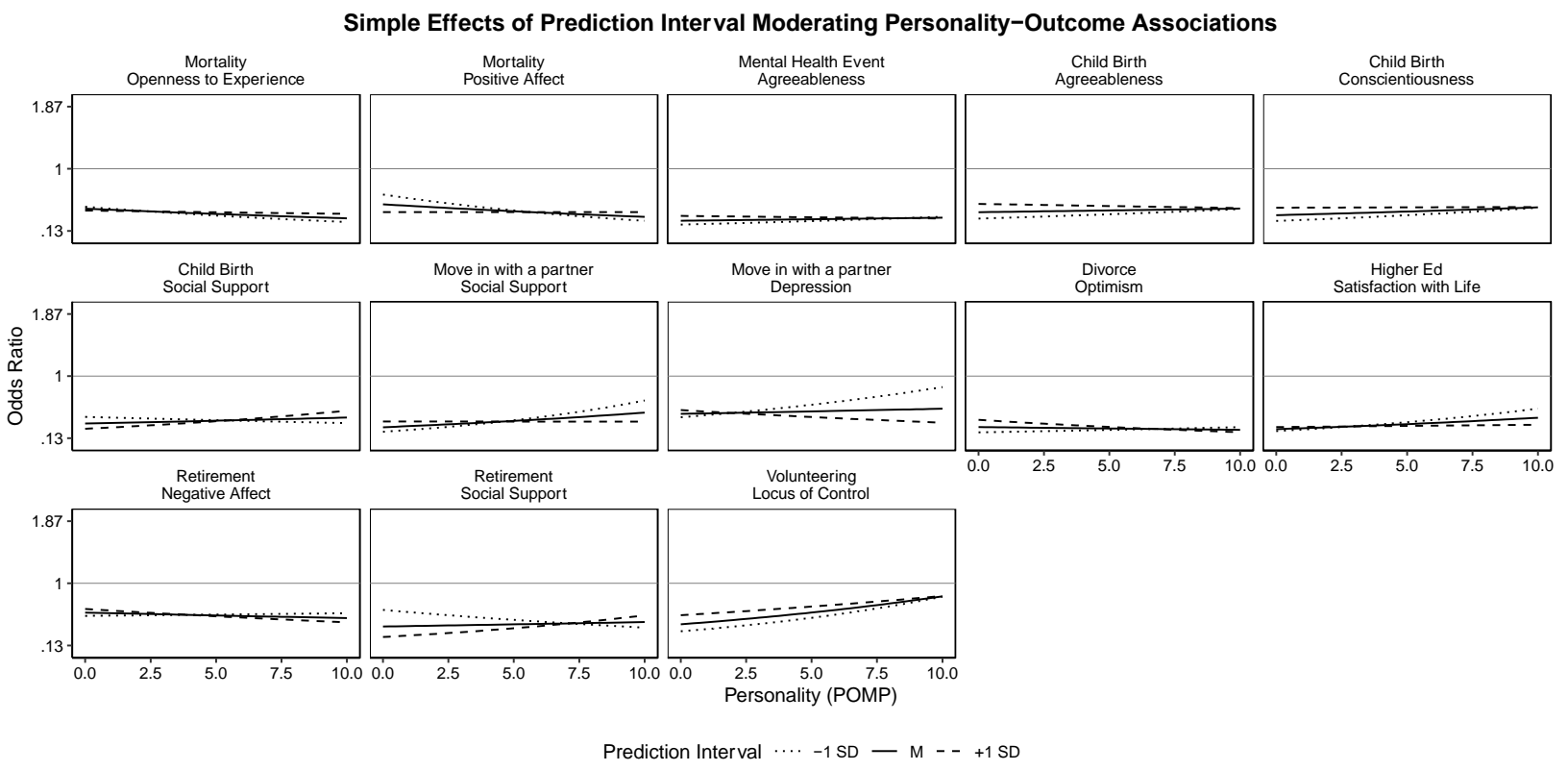

Figure 3.7. Simple effects of all personality-outcome associations that were reliably moderated by prediction interval. Each panel indicates a separate personality-outcome association in terms of the odds ratio associated with a particular personality score for different levels lengths of time between baseline personality and the last measurement of outcomes. Solid lines represent the mean prediction interval across studies, while dotted and dashed lines represent prediction intervals one standard deviation below and above the mean, respectively. Shaded regions represent the $89 \%$ credible interval around the fitted estimates. Personality characteristics are presented as Percentage of Maximum Possible (POMP), which ranges from 0-10 for each study, such that 10 represents the maximum possible score, while 0 represents the minimum possible score.

In sum, personality-outcome associations were relatively robust following matching, with nearly one-third of tested associations demonstrating reliable effects. In comparison, there were relatively few moderators of personality-outcome associations, suggesting that personality does reliably predict a number of outcomes across many of the tested moderators. Despite this, some moderators, like age and parental education (an indicator of SES) appear to more often moderate 
personality-outcome associations than others, with race and scale reliability moderating almost no personality-outcome associations.

\subsection{Study 2: Specification Curve Analysis}

Although using propensity score matching to control for selection bias and reverse causality gives one estimate of the robustness of personality-outcome associations, they cannot answer questions about which covariates used in the matching procedure may have been the most consequential in estimating the robustness of personality-outcome associations. Instead, I next turn to the specification curve analysis results for a second estimate of the robustness of personality-outcome associations as well as a search for key variables that influence the presence, direction, and magnitude of personality-outcome associations.

\subsubsection{Inferential Tests}

Specification curve analysis includes three permutation-based inference tests. Because the permuted curves are created by shuffling the scores on each personality characteristic (separately for each trait, outcome, and study combination), which retains the relationships between all covariates and outcomes, the observed personality-outcome associations in the permuted curves create a distribution of expected personality-outcome associations under the null of no personality-outcome association.

The permutation-based inference tests test the percentage of the 500 permutations in which (1) the median effect size of the observed specification curve is greater than the median effect size of each permuted curve, (2) the number of specifications of the dominant sign in the observed curve is greater than the number of specifications of the dominant sign in the permuted curve, and (3) the number of statistically significant specifications of the dominant sign in the observed curve is greater than the number of statistically significant specifications of the permuted curves. Each of 
these percentages can be treated as a " $p$-value" indicating whether the observed specification curve is more extreme than would be expected under the null. Because there are three tests, I will interpret personality-outcome associations with at least two $p$-values below threshold as somewhat robust and those with three $p$-values below threshold $(.05 / 3=.0167)$ as very robust.

The results of the three permutation-based inference tests for each personality-outcome combination are displayed in Table 3.5 as the percentage of permutations in which the permuted results were more extreme than the observed results. The full results, including numbers and counts of the median effect sizes, dominant signs, and statistically significant dominant signs of the observed curves, can be found in the online materials (https://github.com/emoriebeck/selection/tree/master/results/sca/inf_test). As is clear from the table, the overall results from the permutation-based tests suggest that personality-outcome associations are generally quite robust. Indeed, each personality-outcome association was robust on at least one of the inference tests. Of the 196 personality-outcome associations tested, 102 (52.04\%) were below a .0167 (.05/3) significance threshold on all three permutation tests (very robust), 44 (22.44\%) were below threshold on two of three permutation tests (somewhat robust), and the remaining $50(25.51 \%)$ were significant on only one permutation test (not robust).

Table 3.5

Results of the Permutation Based Inference Tests from Specification Curve Analyses

\begin{tabular}{|c|c|c|c|c|c|c|c|c|c|c|c|c|c|c|c|}
\hline e & Test & $\mathbf{E}$ & $\mathbf{A}$ & C & $\mathbf{N}$ & O & SE & OP & SWL & PA & NA & LOC & SS & IQ & DEP \\
\hline \multirow{3}{*}{ Mortality } & Median & 0.00 & 0.00 & 0.00 & 0.05 & 0.00 & 0.69 & 0.00 & 0.00 & 0.00 & 0.00 & 0.00 & 0.00 & 0.00 & 0.00 \\
\hline & Sign & 0.73 & 66 & 0.00 & 35 & 0.82 & 0.96 & 0.00 & 0.17 & 0.83 & 0.85 & 0.00 & 1.00 & 0.00 & 0.63 \\
\hline & cance & 0.00 & .00 & 0.00 & 0 & 0.00 & 0.00 & 0.00 & & & 0 & 00 & 0 . & 0 & 0.00 \\
\hline \multirow{3}{*}{$\begin{array}{r}\text { Major Health } \\
\text { Event }\end{array}$} & Median & 0.08 & 0.18 & 0.64 & & 0.06 & 0.00 & 0.00 & 0.66 & 0.00 & 0.00 & 0.00 & 0.00 & 0.02 & 0.00 \\
\hline & Sign & 0.53 & 0.72 & 0.91 & 9 & 0.59 & 0.54 & 0 . & & 0 & 0.00 & 0.00 & 0.40 & 0.00 & 0.00 \\
\hline & snificance & 0.00 & 0.00 & 0.00 & 0.00 & 0.00 & 0.00 & 0.00 & 0 & 0.00 & 0.00 & 0.00 & 0.00 & 0.00 & 0.00 \\
\hline \multirow{3}{*}{$\begin{array}{r}\text { Mental Health } \\
\text { Event }\end{array}$} & Median & 0.00 & 0.01 & 0.00 & 0.00 & 0.00 & 0.00 & 0.00 & 0.00 & 0.00 & 0.00 & 0.00 & 0.00 & 0.51 & 0.00 \\
\hline & Sign & 0.00 & 0.73 & 0.00 & 0.00 & 0.00 & 0.00 & 0.00 & 0.00 & 0.00 & 0.00 & 0.00 & 0.00 & 0.87 & 0.00 \\
\hline & Significance & $\mathbf{0 . 0 0}$ & 0.00 & 0.00 & 0.00 & 0.00 & 0.00 & 0.00 & 0.00 & 0.00 & 0.00 & 0.00 & 0.00 & 0.00 & 0.00 \\
\hline \multirow{2}{*}{ Child Birth } & Median & $\mathbf{0 . 0 0}$ & 0.41 & 0.00 & 0.25 & 0.20 & 0.40 & 0.00 & 0.00 & 0.00 & 0.01 & 0.00 & 0.00 & 0.01 & 0.44 \\
\hline & Sign & 0.00 & 0.64 & 0.00 & 0.80 & 0.77 & 0.79 & 0.00 & 0.00 & 0.52 & 0.72 & 0.00 & 0.00 & 0.59 & 0.87 \\
\hline
\end{tabular}




\begin{tabular}{|c|c|c|c|c|c|c|c|c|c|c|c|c|c|c|c|}
\hline \multirow{4}{*}{$\begin{array}{c}\text { Move in with } \\
\text { a partner }\end{array}$} & Significance & 0.00 & 0.00 & 0.00 & 0.00 & 0.00 & 0.00 & 0.00 & 0.00 & 0.00 & 0.00 & 0.00 & 0.00 & 0.00 & 0.00 \\
\hline & Median & 0.00 & 0.03 & 0.53 & 0.00 & 0.00 & 0.00 & 0.00 & 0.00 & 0.01 & 0.00 & 0.78 & 0.00 & 0.00 & 0.17 \\
\hline & Sign & 00 & 26 & .90 & 0 & .00 & 34 & & 22 & 58 & 33 & .91 & & 59 & 77 \\
\hline & Significance & .00 & .00 & .00 & 0 & .00 & 00 & & & 00 & .00 & .00 & 00 & 00 & 0.00 \\
\hline \multirow{4}{*}{ Marriage } & an & 00 & 00 & & & .00 & 29 & & & & & 00 & & 0 & .02 \\
\hline & Sign & 00 & 00 & 74 & 45 & 00 & 68 & 67 & & 85 & & 49 & 00 & 00 & .45 \\
\hline & Significance & 0 & 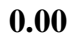 & & & $\mathbf{0}$ & & & & & & 0 & 0 & 0 & 00 \\
\hline & Median & .00 & .00 & .00 & 0.00 & 0.00 & 26 & 11 & 0 & 00 & 00 & 00 & 00 & 03 & 00 \\
\hline \multirow[t]{2}{*}{ Divorce } & Sign & 00 & .00 & .00 & 00 & 0.00 & 47 & 48 & & 00 & 00 & 00 & 00 & 85 & .46 \\
\hline & nificance & 00 & .00 & .00 & 00 & 0.00 & 00 & 00 & & 00 & 00 & 00 & 00 & 00 & 0.00 \\
\hline \multirow{4}{*}{$\begin{array}{r}\text { Child Moves } \\
\text { Out }\end{array}$} & ledian & 37 & .94 & .32 & 3 & 0.91 & 79 & & & & & & 75 & 87 & 0.00 \\
\hline & Sign & .61 & 0.80 & 0.85 & 0.72 & & & & & & & & 95 & 93 & 00 \\
\hline & Signi & 0.00 & 0.00 & 000 & & 0.00 & 0 & & & & & & & & \\
\hline & ledian & .06 & 61 & .00 & 8 & 0.00 & 05 & 0 & 02 & 33 & & .00 & 00 & 00 & 0.0 \\
\hline \multirow[t]{3}{*}{ Higher Ed } & ign & .71 & 0.94 & 0.72 & 1.00 & 0.00 & .72 & 00 & & .76 & .91 & .00 & 00 & 00 & 0.7 \\
\hline & cance & 0.00 & 0.00 & 0.00 & 0.00 & 0.00 & 0.00 & 00 & 0 & 00 & 0.00 & 00 & 00 & 00 & 0.0 \\
\hline & ian & .01 & 0 . & $\mathbf{0}$ & & 0.00 & 0 & & & & & 00 & 0 & 00 & 0.0 \\
\hline \multirow[t]{2}{*}{ First Job } & & & & & & & & & & & & & & & \\
\hline & S15 & 00 & & & & 0.00 & & & & & & & & & 0 \\
\hline \multirow{4}{*}{$\begin{array}{r}\text { Unemploy- } \\
\text { ment }\end{array}$} & Median & 0.00 & 0.00 & 0.00 & 0.00 & 0.00 & 0.00 & 0.00 & 0.00 & 0.00 & 0.00 & 0.00 & 00 & .00 & 0.0 \\
\hline & Sign & 0.00 & 0.00 & 0.00 & 0.00 & 0.00 & 0.00 & 0.00 & 0.00 & 0.00 & 0.00 & 0.00 & 00 & 00 & 0.0 \\
\hline & Significance & 0.00 & 0.00 & 0.00 & 0.00 & 0.00 & 0.00 & 0.00 & 0.00 & 0.00 & 0.00 & 00 & 0.00 & .00 & 0.0 \\
\hline & Median & 0.20 & 0.00 & 0.00 & 0.00 & 0.00 & 00 & 0.63 & 0 & 00 & 0.00 & 02 & $\mathbf{0 3}$ & .34 & 0.0 \\
\hline \multirow[t]{3}{*}{ Retirement } & ign & 0.84 & 0.00 & 0.00 & 0.97 & 0.00 & 0.90 & 0.88 & & 0.00 & & 00 & .00 & 96 & 0.0 \\
\hline & cance & & & 0.00 & & 0.00 & & & & & & 0.00 & & .00 & 0.0 \\
\hline & Median & 0.00 & 0.00 & 0.00 & 0.00 & 0.00 & $\mathbf{0 . 0 3}$ & 0.00 & & 0.00 & 0.00 & 0.00 & 0.00 & 0.00 & 0.0 \\
\hline \multirow[t]{3}{*}{ Volunteering } & Sign & 0.00 & 0.00 & 0.00 & & 0.00 & & & & & 0.00 & 0.00 & .00 & 0.00 & 0.0 \\
\hline & Significance & 0.00 & 0.00 & 0.00 & 0.00 & 0.00 & 0.00 & 0.00 & 0.00 & 0.00 & 0.00 & 0.00 & 0.00 & .00 & 0.0 \\
\hline & & 0.98 & & & & & & & & & & 0.00 & 0.00 & .01 & . \\
\hline \multirow[t]{2}{*}{ Criminality } & Sign & 0.89 & 0.00 & 0.00 & 0.00 & 0.00 & 0.00 & 0.93 & 0.00 & 0.00 & 0.00 & 0.00 & 0.00 & 0.00 & 0.0 \\
\hline & Significance & 0.00 & 0.00 & 0.00 & 0.00 & 0.00 & 0.00 & 0.00 & 0.00 & 0.00 & 0.00 & 0.00 & 0.00 & 0.00 & 0.0 \\
\hline
\end{tabular}

Note $:$ Median $=$ Percentage of permutations in which the raw median effect size of the dominant sign was larger than the permuted median effect size; Sign = Percentage of permutations in which the total number of raw specifications of the dominant sign was greater than permuted. Significance $=$ Percentage of permutations in which the total number of raw, significant specifications of the dominant sign was greater than the permuted.

Some outcomes and traits appeared to be more robust than others. Using the strongest inference criterion (all three permutation tests significant), outcomes were predicted by a median of 6 personality characteristics (range 2 to 14). For example, each of the 14 personality characteristic's association with unemployment was significant for each of the three permutation tests, suggesting that personality is highly predictive of unemployment overall. Similarly, volunteering was predicted by 13 personality characteristics (all but Self-Esteem) and criminal 
justice system contact (all but Extraversion and Optimism) and mental health events (all but Agreeableness and IQ) were predicted by 12 characteristics each. In contrast, having a child move out (2; Depression and Locus of Control) and starting a first job (3; Openness, IQ, and Optimism) were the least predictable outcomes.

Although the median number of outcomes personality characteristics predicted (7) was comparable to the median predictability of outcomes, the range was somewhat smaller. Only one personality characteristic very robustly predicted more than 10 outcomes, with Locus of Control predicting 11 of 14 outcomes (all except marriage, moving in with a partner, an starting a first job). The least predictive personality characteristic was self-esteem, which predicted only contact with the criminal justice system, a mental health event, and unemployment.

\subsubsection{Deconstructing Specification Curves}

The previously reported propensity score matched personality-outcome associations are ideal for controlling for selection bias and reverse causality. In other words, such analyses are meant to test whether baseline characteristics may explain personality-outcome associations. However, these models were less ideal for identifying which of those background characteristics were critical for the presence, direction, and magnitude of reliable personality-outcome associations.

Although a discussion of each of the 196 specification curves is beyond the scope of the current paper, a written analysis of each is available in the online materials and in the Specification Curve tab of the web application. Below, I outline the four most common patterns I observed in the curves: personality-outcome associations that were (1) robust across nearly all specifications, (2) robust across almost no specifications, and differed greatly across specifications with (3) unclear or (4) clear sources. In doing so, I examined each of the curves for a number of patterns. In the top panel I looked for instances in which an observed personality-outcome association (1) 
flipped signs, (2) flipped significance, or (3) had a cusp (i.e. an abrupt change in effect size). In the bottom panel, I looked for patterns of "blanks." In other words, I looked for patterns wherein effect sizes were clustered by the presence or absence of variables. Given the large number of specifications, if there were no blanks, this indicates there is no clear association between covariate inclusion and the presence, direction, and magnitude of an effect.

First, 18 of 196 (9.18\%) of personality-outcome associations were robust across most specifications regardless of which covariates were included. Similar to propensity score matched analyses, Social Support had a robust protective effect on divorce, such that individuals who reported more social support were less likely to get divorced across studies. As is clear in Figure 3.8, with the exception of models that did not control for key demographic variables (age, gender, race) and health behaviors (smoking, alcohol use), Social Support's protective effect on divorce was very reliable. 

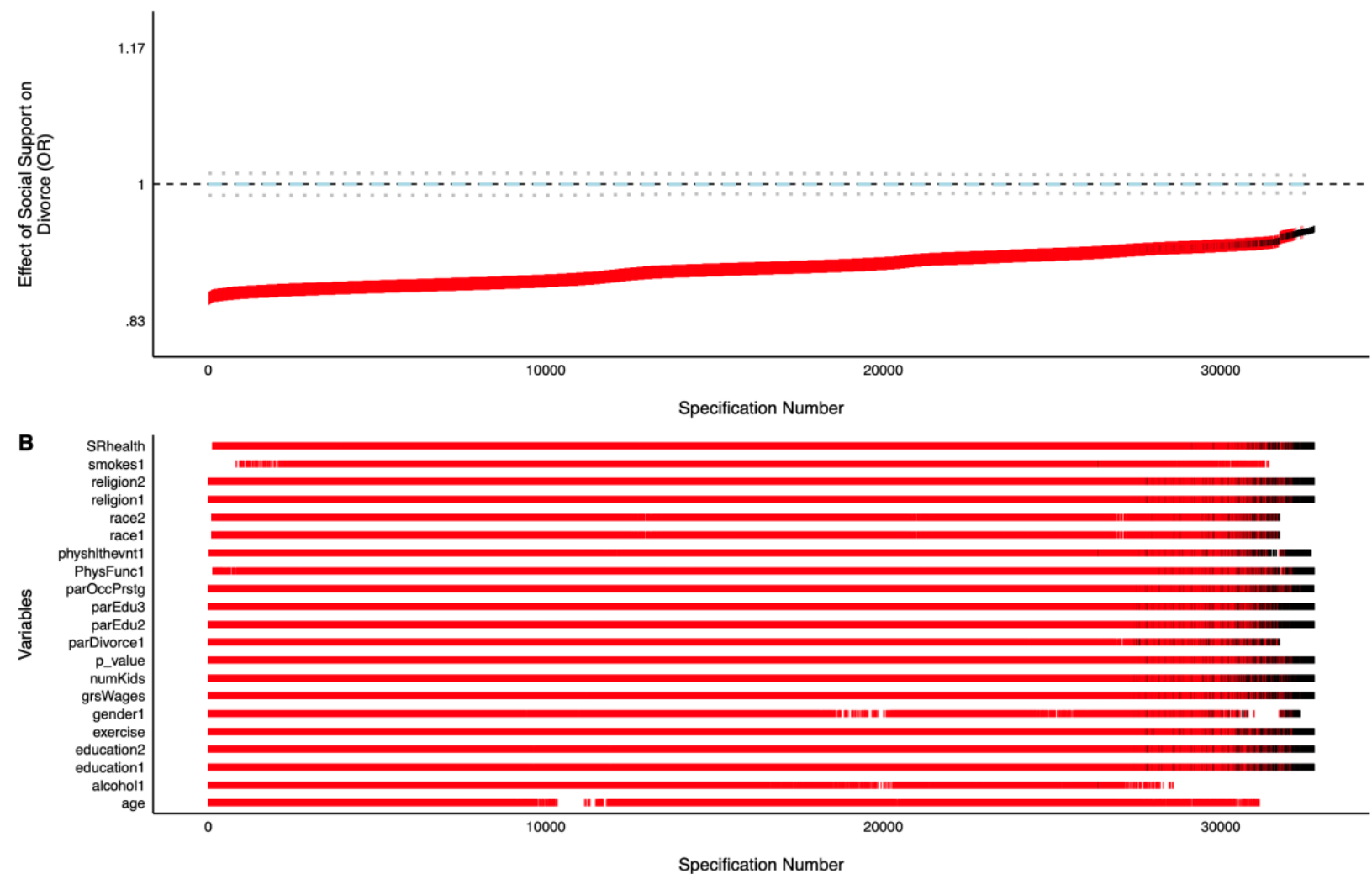

Figure 3.8. Specification Curve of mega-analytic estimates of Social Support predicting divorce across studies. The top panel displays the odds ratio associated with a one-unit change in personality level (operationalized as POMP, 0-10) from each specification arranged by the size of the odds ratio from low to high. The bottom panel displays the details of the specifications by indexing which covariates were included in each specification and the significance of the relationship between Social Support and divorce. Specifications with significant Social Supportdivorce effects ( $p<.05$, using cluster-corrected robust standard errors) are in red and indicated by longer lines.

Second, 60 of $196(30.61 \%)$ personality-outcome associations were not robust across any or most specifications, regardless of which covariates were included. For example, contrary to my expectations, Conscientiousness did not reliably predict a major health event across studies. As is clear in Figure 3.9, with very few exceptions, Conscientiousness was largely unassociated with major health events. As is also clear in the figure, the few exceptions were typically specifications that did not include self-rated health, BMI, and age, suggesting that any 
association between Conscientiousness and health events appear to be driven by health status and age. Indeed, looking closely at the curve, a small subset of associations that controlled for age, but not self-rated health or BMI, suggested a significant protective effect, while a small subset of specifications that did not control for race or age suggested a significant risk effect. Those that controlled for all four had a null, almost 0 effect. Such a pattern highlights the importance of which patterns of covariates are used. A few seemingly unimportant covariate omissions could have great consequences for the direction of the effect.

A

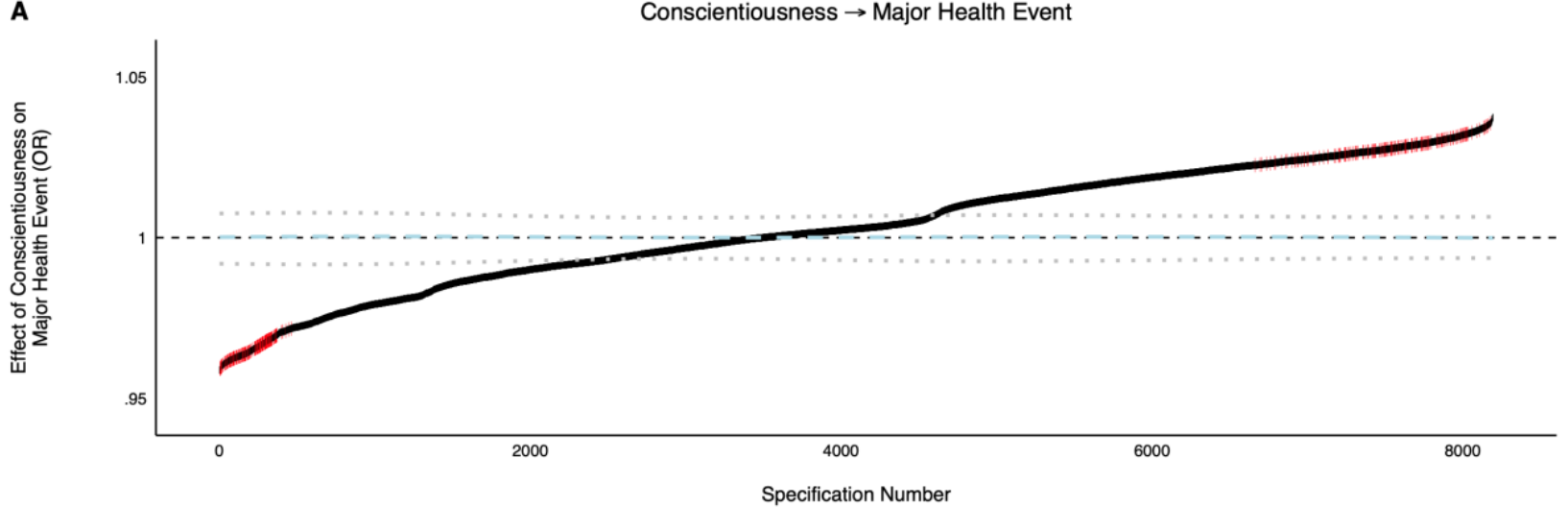

B

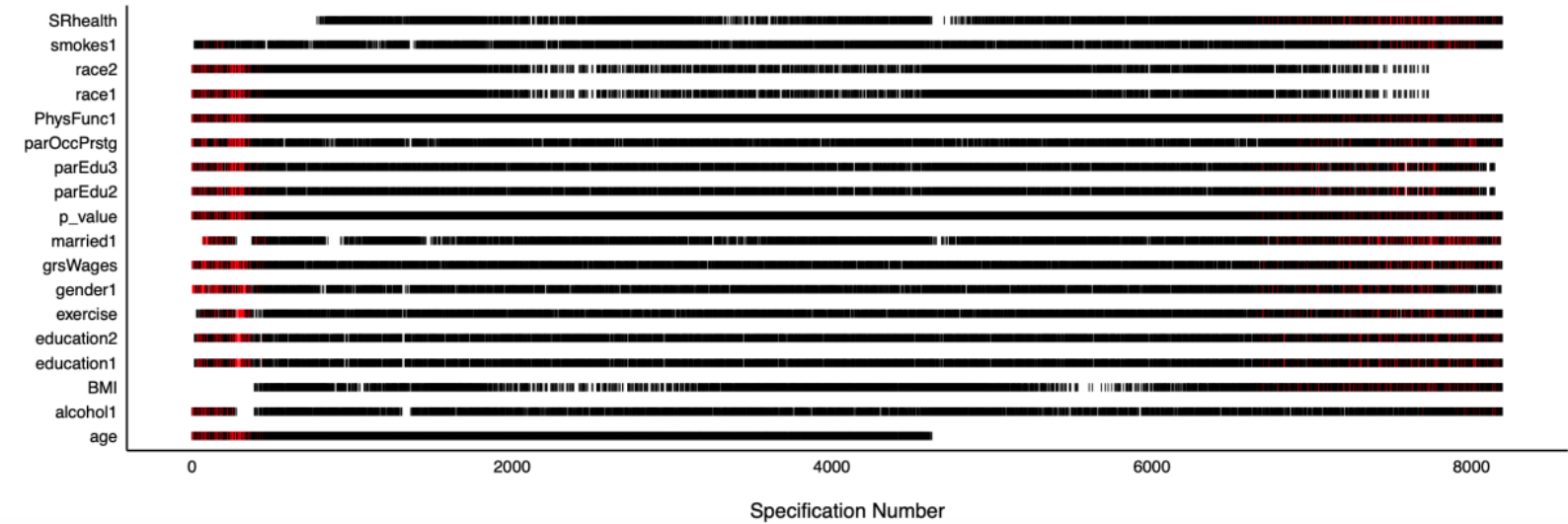

Figure 3.9. Specification Curve of mega-analytic estimates of Conscientiousness predicting a major health event across studies. The top panel displays the odds ratio associated with a oneunit change in personality level (operationalized as POMP, 0-10) from each specification arranged by the size of the odds ratio from low to high. The bottom panel displays the details of the specifications by indexing which covariates were included in each specification and the significance of the relationship between Conscientiousness and major health events. 
Specifications with significant Conscientiousness-major health event effects $(p<.05$, using cluster-corrected robust standard errors) are in red and indicated by longer lines.

Third, 16 of $196(8.16 \%)$ personality-outcome associations were differentially robust across specifications but demonstrated no clear pattern in what was driving such patterns. For example, although Self-Esteem demonstrated a largely robust protective effect on criminal activity across many specifications, there is no clear pattern indicating which covariates' inclusion may have been driving this, which is demonstrated by the mix of colors in each row in the lower panel of Figure 3.10. There are some indications that including age, education, and physical health do attenuate the results, which suggests that these variables may partially drive self-esteem's relationship to criminal activity. However, the personality-outcome associations are largely robust even when those are included, which ultimately leaves no clear pattern to explain the overall mixed pattern of results.

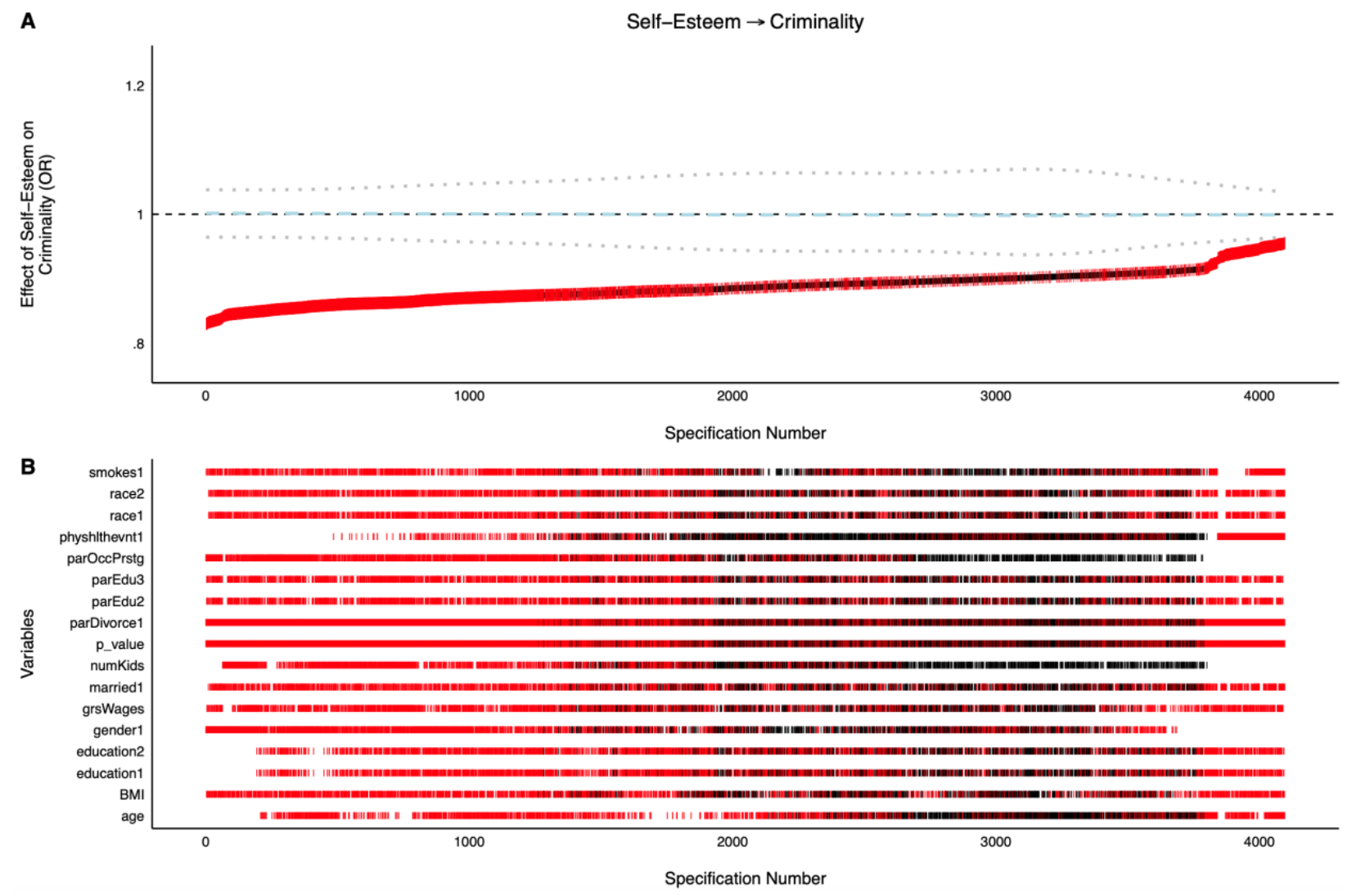


Figure 3.10. Specification Curve of mega-analytic estimates of Self-Esteem predicting contact with the criminal justice system across studies. The top panel displays the odds ratio associated with a one-unit change in personality level (operationalized as POMP, 0-10) from each specification arranged by the size of the odds ratio from low to high. The bottom panel displays the details of the specifications by indexing which covariates were included in each specification and the significance of the relationship between Self-Esteem and contact with the criminal justice system. Specifications with significant Self-Esteem-contact with the criminal justice system effects $(p<.05$, using cluster-corrected robust standard errors) are in red and indicated by longer lines.

Finally, nearly half (102 of 196, 52.04\%) of personality-outcome associations were differentially robust across specification but had clear sources of differential robustness. For example, Neuroticism did not predict mortality in the propensity score matched models, nor was it moderated by the moderators (e.g., age, gender, SES) that I tested. However, propensity score matching does not allow me to isolate which matched variables may be driving such results. But by examining the Neuroticism-mortality specification curve in Figure 3.11, it quickly becomes clear which covariates are consequential and influential. In the figure, there are two clear inflection points in the specification curve, both in terms of the magnitude (demonstrated by a jump in the size of the odds ratio) and significance of the effect (demonstrated by a change in the color the odds ratio in the figure). First looking at the portion of the curve to the far left before the first inflection point, there is a clear, protective association between Neuroticism and mortality. The curve tells us several important features of these results: (1) they do not control for age; (2) they do control for self-rated health; (3) they are most protective when also not controlling for gender and alcohol use but (4) controlling for gender seems to reduce the magnitude of the association more than alcohol use. Next, looking at the middle portion of the figure, in which only a small minority of associations were significant, there do not immediately appear to be specific covariates whose absence or presence influences whether Neuroticismmortality associations were significant. Instead, it appears that when controlling for most to all of 
the identified theoretically plausible covariates, the Neuroticism-mortality association is negligible and non-significant. Finally, looking at the far right of the curve, there are again a number of important features of the results that show that Neuroticism predicts higher odds of mortality: (1) they do control for age; (2) they do not control for self-rated health; (3) the association becomes stronger when controlling for gender; (4) they are strongest when not controlling for previous major health events and exercise. Thus, the summary from the full curve is that age and self-rated health appear to have the strongest consequences for the presence, magnitude, and direction of Neuroticism-mortality associations but that a number of other covariates, such as gender, alcohol use, major health events, and exercise.

A
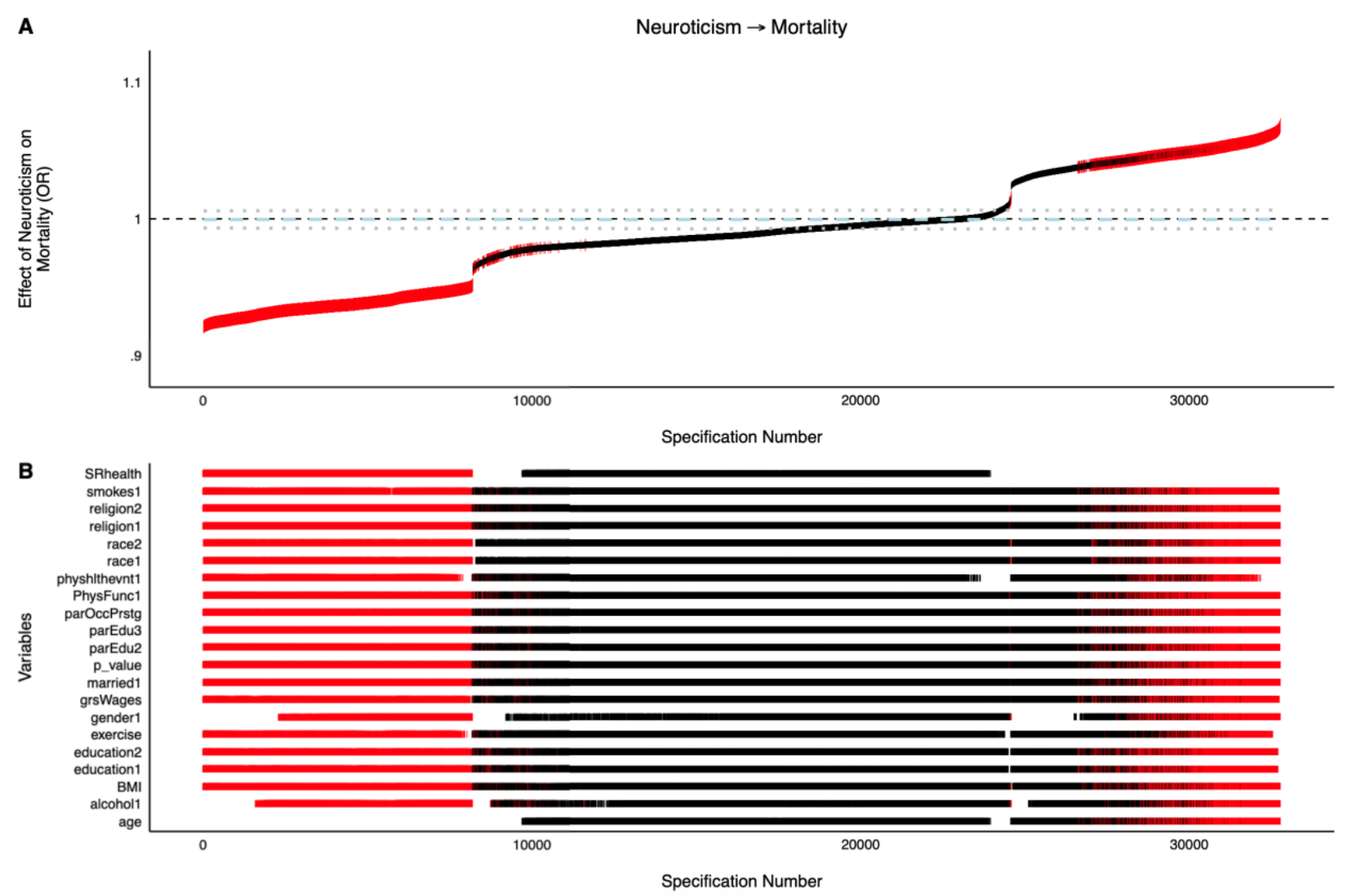

Figure 3.11. Specification Curve of mega-analytic estimates of Neuroticism predicting mortality across studies. The top panel displays the odds ratio associated with a one-unit change in personality level (operationalized as POMP, 0-10) from each specification arranged by the size 
of the odds ratio from low to high. The bottom panel displays the details of the specifications by indexing which covariates were included in each specification and the significance of the relationship between Neuroticism and mortality. Specifications with significant Neuroticismmortality effects ( $p<.05$, using cluster-corrected robust standard errors) are in red and indicated by longer lines.

In sum, specification curve analysis suggested slightly more than half (52.04\%) of personalityoutcome associations were robust across specifications. However, close examination of the curves suggests that there were different patterns in the specification curves, regardless of the robustness suggested by the permutation-based inference tests. Thus, the specification curve results suggest that (1) personality-outcome associations are quite robust but (2) patterns of covariate inclusion can be quite consequential for the presence, magnitude, and direction of observed personality-outcome associations. 


\section{Chapter 4: Discussion}

The present study examines the robustness and boundary conditions of personality prediction using 14 personality characteristics to predict 14 life outcomes across eight different person- and study-level moderators in 10 longitudinal panel studies in a mega-analytic framework coupled with propensity score matching to control for selection bias and specification curve analysis to test boundary conditions. In doing so, it is perhaps the most comprehensive test of personality prediction to date, both in scope and through the measures to taken to ensure that the estimates of personality-outcome associations were robust.

Despite using two techniques - propensity score matching and specification curve analysis - to make conservative estimates of personality prediction, the present study found that personalityoutcome associations were quite robust, with $32.65 \%$ of the tested propensity score matched personality-outcome associations being robust in the propensity score matching study, and $52.04 \%$ of the tested personality-outcome associations being robust in the permutation-based inference tests of specification curve analysis. Moreover, relative to main effects of personality prediction, there were fewer moderators of personality prediction, with just $6.70 \%$ of tested moderators significantly moderating personality-outcome associations - and nearly half of those moderators were age (19.04\%) and parental education (20.95\%).

Most of the observed personality-outcome associations were expected, such as Openness and Intelligence / Cognitive Ability predicting higher education and Social Support predicting lower odds of divorce. Others' presence and direction were unexpected, with, for example, Agreeableness predicting higher odds of divorce and Conscientiousness predicting mental health 
events in both the propensity score matched and specification curve studies. There are a number of reasons that the results in the present study may differ from previous studies.

First, although there have been a few previous mega-analyses of, for example, Big Five personality and mortality (Jokela et al., 2013), the present was the first large-scale mega-analysis of both a large number of personality characteristics and outcomes. Mega-analytic techniques have incredible power because they can combine sources of raw data and test mega-analytic and study-level effects. Moreover, instead of attempting to combine covariance matrices and test statistics from published studies, some of which may be based on the same raw data sources, as meta-analyses do, mega-analyses can directly test questions with assurance that the data were cleaned using consistent procedures and that covariates and moderators were tested systematically. As a result, the results of the present mega-analysis go above and beyond previous meta-analytic work demonstrating pooled personality-outcome associations by directly examining these associations.

Second, many previous investigations of personality prediction have been cross-sectional (e.g., Soto, 2019), which makes it impossible to determine whether personality predicts outcomes or whether life outcomes predict personality. However, using longitudinal data can help to tease apart the direction of such relationships. Indeed, the longitudinal nature of the data used in the present study allowed me to remove people who had previously experienced life outcomes. Because including people who had previously experienced tested outcomes confounds prediction with possible socialization effects of outcomes, the findings in the present study are likely more conservative than previous studies. Despite this, reducing the confound of previous events brings the results of study closer to how personality prediction unfolds. 
Third, I controlled for selection bias of other social, psychological, health, and demographic variables using propensity score matching. Given that individuals cannot be assigned to experience life outcomes, observational research suffers from the possibility that baseline differences among people who do and do not experience different outcomes may explain personality's relationship to them, rather than anything about the personality characteristics themselves. In the present study, using propensity score matching to control for baseline differences should result in estimates of personality-outcome associations that are more robust across samples than when unmatched. Thus, previously observed associations, such as those between Conscientiousness and Neuroticism and health, that were not found in the present study may indicate that selection bias partially explains why they have been observed in previous studies. In other words, health may have more of an impact on personality than vice versa.

Fourth, rather than choosing a subset of covariates, I tested the robustness of personality prediction across combinations of covariates using specification curve analysis. Given the huge number of covariates and pathways to which both personality and outcomes have been linked, a systematic test of which are most consequential to the direction, magnitude, and presence of personality-outcome associations is challenging, especially from a statistical inference standpoint. However, the often somewhat arbitrary choice of covariates in the previous literature has led to great heterogeneity in which covariates have been included across studies in ways that make determining consequential covariates by reviewing the literature likely impossible. But using specification curve analysis, I was able to use three permutation-based inferential tests to determine whether personality-outcome associations were robust across all possible patterns of covariates (see Simonsohn et al., 2015). Moreover, by examining the specification curves, I was able to make observations about which covariates were consequential to the direction, 
magnitude, and presence of personality-outcome associations. These observations have been collected into a set of key variables that are displayed in Table 4.1 along with significant moderators from the propensity score matching study. This table can be considered a minimal guideline as to which covariates should always be included tests of personality prediction for different personality-outcome associations but does not indicate that these are the only covariates that may be of interest. Researchers should continue to search for boundary conditions of prediction but using more methodical methods for doing so, such as those used in the present study. Indeed, the importance of covariate choices is highlighted across personality-outcome combinations, wherein some outcomes, like retirement, had consistent consequential covariates, like age and health, while others, like marriage, had less consistent consequential covariates across personality characteristics. 


\section{Table 4.1}

Significant Moderators of Propensity Score Matched Models and Critical Covariates of Specification Curve Analyses

\begin{tabular}{|c|c|c|c|c|c|c|c|c|c|c|c|c|c|c|c|}
\hline Outcome & Method & $\mathbf{E}$ & $\mathbf{A}$ & $\mathrm{C}$ & $\mathbf{N}$ & O & SE & OP & SWL & PA & NA & LOC & SS & IQ & DEP \\
\hline \multirow[t]{2}{*}{ Mortality } & PSM & $\begin{array}{l}\text { age } \\
\text { gender } \\
\text { parOccPrstg }\end{array}$ & gender & gender & & predInt & & & age & predInt & & & reliability & & \\
\hline & SCA & $\begin{array}{l}\text { age } \\
\text { SRhealth }\end{array}$ & $\begin{array}{l}\text { age } \\
\text { SRhealth } \\
\text { gender }\end{array}$ & $\begin{array}{l}\text { age } \\
\text { SRhealth }\end{array}$ & $\begin{array}{l}\text { age } \\
\text { SRhealth } \\
\text { gender } \\
\text { alcohol } \\
\text { physhlthevnt }\end{array}$ & $\begin{array}{l}\text { age } \\
\text { SRhealth }\end{array}$ & $\begin{array}{l}\text { SRhealth } \\
\text { age }\end{array}$ & $\begin{array}{l}\text { age } \\
\text { SRhealth }\end{array}$ & $\begin{array}{l}\text { age } \\
\text { SRhealth } \\
\text { alcohol }\end{array}$ & $\begin{array}{l}\text { age } \\
\text { SRhealth }\end{array}$ & $\begin{array}{l}\text { age } \\
\text { SRhealth } \\
\text { gender1 }\end{array}$ & $\begin{array}{l}\text { age } \\
\text { SRhealth } \\
\text { alcohol }\end{array}$ & $\begin{array}{l}\text { SRhealth } \\
\text { age } \\
\text { gender }\end{array}$ & $\begin{array}{l}\text { age } \\
\text { SRhealth }\end{array}$ & $\begin{array}{l}\text { age } \\
\text { SRhealth }\end{array}$ \\
\hline \multirow[t]{2}{*}{$\begin{array}{l}\text { Major Health } \\
\text { Event }\end{array}$} & PSM & parEdu & & age & & & & & age & & & parOccPrstg & $\begin{array}{l}\text { age } \\
\text { grsWages } \\
\text { parOccPrstg }\end{array}$ & parEdu & \\
\hline & SCA & $\begin{array}{l}\text { SRhealth } \\
\text { age }\end{array}$ & & $\begin{array}{l}\text { age } \\
\text { race } \\
\text { SRhealth } \\
\text { BMI }\end{array}$ & $\begin{array}{l}\text { age } \\
\text { race } \\
\text { SRhealth }\end{array}$ & $\begin{array}{l}\text { SRhealth } \\
\text { age }\end{array}$ & $\begin{array}{l}\text { age } \\
\text { SRhealth }\end{array}$ & $\begin{array}{l}\text { age } \\
\text { race } \\
\text { SRhealth }\end{array}$ & race & $\begin{array}{l}\text { race } \\
\text { age }\end{array}$ & $\begin{array}{l}\text { age } \\
\text { race } \\
\text { SRhealth }\end{array}$ & $\begin{array}{l}\text { SRhealth } \\
\text { age }\end{array}$ & $\begin{array}{l}\text { race } \\
\text { age } \\
\text { alcohol }\end{array}$ & $\begin{array}{l}\text { age } \\
\text { parOccPrstg } \\
\text { parEdu }\end{array}$ & \\
\hline \multirow[t]{2}{*}{$\begin{array}{l}\text { Mental Health } \\
\text { Event }\end{array}$} & PSM & & $\begin{array}{l}\text { parOccPrstg } \\
\text { predInt }\end{array}$ & & race & & parOccPrstg & age & age & & & & & $\begin{array}{l}\text { gender } \\
\text { grsWages }\end{array}$ & $\begin{array}{l}\text { gender } \\
\text { grsWages }\end{array}$ \\
\hline & SCA & $\begin{array}{l}\text { SRhealth } \\
\text { gender } \\
\text { age } \\
\text { alcohol }\end{array}$ & $\begin{array}{l}\text { age } \\
\text { SRhealth } \\
\text { gender1 }\end{array}$ & $\begin{array}{l}\text { age } \\
\text { SRhealth } \\
\text { gender1 } \\
\text { alcohol }\end{array}$ & SRhealth & $\begin{array}{l}\text { SRhealth } \\
\text { age }\end{array}$ & $\begin{array}{l}\text { SRhealth } \\
\text { age } \\
\text { exercise }\end{array}$ & & race & $\begin{array}{l}\text { SRhealth } \\
\text { race } \\
\text { physhlthevnt } \\
\text { PhysFunc1 }\end{array}$ & $\begin{array}{l}\text { race } \\
\text { parOccPrstg }\end{array}$ & parOccPrstg & race & $\begin{array}{l}\text { education } \\
\text { exercise } \\
\text { age }\end{array}$ & race \\
\hline \multirow[t]{2}{*}{ Childbirth } & PSM & parEdu & $\begin{array}{l}\text { age } \\
\text { predInt }\end{array}$ & $\begin{array}{l}\text { gender } \\
\text { parEdu } \\
\text { predInt }\end{array}$ & gender & parEdu & & & & & & parOccPrstg & $\begin{array}{l}\text { parEdu } \\
\text { predInt }\end{array}$ & & \\
\hline & SCA & $\begin{array}{l}\text { race } \\
\text { parDivorce }\end{array}$ & $\begin{array}{l}\text { age } \\
\text { parOccPrstg }\end{array}$ & $\begin{array}{l}\text { race } \\
\text { age } \\
\text { parDivorce } \\
\text { married } \\
\text { smoking }\end{array}$ & $\begin{array}{l}\text { age } \\
\text { gender } \\
\text { parOccPrstg }\end{array}$ & $\begin{array}{l}\text { race } \\
\text { parDivorce } \\
\text { parEdu }\end{array}$ & $\begin{array}{l}\text { parOccPrstg } \\
\text { gender }\end{array}$ & $\begin{array}{l}\text { age } \\
\text { physhlthevnt }\end{array}$ & $\begin{array}{l}\text { SRhealth } \\
\text { race } \\
\text { physFunc } \\
\text { parDivorce } \\
\text { age } \\
\text { smokes }\end{array}$ & $\begin{array}{l}\text { age } \\
\text { race } \\
\text { parDivorce }\end{array}$ & $\begin{array}{l}\text { race } \\
\text { grsWages } \\
\text { age }\end{array}$ & $\begin{array}{l}\text { smokes } \\
\text { physhlthevnt } \\
\text { exercise }\end{array}$ & $\begin{array}{l}\text { race } \\
\text { parDivorce }\end{array}$ & $\begin{array}{l}\text { parOccPrstg } \\
\text { exercise }\end{array}$ & $\begin{array}{l}\text { exercise } \\
\text { physhlthevnt } \\
\text { parOccPrstg }\end{array}$ \\
\hline \multirow[t]{2}{*}{$\begin{array}{l}\text { Move in with a } \\
\text { partner }\end{array}$} & PSM & & & $\begin{array}{l}\text { age } \\
\text { parOccPrstg }\end{array}$ & & gender & $\begin{array}{l}\text { age } \\
\text { gender } \\
\text { parOccPrstg }\end{array}$ & & parOccPrstg & & gender & & $\begin{array}{l}\text { predInt } \\
\text { race }\end{array}$ & & $\begin{array}{l}\text { gender } \\
\text { predInt }\end{array}$ \\
\hline & SCA & & age & $\begin{array}{l}\text { age } \\
\text { alcohol }\end{array}$ & $\begin{array}{l}\text { age } \\
\text { alcohol } \\
\text { race }\end{array}$ & $\begin{array}{l}\text { age } \\
\text { alcohol }\end{array}$ & $\begin{array}{l}\text { grsWages } \\
\text { age } \\
\text { race } \\
\text { parDivorce }\end{array}$ & $\begin{array}{l}\text { age } \\
\text { smokes } \\
\text { grsWages }\end{array}$ & alcohol & $\begin{array}{l}\text { age } \\
\text { parOccPrstg }\end{array}$ & $\begin{array}{l}\text { age } \\
\text { parOccPrstg }\end{array}$ & & $\begin{array}{l}\text { age } \\
\text { alcohol } \\
\text { race }\end{array}$ & $\begin{array}{l}\text { age } \\
\text { parOccPrstg } \\
\text { exercise }\end{array}$ & $\begin{array}{l}\text { age } \\
\text { parOccPrstg }\end{array}$ \\
\hline \multirow[t]{2}{*}{ Marriage } & PSM & & age & age & gender & $\begin{array}{l}\text { age } \\
\text { grsWages } \\
\text { parEdu }\end{array}$ & & & & parOccPrstg & parEdu & & & & \\
\hline & SCA & $\begin{array}{l}\text { age } \\
\text { alcohol }\end{array}$ & age & $\begin{array}{l}\text { age } \\
\text { alcohol } \\
\text { race } \\
\text { parOccPrstg }\end{array}$ & age & $\begin{array}{l}\text { age } \\
\text { race } \\
\text { parDivorce }\end{array}$ & age & $\begin{array}{l}\text { race } \\
\text { parDivorce } \\
\text { alcohol } \\
\text { age }\end{array}$ & parOccPrstg & $\begin{array}{l}\text { race } \\
\text { parOccPrstg } \\
\text { age }\end{array}$ & age & $\begin{array}{l}\text { age } \\
\text { parOccPrstg }\end{array}$ & $\begin{array}{l}\text { age } \\
\text { alcohol } \\
\text { smokes }\end{array}$ & $\begin{array}{l}\text { exercise } \\
\text { parEdu }\end{array}$ & $\begin{array}{l}\text { physhlthevnt } \\
\text { age }\end{array}$ \\
\hline \multirow[t]{2}{*}{ Divorce } & PSM & grsWages & & age & parEdu & parEdu & & predInt & & & age & & $\begin{array}{l}\text { age } \\
\text { parEdu }\end{array}$ & & race \\
\hline & SCA & $\begin{array}{l}\text { age } \\
\text { SRhealth }\end{array}$ & $\begin{array}{l}\text { grsWages } \\
\text { gender }\end{array}$ & $\begin{array}{l}\text { age } \\
\text { SRhealth }\end{array}$ & age & $\begin{array}{l}\text { SRhealth } \\
\text { age }\end{array}$ & $\begin{array}{l}\text { grsWages } \\
\text { alcohol } \\
\text { smokes }\end{array}$ & $\begin{array}{l}\text { SRhealth } \\
\text { alcohol }\end{array}$ & & & $\begin{array}{l}\text { race } \\
\text { parDivorce } \\
\text { age }\end{array}$ & alcohol & $\begin{array}{l}\text { age } \\
\text { gender } \\
\text { race } \\
\text { smokes } \\
\text { alcohol }\end{array}$ & $\begin{array}{l}\text { race } \\
\text { exercise } \\
\text { age }\end{array}$ & $\begin{array}{l}\text { parDivorce } \\
\text { race } \\
\text { physhlthevnt } \\
\text { exercise }\end{array}$ \\
\hline
\end{tabular}


Table 4.1
Significant Moderators of Propensity Score Matched Models and Critical Covariates of Specification Curve Analyses

\begin{tabular}{|c|c|c|c|c|c|c|c|c|c|c|c|c|c|c|c|}
\hline Outcome & Method & $\mathbf{E}$ & A & $\mathrm{C}$ & $\mathbf{N}$ & $\mathbf{O}$ & SE & OP & SWL & PA & NA & LOC & SS & IQ & DEP \\
\hline Child Moves & SCA & age & age & race & race & race & race & race & race & race & race & race & race & race & race \\
\hline Out & & & & age & $\begin{array}{l}\text { age } \\
\text { grsWages }\end{array}$ & & age & $\begin{array}{l}\text { age } \\
\text { numKids } \\
\text { grsWages }\end{array}$ & numKids & $\begin{array}{l}\text { age } \\
\text { numKids } \\
\text { grsWages }\end{array}$ & $\begin{array}{l}\text { age } \\
\text { grsWages } \\
\text { married }\end{array}$ & $\begin{array}{l}\text { age } \\
\text { education }\end{array}$ & $\begin{array}{l}\text { age } \\
\text { numKids }\end{array}$ & $\begin{array}{l}\text { parEdu } \\
\text { age } \\
\text { grsWages }\end{array}$ & age \\
\hline \multirow[t]{2}{*}{ Higher Ed } & PSM & & & gender & & & & & $\begin{array}{l}\text { gender } \\
\text { predInt }\end{array}$ & & & predInt & & & \\
\hline & SCA & age & $\begin{array}{l}\text { age } \\
\text { gender } \\
\text { parOccPrstg } \\
\text { numKids }\end{array}$ & $\begin{array}{l}\text { age } \\
\text { married } \\
\text { numKids } \\
\text { parOccPrstg }\end{array}$ & age & age & $\begin{array}{l}\text { age } \\
\text { physhlthevnt } \\
\text { parOccPrstg } \\
\text { numKids }\end{array}$ & $\begin{array}{l}\text { age } \\
\text { t parOccPrstg }\end{array}$ & $\begin{array}{l}\text { age } \\
\text { parOccPrstg } \\
\text { numKids }\end{array}$ & $\begin{array}{l}\text { age } \\
\text { parOccPrstg }\end{array}$ & $\begin{array}{l}\text { age } \\
\text { parOccPrstg } \\
\text { numKids }\end{array}$ & $\begin{array}{l}\text { physhlthevnt } \\
\text { parOccPrstg } \\
\text { numKids }\end{array}$ & $\begin{array}{l}\text { age } \\
\text { gender }\end{array}$ & $\begin{array}{l}\text { age } \\
\text { parOccPrstg } \\
\text { numKids }\end{array}$ & $\begin{array}{l}\text { numKids } \\
\text { parOccPrstg } \\
\text { physhlthevnt } \\
\text { age }\end{array}$ \\
\hline \multirow[t]{2}{*}{ First Job } & PSM & & & & & & & & & & & & & & \\
\hline & SCA & $\begin{array}{l}\text { race } \\
\text { parDivorce }\end{array}$ & age & $\begin{array}{l}\text { age } \\
\text { race } \\
\text { parDivorce }\end{array}$ & age & $\begin{array}{l}\text { race } \\
\text { age } \\
\text { parDivorce }\end{array}$ & age & $\begin{array}{l}\text { race } \\
\text { parDivorce } \\
\text { parEdu } \\
\text { parOccPrstg } \\
\text { age }\end{array}$ & $\begin{array}{l}\text { race } \\
\text { parOccPrstg } \\
\text { parDivorce }\end{array}$ & $\begin{array}{l}\text { parEdu } \\
\text { age } \\
\text { parOccPrstg }\end{array}$ & $\begin{array}{l}\text { age } \\
\text { parOccPrstg }\end{array}$ & physhlthevnt & $\begin{array}{l}\text { age } \\
\text { race } \\
\text { parDivorce }\end{array}$ & age & parOccPrstg \\
\hline \multirow[t]{2}{*}{ Unemployment } & PSM & grsWages & & age & $\begin{array}{l}\text { gender } \\
\text { parEdu }\end{array}$ & $\begin{array}{l}\text { age } \\
\text { parEdu }\end{array}$ & parEdu & & parEdu & $\begin{array}{l}\text { parOccPrstg } \\
\text { race }\end{array}$ & & & $\begin{array}{l}\text { parEdu } \\
\text { reliability }\end{array}$ & & $\begin{array}{l}\text { age } \\
\text { gender } \\
\text { parEdu }\end{array}$ \\
\hline & SCA & $\begin{array}{l}\text { age } \\
\text { married }\end{array}$ & & $\begin{array}{l}\text { age } \\
\text { married }\end{array}$ & $\begin{array}{l}\text { age } \\
\text { alcohol }\end{array}$ & age & & $\begin{array}{l}\text { age } \\
\text { alcohol }\end{array}$ & age & age & $\begin{array}{l}\text { age } \\
\text { parOccPrstg }\end{array}$ & & $\begin{array}{l}\text { race } \\
\text { age }\end{array}$ & age & $\begin{array}{l}\text { age } \\
\text { physhlthevnt } \\
\text { married }\end{array}$ \\
\hline \multirow[t]{2}{*}{ Retirement } & PSM & $\begin{array}{l}\text { age } \\
\text { grsWages }\end{array}$ & parEdu & parEdu & & $\begin{array}{l}\text { gender } \\
\text { grsWages }\end{array}$ & & & & $\begin{array}{l}\text { parEdu } \\
\text { predInt }\end{array}$ & predInt & & $\begin{array}{l}\text { parEdu } \\
\text { predInt }\end{array}$ & & \\
\hline & SCA & age & & $\begin{array}{l}\text { age } \\
\text { SRhealth } \\
\text { grsWages }\end{array}$ & $\begin{array}{l}\text { age } \\
\text { SRhealth } \\
\text { physhlthevnt } \\
\text { grsWages }\end{array}$ & $\begin{array}{l}\text { age } \\
\text { parEdu }\end{array}$ & $\begin{array}{l}\text { age } \\
\text { married } \\
\text { grsWages }\end{array}$ & SRhealth & $\begin{array}{l}\text { age } \\
\text { SRhealth } \\
\text { grsWages } \\
\text { married } \\
\text { numKids }\end{array}$ & $\begin{array}{l}\text { age } \\
\text { SRhealth } \\
\text { physhlthevnt } \\
\text { grsWages } \\
\text { exercise }\end{array}$ & $\begin{array}{l}\text { age } \\
\text { SRhealth } \\
\text { t physhlthevnt } \\
\text { grsWages }\end{array}$ & $\begin{array}{l}\text { age } \\
\text { physhlthevnt } \\
\text { t SRhealth }\end{array}$ & age & $\begin{array}{l}\text { age } \\
\text { SRhealth }\end{array}$ & $\begin{array}{l}\text { age } \\
\text { physhlthevnt } \\
\text { grsWages }\end{array}$ \\
\hline \multirow[t]{2}{*}{ Volunteering } & PSM & & & & & grsWages & & parEdu & race & & $\begin{array}{l}\text { gender } \\
\text { race }\end{array}$ & $\begin{array}{l}\text { grsWages } \\
\text { predInt }\end{array}$ & & race & \\
\hline & SCA & age & $\begin{array}{l}\text { SRhealth } \\
\text { parOccPrstg } \\
\text { age }\end{array}$ & $\begin{array}{l}\text { SRhealth } \\
\text { parOccPrstg } \\
\text { age }\end{array}$ & $\begin{array}{l}\text { age } \\
\text { SRhealth }\end{array}$ & $\begin{array}{l}\text { age } \\
\text { education } \\
\text { SRhealth }\end{array}$ & $\begin{array}{l}\text { parOccPrstg } \\
\text { age } \\
\text { education } \\
\text { gender } \\
\text { exercise }\end{array}$ & & $\begin{array}{l}\text { SRhealth } \\
\text { exercise }\end{array}$ & $\begin{array}{l}\text { SRhealth } \\
\text { parOccPrstg }\end{array}$ & age & $\begin{array}{l}\text { age } \\
\text { SRhealth } \\
\text { parOccPrstg }\end{array}$ & $\begin{array}{l}\text { age } \\
\text { physhlthevnt } \\
\text { SRhealth }\end{array}$ & $\begin{array}{l}\text { age } \\
\text { t parOccPrstg }\end{array}$ & $\begin{array}{l}\text { parOccPrstg } \\
\text { age } \\
\text { grsWages }\end{array}$ \\
\hline \multirow[t]{2}{*}{ Criminality } & PSM & & & & & & & & & & & & & & \\
\hline & SCA & $\begin{array}{l}\text { gender } \\
\text { race }\end{array}$ & $\begin{array}{l}\text { race } \\
\text { age } \\
\text { gender }\end{array}$ & $\begin{array}{l}\text { gender } \\
\text { race }\end{array}$ & $\begin{array}{l}\text { race } \\
\text { age }\end{array}$ & $\begin{array}{l}\text { marriage } \\
\text { age } \\
\text { gender }\end{array}$ & $\begin{array}{l}\text { physhlthevnt } \\
\text { gender } \\
\text { parOccPrstg } \\
\text { numKids }\end{array}$ & $\begin{array}{c}t \text { race } \\
\text { age }\end{array}$ & $\begin{array}{l}\text { smokes } \\
\text { married } \\
\text { grsWages }\end{array}$ & $\begin{array}{l}\text { parOccPrstg } \\
\text { numKids } \\
\text { smokes } \\
\text { age }\end{array}$ & $\begin{array}{l}\text { parOccPrstg } \\
\text { numKids } \\
\text { gender }\end{array}$ & $\begin{array}{l}\text { physhlthevnt } \\
\text { numKids } \\
\text { gender } \\
\text { parOccPrstg }\end{array}$ & $\begin{array}{l}\text { race } \\
\text { age } \\
\text { married }\end{array}$ & $\begin{array}{l}\text { age } \\
\text { smokes }\end{array}$ & $\begin{array}{l}\text { physhlthevnt } \\
\text { gender } \\
\text { age }\end{array}$ \\
\hline
\end{tabular}

PSM = Propensity Score Matched Models. SCA = Specification Curve Analyses. All variables indicate either significant moderators of personality-outcome associations in the propensity score matched study or critical covariates (in terms of direction, magnitude, and significance) in the specification curve analyses. 
Fifth, because of the mega-analytic framework used in the current study, I was able to test a large set of moderators, including age, gender, race, socioeconomic status (parental education, parental occupational prestige, and gross wages), scale reliability, and prediction interval. Two of these reliability and prediction interval - can only be tested using a meta-analytic or mega-analytic framework. Such a large set of moderators is rarely examined in a single study because of limitations of a single source of data. However, by pooling the data in a mega-analytic framework, the limitations of any single study can partially be overcome and a broader set of questions can be answered. For example, restricted ranges of age, such as is found in studies like HRS (primarily older adults) and NLSY (primarily younger adults), may give biased results because they are not representative. However, when coupled together, they create a more balanced and representative sample. In addition, by coupling the moderator analyses with propensity score matching, examinations of moderators in the present study exhibit the boundary conditions of personality prediction while controlling for the effect of all background covariates - except the target moderator - on the outcome.

In sum, the present study is perhaps the broadest and most rigorous test of personality prediction to date. By coupling a mega-analytic procedure with both propensity score matching and specification curve analysis, I addressed previous concerns about selection bias and reverse causality in order to better estimate the boundary conditions of personality prediction and found that personality remained a powerful predictor of outcomes. Moreover, I investigated the robustness of and consequential covariates of personality prediction using specification curve analysis, found personality prediction to be quite robust, and identified consequential covariates 
for each personality-outcome association. Together, these results paint a picture about the great power of personality prediction.

\subsection{Processes of Personality Prediction}

One reason that the choice of covariates and moderators when testing the robustness and boundary conditions of personality prediction is that these may shed light on the processes through which personality characteristics predict outcomes. Previous studies have investigated the pathways through which personality predicts health-related (e.g., Friedman et al., 1993; 1995; Hampson, 2012; Hampson et al., 2007), social and interpersonal (e.g., Neyer \& Lehnart, 2007; Neyer, 1999; Solomon \& Jackson, 2014), education- and work-related (e.g., Bodovski, 2010; Malouff et al. , 2010; Poropat, 2009) and societal outcomes (e.g., Clary et al., 1998; Donnellan et al., 2005), but the present study is the first to (1) control for these pathways using propensity score matching, (2) to test for patterns in the combinations of covariates that capture these pathways, and (3) to test whether a subset of these sociodemographic pathways moderate these associations. Although a full discussion of all pathways of tested personality-outcome associations is beyond the scope of the present study, below I detail a number of these pathways that were expected, unexpected, and contrary to expectations and discuss the implications for understanding pathways through which personality predicts outcomes.

\subsubsection{Health-Related Outcomes}

I examined four health-related outcomes: all-cause mortality, major physical health events, major mental health events (e.g., diagnosis of depression), and having a child, each of which were predicted by at least three personality characteristics in the propensity score matching study and at least four personality characteristics in the specification curve analysis study. Across the two approaches, most of these associations were consistent, suggesting that personality was a robust 
predictor of health-related outcomes, even when controlling for some of the key pathways through which it might do so.

Although some of the personality-health associations were expected, a number of personalityoutcome associations that were previously considered quite robust, such as the relationship between Conscientiousness and major health events, were not found in the current study. For example, although a myriad of previous studies (e.g., Friedman, 1993; 1995; Hampson et al,. 2013; Weston \& Jackson, 2015) have found that Conscientiousness supports health and longevity, the present study found that Conscientiousness was not a robust predictor of major health events using either propensity score matching or specification curve analysis. However, both approaches suggest that age may play perhaps the most important role in the relationship between Conscientiousness and health. In the propensity score matched study, Conscientiousness did not predict health, but was moderated by age, such that Conscientiousness had a larger protective effect against major health events among younger individuals in each study relative to older individuals. In the specification curve analysis study, specifications that did not control for age suggested that Conscientiousness was a risk factor for major health events, while specifications that did control for age suggested that Conscientiousness was a protective factor against major health events. In addition, the specifications in which the Conscientiousness-major health event association was strongest and most positive (i.e. predicted higher odds of a major health event) also did not control for participant race. Finally, although the proposed pathways through which Conscientiousness predicts health is thought to be through health behaviors, the health behaviors (or proxies of behavior, like BMI) examined in the current study (smoking, exercise, alcohol use, BMI, and physical functioning) did not appear to play consequential roles in the direction, magnitude, and presence of Conscientiousness-major health event associations. 
Together, these results indicate that the most important pathways through which Conscientiousness may predict health are through age and, to a lesser degree, race-related experiences, such as access to healthcare. In other words, it may be that the co-development of Conscientiousness and health / health risks throughout the lifespan that appears to drive the relationship between Conscientiousness and health, rather than the health behaviors that Conscientious individuals engage in (see also Jokela, Airaksinen, Kivimäki, \& Hakulinen, 2018).

In addition, relative to other health-related outcomes and to my expectations based on the published personality prediction literature, mortality was consistently predicted by relatively few personality characteristics in the current study. Across both approaches, only Optimism, Locus of Control, and Intelligence predicted mortality, all of which are aligned with previous studies (e.g., Gottfredson \& Deary, 2004; Kubzansky, Kubzansky, \& Maselko, 2004; Wurtele, Britcher, \& Saslawsky, 1985). Notably absent, however, were consistent associations between the Big Five personality traits as well as Negative and Positive Affect and Social Support. Moreover, there were few moderators of personality-mortality associations. Gender moderated the associations between Extraversion and Agreeableness with mortality, age moderated the relationship between Extraversion and Satisfaction with Life with mortality, and the prediction interval moderated the relationship between Openness and Positive Affect with mortality. In contrast, in the specification curves, self-rated health and age played the largest role, resulting in a cusp in effect sizes (e.g., a large positive or negative change in the effect size in the observed specification curves; see Figure 11) of personality-mortality associations for each of the 14 personality characteristics. Thus, contrary to expectations, nearly all of the expected pathways through which personality predicts mortality (i.e. health behaviors, social support, education, socioeconomic status) did not play a large role, with the exception of age, which largely 
attenuated personality-mortality associations. In other words, similar to major health events, it appears that the most consistent pathway through which personality predicts mortality may be through aging processes that affect both personality and health.

Mental health events were predicted by a large number of personality predictors using both propensity score matching and specification curves. As expected, Neuroticism, Negative Affect, and Depression were all positive predictors of mental health events, while Self-Esteem, Optimism, Satisfaction with Life, and Locus of Control were negative predictors of mental health events. Surprisingly, Positive Affect and Social Support were not protective against mental health events. When examining both the specification curves and moderator analyses, race and socioeconomic status variables appear to be the most consequential pathways through which personality predicted mental health events. For example, in the specification curves, not controlling for race greatly attenuated the relationship between depression and experiencing a mental health event. Statistically, this likely means that controlling for race reduces heterogeneity in the level of depressive symptoms associated with mental health events. Practically, this may suggest that Black individuals and other people of color are disproportionately at risk for experiencing mental health events, perhaps because of ongoing disparities in mental health care (e.g., Holley, Tavassoli, \& Stromwall, 2016).

In sum, a number of personality characteristics - both expected and unexpected - were reliable predictors of health-related outcomes. Despite this, many of the pathways through which personality appeared to predict health-related outcomes in the present study were related to age, rather than health behaviors, social support, and socioeconomic status, as expected. Given decades of evidence on the pathways through which personality predicts health through these pathways, these results suggest a need for broader and more nuanced investigations of the 
pathways through which personality predicts health-related outcomes using more representative and diverse studies.

\subsubsection{Social and Interpersonal Outcomes}

I also examined four social and interpersonal outcomes: moving in with a partner, marriage, divorce, and having a child move out of one's home. Across the propensity score matched and specification curve studies, a number of personality characteristics predicted moving in with a partner, marriage, and divorce, while no personality characteristic predicted having a child move out of one's home in both methods. Unlike with health-related outcomes, where a number of expected associations were notably absent, the personality-outcome associations for social and interpersonal outcomes were more in line with the published personality prediction literature.

The patterns of personality characteristics that predicted each outcome were different, which may be indicative of different pathways through which personality predicts these outcomes. For example, both moving in with a partner and marriage were predicted by Extraversion using both propensity score matching and specification curve analysis. However, Neuroticism, Openness, and Optimism were all positive predictors of moving in with a partner, while Agreeableness, Social Support, and Intelligence were all positive predictors of marriage. In other words, while Extraversion may be important across relationship stages, social support - both inside and outside one's marriage - and affiliative behaviors (e.g., Gottman et al., 1998) may be critical for relationship maintenance long-term.

Sociodemographic factors also appear to play a consequential role in the relationship between Optimism and marriage but not moving in with a partner. In the specification curve, both race and parental divorce appeared to affect the direction, magnitude, and significance of the association between Optimism and marriage. When controlling for parental divorce but not race, 
the association is largely negative. However, when both parental divorce and race are controlled for, the association remains largely positive. This may indicate an interplay between race and parental divorce such more Optimistic individuals are not uniformly more likely to marry. From the moderator analyses, it appears that white individuals who are more Optimistic are more likely to marry than Black individuals who are more Optimistic. It is possible that parental divorce exaggerates this effect. In contrast, for moving in with a partner, age-related processes appear to be the most consequential, demonstrating a strong attenuation of the relationship.

High levels of Depression and Social Support were more predictive of moving in with a partner over shorter than longer prediction intervals. It is possible that the reach of Depression and Social Support in predicting moving in with a partner is relatively short. The most likely explanation for why personality predicts outcomes over different intervals concerns the temporal stability of personality over time (see Hill, Edmonds, Jackson, 2019). Thus, if Depression and Social Support are less stable over time, then changes in them over time may influence the duration of time which a one-time measure of them predicts. In other words, personality change, as well as level, may be important in predicting distal outcomes.

Personality was also an important predictor of relationship dissolution. Using both propensity score matching and specification curve analysis, Agreeableness, Conscientiousness, and Negative Affect were risk factors for divorce, while Satisfaction with Life and Social Support were protective factors against divorce. That Agreeableness and Conscientiousness predicted higher odds of divorce was surprising given that both have been linked to lower odds of divorce in prior studies (e.g., Solomon \& Jackson, 2014a). The general pathway through which Agreeableness and Conscientiousness have generally been thought to predict relationship dissolution is through satisfaction (e.g., Solomon \& Jackson, 2014a; Watson et al, 2000), which I 
was unable to control for in the present study. However, given that overall Satisfaction with Life was negatively predictive of divorce, satisfaction does play a role in later relationship dissolution, and the precise pathway through which Agreeableness and Conscientiousness predict higher odds of divorce remains unclear.

Similar to moving in with and marrying a partner, sociodemographic factors, particularly, race and parental education, influenced the relationship between personality and divorce. Parental education moderated the relationship between Neuroticism, Openness, and Social Support and divorce, such that individuals whose parents had more education and were lower in Openness and Social Support or were higher in Neuroticism were more likely to get divorced. It may be that individuals whose parents had more education were more willing to dissolve their relationships because they had more economic and educational resources to fall back on. For race, Black individuals who were low in Depression were less likely to get divorced than white individuals, but Black individuals who were high in Depression were more likely to get divorced than white individuals. Similar to findings about race and mental health events discussed previously, it could be that disparities in mental health care result in more mental health-related stress in everyday life that may have consequences for relationships.

In sum, a number of personality characteristics predicted social and interpersonal outcomes, such as Extraversion predicting moving in with and marrying a partner and Social Support predicting lower odds of divorce. Despite this, a few associations, such as the positive association between Agreeableness and divorce, were in the opposite direction as expected. Sociodemographic factors appeared to play a role in relationship stages and dissolution, suggesting that these are critical pathways through which personality and relationships become associated, but more work 
is needed to disentangle sociodemographic effects from other processes through which personality may influence relationships, such as satisfaction.

\subsubsection{Education and Work Outcomes}

The current study examined four education- and work-related outcomes: completing higher education, starting a first job, becoming unemployed, and retiring. Previous research indicated that Extraversion, Conscientiousness, Neuroticism, Openness, Intelligence, Self-Esteem, Locus of Control and Depression (e.g., Bodovski, 2010; Deci \& Ryan, 1980; Malouff et al., 2010; Poropat, 2009; Watt \& Eccles, 2008) have been linked to educational and occupational outcomes. In the present study, I observed some associations between these personality characteristics and education- and work-related outcomes as well as between additional personality characteristics, like Satisfaction with Life and Social Support. Relative to other types of outcomes, education and work-related outcomes had the least consistent results across the two methods (propensity score matching and specification analysis). In addition, two of the workrelated outcomes, starting a first job and retiring were the least predictable outcomes in the present study, with no personality characteristics consistently predicting either across the two methods.

Across methods, Openness, Satisfaction with Life, and Intelligence were predictive of completing higher education. Unexpectedly, Conscientiousness and Locus of Control, two of the personality characteristics most consistently linked to education, were only robust in either the propensity score matching or specification curve analyses, respectively. Importantly, although prior studies suggested that the pathways between personality and education- and work-related outcomes are through the capacities to (Strenze, 2007), opportunities to (e.g., Traag et al., 2005), and willingness to perform (Blumberg \& Pringle, 1987; Poropat, 2009), moderator analyses in 
the propensity score matching study and patterns of covariates in the specification curve study suggest that the opportunities pathway was the most important pathway in the current study.

In particular, parental occupational prestige, race, and having kids played consequential roles in the direction and magnitude of relationships between personality characteristics and education in the specification curves. In general, controlling for parental occupational prestige and having children tended to attenuate the degree to which personality predicted higher education. For example, the specification curve for Locus of Control demonstrated a cusp in the curve when not controlling for parental occupational prestige in which the positive association between Locus of Control and higher education jumped. Similarly, the negative relationship between Positive Affect and higher education was almost completely attenuated when either parental occupational prestige or having kids were controlled for. Such a pattern also held for Extraversion, Agreeableness, Conscientiousness, Negative Affect, IQ, and Depression. Together, the attenuation of personality-higher education associations by parental occupational prestige and having kids could suggest that individuals with children may lack time to finish higher education and individuals whose parents have more prestigious occupations may have both for social and economic capital that makes finishing higher education easier. Alternatively, given that personality characteristics (e.g., Briley \& Tucker-Drob, 2014) and family environment (e.g., Plomin \& Bergeman, 1991; Plomin, 1994) are both quite heritable and even share patterns of heritability (Krueger, Markon, \& Bouchard, 2003), controlling for parental occupation may capture much of the shared variance between personality and educational outcomes.

Studies of Intelligence and race have a long and controversial history. Despite this, there is clear evidence that Black individuals and other people of color tend to have access to fewer opportunities than white individuals, including in education (e.g., Pitre, 2014). One way that this 
may occur is by lessening the positive or exaggerating the negative impact of personality in predicting outcomes. In the present study, Intelligence shows a much stronger relationship with education only when controlling for race. Likely, this is because race and opportunity factors, like SES, are often confounded, such that Intelligence opens more educational doors for white individuals than for Black individuals and other people of color.

The relationships between satisfaction and education and work have been tested both by looking at how education and work predict overall Satisfaction with Life as well as how they predict satisfaction specifically within the education and work domains (see Rice, Near, \& Hunt, 1980). In the current study, Satisfaction with Life was predictive both of higher odds of higher education and of lower odds of becoming unemployed, which suggests that satisfaction and education / work likely have reciprocal pathways wherein having a job or having education may be associated with higher satisfaction, but satisfaction, in turn, is also associated with completing higher education and keeping a job.

The opportunities pathway was also critical for understanding the relationship between personality and unemployment. Components of SES moderated the relationship between seven personality-unemployment relationships. Parental education moderated the relationship between Neuroticism, Openness, Self-Esteem, Social Support, Satisfaction with Life, and Depression and unemployment, parental occupational prestige moderated the relationship between Positive Affect and unemployment, and gross wages moderated the relationship between Extraversion and unemployment. Across each of these personality characteristics, higher parental education appears to be protective against unemployment at either the low (Self-Esteem, Satisfaction with Life, and Social Support) or high (Neuroticism, Openness, and Depression) extremes of personality characteristics. Higher gross wages were protective against unemployment at the 
high end of Extraversion. Finally, higher parental occupational prestige was a risk factor for unemployment among those with low Positive Affect. Moreover, in the specification curves controlling for education enhanced the positive relationship between Openness and unemployment. Together, these results suggest that (1) the opportunities afforded by education and socioeconomic status are important pathways through which personality predicts unemployment, but (2) personality is still a powerful predictor of unemployment, above and beyond these pathways.

Finally, no personality characteristics predicted retirement using both methods, and the moderator results of the propensity score matching study did not align with the patterns of covariates in the specification curve analysis study. For example, in the specification curves, age was consistently the most consequential covariate, but in the propensity score matching study, age moderated only the association between Extraversion and retirement. In addition, parental education moderated the relationship between Agreeableness, Conscientiousness, Positive Affect, and Social Support and retirement, and gross wages moderated the relationship between Extraversion and Openness and retirement. However, no SES covariates played consequential roles in the specification curve study for retirement. In the specification curve study, the lack of SES contributors and general lack of clear patterns through which personality predicted retirement may indicate that simply controlling for age does not eliminate the complex pathway through which personality and retirement become associated through age.

In the current study, personality was a powerful predictor of education and unemployment but a less clear predictor of starting a first job and retirement. For education and unemployment, pathways of opportunities appear to be greatly consequential for personality prediction. However, for retirement, there does not appear to a clear pattern of moderators or covariates that 
elucidate the pathways through which personality predicts retirement. Finally, the prediction of starting a first job was weak overall, which may be due to small sample sizes of individuals in each study who both had baseline personality and started a first job after that period.

\subsubsection{Societal Outcomes}

Finally, the present study examined two societal outcomes: contact with the criminal justice system and volunteering. Overall, volunteering appears to be much more predictable than contact with the criminal justice system across the two methods. Moreover, which personality characteristics predicted volunteering and contact with the criminal justice system was more consistent for volunteering.

Across both the propensity score matched and specification curve analysis studies, Agreeableness, Optimism, Satisfaction with Life, Locus of Control, and Intelligence were positive robust predictors of volunteering, while Negative Affect was a robust negative predictor of volunteering. Although a number of these associations were moderated in the propensity score matching study or had consequential covariates in the specification curve study, which moderators and covariates were consequential was not consistent across methods. For example, although gross wages moderated the relationship between Locus of Control and volunteering in the propensity score matching study, self-rated health and age were the two most consequential covariates in the specification curve analysis. Similarly, although race moderated the relationship between Satisfaction with Life and volunteering, self-rated health and exercise were the two most consequential covariates. Indeed, across the specification curves, age and health-related covariates - like self-rated health and exercise - and parental occupational prestige were consistently the most consequential covariates, while across the moderator analyses, parental education and race were the most frequent moderators. Given that age and health-related 
covariates appeared to share common variance and that I did not test any health-related moderators, this may suggest that health issues act as a boundary against volunteering for individuals with personality characteristics typically associated with volunteering.

Although I expected Conscientiousness, Locus of Control, and Depression to predict contact with the criminal justice system (Alihn, 2014; Bechtold et al., 2014; Kofler et al., 2011), the only association that was both significant in the propensity score matching study and consistent across both studies was Agreeableness predicting lower odds of contact with the criminal justice system. Moreover, there were no moderators of the association between personality and contact with the criminal justice system. This likely suggests that in many cases, the relationship between personality and contact with the criminal justice is through the background characteristics in the propensity score matching study. Indeed, the pattern of consequential covariates bolsters such a proposition. Across personality characteristics, the most common and consistent consequential covariates were age, gender, SES indicators (parental education, parental occupational prestige, and gross wages), and race. In many cases, controlling for these variables attenuated the relationship between personality and contact with the criminal justice system, suggesting that the covariate and personality characteristic had overlapping variance they also shared with the outcome. However, in others, such as the relationship between Social Support and contact with the criminal justice system, controlling for these sociodemographic characteristics increased the magnitude of the relationship. In this case, this likely means that Social Support's relationship to contact with the criminal justice system differs across these sociodemographic characteristics. Together, these results suggest that these sociodemographic characteristics may play a more important role in predicting contact with the criminal justice system than personality. 
The two societal outcomes examined in this study stood at two extremes, with volunteering being one of the most predictable outcomes and contact with the criminal justice system being one of the least predictable. Despite this, the heterogeneity in the observed pattern of associations suggests that there are likely many pathways through which personality predicts these societal outcomes.

\subsubsection{Scale Reliability and Prediction Interval}

Given the mega-analytic nature of the present study, it is one of the first to be able to examine how the reliability of a personality scale and the prediction interval between personality and outcome measurement may impact observed personality-outcome associations.

Personality tends to exhibit great test-retest consistency across days, weeks, months, years, and even decades (Damien, Spengler, Sutu, \& Roberts, 2019; Edmonds, Goldberg, Hampson, \& Barckley, 2013; Fraley \& Roberts, 2005; Roberts \& DelVecchio, 2000). As such, there is good reason to think that personality should predict outcomes over long time frames. However, because test-retest consistency does decrease over longer time intervals before reaching a nonzero asymptote (Fraley \& Roberts, 2005; Roberts \& DelVicchio, 2000), there is also good reason to expect the magnitude of personality-outcome associations to decrease.

Personality stability is important, as it may be one mechanism through which personality influences later outcomes, through the opportunities and snares personality provides (Hill, Edmonds, \& Jackson, 2019). Individuals who are less consistent may have fewer opportunities and more snares because they may enact fewer behaviors that lead to positive outcomes or protect against negative ones. In the present study, I found, for example, that higher levels of Depression and Social Support were less predictive of moving in with a partner over shorter intervals than longer intervals, while lower levels of Agreeableness were more predictive of 
having a child over shorter intervals than longer intervals. This could indicate that high levels of Depression and Social Support and low levels of Agreeableness are less stable, which makes them less predictive of outcomes. Indeed, evidence that changes in personality predict outcomes like mortality (e.g., Mroczek \& Spiro, 2007) and health (e.g., Turiano et al., 2012) bolsters the importance of understanding how personality stability influences personality-outcome associations.

The present study found almost no evidence that scale reliability moderated personality-outcome associations. This could indicate that reliability of a scale is not consequential to prediction. However, a brief consideration of what scale reliability does (and does not) capture suggests a different alternative. Scale reliability has been at the heart of personality psychology since its emergence as a discipline (Cronbach, 1951; Spearman, 1904; Lord, 1955; see Revelle \& Condon, 2019 for a review). Because personality is a study of psychological constructs, the study of psychometrics emerged to delineate procedures for defining psychological measurement with good properties.

Scale reliability, in particular, is meant to capture the internal consistency of a scale, or how closely items within a scale are related to one another, under the premise that items that are more related are assumed to capture the same construct. Despite this, most of the procedures that have been developed for scale development and testing scale reliability tend to favor longer scales. Thus, two scales with equivalent reliabilities but different lengths (e.g., 3 items versus 15) may have different relationships to prediction. In this case, the bandwidth of item content in the short scale is likely much narrower than the bandwidth of item content in a longer scale. As a result, even if these two scales are thought to capture the same construct, the shorter scale may capture only a subset of the content of the larger scale. In prediction, to the extent that what is not 
common to the two scales is associated with an outcome, then reliability would not be expected to moderate the scales, as it would erroneously assume the two scales were equivalent. Thus, to understand the interplay between scale length and reliability may require examining how each influence personality-outcome associations, if at all. And scale development should balance the tradeoffs associated with broad long personality questionnaires with overly broad coverage that make it difficult to understand personality-outcome associations and overly short measures that may underestimate personality-outcome associations (Credé, Harms, Niehorster, \& GayeValentine, 2012; Jackson \& Paunonen, 1985; Paunonen \& Jackson, 1985).

\subsubsection{Pathway Heterogeneity}

Across health-related, social and interpersonal, education- and work-related, and societal

outcomes, the most consistent pattern was that the pathways through which both personality and outcomes unfold, both separately and together, are complex, multiply determined, and heterogeneous. In other words, there are different pathways to the same outcomes and similar pathways to different outcomes. As a result, capturing how such pathways unfold across people may be very difficult, in part because most pathways propose dynamic pathways that unfold over time.

For example, one frequent attempt to understand heterogeneity in pathways is by examining how personality characteristics may interact, such as the pathway through so-called "healthy Neuroticism” (Turiano, Mroczek, Moynihan, \& Chapman, 2013; Weston, Hill, Edmonds, Mroczek, \& Hampson, 2019; Weston \& Jackson, 2015), or the idea that a combination of both high Neuroticism and high Conscientiousness may be protective for health even though high Neuroticism is usually associated with worse health. Given that individuals high in Conscientiousness tend to engage in more health behaviors (e.g., Hampson, Goldberg, Vogt, \& 
Dubanoski., 2007) and that individuals high in Neuroticism tend to be highly vigilant in noticing bodily changes (e.g., Friedman, 2000), healthy Neuroticism could manifest as vigilance coupled with health behaviors to mitigate the noticed changes in one's health. Thus, someone high in both Conscientiousness may notice a stomach pang and see a physician to have it checked out, allowing a chronic stomach issue to be caught and treated earlier, while someone with high Conscientiousness alone may be less likely to notice such changes and someone with high Neuroticism alone may be unlikely to see their physician when a change is noticed. Investigations that have examined healthy Neuroticism have largely done so by examining whether the interaction of overall levels of personality characteristics predict health and have found largely null results. But the timing of how these two characteristics unfold may be critical in understanding how healthy Neuroticism manifests, if it exists. For example, healthy Neuroticism may manifest as individuals who are worried about their health. When they worry about their health, they engage in positive health behaviors, which reduces their worry. Together, both this reduction in worry and the performance of positive health behaviors may result in better health. In contrast, others may not experience a reduction in worry after engaging in health behaviors, which may mitigate any positive benefits those behaviors have in the long term. Although from average, overall level perspective, these individuals may be difficult to distinguish, these time-dependent patterns provide crucial information about the pathways through which they unfold.

Thus, in order to truly understand the pathways through which personality predicts distal outcomes will likely require a much narrower scope than broad personality characteristics alone can afford. Instead, to truly understand how the processes through which personality unfold may require shifting from a between-person perspective on personality traits (a variable-centered 
approach) to a within-person, idiographic perspective on personality (a person-centered approach; Beck \& Jackson, 2020ab; Jackson \& Beck, 2020). An idiographic perspective may help shed light on the timing and patterning of behaviors influences health (Jackson \& Beck, 2020), mental health and well-being (Beck \& Jackson, 2020c; Jackson \& Beck, 2020), work performance (Saef, Beck, \& Jackson, 2020), and personality consistency (Beck \& Jackson, 2020cd) in ways that will help elucidate between-person differences as well.

Thus, outcomes are complex and multiply determined phenomena. As such, to understand why they arise first requires using approaches that can capture the heterogeneity in pathways through which they occur, rather than assuming that individuals should traverse similar pathways. Importantly, this does not discount the importance of broad personality in predicting outcomes. Rather, it highlights the utility of between-person characteristics for prediction and description and the need for more focus on within-person phenomena in order to understand why consistent patterns of between-person phenomena arise.

\subsection{Limitations}

Although the present study pushes the study of personality prediction forward, there are a number of limitations.

First, all studies are as limited as their data are. Each of the samples used herein have great strengths, including their sample size, comprehensiveness, and longitudinal nature. Moreover, different studies have different strengths, including full lifespan samples, samples that are representative for race, gender, and socioeconomic status, and so on. Although using a megaanalytic approach to pool together the samples and get overall estimates as well as study-specific 
estimates, these are statistical corrections that can never completely compensate for shortcomings of the data.

Second, for many of the outcomes, a number of different outcomes, including different major health events, different types of volunteering, and different types of contact with the criminal justice system, were lumped into a single outcome measure. This may mask associations between personality and outcomes to the extent that different outcomes grouped under a single header have different pathways that connect them to personality. Future studies should use a similar approach to examine more nuanced outcomes to test the degree to which this is true.

Third, because not all studies collected information on each of the personality, moderator, covariate, and outcome variables, some personality-outcome combinations ultimately had relatively small numbers of studies available to test them, which limits the reliability of their findings. Despite this, the sample sizes remained large enough to ensure adequate statistical power, but power cannot correct real cross-study differences in the effect. Thus, particularly for personality-outcome associations that had few available studies to test them, such as Optimism and retiring or Intelligence and education, follow-up studies targeting samples that include these variables will offer better estimates of these associations.

Fourth, the present study used 10 longitudinal panel studies to examine personality-outcome associations based on their availability, size, and the presence of a number of target personality and outcome measures. However, there are many more available samples that were not used in the present study but that could be used to examine personality-outcome associations even more robustly and to help delineate the processes and boundary conditions of personality prediction. 
Fifth, using propensity score matching to control for selection bias in personality prediction partially alleviates concerns about reverse causality. However, only looking at personality prediction only examines half of the reverse causality - how personality predicts outcomes - and does not examine how outcomes may influence personality. The available literature that both looks at personality prediction as well as socialization effects of outcomes on personality appear to suggest that personality's power on outcomes is stronger than outcome's power on personality (see Jackson et al., 2012; van Scheppingen et al., 2015) but mega-analytic estimates of the robustness of these patterns are needed, particularly for socialization effects.

Sixth, the significance test of the permutation-based inference tests appeared to lack sensitivity, as each of the 196 tested associations were below threshold. As is clear in the specification curves in Figures 8 to 11 and in the online materials, permuted personality-outcome associations tended to be centered around an odds ratio of 1, suggesting no association, while observed values tended to vary across specifications, with a small number being significant in each. Thus, in this case, the significance permutation test seems to reflect the general tendency for personalityoutcome associations to be significant above chance levels, which does not necessarily mean the association is generally robust across different specifications and should be interpreted accordingly.

Finally, although I endeavored to delineate some of the pathways through which personality and outcomes are associated, neither the propensity score matching procedure nor the specification curve analysis procedure could identify the precise pathways through which this occurs. Other analytic procedures, like path analysis, may be more appropriate for testing specific pathways. Because path analysis can be coupled with propensity score matching and specification curve 
analysis, future studies can use these methods to better estimate the robustness of these pathways.

\subsection{Conclusion}

The present study was the first to mega-analyze a broad range of personality-outcome associations using propensity score matching and specification curve analysis to test their robustness and boundary conditions. Using both techniques, which provide conservative estimates of personality-outcome associations, I found that personality prediction, even over

decades, was quite robust - across studies, personality characteristics, outcomes, moderators, and covariates. Personality is a powerful predictor of life outcomes. 


\section{References}

Ahlin, E. M. (2014). Locus of control redux: Adolescents' choice to refrain from violence. Journal of Interpersonal Violence, 29(14), 2695-2717.

Barrick, M. R., Mount, M. K., \& Judge, T. A. (2001). Personality and performance at the beginning of the new millennium: What do we know and where do we go next? International Journal of Selection and Assessment, 9 (1-2), 9-30.

Beck, E. D., \& Jackson, J. J. (2020a). Idiographic traits: A return to Allportian approaches to personality. Current Directions in Psychological Science, 29(3), 301-308.

Beck, E. D. \& Jackson, J. J. (2020b). Within-person variability. In Rauthmann, J., editor, Handbook of Personality Dynamics and Processes. Elsevier, 1st edition.

Beck, E. D., \& Jackson, J. J. (2020c). Consistency and change in idiographic personality: A longitudinal ESM network study. Journal of Personality and Social Psychology, 118(5), 1080-1100.

Beck, E. D. \& Jackson, J. J. (2020d). Consistency of idiographic personality in the wake of COVID-19: A longitudinal ESM study. Manuscript under review.

Bechtold, J., Cavanagh, C., Shulman, E. P., \& Cauffman, E. (2014). Does mother know best? Adolescent and mother reports of impulsivity and subsequent delinquency. Journal of Youth and Adolescence, 43(11), 1903-1913.

Blatier, C. (2000). Locus of control, causal attributions, and self-esteem: A comparison between prisoners. International Journal of Offender Therapy and Comparative Criminology, 44(1), 97-110.

Blumberg, M., \& Pringle, C. D. (1982). The missing opportunity in organizational research: Some implications for a theory of work performance. Academy of Management Review, 7(4), 560-569.

Bodovski, K. (2010). Parental practices and educational achievement: Social class, race, and habitus. British Journal of Sociology of Education, 31(2), 139-156.

Bolger, N., \& Schilling, E. A. (1991). Personality and the problems of everyday life: The role of neuroticism in exposure and reactivity to daily stressors. Journal of Personality, 59(3), 355-386.

Bollich-Ziegler, K. L., Beck, E. D., Hill, P., \& Jackson, J. J. (2020, April 27). Do Correctional Facilities Correct Our Youth?: Effects of Incarceration and Court-Ordered Community Service on Personality Development. https://doi.org/10.31234/osf.io/s7bxw 
Bogg, T., \& Roberts, B. W. (2004). Conscientiousness and health-related behaviors: a metaanalysis of the leading behavioral contributors to mortality. Psychological Bulletin, 130(6), 887.

Briley, D. A., \& Tucker-Drob, E. M. (2014). Genetic and environmental continuity in personality development: A meta-analysis. Psychological Bulletin, 140(5), 1303.

Brim, O. G., Ryff, C. D., \& Kessler, R. C. (2004). The MIDUS national survey: An overview. How healthy are we, 1-36.

Bureau of Labor Statistics, U.S. Department of Labor, and National Institute for Child Health and Human Development. Children of the NLSY79, 1979-2014. Produced and distributed by the Center for Human Resource Research, The Ohio State University. Columbus, OH: 2017.

Bürkner, P. C. (2017). brms: An R package for Bayesian multilevel models using Stan. Journal of Statistical Software, 80(1), 1-28.

Bürkner, P. C. (2018). Advanced Bayesian Multilevel Modeling with the R Package brms. The $R$ Journal, 10 (1), 395-411. doi: 10.32614. RJ-2018-017.

Burt, C. H., Sweeten, G., \& Simons, R. L. (2014). Self-control through emerging adulthood: Instability, multidimensionality, and criminological significance. Criminology, 52(3), 450-487.

Buuren, S. V., \& Groothuis-Oudshoorn, K. (2010). mice: Multivariate imputation by chained equations in R. Journal of Statistical Software, 1-68.

Cafri, G., Kromrey, J. D., \& Brannick, M. T. (2010). A meta-meta-analysis: Empirical review of statistical power, type I error rates, effect sizes, and model selection of meta-analyses published in psychology. Multivariate Behavioral Research, 45(2), 239-270.

Carlo, G., Okun, M. A., Knight, G. P., \& de Guzman, M. R. T. (2005). The interplay of traits and motives on volunteering: Agreeableness, extraversion and prosocial value motivation. Personality and Individual Differences, 38(6), 1293-1305.

Chen, R., \& Simons-Morton, B. (2009). Concurrent changes in conduct problems and depressive symptoms in early adolescents: A developmental person-centered approach. Development and Psychopathology, 21(1), 285.

Cirino, P. T., Chin, C. E., Sevcik, R. A., Wolf, M., Lovett, M., \& Morris, R. D. (2002). Measuring socioeconomic status: reliability and preliminary validity for different approaches. Assessment, 9(2), 145-155.

Cronbach, L. J. (1951). Coefficient alpha and the internal structure of tests. Psychometrika, 16(3), 297-334. 
Clary, E. G., Snyder, M., Ridge, R. D., Copeland, J., Stukas, A. A., Haugen, J., \& Miene, P. (1998). Understanding and assessing the motivations of volunteers: A functional approach. Journal of Personality and Social Psychology, 74(6), 1516.

Cohen, P., Cohen, J., Aiken, L. S., \& West, S. G. (1999). The problem of units and the circumstance for POMP. Multivariate Behavioral Research, 34(3), 315-346.

Cotton, K., \& Wikelund, K. R. (1989). Parent involvement in education. School Improvement Research Series, 6(3), 17-23.

Credé, M., Harms, P., Niehorster, S., \& Gaye-Valentine, A. (2012). An evaluation of the consequences of using short measures of the Big Five personality traits. Journal of Personality and Social Psychology, 102(4), 874.

Credé, M., \& Kuncel, N. R. (2008). Study habits, skills, and attitudes: The third pillar supporting collegiate academic performance. Perspectives on Psychological Science, 3(6), 425-453.

Damian, R. I., Spengler, M., Sutu, A., \& Roberts, B. W. (2019). Sixteen going on sixty-six: A longitudinal study of personality stability and change across 50 years. Journal of Personality and Social Psychology, 117(3), 674.

Deary, I. J., Whiteman, M. C., Starr, J. M., Whalley, L. J., \& Fox, H. C. (2004). The impact of childhood intelligence on later life: following up the Scottish mental surveys of 1932 and 1947. Journal of Personality and Social Psychology, 86(1), 130.

Deci, E. L., \& Ryan, R. M. (1980). Self-determination theory: When mind mediates behavior. The Journal of Mind and Behavior, 33-43.

Donnellan, M. B., Conger, R. D., \& Bryant, C. M. (2004). The Big Five and enduring marriages. Journal of Research in Personality, 38(5), 481-504.

Donnellan, M. B., \& Lucas, R. E. (2008). Age differences in the big five across the life span: Evidence from two national samples. Psychology and Aging, 23 (3), 558.

Donnellan, M. B., Trzesniewski, K. H., Robins, R. W., Moffitt, T. E., \& Caspi, A. (2005). Low self-esteem is related to aggression, antisocial behavior, and delinquency. Psychological Science, 16(4), 328-335.

DuBois, D. L., Burk-Braxton, C., Swenson, L. P., Tevendale, H. D., Lockerd, E. M., \& Moran, B. L. (2002). Getting by with a little help from self and others: Self-esteem and social support as resources during early adolescence. Developmental Psychology, 38(5), 822.

Dutton, D. G., \& Karakanta, C. (2013). Depression as a risk marker for aggression: A critical review. Aggression and Violent Behavior, 18(2), 310-319.

Edmonds, G. W., Goldberg, L. R., Hampson, S. E., \& Barckley, M. (2013). Personality stability from childhood to midlife: Relating teachers' assessments in elementary school to 
observer-and self-ratings 40 years later. Journal of Research in Personality, 47(5), 505513.

Etzion, D. (1984). Moderating effect of social support on the stress-burnout relationship. Journal of Applied Psychology, 69(4), 615.

Finkelstein, M. A., \& Brannick, M. T. (2007). Applying theories of institutional helping to informal volunteering: Motives, role identity, and prosocial personality. Social Behavior and Personality: An International Journal, 35(1), 101-114.

Fraley, R. C., \& Roberts, B. W. (2005). Patterns of continuity: a dynamic model for conceptualizing the stability of individual differences in psychological constructs across the life course. Psychological Review, 112(1), 60.

Friedman, H. S. (2000). Long-term relations of personality and health: Dynamisms, mechanisms, tropisms. Journal of Personality, 68(6), 1089-1107.

Friedman, H. S., Kern, M. L., Hampson, S. E., \& Duckworth, A. L. (2014). A new life-span approach to conscientiousness and health: Combining the pieces of the causal puzzle. Developmental Psychology, 50(5), 1377.

Friedman, H. S., Tucker, J. S., Tomlinson-Keasey, C., Schwartz, J. E., Wingard, D. L., \& Criqui, M. H. (1993). Does childhood personality predict longevity?. Journal of Personality and Social Psychology, 65(1), 176.

Friedman, H. S., Tucker, J. S., Schwartz, J. E., Martin, L. R., Tomlinson-Keasey, C., Wingard, D. L., \& Criqui, M. H. (1995). Childhood conscientiousness and longevity: health behaviors and cause of death. Journal of Personality and Social Psychology, 68(4), 696.

Gellert, C., Schöttker, B., \& Brenner, H. (2012). Smoking and all-cause mortality in older people: systematic review and meta-analysis. Archives of Internal Medicine, 172(11), 837-844.

Gottfredson, L. S., \& Deary, I. J. (2004). Intelligence predicts health and longevity, but why?. Current Directions in Psychological Science, 13(1), 1-4.

Gottman, J. M., Coan, J., Carrere, S., \& Swanson, C. (1998). Predicting marital happiness and stability from newlywed interactions. Journal of Marriage and the Family, 5-22.

Guo, S., \& Fraser, M. W. (2015). Propensity score analysis. Sage.

Hampson, S. E. (2012). Personality processes: Mechanisms by which personality traits ?get outside the skin? Annual Review of Psychology, 63, 315-339.

Hampson, S. E., Edmonds, G. W., Goldberg, L. R., Dubanoski, J. P., \& Hillier, T. A. (2013). Childhood conscientiousness relates to objectively measured adult physical health four decades later. Health Psychology, 32(8), 925. 
Hampson, S. E., Edmonds, G. W., Goldberg, L. R., Dubanoski, J. P., \& Hillier, T. A. (2015). A life-span behavioral mechanism relating childhood conscientiousness to adult clinical health. Health Psychology, 34(9), 887.

Hampson, S. E., Goldberg, L. R., Vogt, T. M., \& Dubanoski, J. P. (2007). Mechanisms by which childhood personality traits influence adult health status: educational attainment and healthy behaviors. Health Psychology, 26(1), 121.

Harris, K. M., \& Udry, J. R. (2018). National longitudinal study of adolescent to adult health (add health), 1994-2008 [Public Use]. Ann Arbor, MI: Carolina Population Center, University of North Carolina-Chapel Hill [distributor], Inter-university Consortium for Political and Social Research [distributor], 08-06.

Hart, C. L., Taylor, M. D., Smith, G. D., Whalley, L. J., Starr, J. M., Hole, D. J., ... \& Deary, I. J. (2003). Childhood IQ, social class, deprivation, and their relationships with mortality and morbidity risk in later life: prospective observational study linking the Scottish Mental Survey 1932 and the Midspan studies. Psychosomatic medicine, 65(5), 877-883.

Hart, C. L., Taylor, M. D., Smith, G., Whalley, L. D., Starr, J. M., Hole, D. J., ... \& Deary, I. J. (2005). Childhood IQ and all-cause mortality before and after age 65: Prospective observational study linking the Scottish Mental Survey 1932 and the Midspan studies. British Journal of Health Psychology, 10(2), 153-165.

Hauser, R. M., \& Sewell, W. H. (2012). Wisconsin Longitudinal Study (WLS)[graduates, siblings, and spouses]: 1957-2019, Version 13.07.

Hill, P. L., Edmonds, G. W., \& Jackson, J. J. (2019). Pathways linking childhood personality to later life outcomes. Child Development Perspectives, 13(2), 116-120.

Hill, P. L., Weston, S. J., \& Jackson, J. J. (2018). The co-development of perceived support and the Big Five in middle and older adulthood. International Journal of Behavioral Development, 42(1), 26-33.

Ho, D. E., Imai, K., King, G., \& Stuart, E. A. (2011). MatchIt: nonparametric preprocessing for parametric causal inference. Journal of Statistical Software, http://gking. harvard. edu/matchit.

Hohn, R. E., Slaney, K. L., \& Tafreshi, D. (2019). Primary study quality in psychological metaanalyses: An empirical assessment of recent practice. Frontiers in Psychology, 9, 2667.

Holley, L. C., Tavassoli, K. Y., \& Stromwall, L. K. (2016). Mental illness discrimination in mental health treatment programs: Intersections of race, ethnicity, and sexual orientation. Community Mental Health Journal, 52(3), 311-322.

Honaker J, King G, Blackwell M (2011). “Amelia II: A Program for Missing Data.” Journal of Statistical Software, 45(7), 1-47.http://www.jstatsoft.org/v45/i07/. 
Jackson, D. N., \& Paunonen, S. V. (1985). Construct validity and the predictability of behavior. Journal of Personality and Social Psychology, 49(2), 554.

Jackson, J. J., \& Beck, E. D. (2020). Using Ambulatory Assessments to Understand PersonalityHealth Associations. In Personality and Healthy Aging in Adulthood (pp. 93-110). Springer, Cham.

Jackson, J. J., Connolly, J. J., Garrison, S. M., Leveille, M. M., \& Connolly, S. L. (2015). Your friends know how long you will live: A 75-year study of peer-rated personality traits. Psychological Science, 26(3), 335-340.

Jackson, J. J., Thoemmes, F., Jonkmann, K., Lüdtke, O., \& Trautwein, U. (2012). Military training and personality trait development: Does the military make the man, or does the man make the military? Psychological Science, 23 (3), 270-277.

Jackson, J. J., Weston, S. J., \& Schultz, L. H. (2017). Personality development and health. In Personality development across the lifespan (pp. 371-384). Academic Press.

Jackson, J. J., Wood, D., Bogg, T., Walton, K. E., Harms, P. D., \& Roberts, B. W. (2010). What do conscientious people do? Development and validation of the Behavioral Indicators of Conscientiousness (BIC). Journal of Research in Personality, 44(4), 501-511.

Jokela, M., Airaksinen, J., Kivimäki, M., \& Hakulinen, C. (2018). Is within-individual variation in personality traits associated with changes in health behaviours? Analysis of seven longitudinal cohort studies. European Journal of Personality, 32(6), 642-652.

Jokela, M., Batty, G. D., Nyberg, S. T., Virtanen, M., Nabi, H., Singh-Manoux, A., \& Kivimäki, M. (2013). Personality and all-cause mortality: Individual-participant meta-analysis of 3,947 deaths in 76,150 adults. American Journal of Epidemiology, 178(5), 667-675.

Judge, T. A., Higgins, C. A., Thoresen, C. J., \& Barrick, M. R. (1999). The big five personality traits, general mental ability, and career success across the life span. Personnel psychology, 52(3), 621-652.

Juster, F. T., \& Suzman, R. (1995). An overview of the Health and Retirement Study. Journal of Human Resources, 30, S7-S56.

Kelly, E. L., \& Conley, J. J. (1987). Personality and compatibility: A prospective analysis of marital stability and marital satisfaction. Journal of Personality and Social Psychology, 52(1), 27.

Kofler, M. J., McCart, M. R., Zajac, K., Ruggiero, K. J., Saunders, B. E., \& Kilpatrick, D. G. (2011). Depression and delinquency covariation in an accelerated longitudinal sample of adolescents. Journal of Consulting and Clinical Psychology, 79(4), 458.

Krause, N. (1987). Life stress, social support, and self-esteem in an elderly population. Psychology and Aging, 2(4), 349Kubzansky, L. D., Kubzansky, P. E., \& 
Maselko, J. (2004). Optimism and pessimism in the context of health: bipolar opposites or separate constructs?. Personality and Social Psychology Bulletin, 30(8), 943-956.

Krueger, R. F., Markon, K. E., \& Bouchard Jr, T. J. (2003). The extended genotype: The heritability of personality accounts for the heritability of recalled family environments in twins reared apart. Journal of Personality, 71(5), 809-833.

Kruschke, J. (2014). Doing Bayesian data analysis: A tutorial with R, JAGS, and Stan. Academic Press.

Larson, L. M., Rottinghaus, P. J., \& Borgen, F. H. (2002). Meta-analyses of big six interests and big five personality factors. Journal of Vocational Behavior, 61(2), 217-239.

Lee, V. E., \& Smith, J. B. (1999). Social support and achievement for young adolescents in Chicago: The role of school academic press. American Educational Research Journal, 36(4), 907-945.

Lord, F. M. (1955). Sampling fluctuations resulting from the sampling of test items. Psychometrika, 20(1), 1-22.

Lüdtke, O., Roberts, B. W., Trautwein, U., \& Nagy, G. (2011). A random walk down university avenue: Life paths, life events, and personality trait change at the transition to university life. Journal of Personality and Social Psychology, 101 (3), 620.

Malouff, J. M., Thorsteinsson, E. B., Schutte, N. S., Bhullar, N., \& Rooke, S. E. (2010). The five-factor model of personality and relationship satisfaction of intimate partners: A meta-analysis. Journal of Research in Personality, 44 (1), 124-127.

Martin, L. R., Friedman, H. S., \& Schwartz, J. E. (2007). Personality and mortality risk across the life span: The importance of conscientiousness as a biopsychosocial attribute. Health Psychology, 26(4), 428.

McElreath, R. (2020). Statistical rethinking: A Bayesian course with examples in $R$ and Stan. CRC press.

Miller, T. Q., Smith, T. W., Turner, C. W., Guijarro, M. L., \& Hallet, A. J. (1996). Meta-analytic review of research on hostility and physical health. Psychological Bulletin, 119(2), 322.

Moutafi, J., Furnham, A., \& Paltiel, L. (2005). Can personality factors predict intelligence? Personality and Individual Differences, 38(5), 1021-1033.

Mroczek, D. K., \& Spiro, A. (2007). Personality change influences mortality in older men. Psychological Science, 18(5), 371-376.

Mroczek, D. K., Spiro III, A., \& Turiano, N. A. (2009). Do health behaviors explain the effect of neuroticism on mortality? Longitudinal findings from the VA Normative Aging Study. Journal of Research in Personality, 43(4), 653-659. 
Mueller, S., Wagner, J., \& Gerstorf, D. (2017). On the role of personality in late life. In Personality development across the lifespan (pp. 69-84). Elsevier.

Mund, M., \& Neyer, F. J. (2014). Treating personality-relationship transactions with respect: Narrow facets, advanced models, and extended time frames. Journal of Personality and Social Psychology, 107(2), 352.

Neyer, F. J. (1999). Personality of young adults with different life patterns. Kolner Zeitschrift fur Soziologie und Sozialpsychologie, 51(3), 491-+.

Neyer, F. J., \& Lehnart, J. (2007). Relationships matter in personality development: Evidence from an 8-year longitudinal study across young adulthood. Journal of Personality, 75(3), $535-568$.

Neyer, F. J., Mund, M., Zimmermann, J., \& Wrzus, C. (2014). Personality-relationship transactions revisited. Journal of Personality, 82 (6), 539-550.

Nieß, C., \& Zacher, H. (2015). Openness to experience as a predictor and outcome of upward job changes into managerial and professional positions. PloS One, 10(6), e0131115.

Ozer, D. J., \& Benet-Martinez, V. (2006). Personality and the prediction of consequential outcomes. Annu. Rev. Psychol., 57, 401-421.

Paunonen, S. V., \& Jackson, D. N. (1985). On ad hoc personality scales: A reply to Burisch. Journal of Research in Personality, 19(4), 348-353.

Payne, S. C., Youngcourt, S. S., \& Beaubien, J. M. (2007). A meta-analytic examination of the goal orientation nomological net. Journal of Applied Psychology, 92(1), 128.

Pitre, C. C. (2014). Improving African American student outcomes: Understanding educational achievement and strategies to close opportunity gaps. Western Journal of Black Studies, 38(4), 209.

Plomin, R. (1994). Genetics and experience: The interplay between nature and nurture. Sage Publications, Inc.

Plomin, R., \& Bergeman, C. S. (1991). The nature of nurture: Genetic influence on "environmental" measures. Behavioral and Brain Sciences, 14(3), 373-386.

Poropat, A. E. (2009). A meta-analysis of the five-factor model of personality and academic performance. Psychological Bulletin, 135(2), 322.

R Core Team (2018). R: A language and environment for statistical computing. R Foundation for Statistical Computing, Vienna, Austria. URL https://www.R-project.org/.

Rentfrow, P. J., Jokela, M., \& Lamb, M. E. (2015). Regional personality differences in great britain. PLoS One, 10(3), e0122245. 
Revelle, W., \& Condon, D. M. (2019). Reliability from $\alpha$ to $\omega$ : A tutorial. Psychological Assessment, 31(12), 1395.

Rice, R. W., Near, J. P., \& Hunt, R. G. (1980). The job-satisfaction/life-satisfaction relationship: A review of empirical research. Basic and Applied Social Psychology, 1(1), 37-64.

Roberts, B. W., \& DelVecchio, W. F. (2000). The rank-order consistency of personality traits from childhood to old age: a quantitative review of longitudinal studies. Psychological Bulletin, 126(1), 3.

Roberts, B. W., Kuncel, N. R., Shiner, R., Caspi, A., \& Goldberg, L. R. (2007). The power of personality: The comparative validity of personality traits, socioeconomic status, and cognitive ability for predicting important life outcomes. Perspectives on Psychological Science, 2(4), 313-345.

Roberts, B. W., Smith, J., Jackson, J. J., \& Edmonds, G. (2009). Compensatory conscientiousness and health in older couples. Psychological Science, 20(5), 553-559.

Roberts, B. W., Wood, D., \& Caspi, A. (2008). The development of personality traits in adulthood. Handbook of Personality: Theory and Research, 3, 375-398.

Robins, R. W., Caspi, A., \& Moffitt, T. E. (2002). It's not just who you're with, it's who you are: Personality and relationship experiences across multiple relationships. Journal of Personality, 70(6), 925-964.

Rohrer, J. M., Egloff, B., \& Schmukle, S. C. (2017). Probing birth-order effects on narrow traits using specification-curve analysis. Psychological Science, 28(12), 1821-1832.

Ryff, C., Almeida, D. M., Ayanian, J., Carr, D. S., Cleary, P. D., Coe, C., \& Williams, D. (2012). Midlife in the United States (MIDUS 2), 2004-2006. Ann Arbor, MI: Inter-university Consortium for Political and Social Research [distributor], 11-20.

Ryff, C., Almeida, D., Ayanian, J., Binkley, N., Carr, D. S., Coe, C., \& Williams, D. (2016). National survey of midlife development in the United States (MIDUS 3), 2013-2014. ICPSR36346-v4. Ann Arbor, MI: Inter-university Consortium for Political and Social Research [distributor]. https://doi. org/10.3886/ICPS R, 36346, v4.

Saef, R., Beck, E. D., \& Jackson, J. J. (2020) Examining the Dynamic Nature of Worker Subjective Well-Being: The Application of Idiographic Approaches. Manuscript under review.

Saifi, S., \& Mehmood, T. (2011). Effects of socioeconomic status on students achievement. International Journal of Social Sciences and Education, 1(2), 119-128.

Scherpenzeel, A., Das, J. W. M., Ester, P., \& Kaczmirek, L. (2010). 'True' longitudinal and probability-based internet panels: Evidence from the Netherlands. In M. Das, P. Ester, \& L. Kaczmirek (Eds.), Social and Behavioral Research and the Internet: Advances in applied methods and research strategies. New York: Routledge. 77-103. 
Sharpe, D. (1997). Of apples and oranges, file drawers and garbage: Why validity issues in metaanalysis will not go away. Clinical Psychology Review, 17(8), 881-901.

Shavelle, R. M., Paculdo, D. R., Strauss, D. J., \& Kush, S. J. (2008). Smoking habit and mortality: a meta-analysis. J Insur Med, 40(3-4), 170-178.

Simonsohn, U., Simmons, J. P., \& Nelson, L. D. (2015). Specification curve: Descriptive and inferential statistics on all reasonable specifications. Available at SSRN 2694998.

Socio-Economic Panel (SOEP), data for years 1984-2017, version 34, SOEP, 2019, doi: 10.5684/soep.v34.

Solomon, B. C., \& Jackson, J. J. (2014a). Why do personality traits predict divorce? Multiple pathways through satisfaction. Journal of Personality and Social Psychology, 106(6), 978.

Solomon, B. C., \& Jackson, J. J. (2014b). The long reach of one's spouse: Spouses' personality influences occupational success. Psychological Science, 25(12), 2189-2198.

Soto, C. J. (2019). How replicable are links between personality traits and consequential life outcomes? The Life Outcomes of Personality Replication Project. Psychological Science, 30(5), 711-727.

Soto, C. J., John, O. P., Gosling, S. D., \& Potter, J. (2011). Age differences in personality traits from 10 to 65: Big five domains and facets in a large cross-sectional sample. Journal of Personality and Social Psychology, 100 (2), 330.

Spearman, C. (1904). Measurement of association, Part II. Correction of 'systematic deviations'. Am. J. Psychol, 15, 88-101.

Specht, J., Egloff, B., \& Schmukle, S. C. (2011). Stability and change of personality across the life course: The impact of age and major life events on mean-level and rank-order stability of the big five. Journal of Personality and Social Psychology, 101 (4), 862.

Stice, E., Ragan, J., \& Randall, P. (2004). Prospective relations between social support and depression: Differential direction of effects for parent and peer support?. Journal of Abnormal Psychology, 113(1), 155.

Strenze, T. (2007). Intelligence and socioeconomic success: A meta-analytic review of longitudinal research. Intelligence, 35(5), 401-426.

Sutin, A. R., Luchetti, M., Stephan, Y., Robins, R. W., \& Terracciano, A. (2017). Parental educational attainment and adult offspring personality: An intergenerational life span approach to the origin of adult personality traits. Journal of Personality and Social Psychology, 113(1), 144. 
Traag, T., Van der Valk, J., Van der Velden, R., De Vries, R., \& Wolbers, M. H. J. (2005). Why does education matter? Explaining the effect of the highest level of education attained by school leavers on their labor market position. Pedagogische Studiën, 82(6), 453-469.

Trzesniewski, K. H., Donnellan, M. B., Moffitt, T. E., Robins, R. W., Poulton, R., \& Caspi, A. (2006). Low self-esteem during adolescence predicts poor health, criminal behavior, and limited economic prospects during adulthood. Developmental Psychology, 42(2), 381.

Turiano, N. A., Chapman, B. P., Gruenewald, T. L., \& Mroczek, D. K. (2015). Personality and the leading behavioral contributors of mortality. Health Psychology, 34(1), 51.

Turiano, N. A., Hill, P. L., Roberts, B. W., Spiro III, A., \& Mroczek, D. K. (2012). Smoking mediates the effect of conscientiousness on mortality: The veterans affairs normative aging study. Journal of Research in Personality, 46 (6), 719-724.

Turiano, N. A., Mroczek, D. K., Moynihan, J., \& Chapman, B. P. (2013). Big 5 personality traits and interleukin-6: Evidence for "healthy Neuroticism" in a US population sample. Brain, behavior, and immunity, 28, 83-89.

Turiano, N. A., Pitzer, L., Armour, C., Karlamangla, A., Ryff, C. D., \& Mroczek, D. K. (2012). Personality trait level and change as predictors of health outcomes: Findings from a national study of Americans (MIDUS). Journals of Gerontology Series B: Psychological Sciences and Social Sciences, 67(1), 4-12.

University of Essex. Institute for Social and Economic Research. (2018). British Household Panel Survey: Waves 1-18, 1991-2009. [data collection]. 8th Edition. UK Data Service. SN:5151, http://doi.org/10.5255/UKDA-SN-5151-2

University of Essex, Institute for Social and Economic Research. (2019). Understanding Society: Innovation Panel, Waves 1-11, 2008-2018. [data collection]. 9th Edition. UK Data Service. SN: 6849, http://doi.org/10.5255/UKDA-SN-6849-12.

van Scheppingen, M. A., Jackson, J. J., Specht, J., Hutteman, R., Denissen, J. J., \& Bleidorn, W. (2016). Personality trait development during the transition to parenthood: A test of social investment theory. Social Psychological and Personality Science, 7(5), 452-462.

Voorpostel, M., Tillmann, R., Kuhn, U., Lipps, O., Ryser, V. A., \& Schmid, F. (2016). Swiss house-hold panel user guide (1999-2016). Lausanne.

Wagner, J., Becker, M., Lüdtke, O., \& Trautwein, U. (2015). The first partnership experience and personality development: A propensity score matching study in young adulthood. Social Psychological and Personality Science, 6(4), 455-463.

Watson, D., Hubbard, B., \& Wiese, D. (2000). General traits of personality and affectivity as predictors of satisfaction in intimate relationships: Evidence from self-and partnerratings. Journal of Personality, 68(3), 413-449. 
Watt, H. M., \& Eccles, J. S. (2008). Gender and occupational outcomes: Longitudinal assessments of individual, social, and cultural influences. American Psychological Association.

Webb, E. (1915). Character and Intelligence. British Journal of Psychology.

Weisberg, Y. J., DeYoung, C. G., \& Hirsh, J. B. (2011). Gender differences in personality across the ten aspects of the Big Five. Frontiers in Psychology, 2, 178.

Weston, S. J., Hill, P. L., Edmonds, G. W., Mroczek, D. K., \& Hampson, S. E. (2019). No Evidence of "healthy neuroticism" in the Hawaii Personality and Health Cohort. Annals of Behavioral Medicine, 53(5), 426-441.

Weston, S. J., Hill, P. L., \& Jackson, J. J. (2015). Personality traits predict the onset of disease. Social Psychological and Personality Science, 6 (3), 309-317.

Weston, S. J., \& Jackson, J. J. (2015). Identification of the healthy neurotic: Personality traits predict smoking after disease onset. Journal of Research in Personality, 54, 61-69.

Wilkins, R., Laß, I., Butterworth, P, \& Vera-Toscano, E. (2019) The Household, Income and Labour Dynamics in Australia Survey: Selected Findings from Waves 1 to 17. Melbourne Institute: Applied Economic \& Social Research, University of Melbourne.

Willingham, W. W., Pollack, J. M., \& Lewis, C. (2002). Grades and test scores: Accounting for observed differences. Journal of Educational Measurement, 39(1), 1-37.

Wurtele, S. K., Britcher, J. C., \& Saslawsky, D. A. (1985). Relationships between locus of control, health value, and preventive health behaviors among women. Journal of Research in Personality, 19(3), 271-278.

1 Although having a child is not directly a health outcome, I will discuss it under this category because it appears to share many of the same predictive relationships and pathways as health-related events (e.g., health behaviors, impulsivity, education).

2 Due to size, model objects and posterior draws for the propensity score matching study and specification and permutation-level results in the specification curve study available upon request.

3 Due to convergence issues with the model due to scaling, POMP will be operationalized as a 0-10 scale, instead of a $0-100$ scale.

4 In the preregistration of this study, I planned to use 10 imputed sets. However, this was reduced to five imputed sets to lower the high computational burden of the study.

5 I previously preregistered that I would also test (1) binarized and trichotomized personality characteristics and (2) all other personality domains as part of the specifications for all models. However, this ultimately added hundreds of thousands to billions of specifications to each specification curve, making them computationally intractable.

6 I had initially planned to use frequentist logistic multilevel regression models but opted for a different model to increase the speed of the models while maintaining robust estimates in clustered data. 